


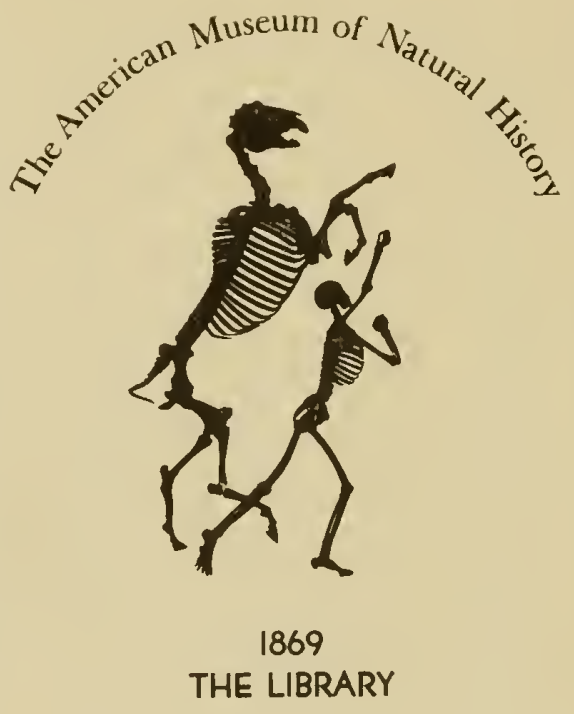







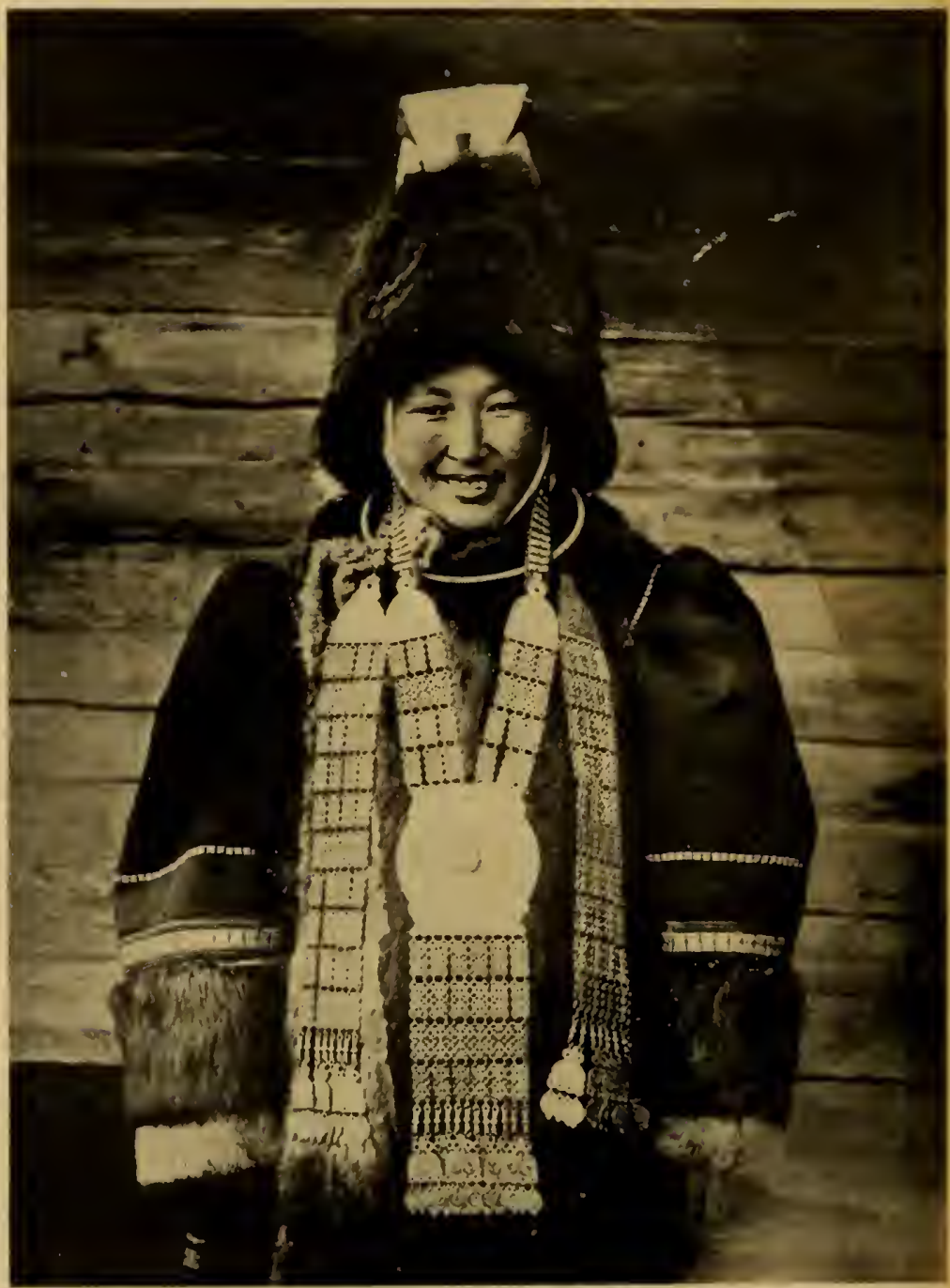

A Yakut Girl in Festive Attire 


\section{PEOPLES OF ASIATIC RUSSIA}

$$
\text { By. }
$$$$
\text { WALDEMAR / JOCHELSON }
$$

The American Museum of Natural History 1928 
$28-1128,3-\operatorname{Dec} \cdot 10$. 


\section{PEOPLES OF ASIATIC RUSSIA}

Br Waldemar Jochelson 



\section{PREFACE}

The writing of a handbook on the peoples of Asiatic Russia is a peculiarly difficult task. These peoples are of many racial strains, the relations of which, the one to the other, are not always clear. For example, the divisions of the so-called Ural Altaic peoples, the PalæAsiatics, the Aryan, and the Semitic elements present complicated problems. Each of these divisions must be considered from the standpoint of its own perplexing anthropological and historical aspects, as well as taking into account kinship and connections with other peoples outside of Asiatic Russia, or even outside of Asia. Further, adequately to present these ethnic divisions, and the various groups of peoples, one nust review their somatological, linguistic, and cultural characters. To this end these divisions have been treated geographically and in accordance with their present locations, as the tribes to be found in Siberia proper, in the Amur region, the Steppe provinces, in Turkestan, the Caucasus, and finally the native populations of bordering countries. Lastly, for the sake of perspective, we add a review of the prehistory and migrations in the region as a whole, together with a résumé of cultural characteristics.

The author was able to consult many Russian publications in the libraries of the American Geographical Society, the Slavic Division of the Congressional Library, and in other American institutions, as well as some of the latest works and information on the population of Asiatic Russia, thus making it possible to include otherwise inaccessible data.

Of personal obligations there are many. Photographs were generously furnished by the Museum of Anthropology and Ethnography of the Academy of Sciences in Leningrad; the Russian Museum of Leningrad (formerly the Museum of Emperor Alexander III); the Central Ethnographic Museum of Moscow (formerly Count Rumiantzev's Museum); Professor A. A. Ivanovsky, University of Kharkov; and Professor M. S. Andreev, University of Tashkent. The greater number of photographs are to be credited to the two last named individuals. Dr. I. I. Sarubin, Curator of the Central Asiatic Division of the Museum of Anthropology and Ethnography of the Academy of Sciences in Leningrad and Professor Andreev have furnished their recent publications, as well as unpublished information on the population of Turkestan. The Central 
Statistical Bureau of the Uzbeg Soviet Republic kindly sent me statistical reports for 1925 on the Autonomous States of Central Asia which were formerly included in the Turkestan Republic. The maps were executed by Mr. S. Ichikawa.

American Museum of Natural History

WaLdeMAR JocheLSON July, 1928 


\section{CONTENTS}

PAGE

PREFACE

Chapter I

THE MONGOLOIDS OF ASIA AND EUROPE . . . . . . 13

Fisic Tribes . . . . . . 16

THE UGRIANS. . .17

WESTERN FINNS . . . . 19

BALTIC FINNS . . . . . . . . . . . . . 19

THE PERMIANS . . . . . . . . . . . . 20

THE BCLGARIAN FINXS . . . . . . . . . . . 20

THE CHCVASH. . . . . . . . . . . 21

SLAVONIZED FINNS . . . . . . . . . . . . . . 21

THE LAPPS . . . . . . . . . . . . . 21

THE SAMOYED . . . . . . . . . . . . . . 22

TLRKICIZED SAMOYED . . . . . . . . . . . 23

The Tltric Tribes . . . . . . . . . . . . . 25

THE YAKUT . . . . . . . . . . . 25

THE TATARS OF TOBOLSK PROVTYCE . . . . . . . 27

THE TATARS OF TOMSK PROYINCE . . . . . . . . 28

THE ALTAIAN TATARS . . . . . . . . . $2 S$

THE KARAGAS . . . . . . . . . 32

The Mongolic Tribes . . . . . . . . . . . 33

THE BURYAT . . . . . . . 34

The Texges Tribes . . . . . . . . . 37

PRESENT DISTRIBUTION, NUMBER, AND TRIBES . . . . . 35

THE TCXGUS PROPER . . . . . . . . . . . . . . 39

LANGLAGE . . . . . . . . . . . 41

RELIGION . . . . . . . . . . . . 41

DIVISIONS AND CLASSES . . . . . . . . . . 42

\section{Chapter II}

THE AMERICANOIDS OF SIBERIA . . . . . . . . 43

THE СнскснеE . . . . . . . . . . . . . 45

THE KORYAK. . . . . . . . . . . . . . 47

REINDEER KORYAK . . . . . . . . . . . 47

MARITIME KORYAK . . . . . . . . . . . 47

The KaMchadal . . . . . . . . . . . . . 49

The CheKchee-Koryak-Kaychadal Physico-Cultural Complex 53

The Yekaghir aNd Chevantzy . . : . . . . . . . 54

THE REINDEER CHCVANTZY . . . . . . . . . . 56

SETTLENENTS OF DOG-BREEDING YCKAGHIR . . . . . . . . 56

DOG-BREEDING CHUVANTZY . . . . . . . 57

RELIGION AND LANGUAGE . . . . . . . . . . . 57

The Gilyak . . . . . . . . . . . 57

The Asiatic Eskimo and Cominder Aleut . . . . . . 60

THE ASIATIC ESKIMO . . . . . . . . . . . 60

THE ALECT OF THE COMHANDER ISLANDS . . . . . . 62 
PAGE

Villages and Dwellings . . . . . . . . . 63

Food . . . . . . . . . . . . . 63

Clothing . . . . . . . 64

Fur Seal Hunting . . . . . . . . . . . . 64

Boats . . . . . . . . . . . . . 64

Dog Breeding . . . . . . . . . . . 64

Domestic Animals . . . . . . . . . . . 64

Chapter III

SIBERIANS OF UNDETERMINED ANTHROPOLOGICAL POSITION 65

The Yeniseians . . . . . . . . . . 65

The Ainu . . . . . . . . . . . . . . . . . 67

Chapter IV

THE NATIONS OF TURKESTAN . . . . . . . . . 71

ARE A . . . . . . . . . . . . . . 71

Administration . . . . . . . . . . . . . . . . . 71

Statistics . . . . . . . . . . . . . . . 72

Population . . . . . . . . . . . . . . . 74

Language and Religion . . . . . . . . . . . . . 75

Ethnical Composition of the Population of Turkestan . . . 77

THE KIRGHZ . . . . . . . . . . . . . 77

Religion . . . . . . . . . . . . . . 83

Costume. . . . . . . . . . . . . . . 83

Social Organization . . . . . . . . . . . . 84

THE UZBEG . . . . . . . . . . . . . . 85

THE TURKOMAN . . . . . . . . 88

THE KARA-KALPAK . . . . . . . . . 96

THE KIPCHAK . . . . . . . . . . . . . 97

THE TATARS . . . . . . . . . . . . . 97

THE TARANCHI . . . . . . . . . . . 97

THE SART . . . . . . . . . . . . . 98

Marriage . . . . . . . . . . . . . 99

Family Life . . . . . . . . . . . . . 99

Comedians . . . . . . . . . . . . . 102

Dancing Women . . . . . . . . . . . 102

Circumcision . . . . . . . . . . . . 102

Funeral; . . . . . . . . . . . . 103

Costume . . . . . . . . . . . . . . 104

Mongolic Tribes of Turkestan . . . . . . . . . . 104

THE DUNGAN . . . . . . . . . . . . . 104

THE SART-KALMUCK $. \quad . \quad . \quad . \quad . \quad . \quad . \quad . \quad . \quad 106$

The Aryans . . . . . . . . . . . . . . . 106

THE TADJIK . . . . . . . . 116

PERSIANS . . . . . . . . 113

THE HINDOOS . . . . . . . . . . . . 113

GYPSIES . . . . . . . . . . . . . 114

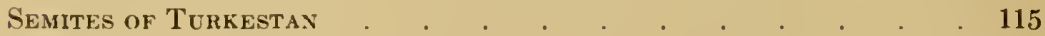


PAGE

JEWS

ARABS

AFGH.ANS

Administrative Changes under the Soviets . . . . . . 118

CZBEKISTAX . 119

THE TCRKOMAN SOVIET SOCIALIST REPUBLIC . . . . . . 120

THE KARA-KIRGHIZ AUTONONOUS PROVINCE . . . . . . 121

THE TADJIK AUTONOMOUS REPUBLIC . . . . . . . . 121

THE KARA-KALPAK AUTONONOUS PROVINCE . . . . . . 122

STATISTICAL DATA ON THE TURKESTAN REPUBLIC . . . . . . 122

\section{Ch.APTER V}

THE ASIATIC STEPPE PROVINCES

The hirghiz. . . . . . . . . . . 125

HISTORICAL DATA . . . . . . . . . . 125

SOMATOLOGY . . . . . . . . . . . . . 128

ETHYOGRAPHY . . . . . . . . 129

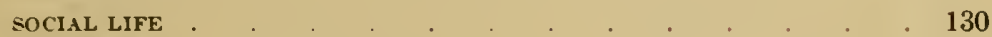

RELIGION . . . . . . . . . . . . 130

DWELLINGS . . . . . . . . . . . . . . 131

The Ressiax Population of the Steppes . . . . . . . . 133

THE COSSACKS . . . . . . . . . . 134

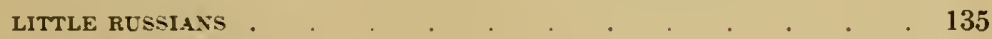

GERMAX COLONISTS . . . . . . . . . . . . 135

OTHER PEOPLES . . . . . . . . . . . . . . . . . 136

Chapter Vi

THE PEOPLES OF THE CAUCASUS . . . . . . . . 137

The Georgiass . . . . . . . . . . . 140

The ABKhas-Cherkess Group. . . . . . . . . . 142

The Chechex Grote ‘ . . . . . . . . . 143

The Lesghix GrotP . _ _ . . . 143

Axthropological Characters of the Japhetides . . . . . 146

THE GEORGIANS . . . . . . . . . . . . 146

THE ARMEXIANS . . . . . . . . . . . . . . . . 146

INDO-ECROPEANS . . . . . . . . . . . . 149

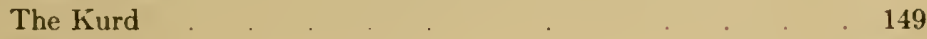

The Ossete . . . . . . . . . . 149

The Tate . . . . . . . . 150

The Talysh . . . . . . . . . 150

Persians . . . . . . . . . . . 151

Gypsies . . . . . . . . . 151

Europeans . . . . . . . . . . . . 151

Semitic Peoples . . . . . . . . . . . 151

JEWS 151

THE AISSOR . . . . . . . . . . . . 152

ARABS . . . . 153

Caccasiax Mongoloids . . . . . . . . . . 153 


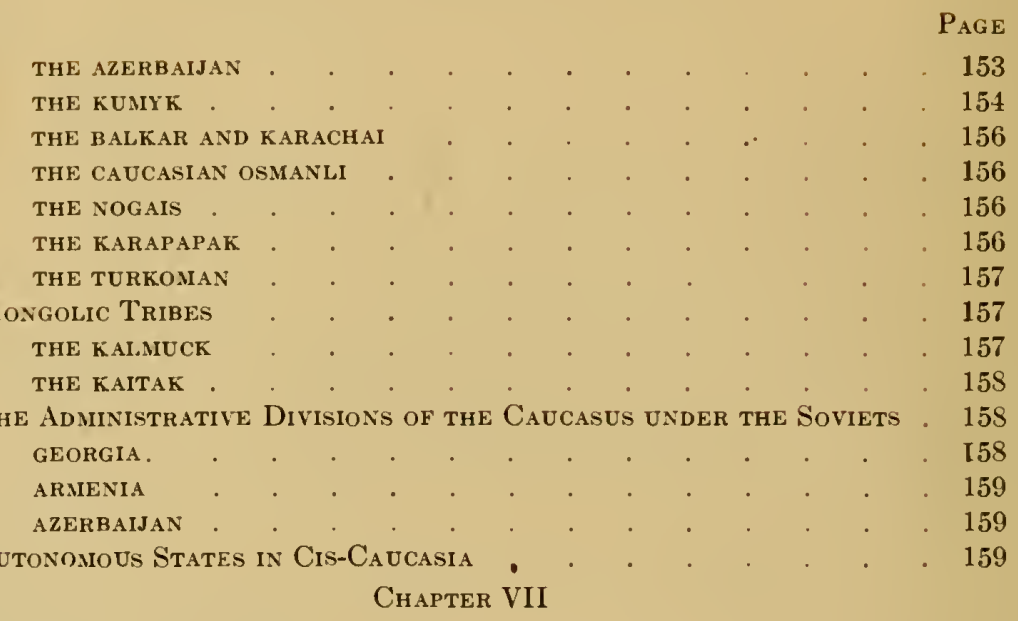

THE IRANIAN PEOPLES . . . . . . . . . . , I61

THE KURD . . . . . . . . . . . . . . . 164

The Ossete . . . . . . . . . . . . . . 166

Sogdians ANd Khorezmians . . . . . . . . . 167

Medians and Bactrians . . . . . . . . . . 168

The Tate and Azerbaijan

The Sarts . . . . . . . . . . . . . 169

The Afghan and Baluchi . . . . . . . . . . . . . 169

The Tadjk and Galcha . . . . . . . . . . . . . . . 169

Armenians . . . . . . . . . . . . . . . 170

The Hindoos and Gypsies $\quad$. $\quad$. . . . . . . . . . 170

SOMATOLOGY . . . . . . . . . . . . 173

The Distribution of Stature . . . . . . . . . . . 173

Distribution of the Cephalic Index _ _ _ _ _ _ . 176

Facial INdex . . . . . . . . . . . 180

The Cephalic Module . . . . . . . . . . . . . . 182

The Cephalic Module Stature Index. . . . . . . . . 184

Chapter IX

MODE OF LIFE . . . . . . . . . . . . . 187

DWELlings . . . . . . . . . . . . 188

Material AND CONSTRUCTION . . . . . . . . . . . . . 189

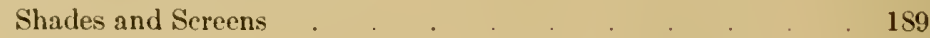

Conical Tents . . . . . . . . . . . . 189

Cylindro-Conical Tents . . . . . . . . 195

Felt-Covered Tents . . . . . . . . . . 198

Cylindro- Conical Felt Tents . . . . . . 198

Cylindro-Dome or Cupola-Shaped Felt Tents $\quad 198$

Pyramidal Dwellings . . . . . . . . . 201 
Truncated Pyramidal Dwellings . . . . . . . 201

Flat-Roofed Block Houses . . . . . . . . 203

Pcnt-Roofed Dwellings . . . . . . . . 203

Sloping-Roofed Block Houses . . . . . . . . 203

Underground Dwellings or Earth Huts . . . . . . 204

Sxow Dwellixgs . . . . . . . . . . 208

Flat-Roofed Dwellings of Mud, Clay, Unbaked Bricks, and Stones 208

Pile Dwellings . . . . . . . . . . 210

DREsS AND ORNAMENT . . . . . . . . . . . 210

PERSONAL DECORATION . . . . . . . . . . . . 210

Painting . . . . . . . . . . . . . 210

Tattooing . . . . . . . . . . 210

Piercing Parts of the Face . . . . . . . . . . 211

Hair Dressing . . . . . . . . . . . 211

Costume . . . . . . . . . . . . . . 212

Graphic Art . . . . . . . . . . . . . . 213

DRAWING AND EXGRAYING . . . . . . . . . 213

CARITYG . . . . . . . . . . . . . 214

RELIGION AND ART . . . . . . . . . . . . . 215

Mesic and Dancing . . . . . . . . . . . . 216

MCSIC . . . . . . . . . . . . . . . . . 216

The Drum . . . . . . . . . . . . 216

The Jew's Harp . . . . . . . . . . . . 217

Wind Instruments $\quad . \quad$. $\quad . \quad$. $\quad . \quad$. . . . . . 217

Stringed Instruments . $\quad . \quad$. . . . . . . . . . 217

DANCING . . . . . . . . . . . . . . 218

Circle Dance . . . . . . . . . . . . . 218

Pantomime or Primitive Drama . . . . . . . . 219

Caucasian Lesghinka Dance . . . . . . . . 221

The Trading Dance of the Chukchee . . . . . . 221

Religious Dances . . . . . . . . . . . . 222

POETRY . . . . . . . . . . . . . . 222

\section{Chapter $\mathrm{X}$}

MIGRATIONS AND HISTORY . . . . . . . . . . 229

Prehistory and Prehistoric Migrations . . . . . . . 229

The Historic Period . . . . . . . . . . . . 234

THE DINLIN . . . . . . . . . . . . . . 235

HISTORICAL WANDERINGS . . . . . . . . . . . 237

Iranians . . . . . . . . . . . . . 237

The Caucasus Peoples . . . . . . . . . 238

The Turkestan Peoples . . . . . . . . . 239

Siberia and the Amur Country . . . . . . . . 240

The Western Siberians . . . . . . . . . . 242

Religiots Classification. . . . . . . . . . . . 243

LANGUAGES . . . . . . . . . . . 245

BIBLIOGRAPHY . . . . . . . . . . . 251

INDEX . . . . . . . . . . . . . . 261 



\section{ILLUSTRATIONS}

PAGe

A Yakut Girl in Festive Attire

Frontispiece

1. Bashkir Men . . . . . . . . 15

2. Soyot Man and Woman . . . . . . . . . . . 23

3. Two lakut Types . . . . . . . . . . . . . 24

4. A Kachin Tatar, Minusinsk District . . . . . 30

5. Kachin Tatar Women and Children, Minusinsk District . . . . 31

6. Buryat Women and Men, Irkutsk Province. . . $\quad 35$

7. Burvat Shaman, Irkutsk Province . . . . . . . . . 35

s. Mongols of the Khalka Division, related to the Buryat . . . . . 37

9. Tungus Men. . . . . . . . . . . . . . 40

10. Koryak Woman and Man. . . . . . . . . . . 48

11. Driving Sledges of the Reindeer Koryak . . . . . . . 51

12. A Kamchatkan Dog Team and Sledge . . . . . . . . . 52

13. Asiatic Eskimo Woman and Man . . . . . . . . 61

14. A Kïrghiz-Kaisak and an Uzbeg Girl . . . . . . . . is

15. A Kïrghiz riding a Yak . . . . . . . . . . . . . . $\$ 2$

16. Uzbeg Woman and Child . . . . . . . . . . . 87

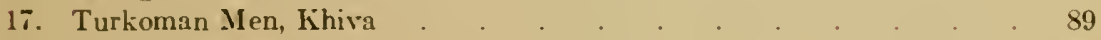

15. A Turkoman Musician, Khiva . . . . . . . . . . 90

19. A Turkoman Woman, Khiva . . . . . . . . . . . . . . . 94

20. Mountain Tadjik Woman resembling a European . . . . . 107

21. Ruins of Fortified Tadjik Drellings on the Upper Course of the Oksus River . . . . . . . 109

22. Types of Tadjik of the Upper Course of the Oksus . . . . 109

23. Tadjik Pot tery and Wooden Yessels, and a Stick for churning Butter . $\quad 110$

24. Agricultural Implements and Tools of the Tadjik. . . . . . 110

25. Gypsy Woman, Samarkand . . . . . . . . . . 114

26. A Georgian Girl and a Gurian Prince . . . . . . . . 141

27. Georgian Women churning Butter . . . . . . . . . . 143

2S. Lesghins selling Cloth and Two Georgians . . . . . . . . 144

29. An Armenian making Musical Instruments and an Azerbaijan Elder . . 147

30. A Terek Cossack . . . . . . . . . . . . 151

31. Karachai Girl and Woman. The Karachai are a Turkic-speaking-tribe living on the upper course of the Kuban River . . . . . . . 155

32. Birchbark Tents of the Soyot . . . . . . . . . 190

33. Summer Dwelling of the Ancient Yakut . . . . . . 190

34. Conical Tent of the Forest Altai Tatar . . . . . . 192

35. A Sod and Grass-Covered Conical Tent of the Yakut from the mouth of the Yana River. . . . . . . . 192

36. A Yukaghir Summer Village on the Korkodon River . . . . . 193

37. Conical Summer Tent of the Cpper Kolyma Yukaghir . . . . 194

39. A Cylindro-Conical Tent of the Tundra Yukaghir . . . . . 196

39. A Cylindro-Conical Tent of the Okhotsk Tungus . . . . . . 196

40. A Felt-Covered Cylindro-Conical Tent used chiefly by Mongoloid Tribes . 197

41. Framework for a Felt Tent . . . . . . . . . . 197 
42. A Felt-Covered Conical Tent of the Northern Mongols _ . . . . 199

43. A Cylindro-Dome-Shaped Felt Tent used by Turkic Tribes _ . . 199

44. A Yakut Dwelling . . . . . . . . . . . . 200

45. A Flat-Roofed Blockhouse of the Upper Kolyma Yukaghir _ . . 200

46. Inner Court of a Tadjik Dwelling, Eastern Bokhara . . . . . 202

47. A Karachai House . . . . . . . . . . . . 202

48. A Polygonal Altaian Sloping-Roofed Blockhouse . . . . . . 204

49. An Earth-Covered Blockhouse of the Altai-Tatar Kumandintzy . . 205

50. A Telcut (or Telengit) Dwelling . . . . . . . . . 205

51. Galcha Summer Dwelling in the Mountains of the Yagnob, a Tributary of the Zarafshan River . . . . . . . . . . . 209

52. A Kamchadal Storehouse which also serves as a Summer Dwelling . . 209 MAPS

1. Ethnographic Map of Asiatic Russia . . . . opposite . 13

2. The Former Administrative Divisions of Asiatic Russia . opposite . 42

3. The Latest Administrative Divisions of Central Asia under the Soviets . 117

4. Administrative Divisions of the Caucasus under the Soviets . . . 138

5. The Former Administrative Divisions of the Caucasus . . . . 139

6. The Distribution of Peoples in the Caucasus _ . . opposite . 159

7. The Distribution of Stature . . . . . . . . . . 174

8. Distribution of the Cephalic Index . . . . . . . . . 177

9. Mode of Life . . . . . . . . . . . . . opposite . 187

10. Distribution of Religions . . . . . . . . opposite . 243 
n-

n,

ly

ne

wo

of

sur

ia.

ast

rn-

he

the

wn

th

ern

lis-

of

ers.

ind

illy

jest

la-

ıces

vs :-

$r$ th, and 


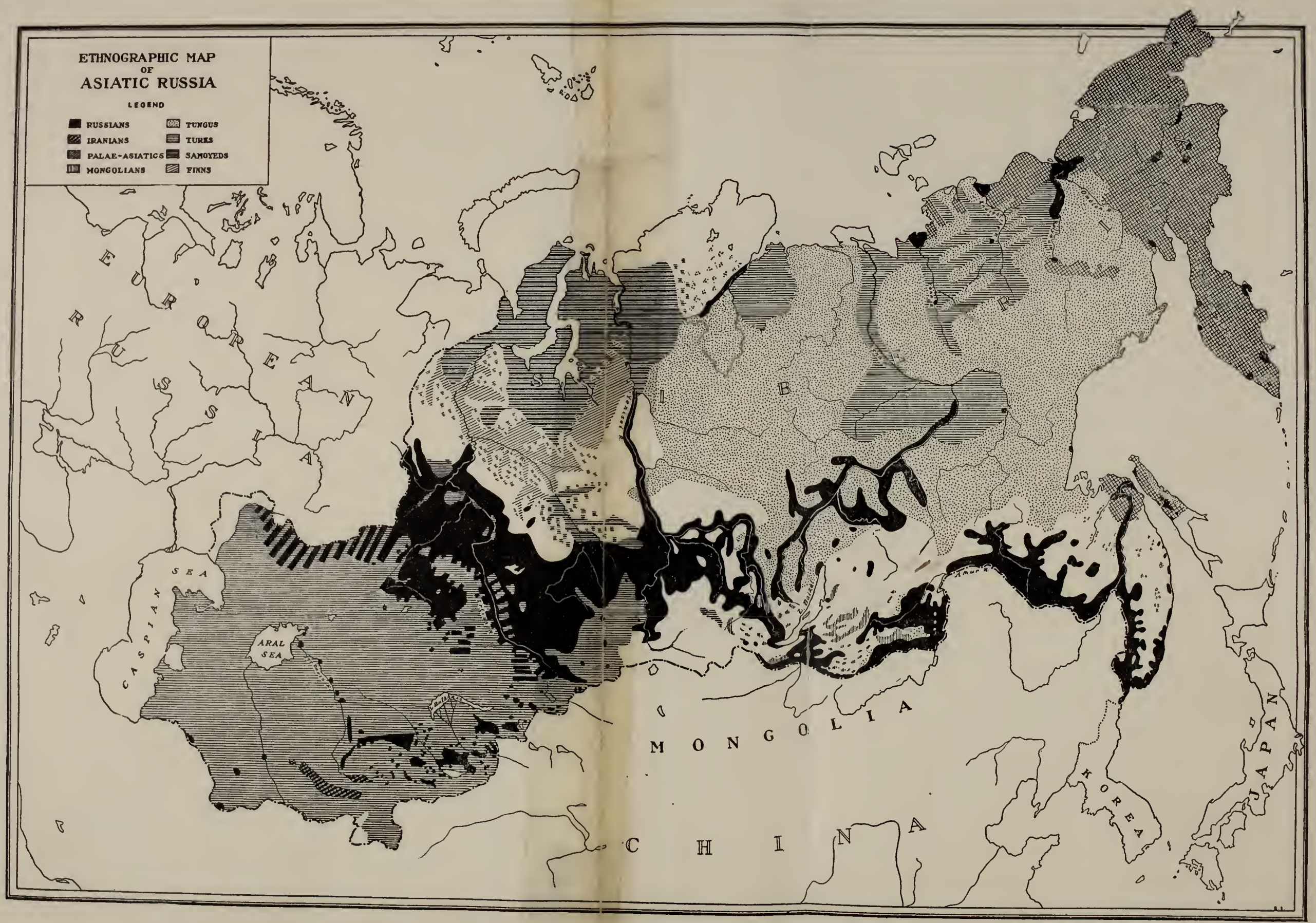




\section{CHAPTER I}

\section{THE MONGOLOIDS OF ASIA AND EUROPE}

In the sixteenth century the name, Siberia (Russian, Sibir) referred to Isker, the chief settlement of the Tatar Khan Kuchum on the Irtysh River, a tributary of the Ob. ${ }^{1}$ Subsequently, the name was extended to include all the Russian dominions in northern Asia, from the Ural Mountains to the Pacific Ocean, and the Amur River region. For this reason, and particularly because the natives of the Amur River region are closely related to some of the tribes of Siberia proper, or belong to the same ethnic units, both territories will be considered in this chapter.

For administrative purposes, Siberia proper was divided into two sections, Western and Eastern Siberia. Western Siberia is composed of the following provinces: 1, Tobolsk; 2, Tomsk. Eastern Siberia has four provinces: 1, Yeniseisk; 2, Irkutsk; 3, Yakutsk; and 4, Transbaikalia. The Russian name for province is Guberniya (Government) or Oblast (Territory). Tobolsk, Tomsk, Yeniseisk, and Irkutsk were called Governments, while Yakutsk and Transbaikalia were called Territories. The districts into which the provinces were divided were called Ouyezd in the Governments and Okrug in the Territories. Each province had its own governor; those called Guberniya were of greater importance, both numerically and economically. A Governor General for all of Eastern Siberia was stationed at Irkutsk.

The advent of Russians in Siberia considerably influenced the distribution of aboriginal tribes. The natives were either forced out of many localities, were exterminated, or were Russianized by the invaders. It may be of interest to cite the relative percentages of Russian and native population. The Russian conquerors and immigrants naturally occupied the territory nearer to European Russia and those districts best fitted for agriculture. Thus the percentage of Russian, or white, population diminishes from southwest to northeast. Enumerating the provinces from west to east, we find the percent of aboriginal population as follows:-

Tobolsk

Tomsk

Yeniseisk

Irkutsk

Yakutsk
5.9 percent

6.0 percent

8.8 percent

22.6 percent

87.5 percent

When we consider the districts of the provinces from south to north, we find the same differences in the relation between the Russian and

I Isker was situated about $t$ welve miles to the south of the city at present known as Tobolsk. 
native population. For instance, in Tobolsk Province, the percentage of natives by districts, is as follows:-

$\begin{array}{lr}\text { Kurgan } & 0.14 \text { percent } \\ \text { Yalutorovsk } & 2.6 \text { percent } \\ \text { Tyumen } & 12.8 \text { percent } \\ \text { Surgut } & 71.9 \text { percent } \\ \text { Berezof } & 72.8 \text { percent }\end{array}$

And if we take the most northeasterly province, Kamchatka, we find the population is almost entirely native. Thus,

$\begin{array}{lll}\text { Petropavlovsk District } & 72.3 & \text { percent } \\ \text { Okhotsk District } & 93.9 \text { percent } \\ \text { Gishiga District } & 97.0 \text { percent } \\ \text { Anadyr District } & 98.9 \text { percent }\end{array}$

The density of population increases with the percentage of Russian settlers. Tobolsk Province has 3.35 men to a quadratic mile; Yeniseisk Province, 1.75 men; Tomsk Province, 6.0 men; Irkutsk Province, 1.76 men; and Yakutsk Province, 0.2 men. The Kolyma District of Yakutsk Province, the farthest to the northeast, has only 0.01 individual to a quadratic mile.

In this chapter, however, we are concerned with the anthropology of aboriginal Siberia: somatology, linguistics, culture, and archæology. Our first task will be to enumerate the several tribes now living, define their habitats, and finally, give their anthropological classification; but, as a preliminary, a general review of the terminology now employed, seems advisable

The term Ural-Altaic was introduced by the Finnish investigator, M. A. Castren, ${ }^{1}$ and applied to the aborigines living in the region between the Ural and Altai Mountains. Lexically, Ural-Altaic is a geographical term, while in meaning it may be compared with Indo-Germanic (IndoEuropean, or Aryan) which owes its origin to the opinion that the Aryans of India and the Germanic peoples form the extreme outposts of the Aryan nations. Müller accepts the name, Ural-Altaic, applying it to the northern division of the Turanian family. ${ }^{2}$ Schren ck $^{3}$ also makes similar use of the term, while Peschel includes in it only the Finnic tribes ; yet according to the first two authorities, the Ural-Altaic group embraces not only the Finns, but also the Samoyed, Turks, Mongols, and Tungus. Originally,

'Castren, (b).

Muller, Max, 322

schrenck, (a).

- Peschel. 
Ural-Altaic was employed in the linguistic sense to characterize the Finnic, Samoyedic, Turkic, Mongolic, and Tungusic languages. Morphologically, these languages belong to the agglutinative order of speech. However, they differ from other languages so classified in the exclusive use of suffixes attached to the unmodified root and partly blended with it, on the principle of progressive vowel harmony, by virtue of which the vowels of the suffixes are assimilated to those of the root. In the UralAltaic languages there are no changes of the root and no prefixes.

Fortunately, the term is also applicable when the group is considered from the somatological point of view, for in physical characters it is closely allied to the Eastern and Southern Asiatics. The skin color of the Ural-Altaic peoples is yellow or yellowish brown; the hair is cylindrical, stiff, and black; the beard and body hair are sparse or totally wanting; the eves are usually obliquely set, and the lids have the epicanthic fold; the head is broad and low; the cheek bones are very prominent; the nose is short and flattened. However, the purity of the Mongoloid characters of the Ural-Altaics decreases toward the west. The vast territory they occupy has, in the past, been invaded by many peoples, and the Finnic tribes especially, during their westward migration, were intermixed to some degree with Aryan peoples.

While the term Ural-Altaic may therefore be considered as covering both the linguistic and somatological classification, so that we may speak of Ural-Altaic languages and Ural-Altaic tribes, nevertheless such a general usage may meet with objections. The Finnic peoples number sixteen millions, only 24,797 of whom (Ostyak and Vogul) are now located in Siberia. Of course, the present European Finnic nations may be called Ural-Altaic, by virtue of their Ural or Altaic origin, but whether the Tungus-Manchu of Eastern Asia are of Altaic origin remains an open question. The Amur region is regarded as their place of origin. ${ }^{1}$ For this reason, it is hardly fair to classify the Tungus-Manchu as Ural-Altaian. Miss Czaplicka proposed an alternative term, "Neo-Siberians"' for the Ural-Altaic tribes as "comparatively recent comers" to Siberia, but the writer believes this should be rejected because it excludes the Mongols, Turks, and Finns living outside of Siberia. Besides, the "Neo-Siberians" are not newcomers to Siberia. They migrated northwest and eastward after the retreat of the last glacier, and afterwards, though in quite early

1See Patkanof. (d), 26. lt should be added, however, that Castren, (b), 76 regurds the Altsi Ridge as the olace of origin of the Tatars and Monzols and of the Tunguy-Manchu, as well. On the other hand. Shirokogoroff, the latest investigator of the Tungus-.Ianchu tribes, places their original abode in northern Chins in the region of the lower courses of the IIwang-llo and Yangtze-kiang abode in northern Chins in the regi
rivers (Shirokogorof, 104. map. 109).

Craplicka, (a), 15. 
times, were driven to the north by related or alien tribes. The cradleland of the Turks appears to have been in the Altai region which is only partly located in Siberia. The Finno-Ugrian and Samoyed stocks originated in close proximity to the Turks about the headwaters of the Yenisei. The foregoing considerations have led the writer to use the term "Mongoloid peoples" instead of "Ural-Altaic," since it may be applied to the Mongol-Turkic peoples of other regions of Asiatic Russia, as well as to the Finno-Ugrians of Europe.

The Siberian Mongoloids may be divided into five branches: Finnic, Samoyedic, Turkic, Mongolic, and Tungusic, whose physical and linguistic affinities have previously been briefly noted and will be discussed in greater detail in subsequent chapters. The linguistic affinities of the Mongoloid tribes may be termed linguo-psychological, as the grouping of their languages is based chiefly on their common phonology and grammatical structure. There is, as yet, no evidence of their common origin from one parent language, as has been assumed for the Indo-Germanic or Semitic stocks. These languages do have a number of roots in common, but these may have been borrowed in the course of migrations.

\section{Finnic Tribes}

As has been previously stated the Finnic peoples, though very numerous, have a comparatively small representation in Siberia, since the great majority live in Hungary, European Russia, Sweden, and Norway. Some Hungarians, however, live in Siebenbürgen, Bukowina, ${ }^{1}$ and Moldavia, Rumania. Outside of Western Siberia, there are at present no Finns in Asiatic Russia, ${ }^{2}$ or in other parts of Asia. MagyarFinnic writers have attempted, on the basis of their somatology, to separate the Finns from the Mongoloids. They have also sought to associate the Ugro-Finnic with the Indo-Germanic languages. ${ }^{3}$ It is true that there is a certain percentage of light-haired persons among the Western Finns due to intermixture with representatives of the Aryan race, but, in the main, their physical characteristics are Mongoloid. This applies to a greater degree to the dark-haired Magyars. ${ }^{4}$

ISiebenbürgen (or Transylvania) and Bukowina were ceded to Rumania by Austria-Hungary in

With the exception of recent immigrants from European Russia.

"Scc, for instance, Szinnyei. This Aryo-Finnic thcory was formulated for the first time by the Russian Academician, P. von Köppen, about the end of the eighteenth century, but was then rejected by other Russian scholars. Doctor 1. Silinich. while reviewing Professor S. Rudenko's work "Anthropological lnvestigation of the Natives of Northwestern Siberia" came to the conclusion that these natives belong to the great Mongoloid family, despite the fact that the Vogul and some Ostyak deviate somatologically from the Mongoloid type, as is evidenced by a certain percentagc of dolichocephalic, light-haired, and gray-eyed individuals.

SVon Luschan, (b), 162-165. 
Szinnyei maintains that the hypothesis that the place of origin of the Finno-Ugrians was in the Altai Mountains should be abandoned' and that it should be sought in the middle of the Urals, chiefly on the European slope, or in southeastern Russia. Admitting that the FinnoUgrian languages are closely related to Samoyedic, he divides the UralAltaic languages into two groups: the Ural, including the Finno-Ugrian and Samoyedic languages and the Altaic, comprising the Mongolic, Turkic, and Manchu-Tungusic stocks. In the exposition of this theory we may again draw an analogy from the Indo-Germanic languages. Since philologists have discarded the view that Sanskrit represents the most archaic form of the Indo-European languages, the defenders of the Asiatic origin of the Indo-Europeans have lost their strongest point. Various theories have been advanced, placing their original home in northern France, the valley of the middle Danube, Scandinavia, the Vistula region, or western Russia. So we see that the original home of the Aryans is still unknown and the places mentioned as points of origin may well have been secondary places of dispersion. ${ }^{2}$ Similarly, the Ural region and southeastern Russia may be considered secondary places of origin of the Finnic nations. As for the original home of the Finns, we must turn back to Castren and other authorities. Castren based his beliefs that the Finns formerly inhabited the Altai region on the fact that the names of streams in the Yenisei District, such as Oya, Yoga, Kolba mean in Finnic and Lapp, brook, water, and fishing water, and that in its upper course the Yenisei itself is called, Kem, which signifies stream in Finnic. ${ }^{3}$ The original home of the Samoyed, who are related to the Finn, will be discussed below (p. 22).

The multiform Finnic group of peoples may be divided, according to dialectic affinities into four branches: namely, the Ugrians, the Baltic Finns, Permians, and Bulgarians.

\section{THE UGRIANS}

Castren includes in the Ugrian group the Ostyak living on the right bank of the Ob River, the Vogul on the eastern slopes of the northern Urals, and the Magyar. According to the latest statistics the Magyar number about 9,500,000; the Ostyak, 17,221; and the Vogul, 7,476. Though now an aristocratic and highly civilized European nation, about $800 \mathrm{~A}$.D. the Magyar appeared in their present abode as wild nomadic

Szinnyei, 20

There were also theories that the forefathers of the Indo-Europeans descended frorn Panir or that they originated in Turkestan or in Bactria (see Schwarz).

${ }^{3}$ Castren, (d), 82, 8t and 107 ; also, (b). 
horsemen. According to Szinnyei, there is not only lexical but grammatical conformity between the Finnic and Indo-Germanic languages, thus leading to the assumption of an old relationship between the IndoGermanic and Finno-Ugrian peoples. However, this supposition is repudiated by Winkler ${ }^{1}$ from the point of view of linguistics, and von Luschan ${ }^{2}$ from that of somatology. In spite of the borrowing of Aryan lexical and structural elements, Hungarian remains a Mongoloid language. Also, Mongoloid characters are retained in the Magyar

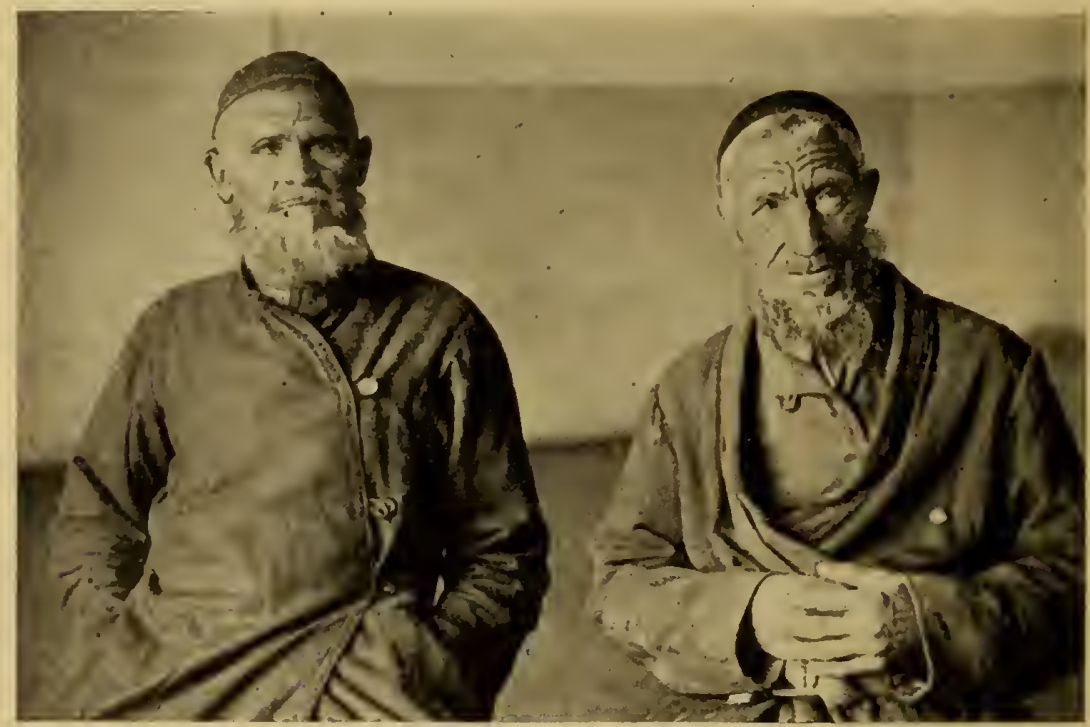

Fig. 1. Bashkir Men. The Bashkir are a Turkic-speaking Mohammedan tribe, living between the Volga River and the Ural Mountains, and are regarded as Tatarized Finns.

physical type despite a certain amount of mixture with Aryan peoples. The Magyar, a fishing, hunting, and to some degree, an agricultural tribe, before their intrusion into Hungary, lived in southeastern Europe where they were subjected to lasting influences from peoples of different races. Thus, from the Iranian Alan they acquired and have preserved much of their outer life, dress, and ornamentation. However this may

JWinkler.

'von Luschan, (b). 
be, the Mongoloid influence is dominant. For a long time the Magyar were ruled by the Finno-Turkic Kihazar.'

The Hungarian language contains many Turkic roots applicable to military and political organizations and primitive agriculture. The Magyar invaded western Europe under pressure by the Pechenyeg, ${ }^{2}$ a Turkic tribe, which was, in turn, driven to the west, first by the Khazar and later by the Polovtzy. ${ }^{3}$ In their new home the Magyar also absorbed some Turkic elenients. The remnants of the Avar were amalgamated with the Magyar.

\section{WESTERN FINNS}

The Finns proper, the so-called Suomi, the Karelians, and Baltic Finns, are known as the Western Finns. Present independent Finland is inhabited by Suomi Finns, a subdivision of the Karelians, and a small number of Swedes, and is as highly civilized a country as Hungary. Although now autonomous, before the Russian revolution, Finland was a part of the Russian Empire. The present-day Suomi Finns are on a par with the European civilized nations in the development of trade, industry, manufactures, science, and art. As they are now and have been in the past a cattle-breeding and agricultural people, they prosper in these pursuits despite the unfavorable climatic conditions of their country. With indefatigable labor they have turned stony soil and desolate forests into meadows and farns, colonizing the country far to the north and penetrating the territory of the Lapps. Of the total present population of Finland 2,352,990 are Finns and 439,733 are Swedes.

The Kiarelians inhabit the provinces of Archangelsk, Olonetz, Tver, and Novgorod, and number something over 200,000.

\section{BALTIC FINNS}

The Esthonians, Vesp, Vod, Livonians (now reduced to 2000) and the extinct Krevin are known as Baltic Finns.

Small groups of Esthonians are to be found in the Russian provinces of Petrograd, Vitebsk, and Pskof, and about a million live in Esthonia and Livonia. The Vesp, also called the Northern Tchud, number about 20,000 and live on the southwestern shores of Lake Ladoga: the Vod. or

\footnotetext{
'Russian investigators are not agreed upon the racial oricin or the language of the Khazar, some ranking them with the Finns and others with the Turks. See Samoilovich, (a), 200-210.

It is known that the upper classes of the Khazar were converted to Judaism. supposedly by Caucasian Jews with whom they intermarried. Some scholars regard the Karaites and the Krimchak (Crimea Jew8), both speaking Turkic dialects, as remnants of these Khazar-Jewish mixed-bloods, thus proving that the Khazar spoke a Turkic language. Crimea was a part of the Khazar kingdom. Profeasor Rostovtzeff designates the Khazar as a "Mongolian" tribe (Rostovtzcf, 219).

2 Known also under name of Kangli.

a Turkic tribe known also under the names of Kuman and Kipchak.
} 
Southern Tchud, having a population of 14,000 , live to the northeast of the town of Narva.

THE PERMIANS

The Permian branch of Finns includes two closely related tribes: the Votyak and Zyryan.

The Votyak are a numerous Finnic tribe, more than 500,000 living on the banks of the Kama, an affluent of the Volga, and its tributaries. They belong to the Greek Catholic Church, but have also retained their ancient pagan beliefs, mode of thinking, superstitions, and customs. They are agriculturists and skilful artisans.

The Zyryan live to the north of the Votyak, occupying a vast stretch of territory from the 58 th degree of latitude to the shores of the polar ocean and from the Urals westward to the Pinega, a tributary of the Dvina River. To the east they come into contact with the Ostyak and a division of the Samoyed. Though closely resembling the Votyak in physical traits, the Zyryan may be distinguished from them by their considerably higher culture. They are devoted Christians and have no pagan superstitions. They are sharp traders and many centuries ago were active in commercial intercourse with the peoples to the west, south, and east. They are industrious agriculturists, and with the stubborn persistence and care, peculiarly Finnish, cultivate the soil as far north as the 65th degree of latitude and somewhat higher. In the northern part of their territory, where they may properly be regarded as newcomers, they are nomadic reindeer breeders, own large herds, and carry on a profitable trade in reindeer skins and meat. It is said that the Zyryan are wont to exploit their less civilized and poorer kin. They number about 260,000.

\section{THE BULGARIAN FINNS}

The Mordvin, Cheremiss, and Chuvash, inhabiting some isolated districts of the Volga River are Bulgarians. The Mordvin are distributed in the provinces of Tambof, Nijni Novgorod, Simbirsk, Penza, Saratof, and Orenburg. In spite of its peculiarities, their language appears to be closely related to that of the Western Finns, so that the Mordvin and the Western Finns may be regarded, linguistically at least, as near relatives. They belong to one of the numerous Finnic groups and number more than 500,000. They are excellent agriculturists and, because of this quality, were sent to colonize certain districts in Astrakhan and other provinces.

The Cheremiss may be distinguished from the Mordvin by their 
language. They occupy the same localities as the Mordvin, but live in more compact masses. Under the sovereignity of the Tatars they formed a separate khanate. Their population is about 400,000 . The so-called Forest Cheremiss, dwelling in the low country on the west bank of the Volga River, westward of Kazan, differ, both in dialect and customs, from the Mountain Cheremiss who are more isolated from the Russian population and consequently hare preserved many of their pre-Christian customs and superstitions. They also are perfect cultivators of the land; in addition, they rear bees, hunt, and fish. Their language is intermediate between eastern and western Finnic. Physically, they are representatives of the Finnic type, although many light-haired people may be found among them.

\section{THE CHUVASH}

The Churash live in isolated parts of the provinces of Kazan, Simbirsk, Samara, Saratof, Orenburg, and Perm. They number some half a million. Although they are of Bulgarian origin they became Tatarized and now speak a Turkic dialect mingled with traces of Finnic. Physically they resemble most closely the Finnic type.

\section{SLA VONIZED FINNS}

The Danube Bulgarians no longer belong in this branch of the Finnic family, but are now Slaronic in language and some physical characters, and have also completely absorbed the remnants of the former Bulgarians of the Middle Ages. While the Volga Bulgarians maintained their independent government until the thirteenth century and their nationality until their permanent subjugation by the czars of Moscow, the Bulgarians of the Danube forfeited their language in the tenth century and their independence at the beginning of the eleventh century. They became a free nation again in 1878. The Bulgarians first appeared on the banks of the Pruth in the latter part of the seventh century. In 677 they crossed the Danube, subjugated the more civilized Slavonic population, and adopted its customs, local institutions, and language. Some Finnic elements are present in modern Bulgarian and have given the Finnic name to the nation. Mongoloid characters may still be recognized in the Bulgarian physical type.

\section{THE LAPPS}

The Lapps are a distinct Finnic group inhabiting the northern parts of Sweden, Norway, and Finland, and the Kola Peninsula, and number about 30,000 . In former times, their territory extended further to the 
south. In the middle of the sixteenth century they lived on the shores of Lake Saima and in the fourteenth century on the shores of Lake Onega. Fishing is their chief occupation, but wherever possible, they rear cattle and cultivate the land. About a fifth of the tribe are reindeerbreeding nomads. The language of the Lapps, according to Szinnyei, is closely akin to that of the Baltic Finns, but physically, the Lapps differ from them and stand quite isolated. Therefore, it must be admitted that in olden times, the Lapps spoke another language and their present tongue was borrowed from one of the Finnic-Ugrian tribes. Professor Rudenko ${ }^{1}$ found that the Lapps have some physical characters in common with the Samoyed and is inclined, therefore, to regard the LappoSamoyed and Finno-Ugrian as two distinct somatological groups. On the other hand, the linguist, Winkler, ${ }^{2}$ is of the opinion that in their mode of life and physical traits the Lapps strongly resemble the Ostyak and are probably an eastern Finnic division which has been dispersed to the west. Their language, although much influenced by that of the Baltic Finns, contains traces of the languages of Eastern Finns and even of the Hungarians.

\section{The SAMOYed}

In comparison with the Finno-Ugrians the Samoyed branch of the Mongoloids is numerically quite insignificant. The Samoyed never formed political organizations or civilized states as did the kindred Finns, but remained chiefly an Asiatic people and only a small number have recently migrated westward into the tundras of European Russia. However, they are of great importance as aids in clearing up some ethnological problems. Those who believe that the Finns are related to the Aryans and not to the Mongoloids are obliged to acknowledge their close relationship to the Samoyed and must therefore include the latter in the circle of early kinship with the Indo-Europeans. For that reason Professor Szinnyei ${ }^{3}$ segregates the Finnic and Samoyedic languages into a distinct group of the Ural peoples, as opposed to the Altaic group which in cludes the languages of the Turks, Mongols, and Tungus-Manchu.

The Samoyed are divided into three branches: 1, The Yurak (2519 men and 2852 women); 2, the Yenisei Samoyed and the Tawgi (639 men and 687 women); and 3, the Ostyak-Samoyed (2843 men and 2962 women). If we add to the above the 4000 Samoyed (1924 men and 2076 women) who immigrated into Archangelsk Province, the total number of Samoyed is 16,512 (7905 men and 8607 women). 
The Yurak Samoyed occupy the northern tundra between the Urals and the Yenisei River. The Tawgi Samoyed live on the tundra between the Yenisei and the Kihatanga River while the Ostyak Samoyed ${ }^{1}$ wander to the south of the two preceding branches in the northern forest zone of the provinces of Tobolsk, Yeniseisk, and Tomsk. A part of the Ostyak Samoyed have turned to a sedentary life and have horses and cattle, instead of reindeer.

The Samoved newcomers in Archangelsk Province, European Russia, wander over the northern tundra, and come into contact with Finnic tribes and Russians. On the west they have reached the Kola Peninsula and some Samoved families have moved to Nova Zembla Island.

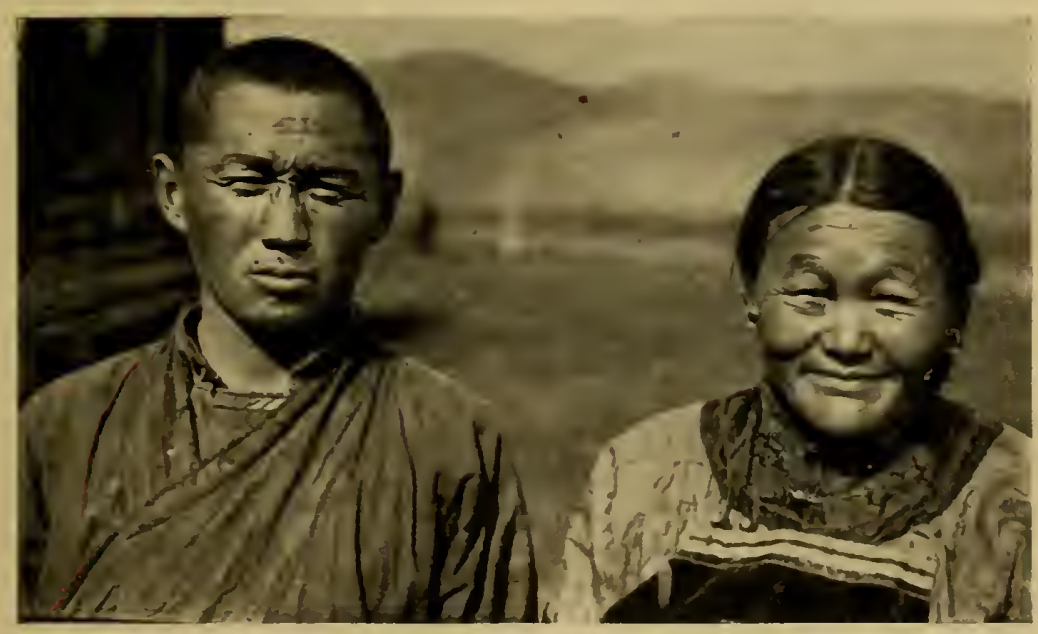

Fig. 2. Soyot Man and Woman. The Soyot or Uriankhai live in Yeniseisk Province and in Mongolia, and are regarded as Tatarized Samoyed. In Uriankhai they rear reindeer, in Mongolia, cattle.

\section{TURKICIZED SAMOYED}

Pallas, ${ }^{2}$ Castren,${ }^{3}$ and Radloff ${ }^{4}$ have pointed out that some of the present Turkic tribes of the southern parts of the provinces of Tomsk, Ieniseisk, and Irkutsk originated in an intermixture of the Turkic invaders with the Samoyedic aborigines. The Beltir and Koibal ${ }^{5}$ live

\footnotetext{
Is will be noted in the section on the Yeniseians, the writer proposes to call this Samoyed division, Narym-Samoyed

Pallas, $433,505,510,515$

2Castren, (a), $3.50,351,359,371$

- Radlof. (a), 20.j.

Acrording to Castren, (b), 322 three of the Koibal clans were of Ostyak origin, while the remainder were of Samoyed origin.
} 
in the southern part of Yeniseisk Province; the Karagas wander in the Nijni Udinsk District of Irkutsk Province, the Kamassintzy live in the Kansk District of Yeniseisk Province; and the Soyot, according to Patkanoff, ${ }^{1}$ live in the Biisk District of Tomsk Province and in the Minusinsk District of Yeniseisk Province. A part of the Soyot, also called Uriankhai, wander in Chinese territory in Mongolia. The Soyot, as well as the Karagas, and some other Tatarized Samoyedic tribes and
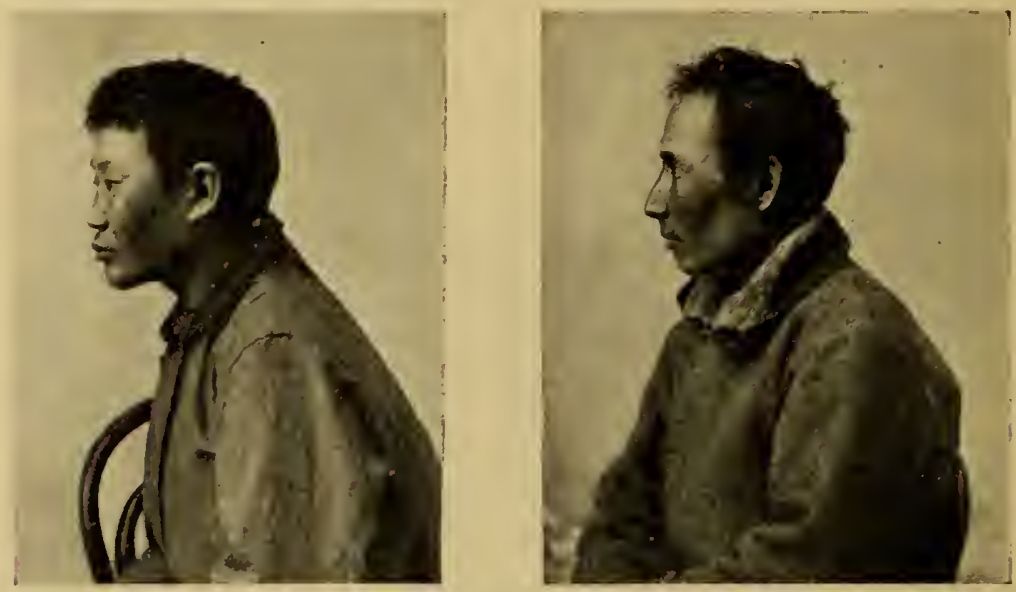

Fig. 3. Two Yakut Types. At the left is a flat-faced Mongol with prominent cheek bones and narrow eyes; at the right, a Tatar, with a high-bridged nose and wide eye fissure.

subtribes call themselves Tuba. ${ }^{2}$ Patkanoff believes this name to be testimony in favor of their Samoyedic origin. The reindeer-breeding of the Soyot and Karagas gives further evidence of their Samoyedic origin. The original place of domestication of the reindeer, or rather one of the places of its early domestication, was undoubtedly the region of the Upper Yenisei.

Quite recently the writer received from Professor Petri of the University of Irkutsk, his very interesting narrative of his trip to the Karagas. ${ }^{3}$ The chief interest of his account lies in the description of the Karagas reindeer, a strong, tall, and highly domesticated race. The Karagas place the saddle on the back and not on the shoulder blades,

1Patkanofi, (c), 78.

In the Chinese annals the name Tuba is applied to the peoples wholived in the southern Yenisei region and it is probable the Samoyedie tribes were meant. The Turkie peoples were called Tu-kiu. Petri, (e). 
over the front legs of the reindeer, as is done by all other reindeer breeders who ride the animal. Professor Petri also mentions the reincleer of the Uriankhai people, which is of the same variety as that of the Karagas. In another place he writes of the Soyot, identifying them with the Uriankhai. He had written to me before going to the Sayan Mountains and I had asked him to clear up the question of the relation of the Soyrot to the Uriankhai as some authors (for instance, Weule and Czaplicka) are in doubt as to their identity, which identity Petri positively confirmed.

\section{The Turkic Tribes}

We have seen that, with the exception of the Magyar, of the SwedishNorwegian Lapps, and of the Suomi and Baltic Finns who became independent after the Great War, the remaining Finnic peoples may be found within the boundaries of European and Asiatic Russia. It seems desirable to consider the Turkic tribes in the same way, inchuding in our review the non-Russian Turks. The total number of Turks, about twenty-three million, is nuch greater than that of Finns. Subtracting from this total ten million of Osmanli, Persian, and Afghanistan Turks and about two million Turks subject to China (in Jungaria and northern Mongolia) we have about eleven million Turks in European and Asiatic Russia. It may be said that no other Old World race is so widely distributed. The Turkic language may be heard from the shores of the Adriatic to the Aretic Coast and the Okhotsk Sea. No other people have displayed so great an assimilative porver as have the Turks who have Turkicized not only many Finns, Samoyed, Tungus, and Mongol tribes, but also some Arvans, for instance, the Sart and Tadjik of Turkestan, Russians of Yakut Province. Greeks of Crimea, the Kirimchak (the aboriginal Crimean Jews) and the Karaites, the Jews and Arabs of Turkestan. The ancient Kihazar were probably Turkicized Finns. Some Turkic divisions are known as Tatars or Tartars. It should be pointed out that the term Tatars is more correct than Tartars, as the latter was originally applied to both the Mongol and Turkic stocks which invaded Europe seven centuries ago.

The Turkic tribes of Siberia are, however, our chief interest in this publication, and comprise the Yakut, Tatars, and the Karagas, each of which will now be discussed in the orcker given.

\section{THE YAK I'T}

According to the Russian general census of 1897 there were at that time 226,739 Yakut (113,409 men and 113,330 women), but in 1911 they 
numbered 245,000 . To this number may also be actuded the small tribe of Dolgan, evidently of Tungus origin, living in the Turukhansk District of Yeniseisk Province. They number 967 (472 mbn and 495 women) and have become quite Yakutized. They speak 'Tungus, but regard Yakut as their native tongue. ${ }^{1}$

Two physical types can be distinguished amon the Yakut: one, pure Mongol, with broad face and flat nose; the other, is more like the Tatar of southwestern Siberia, with long face and narrow and more prominent nose. The so-called "noble" and wealthy Yakut, the elders, are mostly of the second type.

Yakut traditions of their tribal origin picture their descent from a Tatar hero and a Buryat girl. According to Radloff, ${ }^{2}$ the Yakut language is of Turkic structure; its roots, however, are only one third Turkic, the second third is Mongolic, and the remainder of unknown origin.

The Yakut now call themselves Sakhá (plural, Sakhalar). In olden times sakhá meant man. In tales and songs the Yakut use, instead of the term kisí, man, sakhá-kisi, i.e., the reduplication of man. Sakhá is the name of one subtribe of the Kachin Tatars (Minusinsk District, Yeniseisk Province). The ancient name of the Yakut was Uriankhai, at present applied to a troublesome, cranky, or foolish person. As has been noted before, Uriankhai is the name of a Turkic-Tatar tribe in Mongolia.

Katanoff, ${ }^{3}$ the student of Turkic languages, believes Uriankhai to be a Turkic dialect, influenced to some degree by Mongolic elements. On the other hand, Castren and his followers are inclined to see in the Uriankhai a Samoyed tribe that mixed with Turks and adopted a Turkic language. It is as difficult to ascertain whether the Yakut had some historical connections with the Uriankhai as it is to determine definitely their original home. Radloff believes the Uriankhai were the ancestors of the present Yakut, a supposition denied by other investigators. But if Radloff's hypothesis be true, the unknown lexical elements of the Yakut language may be attributed in part to Samoyedic origin, and in part to the language of the Yeniseians, Tungus, and Yukaghir with whom the Yakut were in contact during their wanderings to the northeast. According to historical and archæological data, the Yakut lived on the shores of Lake Baikal, whence they were forced out by the Buryat at the time of the invasions of Jenghis Khan. Professor Petri, who has recently conducted excavations

1About five percent of the Dolgan having intercourse with Samoyed, consider the Tawgi-Samoyed dialect their native tongue.

2Radloff, (e).

'Katanoff. 
on the shores of Lake Baikal and some other localities in Irkutsk Province, came to the conclusion that the Yakut formerly lived in the districts now occupied by the Buryat or Tungus. This is borne out by the finding of archæological objects of the age of metals. In form and ornamentation the clay vessels found are reminiscent of present day Yakut pottery. The Buryat and Tungus who now occupy this region do not make pottery. Dwellings, remains of which were discovered, are similar to the present earth huts of the Yakut. Iron knives, sickles for hay making, bifurcated arrowheads and metal parts of horse riding gear resemble objects of Yakut manufacture. ${ }^{1}$ But the Baikal region may have been the secondary home of the Yakut and their place of origin, and like that of other Turkic peoples, should be sought in the Altai region of central Asia. Some traditions and customs of the Yakut show that they were a nomadic horse-breeding tribe of the central Asiatic steppes. Also, their kumiss festivals and religious attitude toward the horse certify that in their old home they were principally pastoral horse breeders." The Yakut introduced horses and cattle into the region now called Yakutsk. For a time after their arrival in their new abode, the horse remained their principal domestic animal and kumiss their essential article of food. Gradually, however, clinatic conditions and the contact with Russians modified both their mental and material culture, so that at present cattle breeding is more predoninant than horse breeding. A small part of the tribe living in the extreme north of Yakutsk Province experienced a breakdown of their former material culture and became reindeer breeders, ${ }^{3}$ dog breeders, or hunters, and fishermen. But the Yakut introduced more advanced methods even in these new modes of life. In the southern parts of the Yakut territory, the cultivation of cereals, a trait borrowed from the Russians, has so progressed in the last thirty or forty years that agriculture is now the chief occupation and bread the staple food of many Yakut of the districts of Yakutsk, Viluisk, and Olekminsk.

\section{THE TATARS OF TOBOLSK PROVINCE .}

The Turkic tribes of Siberia, except the Yakut, are better known under the name, Tatar. We shall review them, by provinces, in the order of their present location.

\footnotetext{
IPetri, (a). (c).
Jochelson, (c).

"It is erroneous to speak of the Yakut as "the most typical representatives of a reindeer culture" as do Miss Czaplicka. (b), 52, and Doctor Laufer, (c). Of the 245,000 Yakut, only about ten or fifteen thousand rear reindeer and even among these, it is a secondary occupation. Rich reindeer owners among them do not wander with their herds but keep special Tungus herders for that purpose. The Yakut herd owners lead a sedentary or half sedentary life. For particulars as to different types of reindeer breeding and herding. see Jochelson, (d)
} 
The Tobolsk, otherwise called the West Siberian Tatars, inhabit the forested and the forest-stepped zones of the province of the same name, chiefly the middle course of the Irtysh River, the lower course of the Tobol River, and the middle course of the Tura River, in close proximity to Russian settlers. There were, according to the Russian census of $1897,37,637$ (19,821 men and 17,816 women) aboriginal Tobolsk Tatars. Only 1.2 percent of them lived in towns, the remainder in separate villages called yurts.

The so-called "Siberian Bukhartzy" are included with the West Siberian Tatar aborigines. They are descendants of Sarts, Uzbeg, Tadjik, and other central Asiatic merchants who came to Siberia at the end of the sixteenth century, settled there, became assimilated with the Tatars, and adopted their language. In 1897 they numbered 11,659; most of them $(11,307)$ now live in Tobolsk Province, mainly in the Tatar villages. They speak a Turkic dialect, though they know Russian also, and are Mohammedans. Only 268 have been Russianized, converted to Christianity, and regard Russian as their native tongue.

\section{The Tatars of Tomsk Province.}

The Baraba Tatars (2,278 men and 2,158 women) are agriculturists and live in the Kainsk District of Tomsk Province, in villages adjacent to Russian settlements. With few exceptions, they have retained their Tatar language. The Baraba Tatars are believed to be Turks who have mixed with Tatarized Finno-Ugrians, but, judging from the names of certain localities in their territory, Yeniseians seem to have occupied it at one time.

Chulyma Tatars numbering 11,123 (5,451 men; 5,672 women) live in the Tomsk and Mariinsk districts of the same province, and partly in the Achinsk District of Yeniseisk Province. The Achinsk division of the Chulyma Tatars are sometimes called Meletski Tatars. Only a third of the Chulyma Tatars have preserved their Turkic language; two thirds have become Russianized. To the north, they are in contact with the Samoyed.

THE ALTAIAN TATARS

There are two groups of Altaian Tatars: the Turks of the Altai Mountains proper, and of the northern Altai and Ala-Tau Mountains. The Turks of the Altai Mountains proper are the most typical Turkic division of Western Siberia. In consequence of their former subjection to the Oirat Kalmuck, they are also called Mountain or White Kalmuck. 
They number 26,084 (13,198 men and 12,856 women) and live in the Biisk District of Tomsk Province. Only a snrall proportion of the group leads a sedentary life; the majority are nomadic cattle breeders. They have preserved their Turkic language and only 139 persons consider Russian their native tongue. With the Turks of the Altai Mountains proper may be reckoned the Teleut (or Telengit), also called KaraKalmuck (i.e., Black Kalmuck) who live in the Tomsk, Kusnetzk, and Biisk districts of Tomsk Province and number 9,200 (4,543 men; 4,657 women). Only thirty-eight percent of them have preserved the Teleut Turkic dialect: the remainder are quite Russianized.

The Tatars of the northern Altai and Ala-Tau Mountains represent a mixture of many small Turkic tribes, partly of pure Turkic origin, partly intermixed with Yeniseians and Samoyed. They include the Kumandintzy, Lebedintzy, Shortzy, and Cherneviye Tatars.

The Kumandintzy live in the Biisk District of Tomsk Province, and have a population of 4,092 (2,102 men, 1,990 women). They speak an Altaian Turkic dialect, but a few regard Russian as their native language. They are called "nomadic natives," but most of them are sedentary.

The Lebedint zy, numbering 907 (446 men; 461 women), live in the Biisk and Kusnetzk districts of Tomsk Province and speak a dialect closely related to that of the Kumandintzy.

The Shortzy having a population of 13,902 (7,081 men: 6,821 women) live in the Kusnetzk District of Tomsk Province. About 12,000 of these consider the Shortzy Turkic dialect their native tongue. They are officially recorded as a nomadic people, but some groups maintain permanent settlements.

The Tomsko-Kusnetzk Tatars a re a sedentary Turkic people dialectically related to the Teleut and to the Shortzy. The Russians called them Kuznietzy (smiths) because of their skill as iron workers. At the time of the Russian conquest they paid tribute to China with iron implements of their own manufacture. They number 8,164 (3,927 men; 4,237 women). They live in the Kusnetzk, Tomsk, and Barnaul districts of Tomsk Province.

The Cherneviye Tatars (3,146 men; 3,196 women) live in the dense forests, called in Russian, chern (black, dark), covering the northern slopes of the Altai Mountains in the Biisk District. They are a semi-nomadic people speaking a Turkic dialect. Only a few of them have been Russianized. 
Under the name Abakan Tatars Radloff ${ }^{1}$ has combined all the native Turkic tribes of Yeniseisk Province (with the exception of the Chulym or Melet Tatars). This group consists of both small and large tribes of diverse origin (pure Turkic peoples, Tatarized Yeniseians, and Samoyed) who now speak Turkic dialects. Judging by the similarity of some of their tribe names to those found in Tomsk Province, we must admit that some of these Turks came from that Province. The following peoples have been assigned to the Abakan Tatar group:-

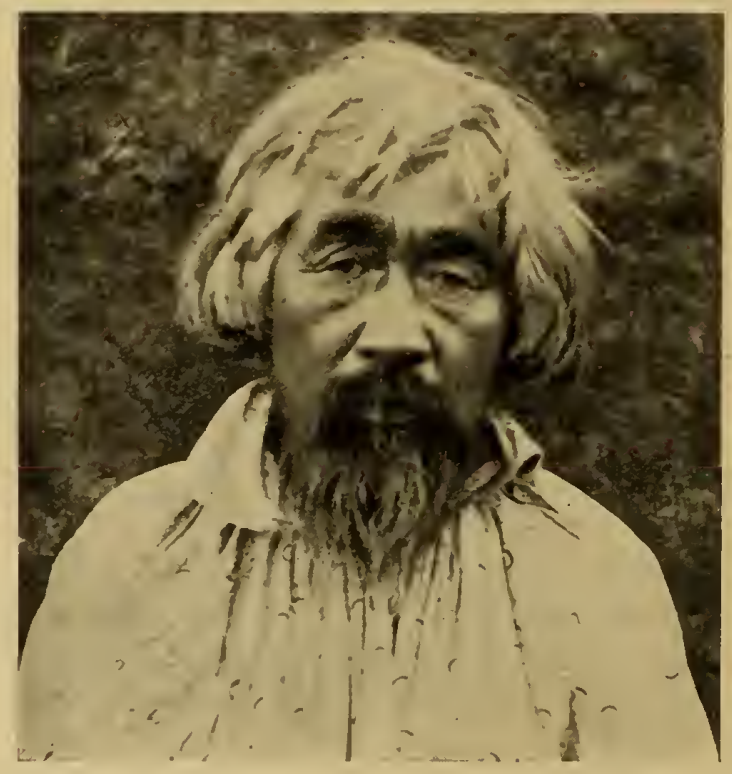

Fig. 4. A Kachin Tatar, Minusinsk District. The Kachin are a division of the Abakan Tatar of diverse origin, Turkic and Tatarized Samoyed and Yeniseian.

The Kizyl Tatars (4,044 men; 3,715 women) live in the southwestern part of Achinsk District. About six thousand of them speak their native Turkic dialect, while the remainder live annong Russians and have become Russianized. They are said originally to have lived in Tomsk Province.

The Kachin Tatars live on the banks of the Abakan River and its tributaries in the northwestern part of Minusinsk District. They are called Kachin Tatars because in the beginning of the eighteenth century they migrated to their present abode from the banks of the Kacha River,

'Radloff, (a), 206. 


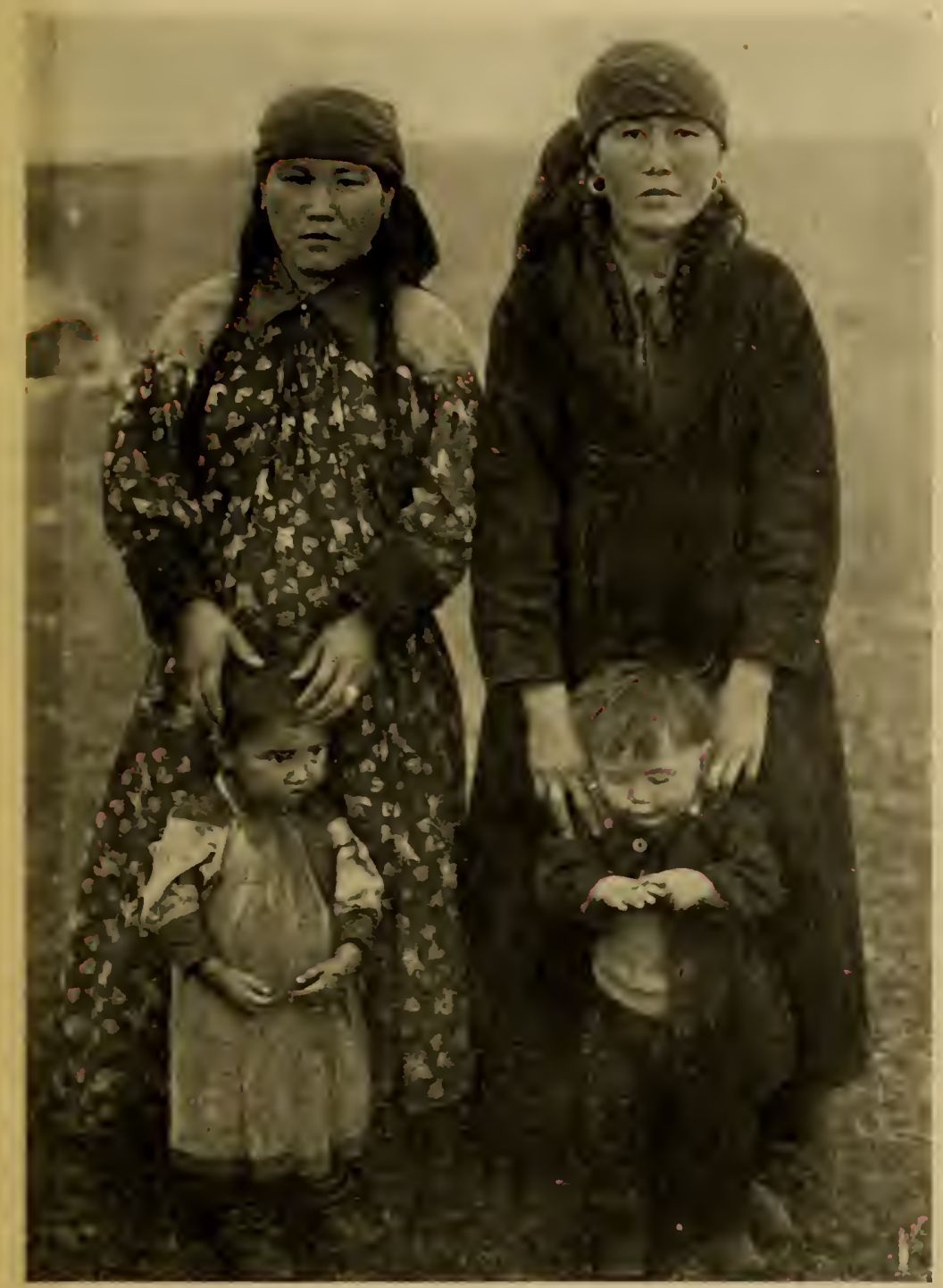

Fig. 5. Kachin Tatar Women and Children, Minusinsk District. 
a tributary of the Yenisei, in Krasnoyarsk District. The population is 11,974 ( 6,048 men; 5,926 women). They have retained their Turkic dialect. Only about five percent of the group who live among Russians have adopted the Russian language.

The Sagai Tatars consist of twelve small tribes, which have been erroneously called clans. They live on the banks of the Abakan River and its tributaries and continue to speak a Turkic dialect. They number 19,570 (9,750 men; 9,820 women). The Beltir is the most numerous of these groups and has a population of 4,859 (2,389 men; 2,470 women). Another Sagai tribe is the Koibal who are Tatarized Samoyed numbering 1,015 (497 men; 518 women).

Two other tribes belonging to the Altaian Tatar group are the socalled Steppe Kamassintzy and Forest Kamassintzy. The Steppe Kamassintzy are a part of the Yeniseian Kott who are related to the Yenisei Ostyak and to the extinct Yeniseian tribes of the Assan and Arin. ${ }^{1}$ They number about 400, are partly Tatarized, partly Russianized, and live in the Kansk District. The Forest Kamassintzy are a completely Tatarized Samoyed tribe ${ }^{2}$ who live among the Tatars of the Kansk District. Their actual number cannot at present be ascertained.

THE KARAGAS

The Karagas are Tatarized Samoyed related to the Forest Kamassintzy. Castren, who studied the Karagas in 1845 , recognized Samoyedic traits in their physical characters and Samoyedic elements in their Tatar language. ${ }^{3}$ Some clans have Samoyedic names. At the time of Castren's travels (1845-1849) the Forest Kamassintzy spoke a Samoyedic dialect, but when Radloff visited them (1865) only Turkic was spoken. Their reindeer breeding may also be regarded as proof of their Samoyedic origin. The Karagas, Forest Kamassintzy, as well as a part of the Soyot, domesticate reindeer even at the present time. ${ }^{4}$ The pure Turkic tribes, on the other hand, were never reindeer breeders. ${ }^{5}$

Thus, the Siberian Turks, omitting the Yakut and Dolgan, number 176,124 ( 89,165 men; 86,959 women), of whom about 93 percent, though preserving their Turkic dialects, understand Russian also. All the Tatars of western Siberia are Mohammedans and it is noteworthy that they were converted to Islam during the Russian domination, thus checking their Russianization. The Altaian Turks and those living in the steppes of

\footnotetext{
¿Castren, (b), 383.

'Castren, (b), 380 .

Castren, (b), 389

Radloff, (a), 206.

For the Yakut reindeer breeders, see p. 27.
} 
Tomsk and Yeniseisk provinces live practically apart and isolated from the Russian centers and consequently have not been much influenced by Russian culture and language. In addition, there live in Western Siberia about 33,000 Lirghiz who will be described with the rest of this numerous people whose habitat falls outside of Siberia proper in Turkestan and the Steppe provinces.

\section{The Moxgolic Tribes}

The Eastern or true Mongols, the Western Mongols or Kalmuck, and the Buryat constitute the three great Mongol divisions. The Buryat are closely related to the Khalkas tribe of the Eastern Mongols, most of whom are nomads, occupying the vast region known as Mongolia, and including the Gobi Desert. As the result of wars and migrations, the Western Mongols, or Kalmuck, are at present scattered over the immense tract lying between Siberia and Lhassa and from the banks of the Hoangho to those of the Manich, a tributary of the Don. The more compact groups are found in European Russia (the Astrakhan Kalmuck), in the Caucasus (the Terek Kalmuck), in Jungaria (the Torgout) ${ }^{1}$, in nortl-western Mongolia, between the Altai Mountains and Tyan-Shan, and lastly, in Alasha and farther to the west, in the Chinese district of KukuNor in northern Tibet. The Eastern Mongols number about 700,000; the Western about a million; and the Buryat, $28 S .599$ (145,717 men; 142,882 women). Thus, the Buryat are the most numerous aboriginal Siberian tribe, the Turkic Yakut occupying second place (p. 25).

Some authors add a fourth to the three Mongol divisions, the socalled Hezare or Hazara tribes abandoned by Timur, or as he is generally called, Tamerlane, in Afghanistan. It appears that at present these tribes retain only a few physical characters, as evidence of their origin, speak a Turkic dialect, and have mixed with Turkic tribes and adopted their language and religion. The Hazara lead a nomadic life, range between Herat and Kabul, and are divided into a western and eastern group, of which the former are Sunnites and the latter, Shiites.

As compared with the Turks, the Mongols are few in number, about two million in all, and something over this figure, if we include the Hazara.? 


\section{The Buryat}

The Buryat live in two provinces of Eastern Siberia: Transbaikalia and Irkutsk. In Transbaikalia, according to the census of 1897, there were 177,637 Buryat (90,024 women; 87,613 men) who constituted 26.4 percent of the inhabitants of the province. The bulk of the Transbaikalia Buryat live in the southern and western parts of the province. They are zealous Buddhists and belong to the Yellow Hat sect, or Lamaists, followers of Tsou-kapa, a Tibetan reformer. The greatest number of Lamaists live in the districts of Selenghinsk (60.7 percent of the inhabitants), Verkhne Udinsk (31.9 percent), Chita (28.3 percent), Troizkosavskii (32.8 percent), and Bargusin (45.2 percent). The two eastern districts, Nertchinsk and Stryetensk, and the southern district Aksha (or Akshinsk) along the Mongolian border, are inhabited by Russian settlers and by Buryatized Tungus. Very few Buryat can be found in these districts.

The Transbaikalian Buryat lead the nomadic or semi-nomadic life of cattle breeders, although a knowledge of agriculture is at present becoming more prevalent. Their language is an eastern dialect of Buryat, called Mongol-Buryat, and is related to the Mongolic dialect of the Khalkas. Only 5.2 percent of these Transbaikalian Buryat were registered as speaking Russian.

The Buryat of Irkutsk Province number 110,745 (57,905 men; 52,840 women). Their religion is shamanistic. They have become Russianized to a greater degree than their Transbaikalian kin. Most of them have become agriculturists and now live with the Russian settlers and constitute 21.5 percent of the whole population of the province. On the banks of the Uda and Goloustnaya rivers, emptying into Lake Baikal, and the Oka River, they live in more compact settlements. They form the bulk of the population of the southern part of Verkholensk District. The Irkutsk Buryat speak the Western or so-called Barga-Buryat dialect. Twelve and one half percent $(13,858)$ of the Irkutsk Buryat regard Russian as their native language. Among the remaining Irkutsk Buryat are many people speaking both Russian and Buryat. What the Buryat language had lost as a result of the Russianization of a part of the Irkutsk Buryat was recovered by the Buryatizing of the Tungus who live among them. As we shall see later, 9,714 Tungus regard the Western Buryat dialect as their native tongue. 

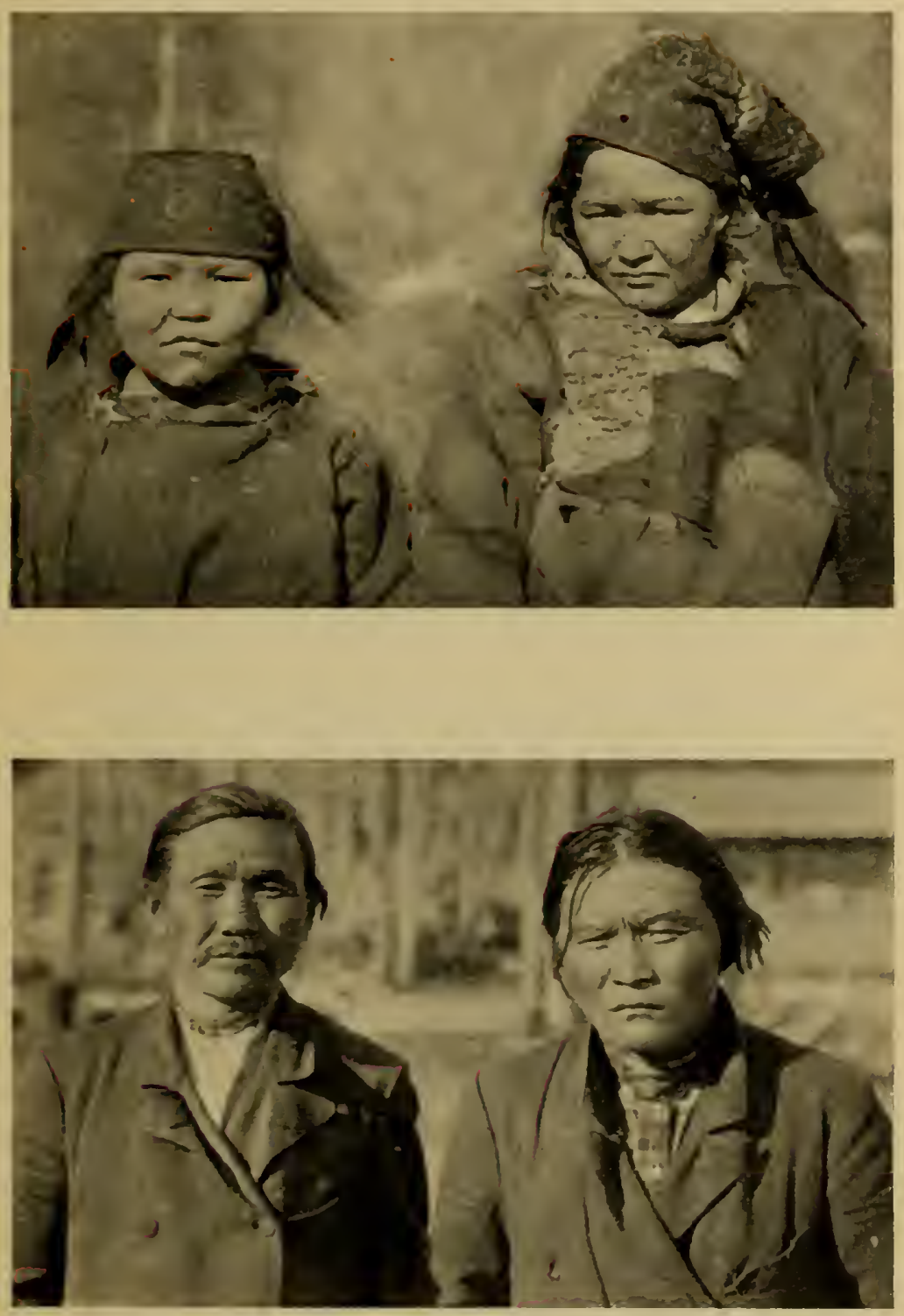

Fig. 6. Buryat Women (above) and Men (below), Irkutsk P'rovince. The Irkutsk Buryat are sedentary agriculturists, speaking the western Buryat dialect. A small number, however, regard Russian as their native tongue. 


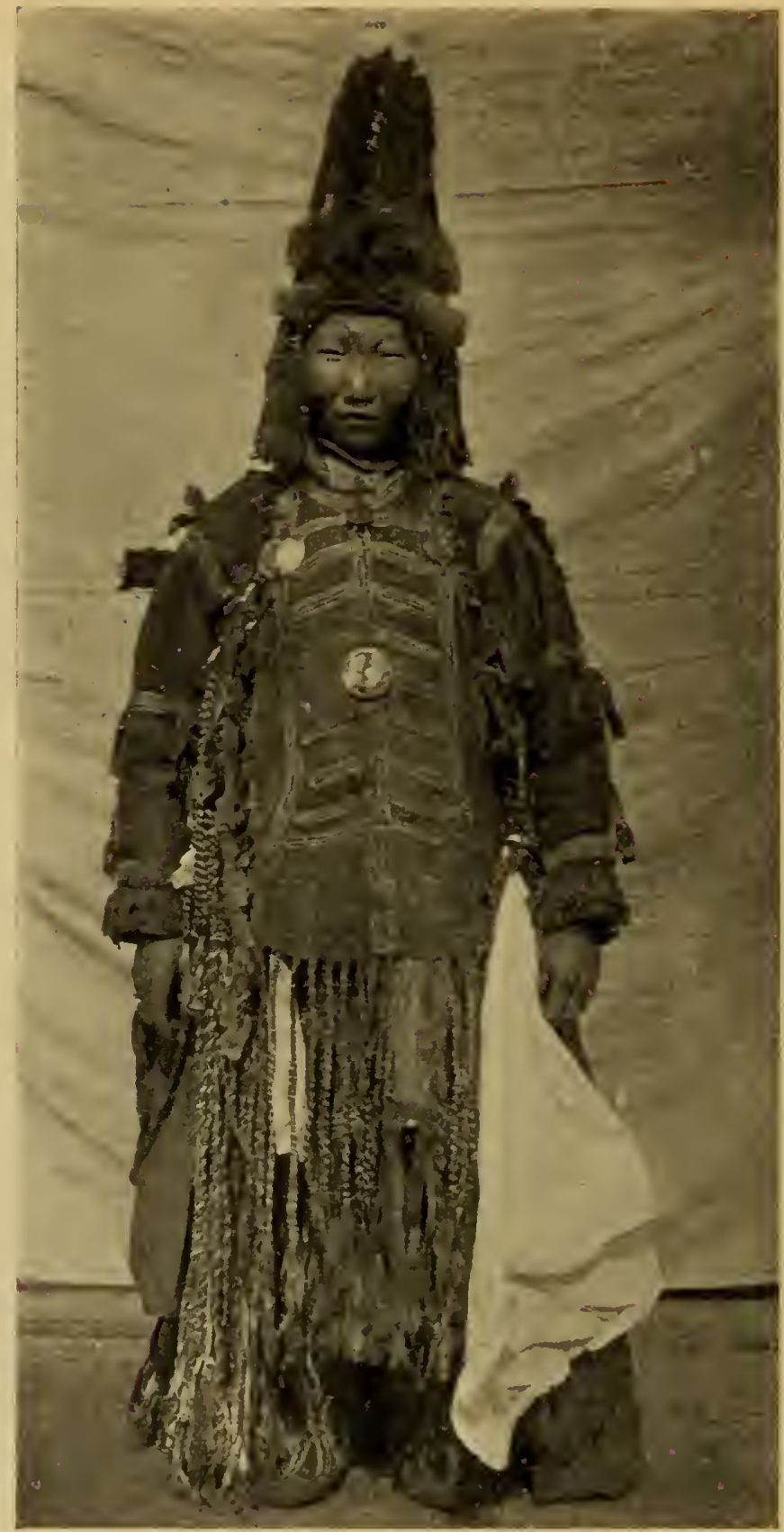

Fig. 7. Buryat Shaman, Irkutsk Province. The Buryat of Irkutsk Province are far more Russianized than those of Transbaikalia, but have retained their old shamanistic beliefs and practices. 


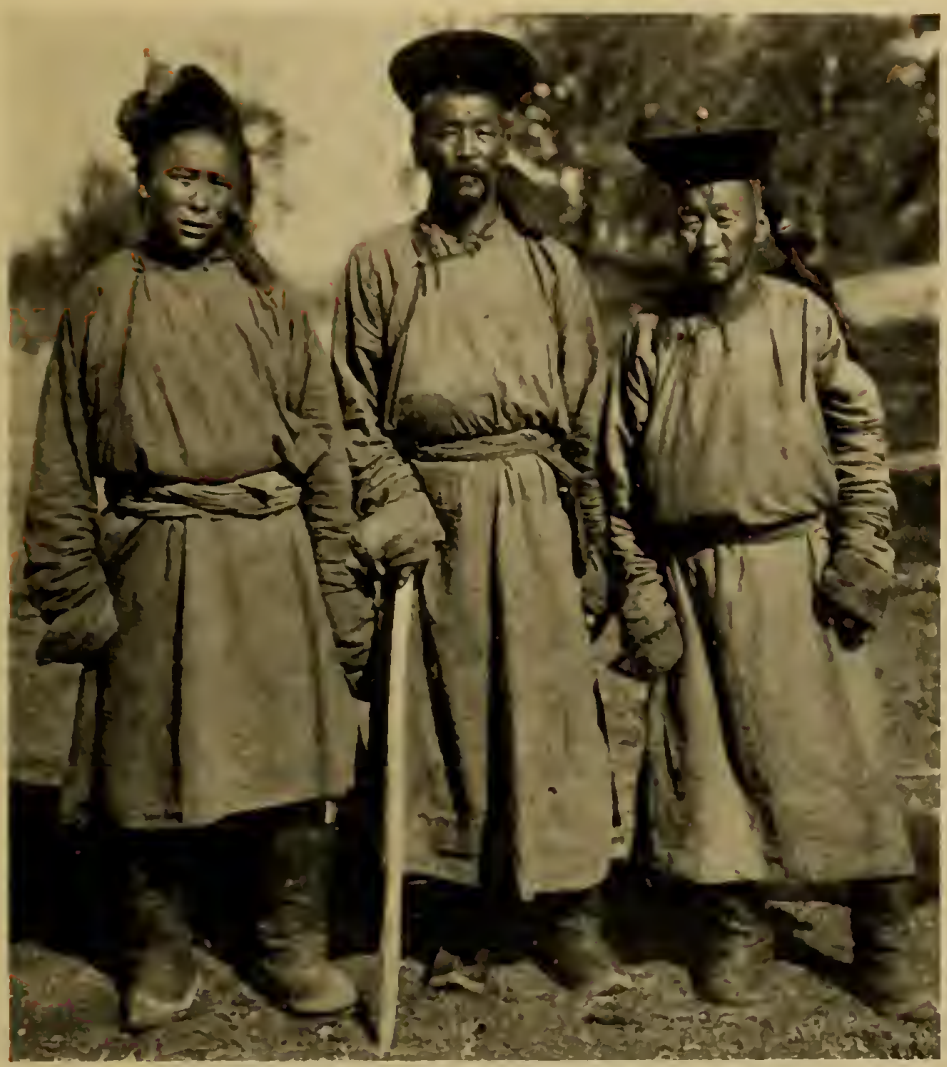

Fig. 8. Mongols of the Khalka Division, related to the Buryat.

\section{The Tunges Tribes}

The original home of the Tungus is, as yet, undetermined, though usually they are said to have spread over the whole of Eastern Siberia from the Valley of the Amur River. Beginning with the second century of our era, the Chinese annals mention Tungus tribes under various names. The actual date of the Tungus inigration from the Manchu country to Siberia is not known. Patkanoff, however, believes ${ }^{1}$ that, beginning with the seventh century, A.D., some of the Tungus tribes, under pressure of more powerful peoples who waged war to the south of the Amur River, migrated to the north from Manchuria. The Tungus are

'Patkanof,, (d), 26. 
related to the Manchu who conquered the Chinese Empire in 1644 and founded a sovereign dynasty. ${ }^{1}$

\section{PRESENT DISTRIBUTION, NUMBER, AND TRIBES}

At present the Tungus are distributed over all of Eastern Siberia, from Manchuria to the Arctic Ocean and from the Okhotsk Sea to the eastern tributaries of the Yenisei River. Small Tungus groups were located to the west of the Yenisei in the region of the Taz River among the Samoyed and on the Kass River, an eastern tributary of the Yenisei, among the Yenisei Ostyak.

In comparison with the other Mongoloid divisions the Tungus are numerically insignificant, for, according to the census of 1897 the population was 76,504 (39,303 men; 37,201 women). Patkanoff, however, believes that this number should be increased to 78,000 or 79,000 , since he considers the census to have been inaccurate. Their kin, the Manchu, number about $12,500,000$. The Koreans are regarded as a mixture of Tungus and Chinese.

Professor L. Schrenck, ${ }^{2}$ who, in the first half of the nineteenth century, studied the Amur peoples, found ten tribes which he divided into four dialectic groups:-

1. Daur and Solon

2. Manchu (a small un-Chinesized branch of the Manchu), Goldi, and Orochi.

3. Orochon, Manegri, Birar, and Kibi

4. Olchi (the Mangun on the lower course of the Amur River and Oroki of Sakhalin), Negidaltzy, and Samaghir

It is still an open question whether these Tungus divisions should be regarded as separate tribes, as blanches, or perhaps as clans of one or another of the groups. Thus, L. Sternberg considers ${ }^{3}$ the Samaghir a branch of the Goldi tribe, dividing the Amur Tungus into two groups:-

The Ivenki, nomadic reindeer-breeding Tungus (Orochon of Transbaikalia and the Upper Amur, Manegri, Birar) and the Nani, sedentary dog-breeding hunters and fishermen (Oroki, ${ }^{4}$ Olchi, Goldi, Samaghir, and the Orochi living on the shores of the Tatar gulf) were formerly also reindeer breeders.

Contrary to Schrenck's contention that the Orochi came from Kiorea, Sternberg asserts that their original home was the Amur Valley, where

\footnotetext{
11t should be stated that Castren, (b), 75 aseribed an Altaic origin, like that of other Mongoloids, to the Tungus-Manchu. Shirokogoroff placed their original abode in northern China. (See p. 15.) ischrenck, (a)

i) a communication to the author.

"It should be noted that the Sakhalin Oroki still have reindeer.
} 
some Tungus groups have clan names in common with the Orochi. He mentions another group of Tungus, called Amguntzy, who live on the banks of the Amga River and were formerly reindeer breeders, but, after losing their reindeer they became settled fishermen and dog breeders. According to Patkanoff, the Anguntzy belong partly to the Nagda or Negidaltzy tribe and partly to the Samaghir. They were mixed with the Gilyak to a great degree.

Professor W. Kotwich of Petrograd, the foremost authority on Manchu-Tungus languages, classifies the Manchu-Tungus tribes according to their dialectic affinities as follows:-

1. Manchu including Sib

2. Tungus proper (including Lamut), Managhir, Solon, and Daur

3. Goldi group, including Olchi, Oroki. and Orok

4. Samaghir and Nagda

Among the Amur Tungus we find sedentary agriculturists (the greater part of the Manchu, the Daur, the Goldi, and the Orochi of the southern Usuri District) who also rear cattle.

\section{THE TUNGUS PROPER}

The Tungus proper number 62,068 and include the sorcalled Lamut and the Amur Orochon. The writer proposed the elimination of the term, Lanut, which is derived from the Tungus word, lam, sea (actually sea means nam in Tungus). Lamut is supposed to mean coast dweller. The Tungus of the Okhotsk region were known as Lamut, but, according to the author's observations the name is unknown on the shores of the Okhotsk Sea. The Okhotsk Tungus, even the sedentary fishermen, are known as Tungus, and the Okhotsk reindeer-breeding Tungus, who wander, in winter, as far as the Kolyma River, and a part of whom have migrated to the Kamchatka Peninsula, call themselves Tungus, and are so known to their neighbors. On the other hand, some Tungus clans who wancler in the mountains of the Kolyma and Verkhoyansk districts are officially recorded as Lamut.

The Orochon whose name means reindeer-breeders (Tungus, oron, meaning reindeer $)^{1}$ are identified, both culturally and dialectically, with the Tungus proper.

The Tungus proper, consisting in the main of nomadic clans, are scattered over all of eastern Siberia, living among Russian settlers, Buryat, Yakut, Yukaghir, and partly among the Chukchee, Koryak, and

The term, Orok, may also be deriverl from Oron, reindeer 

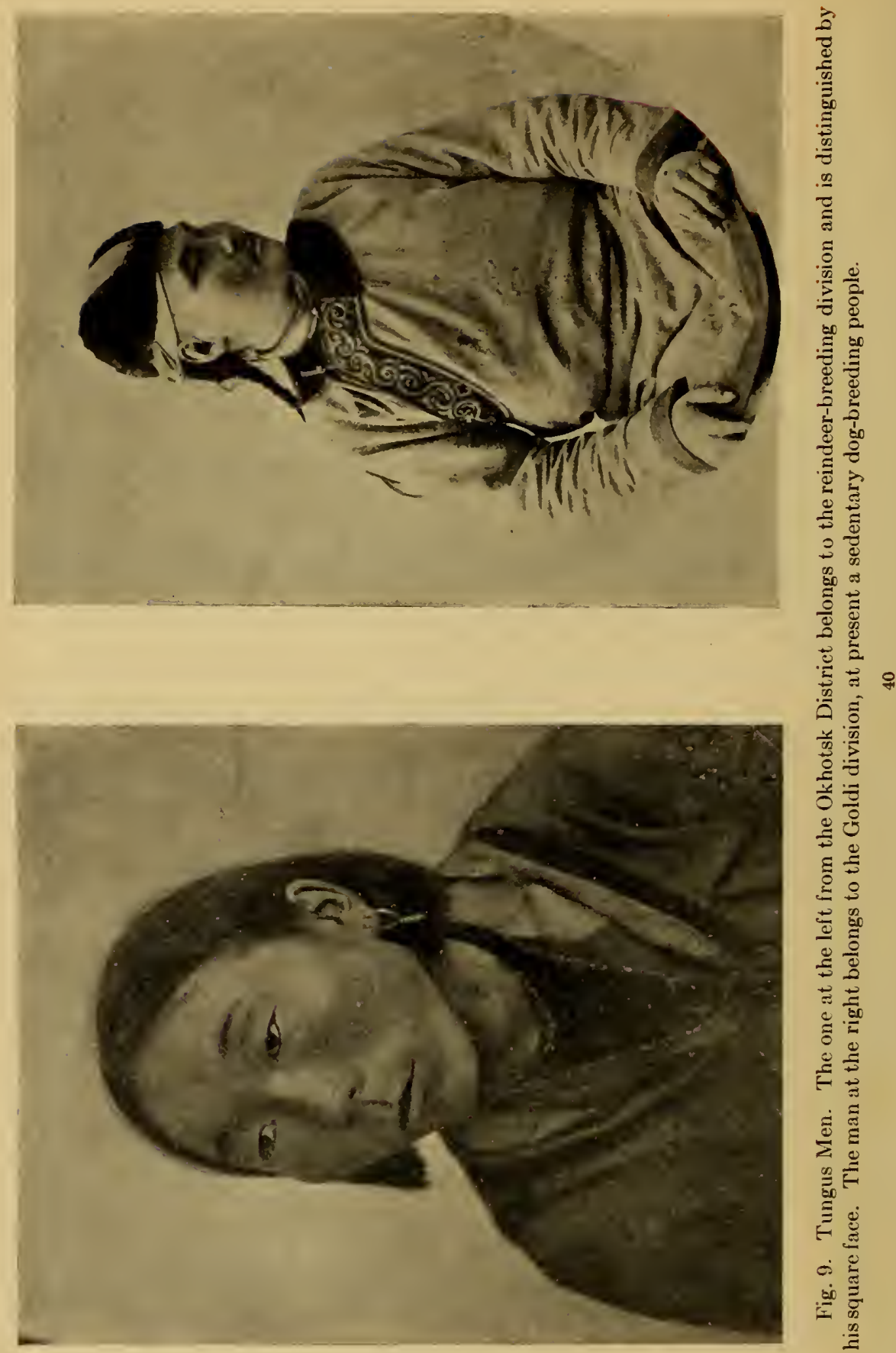
Kamchadal. In the thirties of the nineteenth century, they appeared on the Kamchatka Peninsula. The Tungus proper are distributed among the provinces, as follows:-

Province

Liamchatka

Amur

Sakhalin

Yakutsk

Irkutsk

Transbaikalia

Yeniseisk

\section{Population}

8,848 ( 4,544 men; 4,304 women)

1,104 (623 men; 481 women)

143 ( 83 men; 60 women)

12,231 (6,251 men; 5,980 women)

2,191 (1,103 men; 1,088 women)

34,379 ( 17,108 men; 17,271 women)

3,169 ( 1,662 men; 1,507 women)

These figures are, in all probability, lower than the actual figures, since many nomadic families were not recorded during the census of 1897 .

\section{LANGUAGE}

Their native tongue has not been preserved by all the Tungus, as may be observed in the following tabulation:-

\section{Language spoken}

Tungus

Russian

Buryat

Yakut

Yukaghir
Number

27,597

19,742

9,714

4,760

237
Percent

44.5

31.8

15.4

7.6

.4

Thus we see that 55.5 percent of the Tungus have adopted foreign languages, though a part of the latter also know Tungus.

\section{RELIGION}

The modern Tungus are Christians, Lamaists, and pagans (shamanists). Eighty-two percent, 50,874 (25,933 men; 24,941 women) belong to the Greek Catholic Church. Their conversion to Christianity began in the seventeenth century, and in Transbaikalia, as early as the latter part of the sixteenth century. But, for the most part, these baptized Tungus may still be regarded as Christians in name only. Their nomadic life seldom brings them into contact with their priests, and though they like the church ceremonies and rituals, their religious concepts and psychology remain shamanistic.

The Lamaistic branch of the Buddhistic faith spread in Tibet, Mongolia. and Jungaria. Of the Tungus 14.9 percent or $9,258(4,535$ men; 4,723 women), living in Transbaikalia, are recorded as Lamaists. 
Lamaism appeared in Transbaikalia only two centuries ago, replacing shamanism, and thus beginning a transformation in the spiritual life of the Transbaikalian Tungus and Buryat which is still in progress.

Only 3.1 percent of the Tungus were recorded in the census of 1897 as pagans (shamanists) or, in other words, 1,936 (907 men; 1,029 women) individuals. But actually, the greater number of nomadic Tungus said to be Christians really belong to this category. The shamanists were located in the provinces of Transbaikalia and Yeniseisk.

\section{DIVISIONS AND CLASSES}

The former Russian law classified the Siberian natives as nomadic. (brodyachi), half-nomadic (kochevoi), and sedentary (osyedly) peoples. The nomadic Tungus, numbering 28,472 (14,702 men; 13,770 woinen) wander all over Eastern Siberia with their reindeer. The half-nomadic Tungus, numbering 29,737 (14,763 men; 14,974 women) have seasonal places of abode. They are cattle breeders and fishermen and may be found in the provinces of Transbaikalia and (a small number) Yakutsk. The sedentary Tungus, numbering 3,859 (1,910 men; 1,949 women), are mostly agriculturists and live chiefly in Transbaikalia Province. About 45 percent of this group live in Irkutsk and Primorskaya ${ }^{1}$ provinces and are cattle breeders or fishermen.

The greater number of sedentary Tungus are Cossacks who live along the Mongolian border in the Aksha District of Transbaikalia Province. In the beginning of the eighteenth century, the Russian Government, in addition to its Russian Cossack divisions, organized Tungus and Buryat Cossack divisions to guard the frontier from the intrusion of Chinese-Mongol hordes. In 1750 these were re-organized as special Tungus Cossack and Buryat regiments. The native Cossacks were exempted from taxation, received some other special privileges, and a small salary for their service which had no age limit. The Tungus Cossack chief, Gantimur (Khan-Timur), and his family, were raised to the ranks of the imperial nobility under the name of Gantimuroff. In 1897 there were 371 (194 men) hereditary Tungus nobles.

The Tungus Cossacks are agriculturists and many of them also have large herds of cattle. In certain seasons, under the lead of Mongol herders, the herds cross the Chinese frontier to the pasture lands of the Mongolian steppes. Most of the Tungus Cossacks adopted the Buryat language and habits and only official records disclose their Tungus origin. 




\section{CHAPTER II}

\section{THE AMERICANOIDS OF SIBERIA}

On the basis of their physical, cultural, and linguistic affinities with the American aborigines, the northeastern Siberian Chuckchee, Koryak, Kamchadal, Churantzy, Yukaghir, and Gilyak are grouped under the general term, Siberian Americanoids. While America is geographically and politically separated frond Asia by Bering Strait, it does not constitute an ethnical barrier, and the anthropological boundaries may be extended far to the west of Bering Strait. For the reasons to be enumerated below the writer rejects the terminology applied to these tribes by former investigators.

The tribes named above, including the Ainu and Yenisei Ostyak are classified by Max Müller, ${ }^{1}$ as Siberian peoples, belonging in the northern Turkic division of the Turkic-Altaic family. Of course, tribes now living in Siberia may be called peoples of Siberia, but historically speaking, this may be wrong. It is also incorrect to class them with the Turks.

Friedrich Müller calls these tribes, including the Ainu, Aleut, and Eskimo, "Arctic or Hyperborean races."'-2 Neither the Ainu nor the Kamchadal can be called an Arctic tribe. "Arctic or Hyperborean" is, in the first place, a geographical term, and even if it had any ethnological significance, referring to peoples possessing a circumpolar culture, we cannot correctly ascribe any somatological significance to it.

Oscar Peschel divides these tribes into two groups, ${ }^{3}$ one of which he calls "the Bering nations" in which he includes the Kamchadal, Koryak, Chukchee, Eskimo, Aleut, Tlingit, and the tribes of Vancouver Island. Although embracing tribes with some common affinities, the classification remains, nevertheless, purely geographical. He calls the second group "Northern Asiatics of doubtful position" and includes in it tribes little related to each other, as the Yenisei-Ostyak, Yukaghir, Ainu, and some extinct Yeniseian peoples. If we except the Yukaghir, the name might be applicable even now.

Schrenck refers to both groups by the same name, calling them "Palaeasiatics" (northern and northeastern) as opposed to the "UralAltaians." The scant notes on the languages of these tribes available at that time have shown that structurally they have no affinities with the Ural-Altaic stock. Schrenck believed that they are remnants of a formerly more numerous stock driven to their present abode by more

\Müller, Max, 322

Muller, F. R. 195.

Peschel, 35\%-100. 
recent comcrs. This historico-geographical classification was proposed by him pending a detcrmination of the linguistic affiliations of the Palaeasiatics. ${ }^{1}$ Results of recent careful investigations of the tribes of northcastcrn Sibcria make it clear that the term, Palaeasiatics, should also be eliminated, even when we consider it from the point of view of Schrenck himself. In addition, "Palaeasiatic" does not include any reference to the somatological problems of the region. Further, if we adopt the views of leading anthropologists as to the Asiatic origin of mankind, in general, wc may apply the name "Palaeasiatic" not only to all the old races of Asia, but also to all the races of the world.

We do not consider the substitute term proposed by Miss Czaplicka, "Paleo-Siberians"' as any more suitable. This classification also is not bascd on somatological characters; in addition, there are no reasons why we should regard the Chukchee or Koryak as more ancient inhabitants of Siberia than are the Samoyed or Ostyak.

Another exclusively geographical name we propose to reject is Ratzel's term, "Rand Völker" (marginal peoples) which may include both the Siberian coastal tribes and the Eskimo.

For his part, the writer believes the term, Americanoid, to be the most suitable, for if we disregard the Asiatic, or rather Eurasiatic cultural achievements, such as the domestication of the reindeer, we will find the peoples of northeastern Siberia related to the American aborigines in language structure, spiritual life, material culture, and somatology. Professor Boas has suggested that a mass immigration started from Asia into North America during one of the interglacial periods, or before the last glaciation. The people living in America were cut off from their congeners in the Old World and forced to migrate southward because of the spread of the last ice cap. At the end of this glaciation, as the ice retreated in both North America and Asia, communication between the two continents again became possible. Members of the American race moved back toward the north, crossed to Asiatic soil, and occupied the northeastern part of Siberia. ${ }^{3}$ Therefore, the Chukchee, Koryak, Kamchadal, Yukaghir, Chuvantzy, and Gilyak are classified as Americanoids.

The theory of the Asiatic origin of the American aborigincs and of the re-emigration from America into Asia of the Siberian tribes we call Americanoids, may find a corroborative parallel in the history of the distribution of certain Asiatic zoological species. Professor Peter P. Sushkin of the Russian Academy of Sciences in a paper read before the

ISchrenck, (a), 255-25S.

?'Caplicks, (a), 25.

Jochelson, (c), 90-95. 
National Academy of Sciences in Washington April 25, 1925, said:-

II. Severtzoff and Professor Sassonov, after studying the distrilution and structure of the wild sheep, have both come to the eonclusion that this genus migrated from High Asia to Ameriea before the last glaciation; that in Ameriea they were driven south by the glaciation; that afterwards the. American stock spread again to the north and gave origin to another group; and finally that this new group spread back into the Asian continent and occupied Eastern siberia. so that the present Siberian sheep stand geographieatly and structurally, in no close relation with the sheep of High Asia.

The Chukchee, Koryak, and Kamchadal, in language, somatology, spiritual and material culture, form one ethnic group with a common origin.

\section{The Chlikhee}

According to official census data the Chukchee population was 11,771 (5,811 men; 5,960 women). Bogoras estimates their number at about 12,000. Their territory extends from the shores of the Chukchee Peninsula to the tundra of the lower course of the Indigirka River. They are divided into nomadic reindeer breeders and sedentary coast dwellers. Of the total population only about 3,000 are a maritime people. Traditionally, it is said that a division of the Reindeer Chukchee formerly wandered over the Kolyma tundra between the Alazeya and Kolyma rivers, but, in the eighteenth century, with the advent of the Russian conquerors, they retreated to the east of the Kolyma River. They refused to pay tribute to the Russian officials and after a hard and inconclusive struggle were left to themselves. Only in the sixties of the nineteenth century; after an understanding with some of the Chukchee chiefs did the Russian authorities permit the Reindeer Chuckchee to return to the west of the Kolyma River. Now some Reindeer Chukchee families wander over the tundra between the mouths of the Kolyma and Alazeya rivers; thirteen camps were located by the writer between the Alazeya and Indigirka rivers and ten families were found (in 1902) in the valley of the Yerchen River, a tributary of the Indigirka. This most westerly group of Reindeer Chukchee cross the Indigirka River often during the winter and appear, for trading purposes at Alayikha, a Yakut village, located on the banks of a western tributary of the Indigirka River with the same name.

The greater number of Reindeer Chukchee $(1,186 ; 566$ men and 620 women) of the Kolyma District, Yakutsk Province, live in Yakutsk Province in what was formerly Yukaghir territory, bounded on the south

'sushkin, 522-523. 
by the Dry Anyui River, on the north by the Arctic Ocean, on the west by the Kolyma River, and on the east by the Chaun River.

A third group of Reindeer Chukchee of the Kolyma District, numbering about 400, is located in the valley of the Omolon River and its tributaries. However, the bulk of the Reindeer Chukchee, 6,611 (3,280 men; 3,331 women) wander in the Anadyr District of Kamchatka Province (formerly called Primorskaya). The Anadyr River is regarded as the southern boundary of the Chukchee country, but a number of camps, with a population of 628 (349 men; 279 women) wander in the Gishiga District of the same province among the Reindeer Koryak and partly Reindeer Tungus.

There are no maritime or sedentary Chukchee in the districts of Kolymsk (Yakutsk Province) and Gishiginsk (Kamchatka Province). These groups live exclusively in the Anadyr District, and are located on the shore of the Arctic Ocean between Cape Deshnef and the mouth of the Chaun River, i.e., at the boundary of the Kolyma District. Thirty-two villages are scattered along the coast, one of which, Koluchi, is situated on an island of the same name. Farther to the west, in the Kolyma District, there are no permanent coast dwellers. The author learned, however, that some families of Reindeer Chukchee from this district came to the coast in order to hunt sea animals, after losing their herds in epidemics.

Three villages of sedentary Chukchee are situated on the banks of the lower course of the Anadyr River. One of these, Wueng, is near the Russian administrative post, Novo-Mariinsky, at the entrance to the Anadyr estuary. Another village, Erulen, is located in the northern part of Holy Cross Bay (Svyatoi Krest). Nine villages are located on the shore of Anadyr Gulf. Finally, twenty-four Chukchee villages are situated on the Pacific Coast between Cape Deshnef on the north and Cape Chaplin (Indian Point) on the south, or otherwise stated, between the settlements of the Peekit ${ }^{1}$ Asiatic Eskimo on the north and those of the Aiwan Eskimo on the south. Four of these villages are located on Kiyinen Island (also Arakamchechen), on Yaurakinon. on an island of the same name, and four more on two peninsulas protruding into Mechigme Bay. In this region also is located Chechin Village the population of which is mixed Chukchee and Aiwan and in which the Chukchee language is spoken. Thus, there are in all seventy villages of maritime or sedentary Chukchee. 
The IJorlak

Like the Chukchee, the Koryak are divided into reindeer breeders and maritime people, or, tundra nomads and coast dwellers. In 1900, their total population, according to the author's census taken during the Jesup Expedition, was 7,530 (3,829 men; 3,701 women). Of these, $3,74 \mathrm{~S}(1,96 t$ men; $1,7 \mathrm{St}$ women) were reindeer breeders and $3,7 \mathrm{~S} 2$ (1,865 men; 1,917 women) sedentary people. Thus, it will be observed that the two horyak divisions are almost equal in number, while among the Chukchee the maritime people constitute only a third of the total, This may be due to the extent and indentation of the coast line of the Foryak territory, where settlers can procure maritime food, while the interior is less extensive than that of the Chukchee. The Koryak live in four districts of Kamchatka Province: in Okhotsk, Gishiginsk, Anadyr, and Petropavlorsk.

\section{REINDEER KORYAK}

At present there are no Reindeer Koryak in the Okhotsk District and most of the camps of the nomadic Koryak may be found in the Gishiga District. Their population is 2,3S7 ( $1,2 \mathrm{S7}$ men; 1,100 women). In the Petropavlovsk District in the northern part of Kamchatka live 1,2St Reindeer Koryak (6+2 men; 642 women), while in the Anadyr District there are only 78 individuals (33 men; 45 women). Some Reindeer Koryak wander with the Reindeer Chukchee.

\section{MARITIME KORYAK}

Before the advent of the Russians, Koryak territory reached as far south as Tauisk on the Okhotsk Sea, but now only two Koryak villages, Yamsk and Tumansk, with a population of 244 (126 men; 118 women) are located in the Okhotsk District. These Koryak are Russianized Christians and physically represent a mixture of Russian, Tungus, and Yakut. According to official records 66 percent of the inhabitants of these two villages are Koryak.

In the Gishiga District, forty-three villages have been recorded: one village, Nayakhan on Gishiga Bay; eighteen villages on the shores of Penshina Bay; twenty-four villages on the coast of Bering Sea. The most northerly thirteen villages on Bering Sea are inhabited by the Kerek division of the Maritime Koryak. Their territory is bissected by the official boundary line between the Anadyr and Gishiga districts, thus their five northermmost villages are in the Anadyr District. 


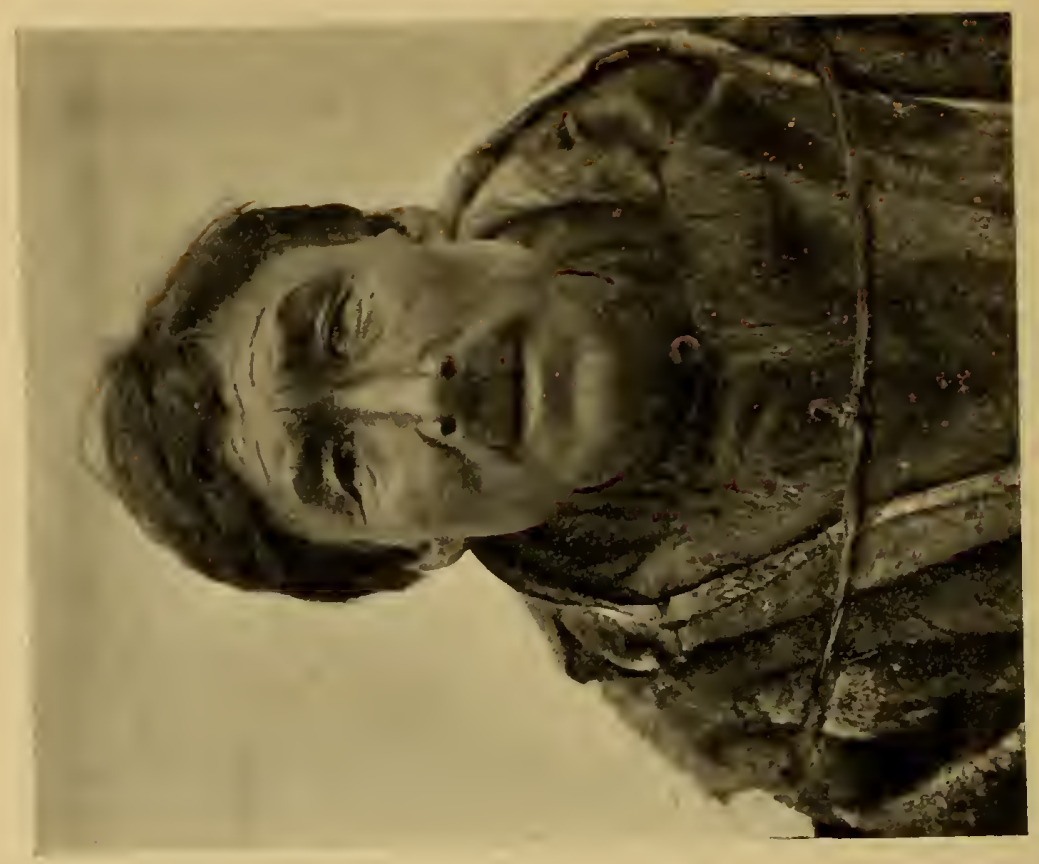

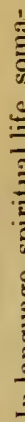

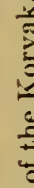

5

绕

릴

峁

苛苞

这

छ

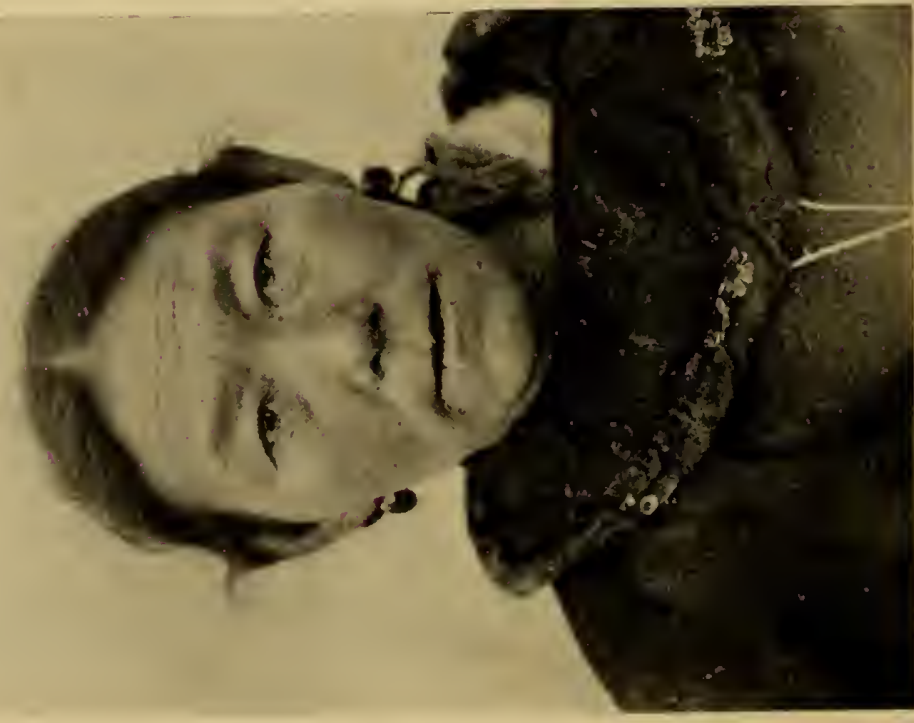

는

品

$E$

롤

空

롤

톯

릴

늘

造

$\stackrel{\circ}{\Xi}$

.

我 
Five Koryak villages are located on the Okhotsk Sea in Petropaylorsk District. The southernmost of these is Vorampolka. Of the six villages on Bering Sea the most southerly is called Osernoye. Thus the total number of Maritime Koryak villages is fifty-four.

\section{The Famchadal}

The Kanchadal occupy the southern part of the Petroparlorsk District of Kamchatka Province on the peninsula of the same name. The territory formerly occupied by them now has a population of $\$, 069$, of which 3,370 are Russian, 3,555 Lamchadal, and 802 Reindeer Koryak and Tungus immigrants. The remaining 310 include Japanese, Chinese, Koreans, and whites (Americans and Europeans).

Since the Kamchadal have become Russianized only the inhabitants of the seven villages between Amanino and Soposhnoye on the western coast have preserved their native language, the western Kamchadal dialect. The inhabitants of Sedanka village on the Tighil River speak the northern Kamchadal dialect. Formerly, four Kamchadal dialects were known. At present, even the abore-mentioned Kamchadal speak a kind of Russian-Kamchadal jargon rather than pure Kamchadal. The younger generation is learning Russian in the schools and before long the Kamchadal language will be altogether forgotten, as was the case with the Kamchatka Rirer and the southern dialect spoken between the Great River (Bolshaya Reka) and Lopatka Cape. While the northern Kamchadal dialect spoken on the Tighil River cont ains a considerable number of Koryak words, the southern dialect had an intermixture of Kurilian words. Krasheninnikoff called the southern Kamchadal, Kurilian.

The Kamchadal have been and still are a true fishing people. Although they hunted the wild Kamchatka variety, they did not adopt the domesticated reindeer from their Koryak neighbors. Fish particularly different species of salmon, ascend the Kamchatka rivers in such abundance that they amply satisfy the needs for food. During the short fishing season the Kamchadal have no time to dry or smoke all the fish for winter use and the greater part are stored in holes dug in the ground and corered with stones and earth, to be consumed later in its clecayed state by both men and dogs.

Sea mammals are hunted to some extent by the Kamcharlal of the western coast. Since they do not possess skin boats, they do not go out to sea, but kill the seals, white whales (Delphinopterus Leucas), and sea lions which enter the river mouths to catch the ascending fish. The seals 
are caught in thong nets. Another method is to spear or shoot them at their rookeries. Sea lions rarely enter the river mouths.

Horned cattle and horses were imported into Kamchatka chiefly from the Yakut of the Okhotsk District. In spite of the fact that they were not well cared for, they were acclimatized and have produced a small-sized, but strong race of domestic animals.

An important, food item of the Kamchadal and Russian inhabitants of the country is cow's milk. They use sweet as well as sour milk and pot cheese. Although the milk is rich in fat, butter is rarely made. Principally becausc of the scant winter feed and the housing in unheated stalls, the cows give but a small quantity of milk, about two or three quarts a day. The Kamchadal make littlc hay, as the seasons for fishing and hay making coincide. If we reckon one cow for every three inhabitants, the number of cattle may be estimated, according to the author's census, at about 2,000.

The Kamchatka horses are small in size, short-necked, wide-breasted, and short-legged. During the winter, they are covered, particularly their legs, with long thick hair. Horses are used only in summer as riding and pack animals; in winter, they are rarely fed hay but are released to graze as best they can; consequently, they turn wild and in the summer must be captured and again broken for riding.

Prior to the arrival of the Russians, the driving dog was the only domestic animal known to the Kamchadal whose dogs were regarded as the best and biggest driving dogs of Siberia. At present, as a result of an unfavorable environment, the dogs are small in size. They are worked hard during the long winter and are tied up far from the village and badly fed during the summer; otherwise, calves and colts, and even cows and horses, are in danger of being injured by dogs. Owing to economic, climatic, and topographic conditions, the Kamchadal cannot dispense with the driving dog and every family has from eight to fifteen. According to the author's census of 1911, there were over 5,000 dogs. The old Kamchadal sledge for riding astride is no longer in use, the Russians having introduced the type of sledge used all over eastern Siberia. The harnessed dogs are tied in pairs to a long thong which is fastened to the sledge.

There are no other domesticated animals, no goats, nor sheep, nor birds, one reason for this condition being that they would be exterminated by the ever hungry dogs which very often find the means to free themselves from their bonds.

The Russian Government tried repeatedly to introduce agriculture 


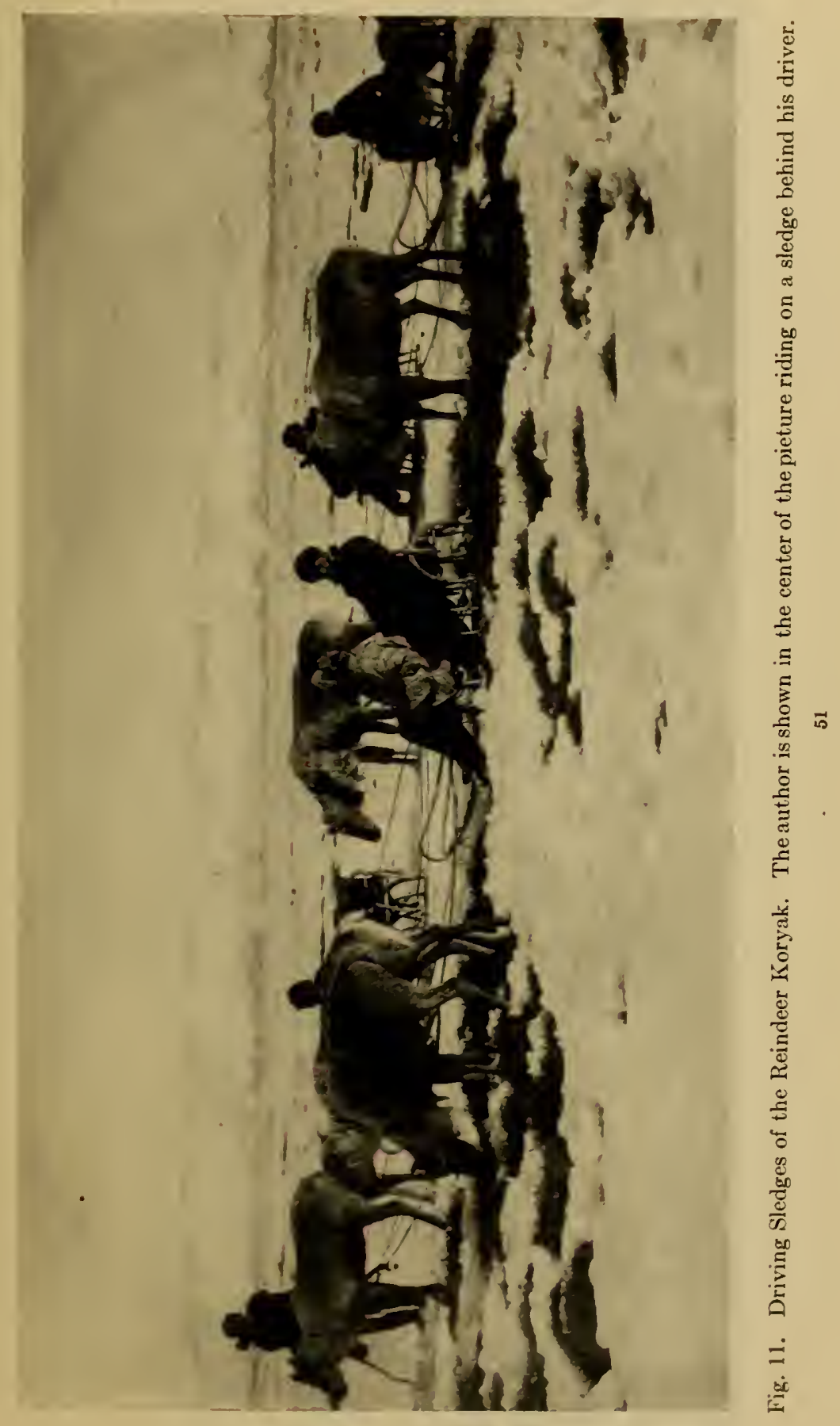




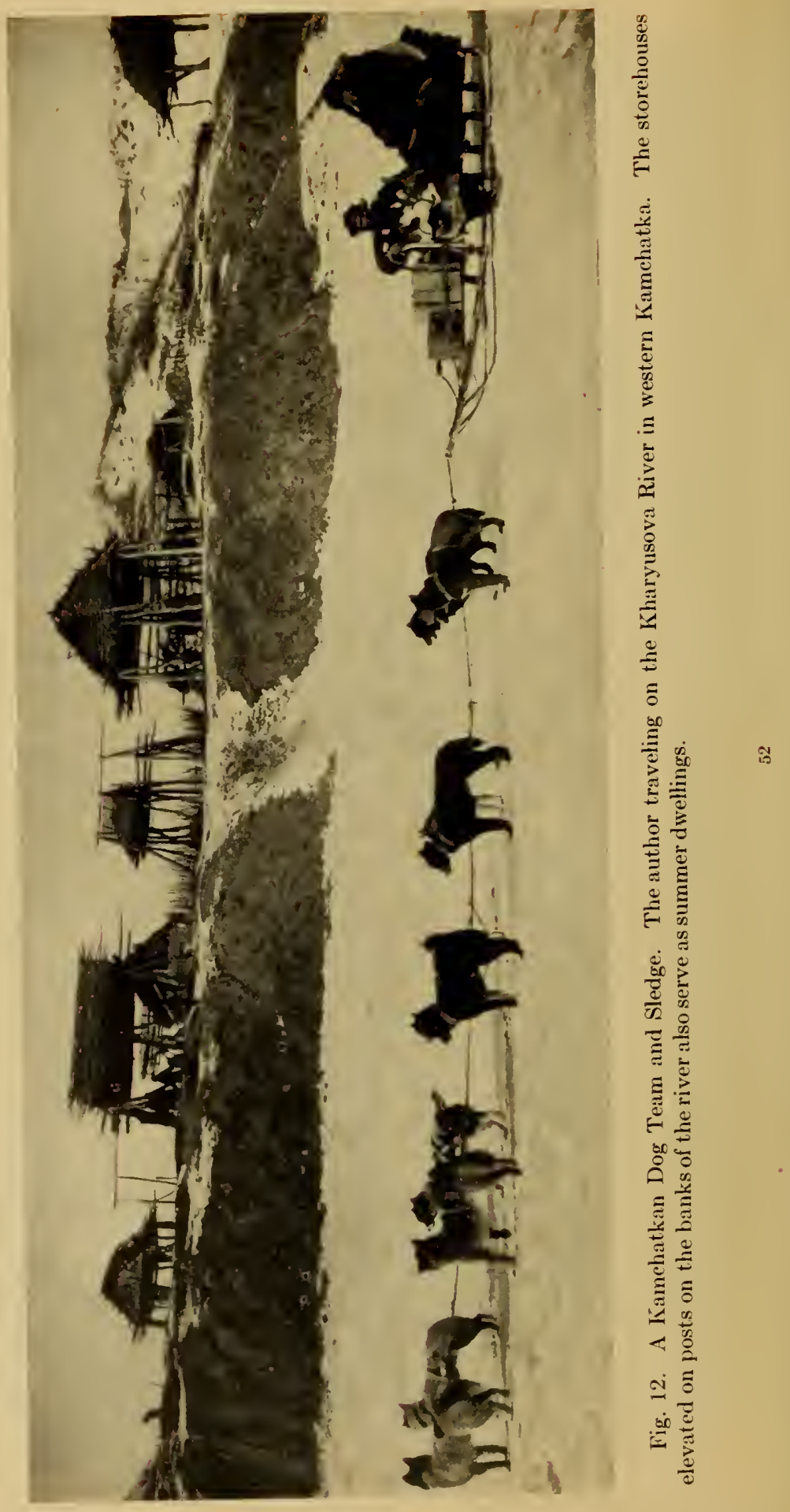


and gardening into Kamchatka. For this purpose peasants from southern Siberia and European Russia were several times transfered to Kamchatka, but all these experiments failed, the imported husbandmen having themselves adopted fishing and hunting. At Klucherskoye Village in the valley of the Kanchatka River barky is grown in small quantities, but the crop has no economic value. Experiments with gardening have been more successful. Potatoes grow everywhere in southern Kamchatka; consequently, digging for other edible roots has almost ceased. Turnips are also grown and the inhabitants of Klucherskoye also grow cabbage which heads well.

\section{The Chenchee-Koryak-Kamchadal Physico-Cultural Complex}

The Chukchee, Koryak, and Kamchadal are closely inter-related and at the same time show considerable affinity with the American aborigines; hence, a brief review of their physical characters and of their common cultural elements may be profitable.

Of the descriptive physical characters, hair form will be given first consideration. Straightness of hair, as is well known, is a common Mongoloid, Americanoid, and Indian character. However, a few cases of wavy hair were recorded among the Chukchee, Koryak, and Kamchadal which may explain how an element, of wary hair once entered the aboriginal population in South America. ${ }^{1}$ As to skin color, it may be pointed out that while the Mongoloids are characterized by pigmentation tending toward shades of yellow, the Americanoids, like the Indians, are pigmented in various tones of brown.

On both sicles of the Pacific, the nose is not of the flattened form, and, in many cases, is high bridged. The oblique eye fissure of the Mongoloids is also rarely encountered among the Americanoids and Indians. The epicanthic eyefold has been observed, but this eyefold has also been known to occur among whites.

The face is wide as compared with the head width. As indicated by the cephatic index, the Americanoids, particularly the Kamchadal, have narrow heads as compared with their broad-headed Mongoloid neighbors.

Perhaps the best known cultural resemblances and affinities between the Anericanoids and northwestern Indians, are recognized in the identity of the Raven myths; the language structure, based on the same principles; and identical hunting and fishing methods. The latter is particularly true of the Fianchadal who have no skin boats and no domesticated reindeer.

IWissler, 325. 
The cultural affinities of the northeastern Siberian Americanoids with the American Eskimo, who form a wedge between the Americanoids and the Indians, may be classified as resemblances of a local Arctic and of a circumpolar character. The wearing of fur clothing, the manufacture of the sinew-backed bow, and dog breeding are components of circumpolar culture; on the other hand, the skin boat and the methods of hunting sea mammals are local achievements of the Eskimo-ChukcheeKoryak Arctic group. Bering Sea seems to present a barrier to the American diffusion of the reindeer breeding complex of the arctic and subarctic regions of Eurasia. ${ }^{1}$ But the fact that in the immediate past the Asiatic Eskimo have acquired domesticated reindeer from the Chukchee, principally because of the extermination of sea mammals by white whalers, indicates that the diffusion of the domesticated reindeer might naturally be expected to have been across Bering Strait. On the other hand, the taking over of the Siberian domesticated reindeer, instead of attempting to tame the American wild reindeer (caribou) would tend to show that achievements in culture are made by the comparatively easy process of adopting a culture complex as a whole than by imitating its development.

The snowhouse appears to be the only genuine Eskimo invention. The Arctic peoples of Eurasia, including the Asiatic Eskimo, do not build snowhouses. This can be explained by environmental differences, as follows:-

1. The forests of Eurasia extend farther to the north than does the tree line in America, so that it is easy to obtain poles for the framework of tents.

2. The numerous herds of domesticated reindeer furnish the skin covers for the shelters, while the hunter of wild reindeer cannot obtain a sufficient number of skins for his dwelling, clothing, and bedding.

3. Only a small proportion of the polar inhabitants of Asia hunt at sea and they seldom go to distant islands. The Eskimo, on the other hand, are sea hunters and many live permanently on the most northerly capes and islands.

\section{The Yukaghir and Chuvantzy}

The Yukaghir are so interbred with Tungus that their somatological affinities are closer to the Mongoloids than to the Americanoids. From the Tungus also they have adopted their mode of life and costume. On

\footnotetext{
1We consider the introduction of the Siberian domesticated reindeer into Alaska by the United States Government as an artificial infuence on what appears to have been the natural course of the diffusion of this culture trait.
} 
the other hand, the structure of their language, their traditions, and history bear witness to their close relation to the Chukchee and Koryak. According to the census taken by the writer in 1900, there were 1,003 Yukaghir (503 men; 500 women) and 453 Chuvantzy (236 men; 217 women). In olden times these two tribes formed a single ethnic unit so that we may give the population of the Yukaghir as 1,456 individuals.

Odul (plur. Odulpe, or Odupe) meaning, the strong one, is the Yukaghir name for themselves. Traditionally, they were reputed to be the best warriors in the extreme northeast of Siberia. The Chukchee and Koryak call the Yukaghir and Chuvantzy, Atal or Etel, which is the Chukchee-lioryak pronunciation of the Yukaghir, Odul. This may be considered as additional evidence that their neighbors regarded the Yukaghir. and Churantzy as divisions of one tribe, which is also corroborated by their folklore and the remnants of the Chuvantzy dialect still extant among the Russianized Churantzy on the Anadyr River. ${ }^{1}$

Like the Chukchee and Koryak, the Yukaghir and Chuvantzy are divided into reindeer ( 764 Yukaghir; 177 Chuvantzy) and dog breeders (239 Yukaghir; 275 (huvantzy), and before their contact with the Russians. were a numerous people, occupying, together with related groups now extinct, the whole region between the Arctic Coast and Verkhoyansk Mountain Ridge and the lower course of the Lena River and the Stanovoi Mountains. We have no evidence as to whether or not the ancient Yukaghir were reindeer breeders. The present Yukaghir reincleer are, however, of Tungus stock. The first Russian records of the Yukaghir mention them as living in earthen huts on the banks of rivers, though some Yukaghir tales refer to roaming with reindeer.

At present the Yukaghir occupy only a small portion of their former territory or wander with alien tribes. There are two Reindeer Yukaghir clans in the Kolyma District of Yakutsk Province. These wander on the tundra between the Kolyma River and the Alazeya Mountains in company with two Yukaghirized Tungus clans. Five Reindeer Yukaghir clans wander in the Verkhoyansk District in the region of the Indigirka River, the Khroma River, and between the Yana and the Omoloi rivers, also partly to the west of the Omoloi River. The Omoloi Yukaghir, together with Tungus clans, adopted the Yakut language. The rest of the Reindeer Yukaghir of the Verkhoyansk District became Tungusized.

'Dyachkofi. 


\section{THE REINDEER CHUVANTZY}

The majority of the Reindeer Chuvantzy roam among the Chukchee camps along the upper course of the Anadyr River and its tributaries in the Anadyr District, sometimes visiting the valley of the Omolon River in the Kolyma District. A small number wander among the Chukchee in the Kolyma District and about twenty persons among the Koryak in the basin of the Penshina River.

\section{SETTLEMENTS OF DOG-BREEDING YUKAGHIR}

The following settlements are found in the Kolyma District: the Hare clan numbering 79 ( 37 men; 42 women), together with 80 ( 35 men; 45 women) Yukaghirized Tungus, spends the winter in small settlements on the Yassachnaya, Nelemnaya, and Korkodon rivers, living in log huts or half underground dwellings. Early in the spring, these Yukaghir leave their permanent houses and with dog sledges and conical skin tents, move to the upper courses of the Kolyma River and its tributaries to hunt wild reindeer, birds, elk, and fur-bearing animals. Early in the summer, they descend the river in boats, stopping on their way to fish, and late in the fall return to their permanent settlements.

The First Omolon clan is an amalgamation of four former Yukaghir clans: the First Omolon and the First, Second, and Third Omok clans. In former times, the First Omolon clan, moved up the Omolon River during the winter, and, when the ice broke, floated down to its mouth in canoes and on rafts. The Omoki wandered in the valleys of the two Anyui rivers, the Big Anyui and the Dry Anyui, and their tributaries. At present the remnants of these four clans, now constituting the First Omolon clan, have so declined in vigor that they have almost given up their wanderings and hunting, and live in a village at the mouth of the Omolon River, in Nishne Kolymsk and other Russian settlements along the lower Kolyma River. They have become entirely Russianized.

The Second Omolon clan became Tungusized and has joined the Tungus in the Omolon Valley. A settlement, Karbashan, on the banks of the Omolon River, about five hundred miles from its mouth, had a population of twenty persons who lived like the Yukaghir of the Yassachnaya River. This group became extinct in 1897 after a famine which ended in cannibalism.

A few dog-breeding Yukaghir ( 81 persons) may also be found in the Anadyr District of Kamchatka Province. They live in the village of Markovo and in other settlements on the Anadyr River among the Chuvantzy and Russians. These Yukaghir have become entirely Rus- 
sianized, and form a "Yukaghir community" and not a clan. They are the descendants of the Kolyma Yukaghir who emigrated to the Anadyr at various times and who formerly belonged to the Omolon and Omok clans.

\section{DOG-BREEDING CHUVANTZY}

To the River Yukaghir should be added the permanent Chuvantzy settlers of whom there were 262 (136 men: 126 women) in the Anadyr District. They have lost their clan name and constitute a "Chuvantzy" community." The greater part of them, 147 persons ( 75 men; 72 women) live in Markovo Village, forming 46 percent of its permanent population. The rest of the sedentary Chuvantzy live in other villages along the Anadyr River, forming the majority of their inhabitants. All the sedentary Chuvantzy have become entirely Russianized.

On the Kolyma River were 13 Russianized Chuvantzy sett!ers $(7 \mathrm{men}$; 6 women) who live in Nishne Kolymsk or in settlements nearby.

\section{RELIGION AND LANGUAGE}

All the Yukaghir and Churantzy are Christians, but many of them have preserved their aboriginal mode of thinking and shamanistic ideas and practices. Russian is spoken by 181 Yukaghir (18 percent) and by 294 Chuvantzy (64 percent); Tungus by 225 Yukaghir (22 percent); Yakut by 17 Yukaghir (1.7 percent); and Koryak or Chukchee by 150 Chuvantzy (33 percent) who wander with Reindeer Koryak or Chukchee. The Yukaghir may be called true polyglots. Besides Yukaghir, the Upper Kolyma Yukaghir speak Tungus and Yakut. The Tundra Yukaghir speak Yukaghir, Tungus, Yakut, and Chukchee. The Russianized Yukaghir of the Lower Kolyma know Russian, Yakut, and Chukchee. The Omoloi Yukaghir of the Verkhoyansk District, having at first become Tungusized, have now, together with the local Tungus groups, become Yakutized, and speak only Yakut.

\section{The Giliak}

The small Gilyak tribe, numbering, according to the census of 1897 , 4,649 (2,556 men; 2,093 women) is scattered over the northern half of Sakhalin Island and the continental coast adjacent to it, being almost equally divided between the two localities. On Sakhalin Island they occupy the western coast line from Cape Sakh-kotan to the northern extremity of the island to Cape Mary; the eastern coast from Cape Levenstern to Cape Delisle de la Croyere; and the interior, the upper and middle course of the only large river of the northern part of the Sakhalin, 
the Tym. Several scores of Gilyak were found in the southern part of the island at the mouth of the Poronaya River and on Cape Patience, among the Ainu and Orok, where they immigrated about a half century ago.

On the continent, the Gilyak are located on both banks of the lower Amur River up to the place where Geri Village is situated; the shores of the Amur estuary; and the coast to the north of the mouth of the Amur to the Kol River; and to the south as far as the Choma River. They sometimes range as far north as the mouth of the Tugur River, but have no permanent dwellings there. If we may judge from historical data, no change has taken place in the location of this group during the last three centuries.

The Gilyak are closely encircled by alien peoples. On Sakhalin Island there is pressure from the south from the formerly numerous Ainu; in the east, the Orok group of Tungus have penetrated to the very heart of the Gilyak settlements. On the continent the Gilyak are surrounded by representatives of Tungus-Manchu tribes: Negidaltzy, Olchi, Goldi, Orochi, Samaghir, and Tungus proper.

The physical appearance of the Gilyak may be indicative, to some degree, of affinities with their nearest neighbors. On the other hand, their language, in structure, phonetics, and vocabulary has no relation to those of surrounding tribes and is structurally and grammatically related to the stocks of the North Pacific Coast of America.

Sternberg states that there is now no well-defined Gilyak physical type, the average Gilyak representing a complex of the modified Mongoloid traits of the Tungus, to which have been added some Ainu characters. In form, their faces are more or less oval, with fairly prominent cheek bones; noses are medium in length; the eye fissure is wide; and facial hair is abundant on the males. The average cephalic index ( 86 and above) is not only higher than that of the Ainu (77), but the head form is also more brachycephalic than that of the Tungus (82). Mongoloid traits appear to be more prominent among the women than among the men. Thus, it will be seen that the somatology of the Gilyak gives no clue to the solution of the problem of their origin.

Schrenck, ${ }^{1}$ on his part, contended that Sakhalin Island should be regarded as the original home of the Gilyak, whence they spread to the continent, while Sternberg ${ }^{2}$ believes that the Gilyak of Sakhalin Island are newcomers who forced the original Ainu population to move southward. It may be profitable to review some of the evidence bearing on this point. 
The Gilyak have Ainu names for the indigenous plants and animals of Sakhalin which are not found on the continent. Perhaps the argument bearing the most weight consists in the fact that over all Sakhalin, extending to its most northern extremities, are the remains of ancient underground dwellings which the Gilyak call, Kugi-Tulkch, i.e., Ainu pits. In addition, tales of bloody wars with the Ainu are prominent and still extant in Gilyak folklore.

On the other hand, Sternberg believes the present territory of the Gilyak on the mainland was not their original home. He attempts to uphold his contention by the citation of many items of Gilyak material culture which he considers merely a part of a single aretic culture complex. And if we grant his hypothesis, the Gilyak must be assumed to have come to their present abode from a region to the north.

The Gilyak earthen house is of the Kamchadal-Koryak type. Although the dwelling has a side door leading to a small entrance passageway, the smoke hole in the roof is used as a means of entrance when the skin and flesh of the bear killed during the bear festival is lowered into the dwelling, and evidently harks back to the time when the smoke hole served as the only means of exit and entrance to this semi-underground dwelling. Then too the Gilyak who adopted the Manchu plank dwelling, which has no smoke hole, remove the fishskin coverings from the windows, despite the winter frost, when sacred objects relating to the bear festival are taken out of the house and returned. The very expressions for "going in" and "going out" of the dwelling (kusind and yugind) mean "to plunge" and "dive out," which notion corresponds to the use of the smoke hole as an entrance.

Dog driving, which is a characteristic trait of arctic life, was adopted from the Gilyak by the Ainu, Goldi, and Orochi. The sledge, the mode of harnessing dogs, and sitting astride when driving, is reminiscent of the ancient Kamchadal dog driving and of Chukchee and Koryak reindeer driving.

But, we have not yet answered the question as to which specific tribe the Gilyak are related. Many origin traditions of Gilyak clans refer to the appearance of these clans on the coasts of Sakhalin on hovyk $h^{\prime} \mathbf{s}^{1}$ from the north. Sternberg also suggests that the Gilyak were related to the Aleut, but all these hypothesis are not based on facts. It is true that the comparative hairiness of the Gilyak approaches that of the Ainu, but their brachycephalic head form is comparable only to that of the

IThe Gilyak apply the term. horykh, to the lumps of earth broken off from the land by the current, or to ice blocks floating in the northern waters. 
Aleut. Generally speaking, the Gilyak, both in language and somatology, occupy an isolated position among the surrounding tribes. It may be added also that the absence of the use of the skin boat can be considered an argument against their supposed northern origin, for instead of this type of boat they employ a light poplar dugout canoe.

The Gilyak arc semi-sedentary and they change their dwelling places scveral times during the summer, moving up and down the rivers and to the seacoast, following the migrating fish and hunting seals in the river mouths.

\section{The Asiatic Eskimo and Commander Aleut}

The Siberian Eskimo and the Aleut of the Komandorski, or, more correctly, Commander Islands, may be classed with the Americanoids. Since both these Eskimo divisions belong politically to Russia, they should be described with the other natives of Asiatic Russia.

\section{THE ASIATIC ESKIMO}

Both Wrangel and Nordenskiold ${ }^{1}$ mention an Eskimo tribe that some two hundred years occupied the whole Arctic Coast, from Cape Shelagsky to Bering Strait, but was driven away by the Chukchee. Their chief argument is based upon the difference between the actual Chukchee dwellings and the remnants of the old underground houses scattered along the coast. In reality, says Bogoras, ${ }^{2}$ this difference means nothing more than that with the increase of reindeer breeding, the underground dwellings bccause of their unwholesomeness, and the necessarily great consumption of oil, were gradually abandoned by the Eskimo and Chukchee for a tent-like type of habitation.

Lütke and Wrangel mention Onkilon and Namollo as tribal names of the Eskimo, but of these, the former resembles the Chukchee-Koryak Ankalin (maritime dweller) and the Koryak Namollo, from the word, nimilu, which means settlers, i.e., coast settlers. It cannot be denied that the Arctic Coast was previously inhabited by a considerable number of Eskimo, who, little by little, were assimilated by the Chukchee. Thus, some of the Arctic Chukchee village names have an Eskimo-like sound which can be accounted for on the basis of the Eskimo language, especially the Aiwan dialect. ${ }^{3}$ At the present time, on the whole western coast of Bering Sea, only five underground houses are still inhabited, one at Uwelen and four at Nookan.

\footnotetext{
Nordenskiold, 406.

3ogoras, 21.

31n discussing the question of former Eskimo occupation of the Siberian Arctic Coast, a very remote period of timc is not ineant, so that in this sense the assumed recent Eskimo migrations from Asia into America and vice versa do not interfere with the general theory of the Asiatic origin of the American population.
} 


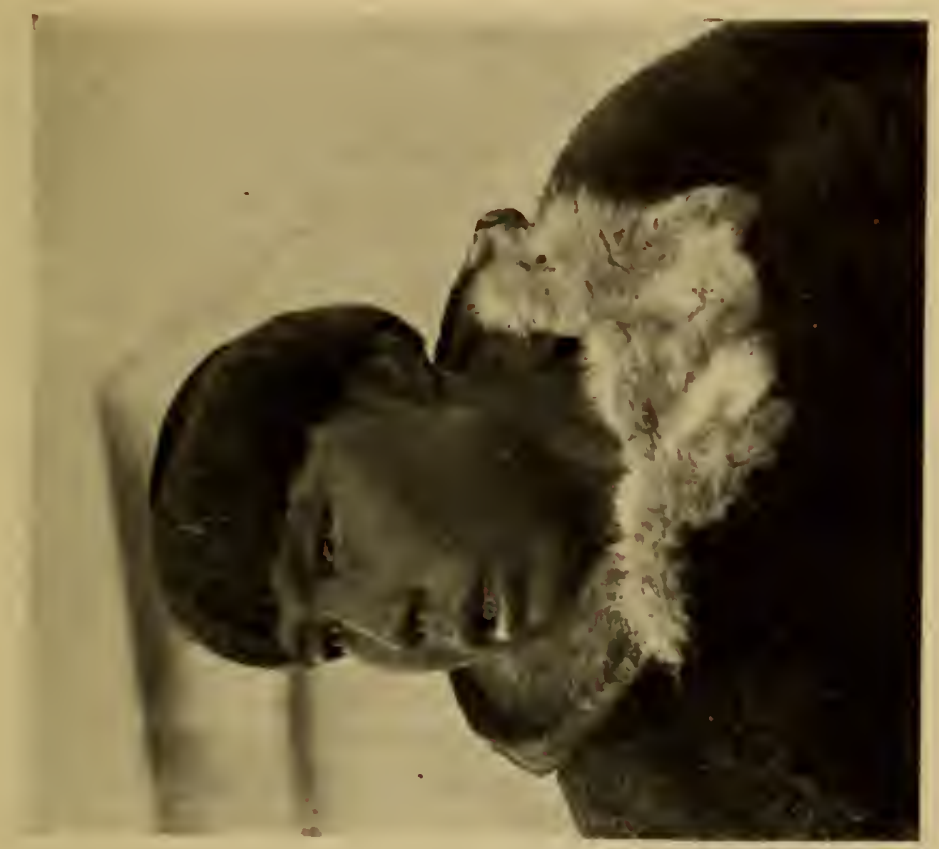

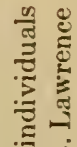

类

E

宊

है ซ్

ำ

है

$\stackrel{5}{\circ}$

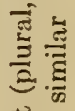

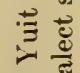

马을

$\frac{2}{0}$

है

造

है क

드

嶂

$\overrightarrow{0}$

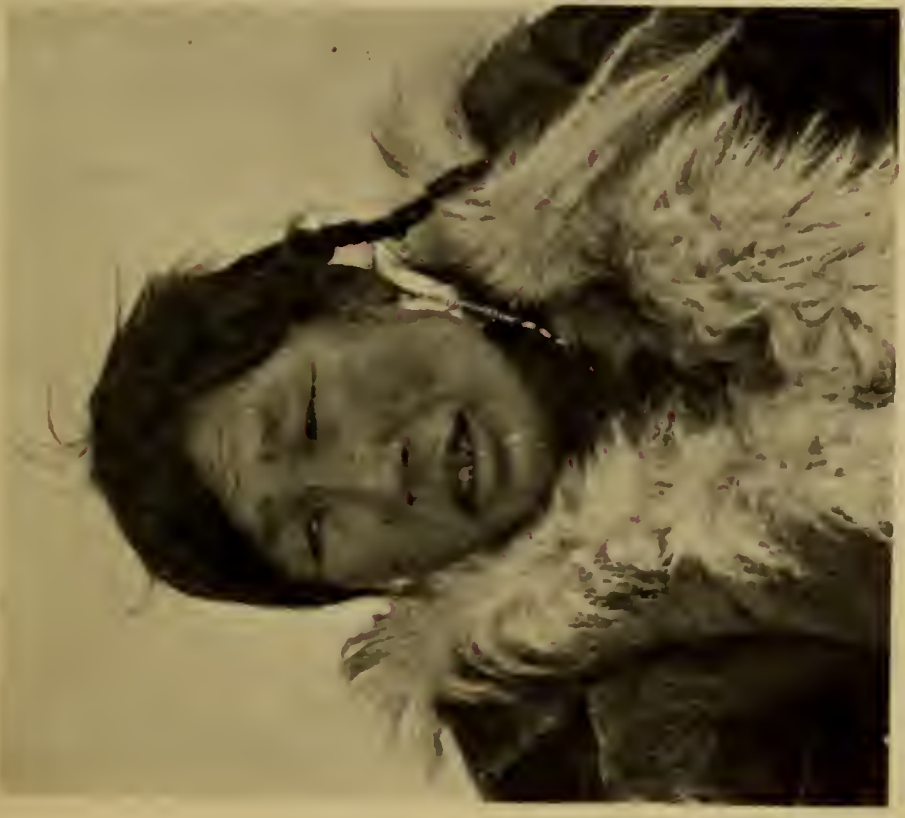

吾

ธี

$\therefore \quad$

胥

昰

สี ษ

ह5 :

证

号导

红 $\bigcirc \frac{5}{13}$

.

蛋

द छ

$\rightarrow$

我经

政 
According to Bogoras, in 1900 the Asiatic Eskimo in the villages of the Chukchee Peninsula numbered 1200, while on the western island of the Diomedes group, belonging to Russia, 108 individuals were found, totaling 1,308 (632 men; 676 women). Ethnically, the Eskimo of eastern Diomede Islands and of St. Lawrence Island, which belong to the United States, should be classified with the Asiatic Eskimo. They number 272. Thus, the total Asiatic Eskimo population is 1580 .

Dialectically, the Asiatic Eskimo may be divided into three groups :-

1. The Aiwanat (plur. from Aiwan) live on Indian Point and at four other coast villages. This name is also applied to the Maritime Chukchee who do not own reindeer.

2. The inhabitants of the Eskimo village, Nookan, on East Cape, are called Nookalit, or derisively, Peekit, from Peek, the Eskimo name for East Cape.

3. The Wootéelit, the inhabitants of Wuteen, the last Eskimo village on Cape Ulakhpen, to the northwest of Plover Bay.'

The Nookalit dialect is intermediate between that of the Aiwanat and the natives of the Diomede Islands which, in turn, is connected with that of the Alaskan Eskimo. Another dialect is spoken by the Wootéelit. The language of the St. Lawrence Eskimo is quite similar to that of the Asiatic Aiwanat who are traditionally believed to have come from the mainland, probably from Indian Point.

The inhabitants of Diomede Islands are called Yikirgaulit (the large mouthed), the labrets which they formerly wore having made their mouths very conspicuous. The Asiatic Eskimo in general call themselves $\mathrm{Yu}^{\prime}$ it (the plural of $y u k$, man), just as the American Eskimo call themselves Inuit (the plural of inuk, or inung, man).

THE ALEUT OF THE COMMANDER ISLANDS

The Commander Islands, when first discovered by Bering in 1741, were uninhabited. That the animals on the islands had no fear of men, and that the latter had to exercise care lest they be bitten by foxes, while asleep in their tents, may be considered good evidence that no man had previously visited the islands. Before 1826 there were no permanent settlements on the Commander Islands, although Russian hunting parties sometimes spent one or more winters on the islands from which large numbers of valuable skins were exported.

In 1826 the so-called Russian-American Company who leased all its American possessions from the Russian Government colonized the Commander Islands, with Aleut from Attu and Atka Islands. Subse-

1Bogoras, 29; also map of the Chukehee Peninsula. 
quently, Aleut from other Aleutian Islands, as well as Kodiak Eskimo and Indians from Sitka were brought to the Commander Islands. The last group from the east ( 30 Aleut from Attu) were brought in 1872 . In 1SSS, 26 Aleut and Kurilians were transported from Kanchatka. In addition, various other Siberian matives and Russian laborers were brought to the Commander Islands, and clerks and attendants and officials of Russian, Polish, Lettish, and American origin have added to the confusion of races. However, the racial nucleus was Aleut, so that the Aleut physical type and language predominate. On Copper Island (Russian, Medny), where descendants of the Attu people are most numerous, the Attu dialect is spoken; on Bering Island, however, the inhabitants are mainly from Atka and that dialect is used.

In 1909 there were, on both islands, 501 natives ( 251 men; 250 women) and 51 whites ( 24 men; 27 women). The native population is constantly decreasing; in 1892 it was 826 . Thus it will be noted that in seventeen years it decreased by twenty percent.

Villages and Duellings. On Bering Island, there are three permanent villages, Nikolskoye, Lodyghinskoye, and Sarannaya, and two temporary summer settlements, Severnoye and Staraya Gavan. There is one permanent village, Preobrashenskoye, and two summer settlements, Glinka and Korabelnoye, on Copper Island.

The Commander Aleut live in wooden houses built of posts and planks brought from America for them by the Russian American Company, but the old earth house which is warmer than the wooden house in the inclement Bering Sea climate is still the prevailing type of dwelling on Bering Island. Coal is imported for fuel; the coastal villages also have drift wood. The islands are treeless, except for low willows, mountain ash (Sorbus sambucifolia), and dwarf birches (Betula ermanni and Betula nana).

Food. There were two varieties of food: local and imported. The local food consists of flesh of fur seals and sea otters, seals, and sea lions, but seals and sea lions are seldom killed now. At rare intervals, whale carcasses are cast ashore, the flesh and fat of which are much liked by the Aleut. Sea urchin roe and octopus meat, either raw or cooked, are considered delicacies. They also eat different species of shellfish and holothuroidea. There is an abundance of sea fish, like corl and halibut, but during the winter storms, sea fishing is impossible, and consequently, there is no fresh food during this period.

In suminer, migrating salmon ascend the rivers and lakes to spawn and many gulls, cormorants, sea parrots, and auks are caught. Also, thousands of eggs are gathered at the nesting places and aclded to the Aleut menu. In winter, ptarmigan and ducks are taken. 
Among imported foods, flour has first place (about 300 pounds a year per person), then biscuits (20 pounds a year for each person), lard, rice, butter, grits, salt meat, corned beef, etc. For the most part, these products, together with wood, metal wares, guns, and clothing, were brought from America, as they are cheaper than those from Russia.

Clothing. The Commander Aleut wear clothing of American make and European fashion. Some clothing of the primitive type, especially that worn on the hunt, is still in use, but of these garments only sealskin boots with soles of sea lion skin and trousers and raincoats of guts of sea mammals or of fur seals have been preserved. The ancient birdskin coats are no longer worn.

Fur Seal Ilunting. Of fur-bearing animals there are blue foxes, sea otters, and fur seals. Sea otter rookeries are now found only on Copper Island. Fur seal hunting is now the most important among the Aleut who are regarded as government employees who kill fur seals and other fur-bearing animals for the government or the lease holders. In return for each skin, the hunters are given a proportionate amount of food, clothing, and fuel.

Boats. The Commander Aleut no longer make skin boats, but use American whale boats. Their prowess as seamen seems to have declined, for now they never venture far from shore, and crossing the straits between Copper and Bering islands is regarded as a heroic deed.

Dog Breeding. Driving dogs are kept only on Bering Island and used in winter as well as in summer, when they drag the sledges over the tundra mosses. When not in harness the dogs are tied up near the villages. In 1909 there were 390 driving dogs on Bering Island. On Copper Island, where no driving dogs are kept, the Aleut use snowshoes in winter and river boats in summer, or travel afoot.

Domestic Animals. There are no horses on the Commander Islands. Of horned cattle in 1909 there were forty head on Bering Island and seventeen on Copper Island where there were also several goats. The Aleut build no stalls nor make hay, so that in the winter the cattle move alone to the mountains or to the coast where the winds blow the snow off the ground and they are able to graze on the withered grass. They have no milk throughout the long winter. They keep pigs; there were not many of them on Bering Island, but on Copper Island, where no dogs are kept and the pigs ran about freely, there were about ninety of them. In the winter the cattle and pigs grow a heavier coat of hair than those on the continent. Of domesticated birds there are few on Bering Island on account of the dogs, but on Copper Island, there were about one hundred hens and ducks in 1909. 


\section{CHAPTER III}

\section{SIBERIANS OF UNDETERMINED ANTHROPOLOGICAL POSITION}

Under this head will be considered two umrelated tribes having no affiliation with other ethnical divisions of Siberia: the Yenisei Ostyak, or more simply, the Yeniseians, and the Ainu.

\section{The Yexiseiaxs}

Three quite distinct tribes are called Ostyak: 1, the Ugrian Ostyak (see p. 17); 2, Samoyed Ostyak (p. 22); and 3, Yenisei Ostyak. This situation is very confusing for the student of Siberian ethnography. We propose to apply the name Ostyak only to the Ugrian Ostyak, or Ostyak proper. The Samoyed Ostyak may be called Narym Samoyed, since the majority $(4,821$ out of 5,805 Ostyak Samoyed) live in the Narym District of Tomsk Province. The Yenisei Ostyak may be designated simply Yeniseians. Klaproth ${ }^{1}$ has proposed that the term Ostyak be discarded and that the Yeniseians include the Kott, the extinct Assam, and the Tartarized Arin. The Yeniseians call themselves Din.' It cannot be ascertained whether or not this name has something in common with the Dinlin ${ }^{3}$ (Ting-Ting) people mentioned in the Chinese annals, who, together with the Ligur and Khakas (Kirghiz) are described as having fair complexions, light hair, and blue eyes. ${ }^{4}$ The present Yeniseians have hair lighter than the dark brown or black hair of their neighbors, the Samoyed, Ugrian Ostyak, and Tungıs. Individuals with blue eves are also found among them, but whether this is an original character or should be ascribed to Russian admixture remains an open question. Before the seventeenth century the Yeniseians were under the influence, first of Turkic and later of Mongol tribes, but since then the Russian influence has over-ridden all others.

The Yeniseian tribes (Assam, Arin, Kott, Sagai) were still numerous in the beginning of our era. Some, Radloff states; were annihilated by invading Ugrian Samoyed, ${ }^{5}$ while others soon becanı Turkicized, like the Khakas, who may originally have been related to the Yeniseians, and who, after being Turkicized, formed the Kirghiz nation. It also remains an open question whether the Turkicized Yeniseians were the makers of

'Klaproth, (a), 266.

Anuchin, 37 .

For further mention of the Dinlin see the chapter on Prehistory and Migrations (p. 235)

Radloff, (s), vol. 1, 123, 13f;; vol. 2, 113; Bichurin, vol. 1, 143.

Radloff, (a). vol 2, 101 . 
the "pisanitzy," the pictographic inscriptions on the Yenisei and the Orkhon, deciphered by V. Thomsen and W. Radloff. ${ }^{1}$

As has been shown by Castren, ${ }^{2}$ the Yeniseian languages are structurally quite different from those of the Mongoloid stock. For example, in the Yeniseian dialects, in pluralizing nouns the root vowels are changed; the genitive case has different endings for animate and inanimate objects; and pronomina and predicates may indicate the sex. All of these morphological modifications are unknown in Mongoloid languages.

The present Yeniseian territory follows the banks of the Yenisei River and its tributaries between the Russian village, Antziferova (near Yeniseisk), on the south, and the mouth of the Kureika (an eastern tributary of the Yenisei) in the north. The Yeniseians number 988 (535 men; 453 women). On the Yenisei River they live in villages segregated from, but in close proximity to, the Russian settlements, or even among the Russians. But the greater number of Yeniseians live on the banks of the eastern tributaries of the Yenisei, Podkamennaya Tunguska, Bakhta, Nishnaya Tunguska, and Kureika. On the west they live chiefly on the banks of the Yelogaya River. In addition, some Tungus groups also live on the banks of the eastern tributaries of the Yenisei River while along its western tributaries dwell the Samoyed. The Russians, however, constitute the major population unit on the Yenisei River.

All the Yeniseians have been baptized, but their Christianity, like that of many Siberian natives, consists chiefly in the observance of certain rites of the Greek Catholic church, and is merely superimposed on their aboriginal shamanistic conceptions and practices. Of 988 Yeniseians, 952 (525 men; 427 women) still regard Yeniseian as their native tongue, while only 36 (10 men; 26 women) recorded Russian as their native language. The Yeniseians are among those Siberian natives who are rapidly becoming extinct. The census of 1859 reported 1,652 Yeniseians, but in 1897 only 988 were recorded. ${ }^{3}$ It is regrettable that there is not yet available a thorough investigation of this interesting tribe which seems to have an admixture of Aryan blood and which is probably a small remnant of a numerous stock which emigrated from Central Asia to Siberia through the gateway of the sources of the Yenisei River.

Castren has given us a somewhat incomplete conception of the Yeniseian language, while other writers $^{4}$ have published superficial

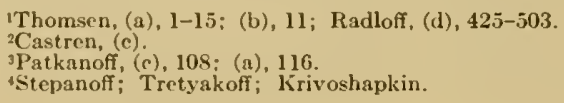


descriptions of the tribe, but no data as to its origin. The same criticism applies to the contributions of V. I. Anuchin who in 1906 was commissioned by the Museum for Anthropology and Ethnography of the Russian Academy of Sciences to study the Yeniseians. ${ }^{1}$ The report of the expedition to the Yenisei (1914-1915) undertaken by the late Miss M. A. Czaplicka and Mr. H. U. Hall, Curator of Ethnology of the University Museum, Philadelphia, has not yet been published.2

\section{The AINu}

Even more complicated than the question of the origin of the Yeniseians is that of the origin of the Ainu. Although at present, the Ainu, numbering about 20,000, are all under Japanese sovereignity, still, in view of their historical and ethnological connections, they should be included with the Siberian natives. First of all, let us sketch their historical background.

After having conquered Kamchatka in the beginning of the eighteenth century, the Russians found their way to the Kurile Islands, inhabited by a division of the Ainu. The Russians made their first permanent settlement on Sakhalin Island in 1857 , but the southern part was held by the Japanese until 1895 , when they ceded it to Russia, in exchange for the Kurile Islands. By the treaty of Portsmouth in 1905 , the southern part of Sakhalin, below $50^{\circ}$, north latitude, was re-ceded to Japan. Before the Japanese migration from the mainland all the islands now Japanese were occupied by the Ainu. At present, 15,000 or more Ainu may be found on Yezo Island. In fiftyfour coast villages in the southern part of Sakhalin Island there were, in 1897, 1,443 (762 men, 681 women) Ainu. ${ }^{3}$ Twenty-nine villages were located on the Pacific Coast and twenty-five on the coast of Tatar Strait, and about 500 Ainu live on the five southernmost Kurile Islands. The inhabitants of the northern Kurile Islands were transferred to the southern ones after the Japanese Government took possession of them, the northern Kurile Islands are now visited only by Japanese hunters and revenue ships.

The presence of a Caucasoid tribe amid Mongoloid and Americanoid peoples had puzzled the first European travelers to the Far East, and

1This investigator should, however, not be confused with the late Professor D. $\mathbb{N}$. Anuchin, the eminent Russian geographer and anthropologist. Of his information on the Yeniseisus. V. I. Anuchin has published but a single article on the shamanism of the lenisei (styak. His physical measurements of the Yeniseians were published by N. A. Sinelnik of who gives the following averages: for staturc, $1,5,7 \mathrm{mms}$ : cephalic index, 83.1 : cephalo-facial index, 79.1 . No facial index is given

Hall has published a brief account of his expedition to Siberia which contsins inany interesting points. but by no means solves the question of the orign of the Yeniseians $(27-45)$.

Accorrling to Japanese data there are at present about 2,000 Ainu Sakhalin on 1 sland. 
many quite contradictory opinions as to their origin were presented. ${ }^{1}$ In view of their hirsuteness they were identified with the Aryans, Semites, Todas, Australians, and even Melanesians. Even an authority like the late Professor Baelz insisted on the relationship of the Ainu to the Caucasian race. ${ }^{2}$ And this seems the only solution of the somatological aspect of the question, although the problem of their migrations and the route and time when a small Caucasian tribe may have fought its way through or was driven to the east by the Asiatic Mongoloid tribes remains unsolved. Schrenck expresses the opinion that the Ainu must have stopped in Korea before landing on the Japanese Islands. As the Japanese invaded the islands more than three thousand years ago, it follows that the Ainu must have long preceded them to have made possible the accumulation of the extensive archæological remains found on the Japanese archipelago.

Also, the question remains whether a pre-Ainu population ever existed, as some authors (Sternberg, Pilsudski) contend, basing their belief on Ainu traditions and on the examination of skeletons excavated by Professor Tsuboi. Of course, it is quite natural to assume that another race preceded the Ainu, or, at least, co-existed with them on the Japanese Islands before the arrival of the Japanese, but the weight of archæological evidence favors the view that the ancestors of the present Ainu were the earliest inhabitants. Sternberg and Pilsudski maintain that the builders of the prehistoric pit dwellings on Sakhalin Island were not Ainu, but a mythical tribe, the Tonchi. ${ }^{3}$ The late Professor Tsuboi ${ }^{4}$ held that the so-called Koropok-guru, the ancient pit-dwellers of Yezo, were a pre-Ainu dwarf people related to the Eskimo. However, later investigators have clearly shown that both the Tonchi and Koropokguru are the ancestors of the present Ainu. Tonchi (or rather Toi-che) means in Ainu, "earthen house" and Koropok-un-guru, contracted to Koropok-guru, means "persons dwelling below." The most important opponents of the views expressed by Professor Tsuboi are Professor Koganei, N. G. Munro, the Rev. John Batchelor, and Doctor Laufer. ${ }^{5}$ Koganei and Munro, after comparing pre-Japanese skeletons with those of the Ainu found them identical with the present Ainu; archaeological objects were also attributed to ancestors of the present Ainu. It is of interest to note that Batchelor who lived among the Ainu for many years as a missionary and studied their language, agreed, at first, with Tsuboi's

ISchrenck, (a), 252-275

2Baclz, 281-310.

Sternberg: Pilsudski.

Tsuboi.

Goganei, (a), (b); Munro, (a), (b); Batchelor; Laufer, (a). 
theory, but later revised his views regarding the Ainu as the original inhabitants of the pits at Yezo. ${ }^{1}$

While in Yokohoma in 1911 the writer visited Doctor Munro who practised medicine there. In discussing the Ainu problem he expressed the opinion that the supporters of Tsuboi's theory were influenced by political motives. The riew that the Ainu are not the original inhabitants of Yezo was regarded as a moral excuse when the Japanese Government forced them out of many localities which were later colonized by Japanese. The original Ainu occupation of the southern part of Sakhalin Island and the Tiurile Islands was also due to Japanese pressure. Not only on Yezo, but also on the main island, have many place names been proved to be of Ainu origin. In their northward movements the Ainu came into contact with the Kamchadal who thus acquired some items of Ainu culture. The clay vessels with thandles attached inside, excavated by the author from ancient Kiamchadal pit dwellings, were adopted from the Ainu. ${ }^{2}$

Physically many Ainu have a Mongoloid appearance, particularly in their prominent cheek bones and the eyefold. The low cephalic index of the Ainu is almost identical with that of the Japanese, and differs greatly from that of the Gilyak and their Sakhalin and Amur River neighbors, which is higher, indicating a shorter and wider head form.

1.lunro, (b), $\$ .5$.
The results of the author's excavations on Kanichatka Peuinsula were published by the Carnegie Institution of Washington [Jochelson, (e).]. 



\section{CHAPTER IV}

\section{THE NATIONS OF TURKESTAN}

Turkestan, or perhaps more correctly, Turkistan, means the land of Turks. However, at the dawn of history, Central Asia was occupied mainly by Aryan peoples, though later, when the Aryan tribes were subjugated by Turkic invaders: the country was named Turkestan. As early as the ninth century, we find the term, Turkestan, mentioned by Arab geographers. As the present Turkic tribes of Turkestan are chiefly descendants of Aryan-Turkic and also of some Mongolian mixtures, they are called Iranian Turks, as opposed to Turanian, or pure Turks.

Historically, as well as ethnically, Turkestan has passed through many vicissitudes. Few countries have experienced so many changes, so many civil and foreign wars, such numerous invasions, and sanguinary disturbances. Lying as it does at the crossroads between northern and southern Asia, on the one hand, and China and western Asia and Europe, on the other, it has served, from time immemorial, as the meeting place of various peoples and cultures and as the arena for the activities of the greatest Asiatic conquerors. Cyrus, Alexander the Great, Jenghis Khan, Timur, Nadir Khan, the Arabian chief, Kuteibabin Muslim, and many minor leaders invaded the country, and with the help of their violent and greedy hordes desolated it. These interminable wars ceased only after Turkestan was conquered by Russia in 1867.

\section{AREA}

Before the revolution of October, 1917, Turkestan occupied an area of 788,317 square miles and included five provinces (having an area of 673,997 square miles) governed by Russian officials, and two vassal Khanates, that of Bokhara and Khiva, which occupied 114,320 square miles.

\section{Administration}

For administrative purposes Turkestan was divided into five provinces:-

1. Semirechye, seat of government at Verni.

2. Syr Daria, the governor's residence at Tashkent.

3. Fergana, the governor's residence at Margelan, later re-named Skobeler.

4. Samarkand, the governor's residence of the same name.

5 Transcaspia, seat of government at Merv. 
Transcaspia and Semirechye provinces formerly belonged to the Steppe country, but in 1899 were transferred to the Turkestan administration. A governor general, with residence in Tashkent, controlled governors of the five provinces named above and of the Khans of Khiva and Bokhara who retained their semi-independence, and were nominally under the protection of Russia.

\section{Statistics}

Because of climatic, topographic, and soil conditions, Turkestan is sparsely and unequally populated. Frequently, the density of population of small well-watered and flourishing oases may be compared with the most thickly populated countries of western Europe, and these heavily populated districts alternate with unpeopled steppes or deserts, covering many thousands of square miles. The presence of human habitations is closely connected with the availability of water, for, wherever the water supply is sufficient we find a dense and prosperous population. Where water is lacking, life, both human and otherwise, deteriorates and disappears. The rainfall which is entirely absent in summer is very scant in winter. Perhaps the most remarkable feature in all Turkestan is its wonderful irrigation system which apparently has considerable antiquity, for without these irrigation canals nothing could ever have grown. Traces of ancient canals in what are now unreclaimed deserts have convinced archæologists that in many districts now uninhabited, rich and populous cities once flourished. Upon excavation, many mounds are found to have been town sites. ${ }^{1}$ So, in Turkestan, water is precious, as is borne out pointedly by the following Sart saying: "Drop upon drop makes a sea; if there are no drops there is a desert."

The following table shows the territorial extent of the population in the five provinces and two Khanates of Turkestan.

\section{Province}

Semirechye

Syr Daria

Fergana

Samarkand

Transcaspia

Bokhara Khanate

Khiva Khanate
Territory in Square Miles

152,280

194,853

86,000

26,627

214,237

92,000

22,320
Population in 1909

$1,158,900$

$1,837,200$

$1,900,200$

$1,154,800$

429,300

$2,500,000$

550,000
Individuals per square mile

\section{6}

9.4

22.1

43.3

2.0

27.1

21.1 
The greater number of the inhabitants of Turkestan are agriculturists and cattle breeders, therefore the rural population far outnumbers that of the cities. In the Russian provinces only 13.8 percent of the population is found in the cities. Some of the cities located in the southeast and south of Turkestan are very old and flourished for hundreds or perhaps thousands of years before the Russian occupation; some towns, on the other hand, have developed since the Russian conquest, and particularly, since the building of railroads. In some places, directly adjacent to the native cities there have developed practically distinct cities populated entirely by Russians, like the Russian quarter of Tashkent, Samarkand, Kokand, and others. Some small villages (auls) became towns and in many places new cities like Krasnovodsk, Verni, Skobeler, Kazalinsk, etc., were established. The relation between the urban and rural population is shown in the following table:-

Province

Semirechye

Syr Daria

Fergana

Samarkand

Transcaspia

Bokhara

Khiva
Urban Percent Rural Percent

$\begin{array}{rr}6.4 & 93.6 \\ 13.9 & 86.1 \\ 18.1 & 81.9 \\ 15.7 & 84.3 \\ 10.9 & 89.1 \\ 13.0 & 87.0 \\ 5.0 & 95.0\end{array}$

Fergana Province has the greatest number of town dwellers and Khiva, the smallest.

The following census figures for 1897 may be of interest with reference to the distribution of the sexes in the five Russian provinces:-

Province

\begin{tabular}{|c|c|c|c|c|}
\hline \multirow[t]{2}{*}{ Province } & \multicolumn{2}{|c|}{$\begin{array}{c}\text { Absolute Number } \\
\text { of }\end{array}$} & \multicolumn{2}{|c|}{$\begin{array}{l}\text { Relative Number } \\
\text { of }\end{array}$} \\
\hline & Men & Women & Men & Women \\
\hline Semirechye & 529,215 & 458,648 & 53.6 & 46.4 \\
\hline Syr Daria & 803,411 & 674,987 & 54.3 & 45.7 \\
\hline Fergana & 852,919 & 719,295 & 54.2 & 45.8 \\
\hline Samarkand & 472,443 & 387,578 & 54.9 & 45.1 \\
\hline Transcaspia & 212,638 & 169,849 & 55.5 & 44.5 \\
\hline & $\overline{2,870,626}$ & $2,410,357$ & $\overline{54.3}$ & $\overline{45.7}$ \\
\hline
\end{tabular}

We note that in all the provinces the men exceed the women. This difference in numbers is more marked in the cities. On the average, there are 83.8 women to 100 men. This excess of men over women is 
common in Mohammedan countries. As the cities of Turkestan are still in the developmental stage, the exceedingly small number of women may be explained by the unsettled mode of life and by the influx of young men looking for work and enjoyment.

\section{Population}

The rural population may be divided, according to mode of life, into sedentary or agricultural inhabitants, and nomadic, or cattle, horse, or sheep-breeding people. The sedentary people are concentrated in the oases, river valleys, and at the foot of mountains, while the nomads wander over the steppes seeking fertile pasture land. The hostility of the nomads towards the settled people is well known and in the past they often subjugated more civilized settlers or devastated their culture. The history of Turkestan is replete with incidents of this kind.

Archæologists contend that the cultivation of cereals in Central Asia preceded the nomadic culture stage. The Central Asiatic population, before 8,000 B.C., was sharply divided into two classes, sedentary agriculturists and migratory hunters. Domestication of animals was achieved by nomadic hunters after 8,000 B.C. The larger the herds of domesticated animals became, the more extensive were the pasture lands required, and the more often did the nomadic herders come into conflict with the agriculturists. After epizootics many nomads became cultivators of cereals. The commodities and comforts of settled civilizations influenced the wandering nomads and the immigration of Russian settlers and the regulations of the Russian Government were also responsible for the disintegration of the nomadic life. One may say that the roaming peoples of Turkestan are now in a transition stage between nomadism and a sedentary life. Some of the tribes, like the Sarts and Tadjik, are sedentary; others, like the Kirghiz and Turkoman, are part nomad and part agriculturists. There are no accurate statistics showing the number of nomadic peoples, but it is assumed that these constitute about thirty percent of the rural population.

The following table shows the relative numbers of natives:-

\begin{tabular}{lccc}
\multicolumn{1}{r}{ Province } & $\begin{array}{c}\text { Natives } \\
\text { Percent }\end{array}$ & $\begin{array}{c}\text { Russians } \\
\text { Percent }\end{array}$ & $\begin{array}{c}\text { Foreigners } \\
\text { Percent }\end{array}$ \\
Semirechye & 87.1 & 12.6 & 0.3 \\
Syr Daria & 95.2 & 3.9 & 0.9 \\
Fergana & 99.1 & 0.9 & $\ldots$ \\
Samarkand & 97.4 & 2.4 & 0.2 \\
Transcaspia & 83.0 & 12.8 & 4.2
\end{tabular}


The Russians are officials, priests, traders, and peasants, though more than half of them are immigrant agriculturists. The so-called foreign group consists chiefly of Persians and subjects of Khiva and Bokhara.

\section{LaNguage aNd RELigion}

Turkestan, dominated as it was by one invader after another, received its chief cultural influences from two nations, the Turkic conquerors who insposed their language on its population and the Arabs who forced their conversion to Mohammedanism.

Coning from the Altai country, the Turkic invaders appeared in Turkestan in the sixth century. They included also some hybrid groups, but all were known under the general name, Turks. In a short time, they subdued all of northern Turkestan and spread far to the south, forming a vast Turkic state which, about the end of the sixth century, was divided into two parts, an eastern and a western one. The subjugated Iranian population not only had a new language superimposed upon its own, but underwent an admixture of Turkic blood. The Chinese, taking advantage of the constant internal troubles in these states, in 657 vanquished the eastern and then the western Turks, destroying their independence. This circumstance aided the new conquerors, the Semitic Arabs, who came from the south to subdue Turkestan.

The first Arab invasion of Persia took place in 633. They gradually conquered all Iran and then moved on into Turkestan and after their defeat of the Chinese, ruled Turkestan from the seventh to the thirteenth centuries. The Arab victory over the Chinese in 751 was the last chapter of Chinese domination in Central Asia and made the Arab preëminent so that Islamic culture and Mohammedanism were practically all-prevailing in Central Asia.

A brief account of the former religious beliefs of Turkestan may here be of interest. The Irano-Turkic tribes of Central Asia were originally shamanists, but even before the beginning of our era, Zoroastrianism, the Persian state religion under the Sasanian dynasty, had spread in Turkestan. And at the same time, the Buddhistic doctrine under Chinese influence also found its way into Turkestan. There is evidence (the Buddhist writings in Uigur characters) that at about the eighth century some Central Asiatic Turks were followers of Buddha, since the conquering Arabs found many Buddhistic convents, monks, and golden statues with eyes of pearls. Besides these religious faiths, Manichaeism, a kind of gnosticism, was current in Turkestan. The Manichaean religion, based on the Mazdeist or Mazdakist ${ }^{1}$ doctrine, arose in Babylonia and

'From Mazdak, a Persian leader of a communistic sect, who based his teaching on Zorosstrianism. 
toward the end of the fifth century, spread into Persia and Turkestan. Finally, in the fourth century the Nestorian heresy of Christianity penetrated Turkestan from the west.

Nestorianism, named after Nestorius, Bishop of Constantinople (428-431 A.D.), became so popular in Turkestan that in 420 the Bishop of Merv was proclaimed metropolitan. The Arab invaders found Christians in Bokhara and, some time later, Nestorianism spread farther to the northeast and found proselytes among the different Turkic tribes of northern Turkestan. It was not until the beginning of the fourteenth century that Christianity was finally supplanted by Mohammedanism.

At present 95.6 percent of the population of the five provinces of Turkestan are Mohammedans; 3.7 percent belong to the Russian church (mostly Russians), and 0.7 percent profess other Christian religions, Judaism, and other faiths. The population of the Khanates, Khiva and Bokhara, with the exception of a small group of Russians, Jews, a few Mennonites, is, as a whole, Mohammedan.

Islamic influence on the political, civil, and economic life of the country is so great, that a review of Mohammedanism in Turkestan may be quite appropriate at this point. The greater number belong to the socalled sunna (or traditions) sect. Besides the Koran, delivered to Mohammed by God himself, the Sunnites recognize the traditions or explanations (kias) of the Koran by the first four Khalifs, and the decisions and judgments (hadis) of Khalifs, other than the first four, and by the Imams and highest spiritual persons. The Sunnites are much more fanatical and zealous in their religious observances than their neighbors, the Persians, who are Shiites, and only recognize Mohammed, his nephew, Ali, and the Koran, without commentaries. The Sunnite conception of the world and of religious institutions may be well exemplified by the Sart among whom the clergy are the keepers of all traditions. There are no priests in the strict sense, since they are neither ordained nor consecrated. Every literate man is called mullah (teacher) and one well versed in the knowledge of the written law, (shariat), is called ulem (scholar, theologist). The mullahs and ulems, whose official positions are in accordance with their degree of learning and familiarity with Islamic theology and law, form the main group of the clergy, which may be divided into four classes:-

1. The parish priest of a mosque (imam) and the sexton (azanchi, muejin, suffi).

2. The judge (kazi) and his assistants (aglam and mufti), who examine court affairs and lawsuits, basing their rulings on the shariat. 
3. The teachers (damullah) of the schools for beginners (makteb).

t. Instructors and professors of law and theology in medresses (colleges).

However, not these, but representatives of the Moslem clergy called ishans, pirs, or sheikhs exercise the greatest influence over the spiritual life of the Mohammedan population of Turkestan, and are their real confessors and preceptors. They occupy no offices, but by their ascetic and moral lives attract many followers and form mystic religious orders called suffism, in which the order of dervishes is conspicuous. Poorly clad, unshod, and long-haired dervishes tear along the streets, singing, shouting, dancing in a mad frenzy, and collecting alms.

The Persians living in Transcaspia Province and a few Tadjik on the upper course of the Zarafshan River, belong to the Shiites, who are less zealous in their religious observances.

\section{Ethrical Composition of the Population of Turkestan}

As we have previously seen, as a result of numerous invasions the original Iranian population of Turkestan was either driven out or physically modified by different races. It is therefore no easy task to differentiate the past population into tribal divisions. We deem it more profitable therefore to enumerate the present tribal groups.

\section{The Kirghiz}

The name Kirghiz is applied to two tribes related in language, customs, and mode of life, but differing in origin, and partly in physical type-the Kirghiz-Kaisak and Kara-Kirghiz.

The Kirghiz-Kaisak, numbering about $1,600,000$, occupy the steppes of the provinces of Semirechye, Syr Daria, and northwestern Transcaspia; they also live in Samarkand Province and in Khiva. They call themselves Kaisak or Kiosack, meaning a free, independent people, or by the name of the divisions to which they belong.

The Kara-Kirghiz, meaning Black-Kirghiz, are called Mountain Kirghiz by the Russians and are also known as Burut. They live on the slopes and in the valley's of Tyan-Shan Mountain. They are called Ki-liki-dzi by the Chinese in whose annals the Kara-Kirghiz of old are mentioned as forming an independent state, but were afterwards subjugated by the Huns and interbred with Mongol and other ethnic elements, and later, with the Kirghiz-Kaisak. According to Aristoff, the well-known authority on the Turkic tribes, the Kara-Kirghiz are a branch of the common Kirghiz tree. ${ }^{1}$ The Kaisak say that they had their origin with

\footnotetext{
Aristoff, (s), 394 .
} 
the Uzbeg, and that the Kara-Kirghiz are sprung from dogs; they, on their part, call themselves brothers of the Kaisak. The exact number of Kara-Kirghiz in Turkestan is not known, but according to official data
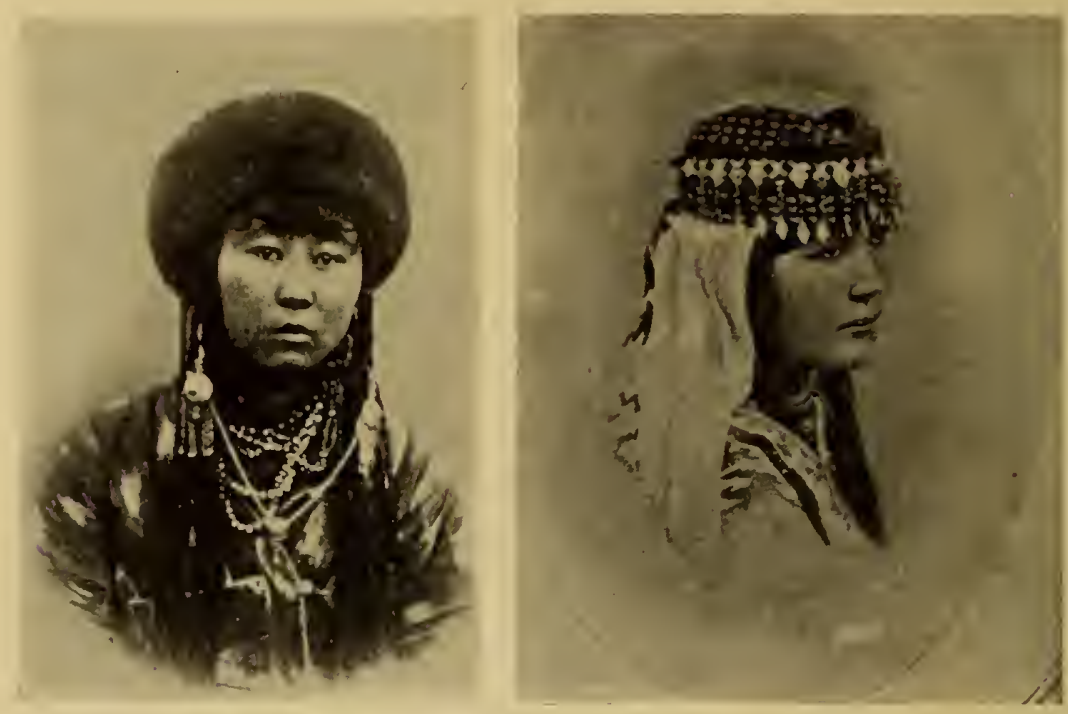

Fig. 14. A Kirghiz-Kaisak and an Uzbeg (right) Girl. Both are Mohammedans of Turkic origin, but the Kirghiz-Kaisak girl (left) shows greater mixture with the Mongols. The Uzbeg were originally nomadic cattle breeders, but now many of them have taken to agriculture.

there were about 540,000 , chiefly in Semirechye, but there are undoubtly more Kara-Kirghiz than this official record would lead one to believe. The total number of both branches of Kirghiz in Turkestan is not less than $2,200,000{ }^{1}$

${ }_{1}$ According to the official statistics of 1911 there were in Turkestan $2,480,443$ of both branches of Kirghiz, but the statistical report of the Turkestan Socialistic Soviet Republic for 1922 gives the number of both branches of Kirghiz as 1,614,217. This decrease may be explained by the political events which have taken place during the last decade.

Before the World War the aborigines of Asiatic Russia were exempt from military service, but a decree of 1916 called them to the colors. The Kirghiz revolted and the uprising was crushed by the czarist government with the utmost severity. After the revolution of October, 1917, the economic life of the country was ruined as the result of civil war. The production of cotton and silk, the railroads and other means of communication, and in part the irrigation system, the very heart of the people's existence, were destroyed. The import of grains from European Russia ceased and a famine followed, resulting in a loss of ten to twenty percent of the population. Then followed the revolt known as the Basmachi Uprising against the communist $\mathbf{r}$ gime. Basmachi is a Turkic word denoting a man who makes a sudden attack, a robber or brigand, from the verb basmák. to fall over unexpectedly. The Basmachi bands devastated unguarded places, killing communists, and robbing their partisans. It has been stated that in 1921-1922 from fifty to sixty thousand men participated in the revolt, among whom were also many Russian peasants. Trotzky himself came to Tashkent to direct the military operations. Many of the bands werc annihilated and others are reported to be still lurking in the mountains. On the other hand, many wealthy Kirghiz moved to Mongolia with their herds to escape nationalization by thc Soviets. 
Perhaps more than other Turkic tribes, the Kirghiz-Kaisak and Kara-Kirghiz have clung to their life as nomadic cattle breeders and to their clan organization. Since the beginning of the seventeenth century the Kirghiz-Kaisak have consisted of three divisions called Ordas (hordes), the Great, Middle, and Little Orda. Fach orda is divided into tribes or unions of paternal clans. Similar divisions may be found anong the Kara-Kirghiz. They are divided into two "wings," on (right) and sol (left), each wing consisting of tribes and each tribe of clans.

Somatologically both divisions of Kirghiz represent a mixed type with many variations, but the fundamental traits are Turkic with some Mongoloid admixture. The Kirghiz-Kaisak are of medium stature (164 cms.), with a well-developed thorax; their hands and feet are small; they have robust constitutions and are inclined to gain considerably in weight with advancing age; the skin color is of yellowish tints; the head hair is straight, coarse, and black, and becomes gray late in life; the beard is scant, growing late, in the form of a wedge; the head is round with a brachycephalic index. Their faces are broad with prominent cheek bones; their noses broad, short, and low-bridged; their eye fissures are almost horizontal and the lids often have a Mongoloid fold; their legs are often bowed from constant horseback riding. The Kara-Kirghiz have almost the same somatological characters. They are somewhat taller (167 cnss.): their cheek bones are more prominent and they are generally more Mongoloid than the Kirghiz-Kaisak. Kirghiz women have more regular and pleasanter features than the men.

The Kirghiz are endowed with fair mental abilities. They have good menories, are sociable, hospitable, good-humored, and inquisitive The majority are, as yet, illiterate. The Kara-Kirghiz look more reserved and unfriendly than the Kirghiz-Kaisak.

The Turkic dialects of both Kirghiz branches may be distinguished from one another by slight phonetic differences and belong to the socalled Tatar division of the Turkic languages. ${ }^{1}$ Owing to the influence of Mohammedanism and the neighboring tribes, many Mongolic, Arabic, Tatar, and Russian words have been adopted into the Kirghiz language. In writing, the ancestors of the Kirghiz used the Uigur characters derived from the Syrian alphabet, which was introduced into Turkestan from

'The students of Turko-Tatar languages, Berezin and Mlirza Kasm Bcg, dividc them into thrce groups: 1. Jagatai; 2, Tatar; 3, Turkic. Radloff divides the Turkic languages into four groups, according to their phonctic characteristics: Eastern, Westcrn. Ccntral Asiatic, and Soutlern dialccts. He believes the Kirahiz dislects belong in the Western group.

There were many other classifications of Turkic languages (1lminsky, Korsh, Vanbery, Katanoff) basnd on phonetic, as well as morphological charactcristics. The latcat studen: of Turkic languages A. . Samoilovich (c), suggests six groups, also based on phonetic characteristics and places the Kirghiz dialects in the Kipchak group. 
Persia by Nestorian preachers. But during the fifteenth century, Uigur writing was supplanted, under Mohammedan influence, by the Arabian alphabet, which is now in use.

The Kirghiz are fond of poetry, eloquence, and rhetoric. Verbal folklore is well developed. Productions of a lyric character, romantic tales, and love songs are more in favor with the Kirghiz-Kaisak, while epic poetry, tales, and songs about strong men and war heroes are more developed among the Kara-Kirghiz. Tales of khans, monsters, animals, and other supernatural beings are numerous and of a great variety. Folk tales are not recited, but sung to the accompaniment of the dombra (a kind of three-stringed guitar, Russian balalaika), or the kobyz (guitar). Contests in the improvisation of songs form the most popular amusement.

Dwellings are of two kinds: that for summer consists of a circular frame with a dome-like top, covered with felt and called ooi. The winter dwelling is a hut (kstau) made of withes and reeds covered with earth. Some of the rich Kirghiz now build log houses for the winter. This change in type of abode is connected with the development of agriculture among the Kirghiz and the shift to a sedentary life.

Food consists chiefly of the products of their cattle and horses: milk and airan (sour milk mixed with water), irimchik (sweet sheep pot cheese), kurt or krut (dry cheese made of sour sheep pot cheese), and among the rich, kumiss, a drink made of fermented mare's milk. During the summer, people of means live almost exclusively on kumiss, consuming it in enormous quantities. Porridge made of millet flour is also a favorite food. The Kirghiz are fond of tea with sugar, using mainly brick tea. Like all herders, they spare their domestic animals and consume very little meat, particularly during the summer. Meat, usually mutton, is cooked, though horse meat is eaten rarely as a special dainty. They are very fond of boursak, pieces of unleavened dough fried in mutton fat, which takes the place of bread, to some degree; kaurdak, roasted meat; and palau, stewed rice. They seldom eat birds, fish, and vegetable foods. They do not use many cooking vessels, but every household has a castiron kettle in which meat is cooked, linen washed, and babies bathed.

The nomadic life of the Kirghiz is entirely the result of his occupation as a herder which necessitates traveling over vast stretches of territory unfit for agriculture. Their domestic animals are horses, cattle, sheep, camels, asses, and goats. Two'species of the domesticated horse are known in Turkestan, the Kirghiz and the Turkoman. The Kirghiz horse is small, but sturdy and strong. He has a large head and a short back. He, like his master, has great powers of endurance and can 
sustain life without food for several days at a time. He is ridden and driven in harness and provides his master with food and drink and materials for clothing and footwear. Like other domestic animals, the Lirghiz horses graze under the watch of a herder. A herd of horses usually consists of one stallion and thirty to forty mares and colts. Several herds form a drove. Rich Kirghiz often own from five hundred to one thousand horses.

Cattle are kept in Turkestan by the nomadic, as well as the settled inhabitants, chiefly as working animals and for milking. The flesh is seldom eaten as the Kirghiz prefer mutton or horse meat. In late years cattle breeding has increased at the cost of horse breeding, and has been found to be more profitable. There is a distinct Kirghiz species of horned mttle. In some mountainous places the Kirghiz rear the domesticated yak (Poephagus grunicus).

Sheep breeding is the chief and most important branch of zooculture in Turkestan, but only the nomadic or semi-nomadic Kirghiz and Turkoman rear sheep. More than three-quarters of the nomadic Kirghiz domestic budget has its source in the income derived from sheep breeding. In the steppes a year-old ram still serves as a unit of value in bartering. The Kirghiz chiefly rear the broad-tailed species of sheep derived from Turkestan. It furnishes very good meat and fat and various milk products. From sheep milk either pure or mixed with cow milk, the Kirghiz prepare katyk (sour milk), krut (a kind of pot cheese), aizan (pot cheese mixed with water), a refreshing drink, and butter. From sheep wool the Kirghiz prepare tent covers, rugs, clothing, rope, bags, etc. In some places the Kirghiz rear other species of sheep. In Transcaspia Province may be found the so-called yomud ${ }^{1}$ species, a hybrid of the Kirghiz and Kurd sheep, and the Persian species called aimak, which furnishes valuable white wool. In Bokhara and also in Samarkand and some districts of Transcaspia is bred the karakul, skins of which are exported to Europe and America. The karakul sheep is traditionally believed to have been brought to Turkestan by the Arảbs. In recent times the angora goat was introduced from the Caucasus into the Ashkabad District of Transcaspia and has been well acclimatized.

Camel breeding is also an important branch of Turkestan animal industry. In spite of the expansion of railroad lines, the camel remains the chief, and sometimes the only, means of transportation over the steppes and deserts of Turkestan. In strength, endurance, and docility, it surpasses all animals domesticated by man, with the probable excep-

1 Yomud is the name of one of the Turkoman divisions. 
tion of the elephant. There are two species of camel, the one-humped (Camelus dromedarius) and the two-humped (Camelus bactrianus).

The one-humped camel (nar) is more sensitive to cold and is used, therefore, in the southern parts of Turkestan; the two-humped camel

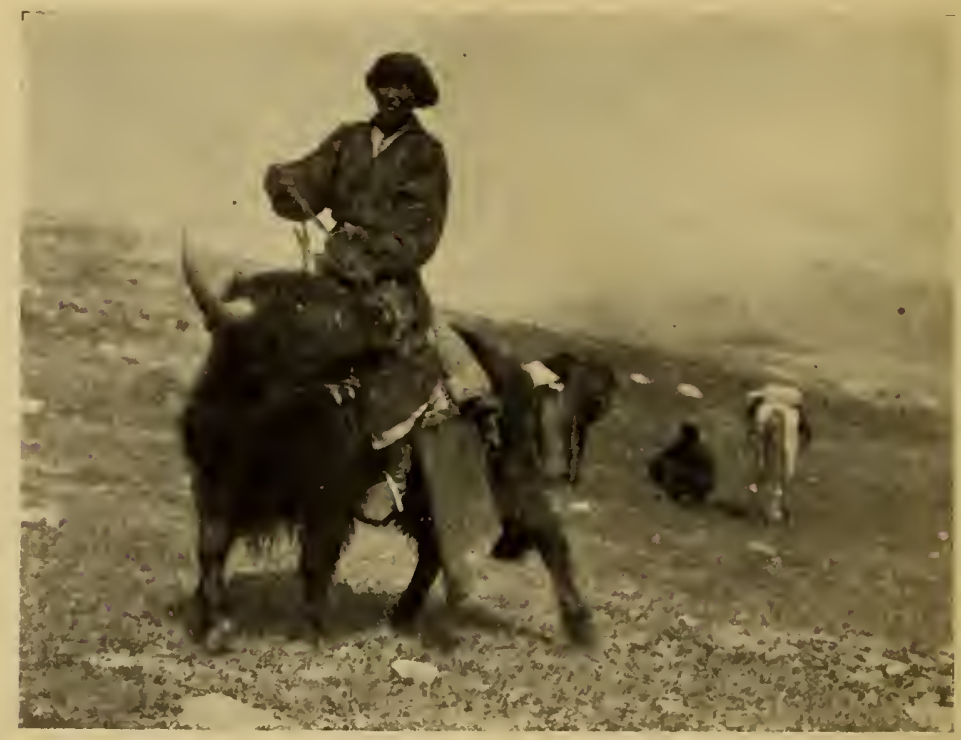

Fig. 15. A Kirghiz riding a Yak.

(air) has more endurance and is employed most frequently in the northern parts of Turkestan. Camels are used not only as beasts of burden, but also in agricultural work. Their flesh is tough and tasteless and they are killed only because of age or incurable sickness. Camel's hair is more valuable than sheep wool; it is removed once a year in the spring or early summer when the camels moult. The milk is rich in fat and when used is mixed with the milk of other domestic animals. Kumiss is also prepared from camel's milk. It is thicker and more nutritious than mare's kumiss. In the nomadic life of the open steppes the camel is a necessary animal, while in the oases, in villages and towns, the donkey is equally indispensable. It has endurance, is docile, obedient, and inexpensive, so that even poor people can afford it.

Swine breeding, which was unknown in Turkestan before the advent of Russian colonists, is now developing in the Russian villages. 
Religion. All the Kirghiz are Sunnites, but are less fanatical in their religious observances than the sedentary Mohammedans. They have no permanent or parish priests and not many of them are literate. Circumcision is performed by Tatar mullahs who wander through the steppes. Some of them live in the camps of the rich people, lead a pious life, and practise medicine. They also take part in funerals, reading verses from the Koran over the deceased. The body, after being washed, is usually put into a cylinder of cotton or silk, open at each end, then the ends are tied up to form a bag. As no coffins are used, the grave is shallow, only three feet below the surface, and is so dug that when the body is lowered, it can be slipped into a niche hollowed out in the side of the grave. Thus, no earth is thrown upon it in filling the grave. In another type of grave, the niche is of bricks plastered with clay.

Some old shamanistic beliefs have also been preserved. The shaman (baksy) cures sick people and also performs on other occasions. According to the written law (shariat), the Kirghiz may have four wives, but only the wealthy can avail themselves of this privilege, since the payment of a bride price (kalym) in cattle or money is necessary. Sometimes the bride price is as much as three hundred head of cattle. A local proverb says: "When a Sart becomes rich he will build a new house, and when a Kirghiz becomes rich he acquires wives."

Kirghiz women enjoy much more freedom than do the women of the sedentary Mohammedan tribes. They do not veil their faces, take part in conversations with men, and freely ride about on the steppes, and though they work hard, their position in the household is far more important than that of the Sart woman. The first wife is called bai-biche, i.e., the elder wife, and she directs the work of the household and apportions it among the younger wives. All the women join in the difficult task of setting up the felt tent. A Kirghiz man would never dream of assisting his wife in her household duties. The men devote themselves almost entirely to the care of their horses, leading, in general, a lazy and shiftless life. This is particularly true of the wealthy herd owners. The Kirghiz are sociable and always eager for fresh news; as soon as a visitor arrives with a piece of news one of the fanily immediately starts off on a fresh horse to pass it on to some distant acquaintance.

Costume. Being Mussulmen, the men shave their heads and grow beards which are usually very insignificant, mere straggly tufts of hair, scarcely covering the chin. They wear immense baggy leather breeches and a coarse shirt with wide flapping collar. Under the leather breeches they sometimes wear cotton trousers. The outer garment is a robe of 
cotton or wool; usually two or three of these are worn, according to the weather. The rich and distinguished have magnificent silk or velvet robes, heavily embroidered in gold and silver. They wear embroidered skull caps and over these, oddly shaped sheepskin hoods, with the wool inside, or conical felt hats, cut with two slits, for convenience in turning up the brims: On important occasions the wealthy don tall steeplecrowned hats of felt or velvet, often embroidered with gold. Their greatest adornments are their belts, saddles, and bridles which are often almost solidly covered with silver, gold, and sometimes precious stones. During the winter they wear sheep or wolfskin robes and fur caps with ear protectors, and high boots with high heels. In winter their stockings and boots are of felt.

The women's dress is almost identical with that of the men. Their shirts, however, are longer, reaching to the heels. The cotton, wool, or silk robe is narrower at the waist and is made of gayly colored material. Their heads and necks are swathed in loose folds of white cotton cloth, forming a combination of bib and turban. Young girl's wear round caps trimmed with fur, with their hair shorn behind, but hanging in front in a score of very long fine braids. Married women wear only two braids.

Social Organization. In their social organization the KirghizKaisak have retained a system of social classes. The descendants of former khans form a kind of nobility, called ak-suck-tyure, i.e., white bene. The hodji, the descendants of the first adherents of Mohammed also belong to this class. The mass of the people are called kara-suck, i.e., black bone. According to the common law (adat) of the KirghizKaisak the "white bone" group had some privileges and advantages in land owning. Marriages between "white" and "black bones" were regarded as a disgrace for the "white" party. Russian cultural influence has, however, diminished the significance of this transgression of the common law.

Among the Kara-Kirghiz there is no privileged class of people, but to a certain degree the so-called chiefs (manap) from whom the judges (bii) are selected may be regarded as privileged. Formerly, the office of a judge was inherited in the male line.

Every aspect of Kirghiz life is regulated by the common law (adat) and accordingly the paternal clan is the basis of ownership and of all social and political relations. The principle of seniority in clan and family relations is still extant. The clan defends its members and theoretically cares for its poor. A bride is regarded as the property of the clan. A Kirghiz proverb says: "It is better to be a herder in one's 
own clan than a czar in an alien clan," or, "Those who do not know the names of their seven ancestors are traitors."

\section{THE UZBEG}

The Uzbeg related, in origin, to the Kirghiz, with the latter comprise the bulk of the population of Turkestan. According to the census of 1597 , there were 726,072 Uzbeg in the Russian provinces, 336,000 in Khiva, and about a million in Bokhara. Thus, the total number is over two million. In Semirechye Province, there are no Uzbeg and only 470 in Transcaspia. In the province of Samarkand, in some districts of Syr Daria and Fergana, and in Khiva and Bokhara not only is the mass of the population Uzbeg, but this is the dominating group. The rulers of Khiva and Bokhara were Uzbeg.

Properly speaking, Uzbeg is a political rather than an ethnical term. It appeared for the first time in the first half of the fourteenth century when Uzbeg-Lihan, a descendant of Dsuchi or Juji (the elder son of Jenghis-lihan), had zealously propagated Mohammedanism among the subject Turkic tribes of northwestern Turkestan. To distinguish themselves from their relatives, who still adhered to shamanism, the Turks who were converted to Islam began to call themselves Uzbeg, after their khan. They became more powerful in the beginning of the sixteenth century when they crushed the might of the Timurides under the command of Sheibani-Khan, a descendant of Uzbeg-Khan. Besides the Turkic hordes, the followers of Sheibani-Khan included a considerable admixture of Mongolic peoples who came with Jenghis Khan and were descendants of the original Iranic population. Thus, the name Uzbeg includes a conglomerate of tribes of Turkic origin with a mixture of some Mongolic and Iranic elements, physically and ethnically differentiated in accordance with local conditions. The Uzbeg speak one of the Jagatai dialects of the Turkic language. The Uzbeg of Khiva are the representatives of the purest Turkic type though they too have some admixture of Aryan blood.

In stature they are a little taller $(168 \mathrm{~cm}$.) than the Kirghiz; the head is oral in form, sub-brachycephalic; the face is oblong with slightly prominent cheek bones; the skin color is yellowish; the hair black; the beard scanty; and the eyes dark brown and horizontally placed.

Most Uzbeg are agriculturists and lead a sedentary life, but a few still remain a nomadic or semi-nomadic people. The process of becoming settled has been accomplished in the Russian provinces as well as in Jihiva during the last fifty years. Semi-nomadic Uzbeg may be found in 
some sections of Bokhara, roaming during the summer and livirg in villages during the winter. As reminders of thcir former social organization, they have prescrved their tribal names and clan federations, but many of them, especially those of Khiva, have forgotten their clan names. According to Khanykoff ${ }^{1}$ there were ninety-seven Uzbeg clans; Khoroshkhin gave ninety-two as the number. ${ }^{2}$ Some of the Uzbeg clan names are similar to those of the Kirghiz, evidence bearing on their origin.

The Uzbeg are still little civilized and most of them are illiterate. Their clerical heads and official representatives are Sarts or Tadjik. The Tadjik regard the Uzbeg as barbarians and seldom intermarry with them.

The Uzbeg arc fervent Mohammedans following the Sunnite doctrine, but are not so fanatical as their Aryan neighbors. Their folklore consists of religious and epic tales and songs. The religious motives are based on Mohammedan traditions and legends and the epics on Kirghiz folklore. Like the Kirghiz, the Uzbeg are fond of music and poetry. The musical instruments (p. 30) found in every Uzbeg dwelling are the same as those of the Kirghiz.

In the family the father is all powerful; even married sons dare not sit or speak first in the father's presence. The position of women is somewhat less favorable than among the Kirghiz, but better than among the Sarts and Tadjik. They veil their faces and arc responsiblc for all the domestic and sometimes, the field labor too, while the men lazily visit the bazaars or acquaintances and seldom stay at home.

Polygamy is found chiefly among the rich Uzbeg. Marriage takes place only after the bride price (kalym) is paid. The ceremony consists in the conclusion of a civil contract before a judge (kazil) and by the reading of a prayer by a mullah. These are followed by a reception, games, and contests.

The common law (adat) which still plays an important role among the Kirghiz, has become almost obsolete among the Uzbeg, who comply only with the written law (shariat).

The mode of life of the nomadic Uzbeg is generally the same as among the nomadic Kirghiz and the life of the settled Uzbeg is similar to that of the sedentary population of Turkestan in general, though its chief parallels are with that of the Sarts, which will be described below. Of course, local differences are numerous. Thus, in the oasis of Khiva, the Uzbeg do not live in villages, but in separate farms (rabat or kurgancha), which are surrounded by high walls of beaten clay surmounted 
by small towers at the corners, and having the general appearance of small forts.

The Lzbeg wear robes of dark brown cotton decorated with red stripes, quite unlike the gayly-colored dresses of the Sarts and Tadjik.

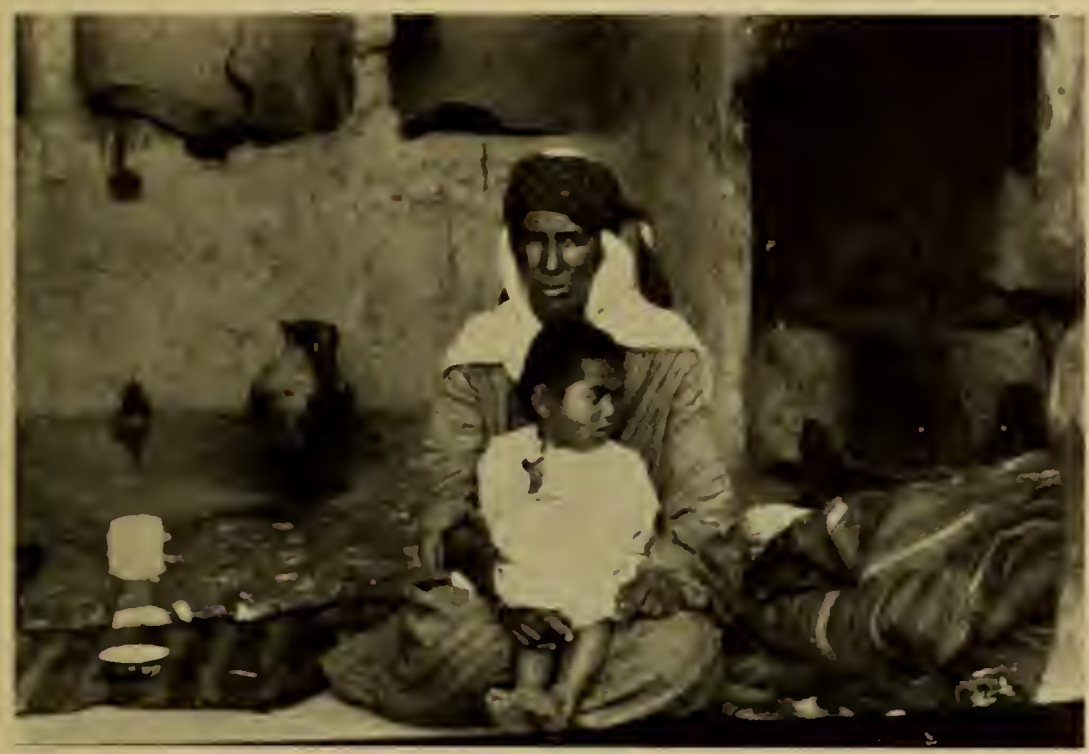

Fig. 16. Czbeg Woman and Child. The illustration shows the interior of an Uzbeg winter house, built of mud and clay.

Usually, a tall sheepskin cap serves as a head covering; the turban is worn only by the judges (kasii), mullahs, and other representatives of the clergy.

As to food, it may be said that the Uzbeg use more meat than do the Sarts. Kumiss, consumed in such quantities by the Kirghiz, finds little favor with the Uzbeg who prefer airan (sour milk mixed with water) and green tea.

Perhaps the most typical mental trait of the Uzbeg is their love of freedom and general restlessness, which of ten brought them into conflict with their rulers, and especially with the Amir of Bokhara and the khan of Kokand." The very name, Uzbeg, meaning "master of himself" from $\mathrm{Cz}_{z}$ (self) and $\mathrm{Beg}$ (master, chief, khan), connotes a somewhat ambitious tendency.

IThe Khanate of Kokand was conquered by the Russians in 1575 and renamed Fergana Province. 
THE TURKOMAN

The Turkoman may be regarded as the tribe most closely related to the Kirghiz and, particularly, to the Uzbeg. They form the bulk of the population of Transcaspia, but also dwell in Khiva and Bokhara and in Syr Daria Province. According to the census of 1897 there were about 450,000 Turkoman in Turkestan. Of this number, 262,378 people of both sexes (4.78 percent of the whole population) were located in the Russian provinces of Turkestan; 139,640 in the Khanate of Khiva (26.8 percent of the population), and about 50,000 in Bokhara.

According to the very contradictory data on their origin, derived from their traditions and other sources, the ancestors of the Turkoman were some clans of the Kangly people, ${ }^{1}$ who, after abandoning their native home on the banks of the Ili River and the shores of Lake Issykkul, settled on the lower courses of the Syr Daria River and took the name of Ogus (or Ohus?). ${ }^{2}$ Because of their wars with the Bedjiye who are regarded as a division of the Pechenyeg, ${ }^{3}$ they were forced to cross the Amu. Daria River and to settle in the region of Merv. On the other hand, some authorities regard the Ogus as Pechenyeg. ${ }^{4}$

The Turkic scholar, Abul-Ghazi, Khan of Khiva, who in 1663 wrote his History of the Mongols ${ }^{5}$ refers the Turkoman settlement in the region of Merv as having taken place in the third century of the Mussulman chronology, in the time of the hero Salor-Kasan, the grandson of the mythical Ogus Khan, whom most of the Turkoman regard as their ancestor. Their settlement in Merv separated the Turkoman from their kin and thus they formed a distinct tribe. The conversion of the Turkoman to Islam is also traditionally ascribed to Salor-Kasan.

Some writers derive the name Turkoman from the Persian "Turkmanend," i.e., one who resembles a Turk, while others derive it from the Turkic, "Turk-men," i.e., I am a Turk. It may be noted, in passing, that one of the Uzbeg clans also bears the name, Turkman.

The Turkoman have preserved their former social organization. They are classified into tribes, clans, and other divisions. The most important tribes are:-

1. The Tekke (the Mountain Goat), or Tekkintzi of the Russians, form the most numerous and prosperous tribe (about 38,000 tents) and occupy the Akhaltekinsky, Ateksky, Tedjensky, and Mervsky clans.

The Pechenyeg were known as Kangly, a name also applied to some lïrghiz-Kaisak and Uzbeg

${ }^{2}$ Ogus means bull in Turkic. Rashid al-Din Tabib regards the Ogus as of purely Turkic blood.

Mlassalsky, 384 .

GGolubowsk

Abul-Ghazi-Bahadur Khan. 


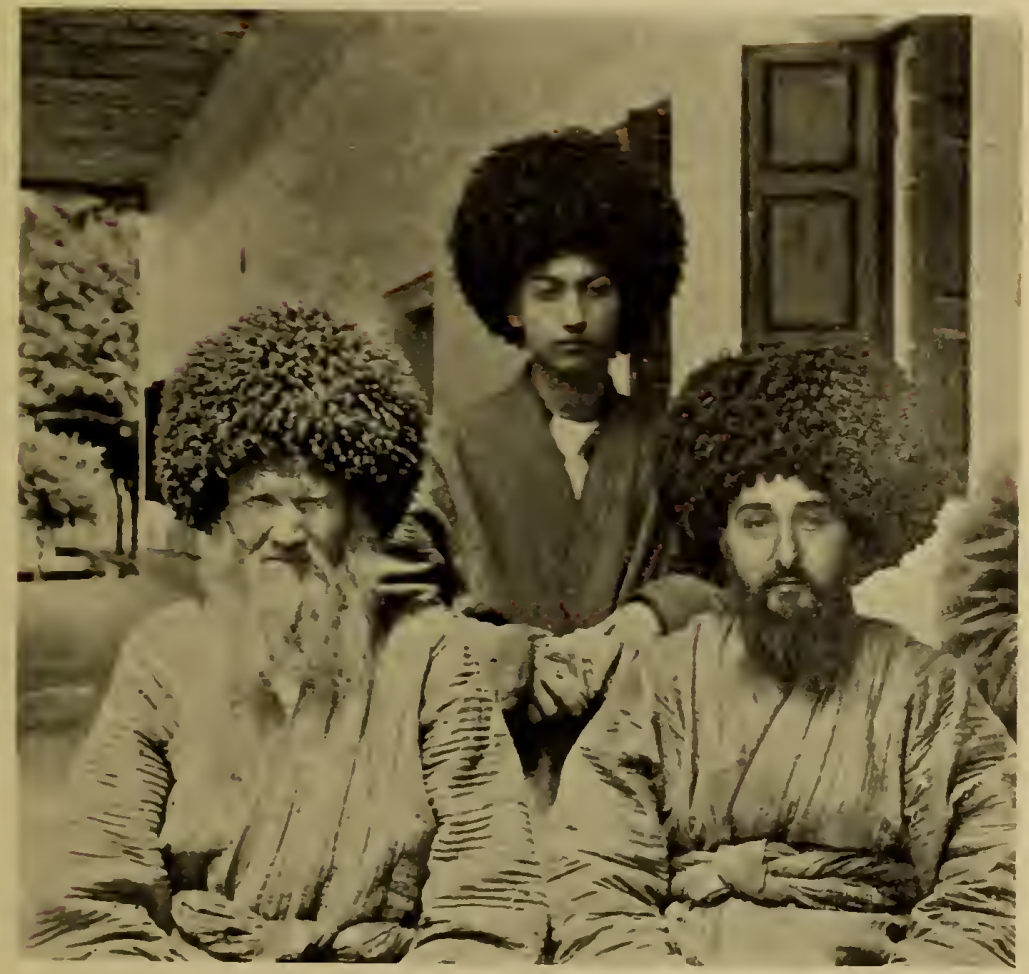

Fig. 17. Turkoman Men, Khiva. Linguistically, a Turkic tribe, the Turkoman are somatologically mixed with Iranians. 


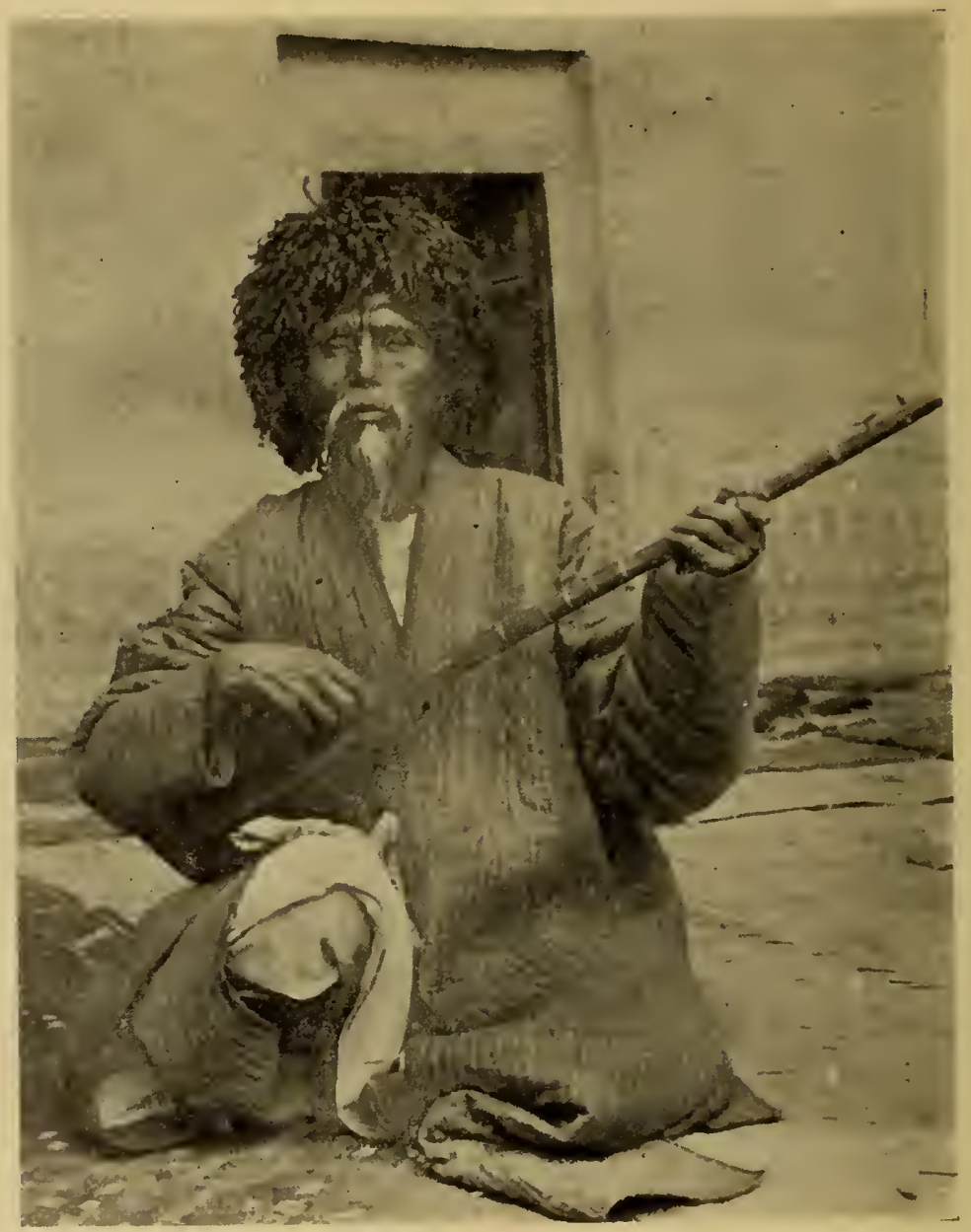

Fig. 18. A Turkoman Musician, Khiva. He accompanies himself on a two-stringed guitar as he sings folk songs. 
oases, and the adjacent steppes. The Tekke consist of two sections, each of which is divided into clans and smaller divisions.

2. The Saryk (about 7300 tents) occupy the Yolatan and Pendin oases on the Murghab River and are divided into six clans and smaller divisions.

3. The Salor or Salyr (about 3,000 tents), are the most ancient of the Turkoman tribes, and are inentioned by Arabian writers of the seventh century as having lived in the region of the Amu Daria. but now occupy the Serakh Oasis, and are divided into thrce divisions.

4. The Yomud (about 4,800 tents) live on the banks of the Sumbar and Artak (or Artrek) rivers flowing into the Caspian Sea, and also in the Amu: Daria District of Syr Daria Province. The Yomud are divided into several divisions and clans.

Beside the four Turkoman tribes there live in Transcaspia Province several other Turkoman divisions, descendants of the ancient Ogus. Thus, the Goklan (about 900 tents) live on the banks of the Atrek and Chandir rivers on the Persian frontier and partly in the district of Amu Daria. The Igdyr (about 400 tents) and the Abdal (60 tents) wander along the shores of the Caspian Sea. The Ogurdjal ( 1,025 tents) live on the shores and islands of the Caspian Sea. The Ata (1,600 families) and Arabachi (250 families) live in the Amu Daria District.

Among the Turkoman of Transcaspia Province there live several tribes, which have become Turkomanized, but whose origin is not exactly known. Some of them (Shik, Seid, Makhtum, Khodja, and Atay, in all about 1,200 tents) regard themselves as of Arabian origin. The Turkoman rank them as clerics, as the descendants of the prophet, and treat them with honor. They do not intermarry with other Turkoman divisions and from them are descended the greatest number of ishans ( $p$. 77). Neither in language, dress, nor mode of life, are they distinguishable from other Turkoman, among whom they live. Some other small Turkoman divisions (Aliel, Nukhurli, Murchali, Anouli, Mekhinle, about 2,000 families) represent the remnants of former Turkic inhabitants of the country and the descendants of various ethnical elements of Turkic and Iranic mixture.

The Yomud and representatives of other Turkoman divisions are to be found in the Khanate of Khiva, a total of about 28,000 families. Of the Turkoman tribes of Bokhara, the Ersar (about 1,000 fanilies) living on the banks of the Amu Daria River, are well known.

Sornatologically the Turkoman represent a great variety of types. In the northern parts of Turkestan the Turkic type has been retained to a great degree, but in the south, Iranian characters become more and 
more conspicuous. Their greatest prominence is noted among the Tekke, who, from time immemorial, have invaded Persia, and captured slaves whom they sold in Khiva and Bokhara, resulting in a mixture with Aryan blood. More than any other Turkic tribe of Turkestan, the Turkoman are entitled to be called Iranic Turks.

The Turkoman may be distinguished by a high stature $(169 \mathrm{cms}$.$) .$ They are thin, but strong, and generally well proportioned. The skin color is brownish, rarely of a light yellowish tint; the beard is luxuriant; the head is high and long (dolichocephaly is predominant); the cheek bones are not very prominent: the eye fissure is mostly horizontal; the eye color is usually of brownish tints, but often gray. The nose is straight and high; the lips are moderate; and the ears are large. The Turkoman is physically strong and easily endures privations and fatigue. Very few of them have a sickly appearance. Among the women the Turkic type seems prevalent. Their cheek bones are more prominent and one can scarcely say that their appearance is generally striking or that they are especially handsome.

In general character and moral qualities the Turkoman is more attractive than the Uzbeg. He is hospitable, trustful, frank, sincere, and brave. On the other hand, he is hot-headed, revengeful, superstitious, and disinclined toward systematic work. Centuries of plundering, brigandage, and robbery have made him lazy and caused him to regard labor as humiliating. Most of their fortifications and irrigation devices were built by Persian slaves and prisoners, and all domestic and industrial activities are carried on by women. The Turkoman cares for his horses and does agricultural work, but in the remainder of his time he hunts, visits neighbors, and gossips, while continually drinking green tea. The Turkoman has a sound mind, is far from stupid, but is still quite illiterate.

The Turkoman speak different Turkic dialects. Those living on the Persian borderland speak a somewhat corrupt Azerbaijan dialect; those of Khiva, Bokhara, and on the borders of Afghanistan speak a dialect allied to the Jagatai or Uzbeg language; and finally, those dwelling near the Kirghiz speak a dialect related to the Kirghiz language.

All the Turkoman are Mohammedans of the Sunnite faith, but they are not distinguished by particular religiosity or fanaticism. In the settlements the mosques, like the dwellings, are rooms of mud or beaten clay, with tiny square windows, covered with parchment. The nomadic Turkoman have no mosques. They have scant knowledge of the Koran and the tenets of the Islamic faith, confining themselves to the observance of certain rites and ceremonies. 
Like the Kirghiz and Uzbeg, the Turkoman, are fond of music, songs, and poetry. The strolling singer (bakhshi), with his two-stringed guitar, is a welcome guest in every dwelling. He may praise folk heroes or sing of historical events or love songs. Of the national poets the best known is Makhtum-kuli, a lyric poet, who lived about a hundred years ago on the Atrek River.

The women skilfully weave rugs and carpets. They show much taste in the combination of colors and arrangement of designs, and one frequently sees rugs of a high artistic value.

The nomadic or semi-nomadic Turkoman live in fclt tents (ui) while those in villages dwell in huts made of mud, clay, or unbaked bricks. The interior arrangement and furnishing of the dwcllings is very primitive and simple. Felt carpets, rugs, wadded quilts, pillows, skin bags, and jars for water, milk, and butter, bags for bread, harness, cups, a tea pot, a trunk, and sometimes a samovar, are the only paraphernalia of a Turkoinan dwelling.

The clothing of a man consists of a cotton shirt, wide trousers, and one, two, or more, cotton or silk (with rich people) robes. The inner robe is belted with a girdle. Some wear robes of cloth or woven camel wool. In winter they wear sheepskin robes. The shaved head is covered by a skull cap ornamented with silk embroidery and a tall sheepskin hat. The footwear consists of woolen stockings and heel-less slippers. In winter they wear yellow and unblackened boots.

The woman's costume consists of a red or gayly colored silk shirt, tight trousers, a cotton or silk robe, a headband, and woolen belt. They wear pendent breast ornaments consisting usually of silver rings or discs. The forehead is covered with a silver band, on the wrists are worn heavy bracelets, silver rings are worn on the fingers, and numerous silver ornaments are hooked in the hair. On festive occasions a Turkoman woman wears a tall hat ornamented with silver dises and pendants. All this jewelry is so heavy that it impedes the movements of the wearer, who, with every movement, tinkles like Swiss cow bells. Some of the pendants are regarded as amulets. Some Salyr women wear silver rings in the septum of the nose. The woman's footwear is the same as that of the man.

Of all Mohammedan women, the Turkoman seem to enjoy the greatest freedom; they go where they please, are unveiled, and mingle with the men from childhood. They seldom have much pretension to good looks. Those of pure Turkoman blood are the ugliest, and have distinctly Mongol features. The better-looking among them are invariably 
descended from Persian slaves and rank low in Turkoman society; consequently a Turkoman of high rank will never choose such a woman for his wife. However, like the Kirghiz women, the Turkoman is regarded as inferior to any males, and she is seldom allowed to take part in

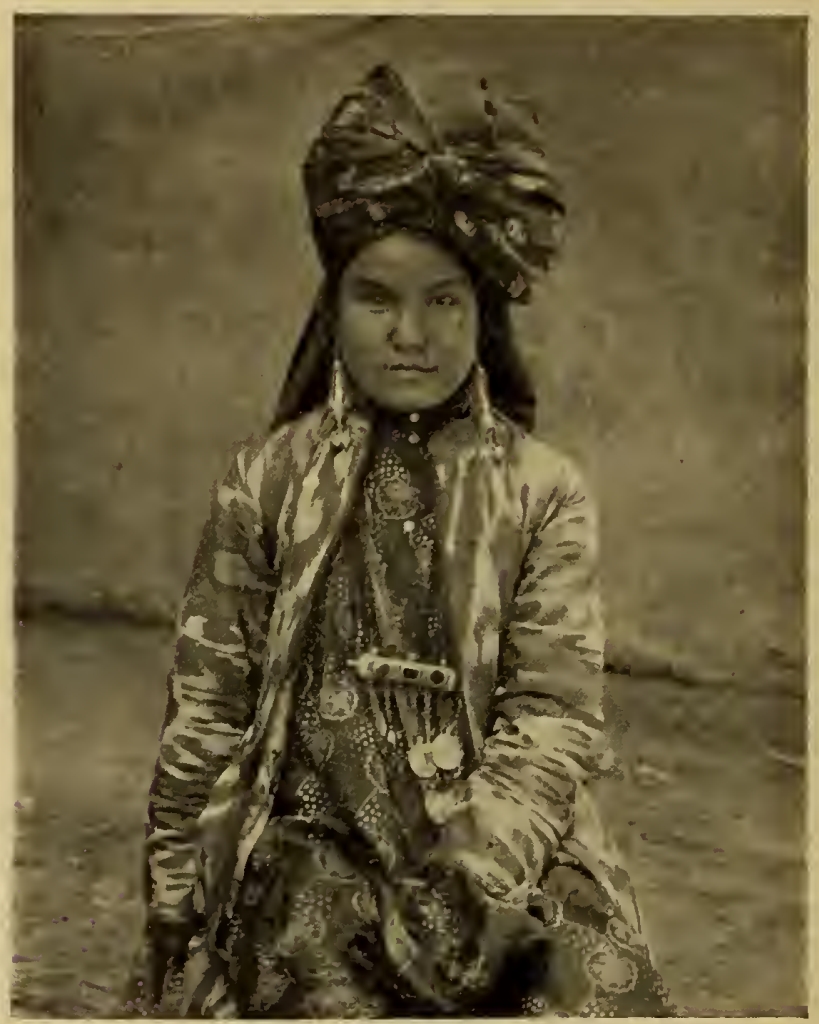

Fig. 19. A Turkoman Woman, Khiva.

social affairs. As a result of the scarcity of women the bride price is so high that only very rich men can afford the privileges of polygamy, while a certain number of men remain single, contrary to Mohammedan rules.

In his food the Turkoman is distinguished from other central Asiatic nomadic people. While the latter live chiefly on meat and milk products, the former's food is mainly vegetarian. Unleavened cakes, gruel, beet soup, melons, and wild herbs are his staple food. He also consumes sweet and sour milk. Pilau of rice, lamb and camel meat are regarded as 
dainties and eaten by rich people or on such occasions as weddings or circumcisions. They seldom use kumiss, but drink chal, a slightly intoxicating sweetish-sour beverage prepared from camel's milk. Green tea finds great favor with them. Most Turkoman smoke or chew tobacco and recently they have adopted the pernicious habit of smoking opiun.

Not long ago, shortly before the Russian conquest of Turkestan, the Turkoman were chiefly nomads and their main occupation, brigandage (alaman). They stole cattle and horses and kidnapped men and wonnen mainly from neighboring Persia. They had no khans or hereditary chiefs. All the Turkoman were considered of equal rank, but when preparing themselves for an attack they selected a temporary leader (serdar), usually an individual known for his courage. After a successful invasion the booty was divided into equal parts among the robbers, called braves (batyrs), the leader receiving a double portion. Turkoman slave dealers used to bring their Persian captives regularly to the market for sale. A man usually brought the equivalent of $\$ 150$ and a woman $\$ 300$. In 1864 when the Russians took Kiva, they liberated nearly forty thousand slaves, among whom were twenty-six Russians. In conquering Turkestan the Russians encountered the most stubborn resistance from the Turkoman inhabitants. At present they have become a peaceful people and are generally turning to agriculture.

In their social relations the Turkoman are guided by the unwritten common law (adat) and only occasionally, as in dividing an inheritance, in family disputes, or divorces, do they, as.Mohammedans, apply the written law (shariat). The Turkoman common law does not distinguish between criminal and civic offences. Every crime is regarded from the point of view of damage caused to some party. A murder may be avenged by death of the killer or by a definite payment (khun), while a theft of any kind is adjusted by returning the stolen goods and paying damages.

In former times the Turkoman had no strictly organized courts. Cases under the jurisdiction of the adat were settled by an assembly of "old men" while those falling under the shariat were solved by the kazii and mullahs. After the subjugation of Turkestan by the Russians a local public court was organized, based on the common law, and consisting of three judicial resorts for appeal.

The principle of clan solidarity is strong among the Turkoman. Tribal divisions occupy territory with definite boundaries, which neighboring divisions must not trespass. Within these boundaries nomadic or sedentary clans are segregated by kin groups. The Turkoman Tekke 
and some other divisions marry women of their own clan only in order that the bride price may remain within the clan.

\section{THE KARA-KALPAK}

The Kara-Kalpak or Kara-Klobuk, i.e., Black Caps, are kindred of the Kirghiz-Kaisak. However, their origin is not strictly known. Their language is related to that of the Western Turks. ${ }^{1}$ According to the census of 1897, there were, in the Russian provinces (chiefly in Syr Daria and Fergana), 104,271 Kara-Kalpak and about 20,000 in Khiva.

Golubowsky ${ }^{2}$ says that the Kara-Kalpak were a mixture of Ghuz Turks, Pechenyeg, and others, and that they were the remnants of the Ghuz Turks who remained in Russia when the new wave of Turkic invaders from Asia, the Polovtzy, drove part of the tribe across the Danube. Some remnants of the Ghuz, possibly with other Turks, settled on the Russian borderlands, accepted Christianity, and were known as Kara-Klobuk, while some of them returned to Asia. According to Moshkoff $^{3}$ about 70,000 of them now live in Bessarabia under the name of Gagauzy. Whether the Kara-Kalpak now living in Asia are the same as the Kara-Kalpak who, in the eleventh century, were the borderland population of Southern Russia, is difficult to ascertain, but possibly they re-migrated to Asia from European Russia in the eighteenth century, where Howorth ${ }^{4}$ thinks they formed the Nogai Pechenyeg tribe on the Yaik River (now called Ural).

Physically, the Kara-Kalpak may be distinguished from the Kirghiz and Turkoman by a higher stature, by a flat and broad face and nose, prominent cheek bones, a large, but scanty beard, and large hands. Kara-Kalpak women are regarded as good looking.

The neighbors of the Kara-Kalpak mock them, regarding them as clumsy and silly, but they are actually a sound-minded, strong, industrious, and peaceful people, who appear timid and reserved as a result of oppression and exploitation by the Uzbeg and other more powerful neighbors.

At present the Kara-Kalpak live in permanent settlements occupying themselves with agriculture and cattle breeding, and partly with fishing. They still preserve the remnants of their former clan organization. Those of the Khiva oasis are divided into two sections which consist of clans and minor divisions. The names of some of these divisions are

${ }^{1}$ Maksimofi, 24

2Golubowsky.

Moshkof, XX11.

'Howorth, I1, 5. 
similar to those of the Kirghiz and L'zbeg and may suggest some relationship with these tribes.

\section{THE KIPCHAK}

The Kipchak are one of a group of tribes related to the Kirghiz, particularly the Uzbeg. They live chiefly in Fergana Province. Their number, according to the census of 1897 , was 45,000 ; but the official records of 1911 give their population as 60,000 . It is possible that there may be more Kipchak, as in many cases they are taken for Uzbeg or Kirghiz. The ancient Comonians, known in Russian chronicles as Polovtzy, were called Kipchak by Mussulman writers, but whether the present Kipchak may be identified with the former Polovtzy remains an open question. At present they are a peaceful people, engaged in agriculture, cattle breeding, and trade, while formerly they took a prominent part in the frequent disturbance and feuds in the Khanate of Kokand (present Fergana Province) before the Russian conquest. A Kipchak was the leader of the Kokand when Tashkent was vanquished and other men prominent in the history of Central Asia belonged to the same tribe.

THE TATARS

The Tatars may be included in the Turkic population of Turkestan. In the Russian provinces, there were, according to the census of 1897 , about 17,000 Tatars. In Kiniva and Bokhara there are very few Tatars. The greater number migrated to Turkestan from the eastern part of European Russian, especially from the Volga provinces. Before the conquest of Turkestan, Russian merchants traded with Turkestan through Tatar intermediaries. The Tatars were also the instructors and teachers of Mohammedanism among the Kirghiz.

\section{THE TARAYCHI}

Before describing the Sarts, the most numerous sedentary ethnical group of Turkestan, some attention should be devoted to the last Turkic tribe of the region-the Taranchi. They are the descendants of a people of mixed Turkic, eastern Iranian, and other elements, and originally lived in Eastern Turkestan, under Chinese rule. In the second half of the eighteenth century, the Taranchi were transferred to the valley of the Ili River by the Chinese Government. In the beginning of the sixtieth year of the nineteenth century, the Dungan (Mohanmedan Chinese), Kirghiz, and Taranchi of Kuldja revolted against their Chinese oppressors and drove them out of the district. The Russians, who had conqueied Bokhara and Kiokand, occupied Kuldja, but ten years later they returned 
it to China, who cruelly punished the rebels. The Taranchi left Kuldja and settled in Semirechye Province of Russian Turkestan. According to the census of 1897, there were 55,977 Taranchi in Semirechye Province and several hundred in Transcaspia. But the latest available data give 70,000 Taranchi $^{1}$ in Semirechye Province, where they constitute a settled agricultural unit in the population. The name Taranchi is derived from Taran, which, according to one writer, means plough land, and to others, millet. The Taranchi speak a Turkic dialect similar to that of the Sart.

\section{THE SARTS}

The Sarts belong to the Iranian Turks and speak a dialect of the Jagatai division of Turkic, adopted from the Uzbeg. This dialect differs in some respects from that of the Uzbeg and is called Sart-tyly, i.e., Sart language. They are regarded as mixed-blood deseendants of the Iranian Tadjik and Turkic Uzbeg in which the Tadjik element predominates. Although distinct from the Kirghiz, Uzbeg, and Tadjik, they do not form a separate ethnological division. Every settled native is called Sart by the Russian newcomers, as opposed to the nomadic or Kaisak (vagabond, wanderer) population. However, the name Sart is mentioned by Arabian writers of the fifteenth and seventeenth centuries and even by Plano Carpini (thirteenth century). ${ }^{2}$ According to Radloff, ${ }^{3}$ the word Sart is of Indian origin and means "merchant," and, if this be so, it would corroborate the contention that the name is a term designating a certain mode of life (settled town people) and having no ethnological significance. According to Professor Andreev in some places the Tadjik of the plains called themselves Sart even before they adopted the Turkic language. ${ }^{4}$

According to the census of 1897 there were $1,458,000$ Sarts, but the official records of 1911 give the figure, 1,847,000. Most of the Sarts live in Fergana and Syr Daria provinces. There are none in Khiva and about 700,000 in Bokhara. However, these figures cannot be regarded as absolutely accurate, especially in view of the vague meaning of the word Sart.

Generally, two types of Sart may be distinguished: one with more Mongoloid traits; the other with more prominent Aryan characteristics. Among the representatives of the second type, which is more prevalent

1The Report of the Turkestan Soviet Socialistic Republic (Tashkent, 1922) gives the number of Taranchi as only 45.526 .

${ }^{2}$ In 1245 Johr de Plano Carpini, a Franciscan Monk, was sent as a missionary by Pope Innocent IV, to Mongolia (See Yule).

'Samoilovich. (c).

Andreev, 159. 
in the southern parts of Turkestan, handsome faces are frequently encountered. As far as is known from their measurements, the Sarts are tall (16S cms.), of a robust constitution, with an inclination to stoutness. The exposed skin color is dark brown and the unexposed yellowish. They are brachycephals (cephalic index, S5.6), but it should be noted that the occiput may be artificially (though perhaps not intentionally) flattened during childhood, due to the manner of cradling. The face is oval and, in most cases, without prominent cheek bones. The eye color is dark brown, gray appears in exceptional cases. Eyes with a Mongoloid fold are frequently seen. The head hair, which is usually shaved, is black, or less often, dark brown. The beard is full and black, and less frequently, dark brown. Sometimes the growth of the beard is much retarded. The nose is long and broad. The hands are small and the fingers thin.

Marriage. When a boy reaches the age of fifteen or sixteen his parents look about for a suitable wife. Girls are considered marriageable between eleven and fifteen. A matchmaker arranges the amount of the bride price (kalym). Properly speaking there is no marriage ceremony, although a mullah is invited to recite a prayer; he is, however, only one of the witnesses who place their seals on the contract. The bride and bridegroom are not present at this ceremony. After the contract is sealed, the brideg:oom obtains admission to the bride. If a feast is held, it usually lasts all night. Men receive refreshments in the outer court, while the women feast in the inner court. Before departing, the men and women guests receive presents, and then the bridegroom is allowed to take the bride home. Mussulman law allows every man four wives at one time.

Family Life. Every Sart house has two courtyards round which the men's and the women's apartments are built. These are entirely separate from each other and only one door, or passage, connects the two. A Sart street looks like a dark corridor since no windows face it.

The wife is obliged to obey her husband in all things and to avoid everything unpleasant to him. and, without his consent, may not make any contracts. She must also make every effort to preserve her beauty in order to please her husband, and for this purpose she is allowed, by law, to use various cosmetics. The most necessary is usma, a species of wood (isatis) which furnishes a black dye for painting the eyebrows. The juice of the fresh leaves is squeezed into a tea cup and applied with a small piece of reed, instead of a brush, or with the finger. The space between the eyebrows is also painted so as to make a continuous line. The eyelashes are painted with surma, a black powder made from antinony, 
which is used also by men, as it is thought to relieve inflammation of the eyes caused by dust and wind. Upa, or white lead, brought from Russia, and rice powder, or powder made of egg shells, are used for whitening the face. Rouge (iglyk) is prepared by soaking cotton wool in an infusion of the root of some boraginous plant. The nails are colored with henna or common garden balsam. It was formerly the custom for the women, especially the old ones, to paint their teeth black (like Japanese married women) with a powder composed of the gall of the pistachio tree mixed with the scales from a blacksmith's forge, but this is now out of fashion. There are no pomades for the hair which is cleaned solely by rubbing with sour milk and then washing in warm water. Baths and houses are perfumed by burning gum or roots of an umbelliferous plant (Euryangium sumbul). Women perfume their persons by carrying a bunch of some sweet-smelling plant, usually basil, or roses. They are fond of flowers. Even men like to have a flower hung from under their turbans.

The position of a woman in the family is not very pleasant. She eats apart from the men, being perforce content with the remains from her husband's meals, so that quite frequently she is poorly nourished. She is regarded by her husband merely as an instrument of his pleasures or as a servant to manage his house. The husband can divorce his wife whenever he chooses, and need give no reason, but must return all her own property, as well as the amount of the bride price, if he has not yet paid it. In case of her adultery the husband not only divorces her but curses her, and after this, she may not re-marry. The wife may also request a divorce which the husband may refuse. But if she is able to give sufficient reason why she should have a divorce, as for instance, the husband's illness, neglect, non-support, the judge (kazi) will compel the husband to divorce her.

The several wives of the same man seldom live together harmoniously, not so much because of jealousy, but because of envy of the privileges that another may enjoy or the presents she may receive. Every husband tries, as far as possible, to keep his wives apart. Wives have a peculiar expression for each other: kyun-dash, day companion.

A respectable Sart woman will not go into the street without a veil. The woven black horsehair veil is manufactured in great quantities in Bokhara. When worn the heavy veil reaches the woman's waist and over it is thrown a dark blue or green robe (khalat), the sleeves of which, tied together at the ends, dangle behind.

The polygamous family life of the Sarts (this concerns, of course, only the prosperous people; poor men seldom have more than one wife) 
does not seem to satisfy them. In spite of their religious fanaticism the Sarts are fond of every kind of amusement, entertaimment, and merrymaking. They stroll about the bazaars, gossiping or bargaining with shopkeepers, examining the work of the artisans, taking tea in a tea house, or meat patties in a cook shop, or eating pistachio nuts. The men often do the shopping for the household. No upper class woman ever goes to the bazaar.

Close to the tea shop is the barber shop. The barber shaves the head and the middle of the mustache, under the nose, but is forbidden by MIussulman law to touch the beard and the ends of the mustache. The barber is a surgeon as well, he will let blood or operate as best he can, but he prescribes no drugs. Nearby is the apothecary's shop where every kind of dried herb and cosmetics can be found.

The Sarts are fond of visiting, particularly on holidays, and like especially to arrange receptions, for men and women separately. During the winter, it is customary to form clubs (jura), the members of which pay certain fees to buy provisions and to hire a cook. They amuse themselves late into the night. The Koran prohibits the use of wine, but a very intoxicating liquor called buza, resembling beer, and made from grain, is used.

The Sarts are especially fond of singing and will sit for hours listening to a monotonous song or the half-chanted recitation of some poem, accompanied by the strumning of a guitar or the beating of a tambourine. Sometimes the batchas, or dancing boys, are invited. These boys are an institution peculiar to Central Asia and are most in vogue in Bokhara and neighboring Samarkand. In Tashkent, batchas flourished until 1872, when a severe epidemic of cholera induced the mullahs to declare that dancing was against the precepts of the Koran. At the request of the leaders of the native population, the Russian authorities forbade public dances during that summer because of the vast crowds which always congregated. It was impossible, however, for the pleasure-loving Sart to continue this abstinence for more than one year, and the mere rumor of a bazem, or dance, was sufficient to draw great crowds to the tea house or garden where it was expected to take place. Dancing boys, chosen for their beauty and effeminate appearance travel round the country under the direction of a manager who is of ten cruel to them. The hair is worn long, trimmed a little at the forehead. They wear long tunies of various hues and loose trousers which are tucked into high leather boots, when boots are worn. The natives prefer these dances when the batcha is dressed as a girl, with long braicls of false hair and tinkling anklets and bracelets. 
While the batcha collects his fees, the spectators try to embrace and kiss him; if the spectator is not very generous, the boy slips from his arms.

During the dances love songs are always sung to the accompaniment of musical instruments. They are not indecent, at least in public, but often very lascivious. The batchas practise their profession sometimes until it is impossible to conceal their beards, and as soon as they begin to lose their girlish appearance, the manager finds them wives and starts them in trade, but, having lived immoral and effeminate lives, they are no longer fit for hard work. Frequently his admirers set up a batcha as a tea house keeper, where he will always have a good clientele. More often he is likely to take to smoking opium or drinking kukhnar, a narcotic made of poppy heads bruised in water, and sinks to the miserable state of a homeless vagabond (gulasha).

Comedians. A very common accompaniment of the dance in a tea house (bazem) is the exhibition of a comedian (maskarabash), who, with whitened face and the addition of a rug or some rags, and the help of a bystander, will represent various scenes of native life, such as a doctor and patient, a judge (kazi) and plaintiff, teacher and pupil, or will mimic dogs, cats, and other domestic animals. Most of these representations are of a very obscene character, though they are of ten very vivid, as well as witty, and are approved with rounds of laughter.

Dancing Women. Not only boys, but girls as well as women, dance in Central Asia. However, their exhibitions are generally confined to the women's court. Women musicians, with their tambourines and pipes sit on rugs or carpets and the girls or women dance in the center of the circle. The dances are similar to those which are danced by boys, but less passionate, vigorous, and graceful. In the Russian quarters women and girls also dance before men. The Mussulmen in general disapprove of women dancing, yet they do not refuse to witness a dance if the opportunity arises.

Circumcision. Perhaps the most important event in the life of a Mohammedan is circumcision. On the ninth day after the birth of a child it is placed in a cradle; the mother rises from her bed and there is a great feast, varying according to the circumstances of the family. This is the only feast given for a girl.

Boys are circumcised between seven and ten years of age; the ceremony may take place at an earlier period, and sometimes, because of poverty, it is deferred until later. As the circumcision feasts (tui) are very expensive, and all the friends of the family must be invited, in order to avoid expense, two or three men usually have their sons circumcised 
at the same time. Naturally, if the father is rich he gives the feast bimself. The boy's' friends gather at some place and form a procession, disguised and decked out with paper caps, wooden swords, and paper shields, and masks made of melon rind. The boy to be circumcised is carried on the back of one of the older boys, in case the feast is not in his own home; if, however, it takes place at home, he is taken from the house, carried through the streets in triumph, and then brought back again. However, he is in a state of unconsciousness, having had administered to him early in the morning, a powerful narcotic, gul-kan (literally flower sugar) which is made of sugar candy mixed with sifted pollen from hop flowers and reduced to a hard paste. When the guests are all assembled there is usually a grand banquet. This is followed by dances, or, what is more usual, native comedians perform a series of farces and impersonations for the amusement of the boys.

During this feasting the boy to be circumcised is kept in the women's court, where he is dressed in his best clothes and at the proper time, brought back to the men's court and laid upon a bed prepared in the guest room; around which are seated the most distinguished guests. The operation is performed with a sharp razcr and gunpowder or fine wood ashes are immediately placed on the wound, which heals in the course of two or three days-the boy then becomes a believer and a member of Islam.

Funerals. As soon as a man dies, the jaws are bound with a cloth, to prevent the lower one from falling. The relatives, together with the people who have come to wash the corpse, wail loudly. The body is then wrapped in a white cloth and carried on a bier to the mosque, where verses from the Kioran are read over it by a mullah. From the mosque, the bier is carried to the graveyard and followed in solemn silence by all the male relatives. Each man carries a stick and a dark blue handkerchief to signify mourning. The interment is carried on in the same way as among the Kirghiz (p.83). The body is always laid with head towards the north. The jug used in washing the body is laid in the grave with it. Mr. and Mrs. Nalivkin say that at a rich man's funeral a coin wrapped in paper is given to each guest. The men who wash the body wear gloves, so as not to touch it. The corpse is usually put into a bag, open at each end, then the ends are tied up. In some districts the women visit the grave early on the clay after the burial; in others, they do not go until the seventh day.

A small lamp is frequently placed on the grave and sometimes ob- 
jects belonging to the deceased, especially the cradle, in case of a child. Feasts called ash (i.e., food) are given to friends on the day of the funeral, and on the seventh day, the fortieth day, the half yearly and the yearly anniversary of the death, men and women come to the tombs to weep and wail and put bread and money upon the grave.

The feasting of the relatives is sometimes accompanied by a mourning dance, which sometimes ends in tearing the hair and distorting the face. For a year the women are obliged to wear dark blue or black clothing, as a sign of mourning; the men, however, do not express their grief in this way. For three days after a death the family does no cooking for itself, but depends upon the food brought by relatives.

Costume. The robes and veils worn by the women have been previously described. The voluminous costume of the men is distinguished by its simplicity and cheapness. It consists of a long cotton shirt, of wide trousers tucked into soft leather boots, over which are worn heeled leather galoshes, which are removed before entering a mosque, dwelling, or shop. The shirt has a girdle of bright-colored calico, and over it are worn one or more robes of printed calico, silk, cloth, or velvet. In Persia only the mullahs wear turbans as a sign of holiness, but among the Sart all may wear these as well as girdles. In Afghanistan a man must wear a girdle that can be used as his shroud, but among the Sart, the turban serves that purpose. In Persia, the head may or may not be shaved, according to the individual taste; shaving is compulsory only for a mullah. But all Sart must shave their heads as soon as the beard begins to grow. The shaved head is covered with an embroidered skull cap and a turban. The mustache is shaved; the upper lip is shaved to insure cleanliness in eating, but the ends of the mustache and the beard are not touched. Barbers (sartorash), or, more correctly head shavers, are very numerous. Sartorash is a Tadjik word from sar, head, and torash, shaver. The local dervishes wear long hair, so they can be easily distinguished from their fellows.

\section{Mongolic Tribes of Turkestan}

THE DUNGAN

The origin of the Dungan has, as yet, not been determined. Some writers regard them as Chinese professing Mohammedanism, ${ }^{1}$ others, as remnants of the old Turkic Uigur who became Chinesized.2 Potanin

Mlassalsky, 410

2Sehuyler, vol. 2, 173; Radloff, (a), vol.2,353. Schuyler, vol. 2, 173, also mentions a Mohammedan people of Chinese Turkestan under the name of Salar, whom he is inelined to eonnect or identify with the Dungan, but there still remains a doubt whether one people ean be meant under these two names. While the Salar, according to l'otanin, speak a Turkie language, the Dungan speak Chinese, but both tribes, though remaining Mlohammedans, have adopted Chinese dress ánd eustoms. 
describes them under the name of Salar. ${ }^{1}$ When Jenghis Khan advanced on Peking there were many Mussulmen from eastern Turkestan in his army. After the conquest he appointed his son, Mongoo, governor of China. These Mohammedans from Eastern Turkestan, the Dungan, remained in China, adopted Chinese customs, manners, and dress, but retained their Mussulman faith. They also adopted the Chinese language . and married Chinese women. They knew but little of Mohammedanism, but rigorously observed the rules for abstinence from the use of swine's flesh, spirits, and opium. The Dungan are a healthy, hardy people, due in part perhaps to their temperance, and are bolder and braver than the Chinese. Consequently, they have always been found to be excellent recruits, and at one time, the police force of Peking was drawn from their ranks. They came to the new western provinces as hired soldiers, but after their terms of service had expired, most of them remained there. One of their chief occupations is as carters, most of those in the north of China being Dungan. When a regular fast route was established to the Ili River, where many flourishing towns developed, the Dungan followed this route in the exercise of their trade, and many of them settled in these towns. In some of them they constituted the major portion of the population. In 1862 it was estimated that there were 60,000 Dungan in the province of Kuldja. ${ }^{2}$ About 1870, the Dungan, together with the Taranchi, losing patience because of the heavy taxation, oppression, and tyranny of the Chinese officials, revolted. The rebellion was suppressed by the Chinese with the utmost cruelty. To pacify the country adjacent to Russian Turkestan, the Russian army occupied the Kuldja region, but ten years later, in accordance with an agreement with China, the Russians left the Kuldja region, taking some of the Dungan with them to Russian Turkestan. The census of 1897 recorded 16,279 Dungan in Turkestan. Most of them $(14,130)$ lived in Semirechye Province; in Fergana Province were 1,640; and about 600 were in Syr Daria Province. ${ }^{3}$ There are no Dungan in the Khanates of Khiva and Bokhara. The Dungan live in towns and villages and are traders, agriculturists, and gardeners. Thanks to their enterprising spirit and capacity for work, and in spite of their recent settlement in the country, the Dungan population is prosperous. Beside Chinese the Turkestan Dungan also speak Dungan, a corrupt Turkic dialect of Uigur origin. Somatologically, they should be regarded as Mongolized Turks.

Potanin, 172-174

: According to Sarubin, (b), 20, in 1917 there were 18,318 Dungan in Turkestan; of these 17,646 lived in Semirechye Province. 


\section{THE SART-KALMUCK}

With the Mongolian branch of the Mongoloids may be included the so-called Sart-Kalmuck. Some explorers regard them as Turks who were assimilated by the Jungarian Kalmuck. Neither in manners, customs, nor language, can they be distinguished from the genuine Kalmuck, except that the latter are Buddhists and the Sart-Kalmuck are Mohammedans. They departed from Chinese territory in the troublous times of the Dungan uprising and, with the permission of the Russian Government, settled in the Prshevalsk District of Semirechye Province. In 1897 the population was 1734 . According to Sarubin, in 1920, there were 553 families of Sart-Kalmuck numbering 2,469. Sarubin calls them Mongolian Mussulmen. ${ }^{1}$ The Sart-Kalmuck are cattle-breeders and wander together with the Kirghiz and are indistinguishable from them in their mode of life.

\section{The Aryans \\ THE TADJIK}

The Tadjik form 7 percent of the population of the Russian provinces of Turkestan, and appear to be the descendants of its old Aryan inhabitants who originated in Iran and in prehistoric times occupied the southern part of Central Asia. This population, which for centuries had suffered from invasions and sanguinary wars, particularly from the devastations wrought by Turco-Mongolic hordes, either intermarried with the conquerors or were forced out of the valleys to the rocky mountains, in which districts they have preserved their racial characteristics in greater purity. According to the census of 1897 the Tadjik population of the Russian provinces of Turkestan was 350,286 forming 6.63 percent of the whole population. Their distribution among the provinces varies. Thus, in Fergana there were 114,081 (7.25 percent of the population); in Samarkand, 230,384 (26.78 percent of the population); in Syr Daria, 5,557 (about 0.4 percent of the population). In Transcaspia no Tadjik were recorded and in Semirechye only 264 were found. There are also no Tadjik in Khiva, but in Bokhara they form the bulk of the inhabitants of the mountains, about 30 percent of the whole population. Their exact number is not known, but it is estimated that in Bokhara, there were from 350,000 to 700,000 . Accepting the last figure as accurate, it may be assumed that in $\mathbf{1 8 9 7}$ there were, in Turkestan and Bokhara, about 1,050,286 Tadjik, i.e., about 10 percent of the total population. According to the Report of the Turkestan Socialist Soviet Republic for 1922

'Sarubin, (b), 24. 
there were 399,912 Tadjik in the five provinces of Turkestan and about $\$ 00,000$ in Bokhara, a total of about $1,200,000$, which exceeds the total of $1 S 97$ by about 200,000 . A number of Tadjik dwell in Afghanistan, partly in the Pamir Mountains, but their exact number was not available. According to the estimate of the Inperial Gazetteer of India (Calcutta, 1908) there were in Afghanistan about 900,000 Tadjik, occupying, after

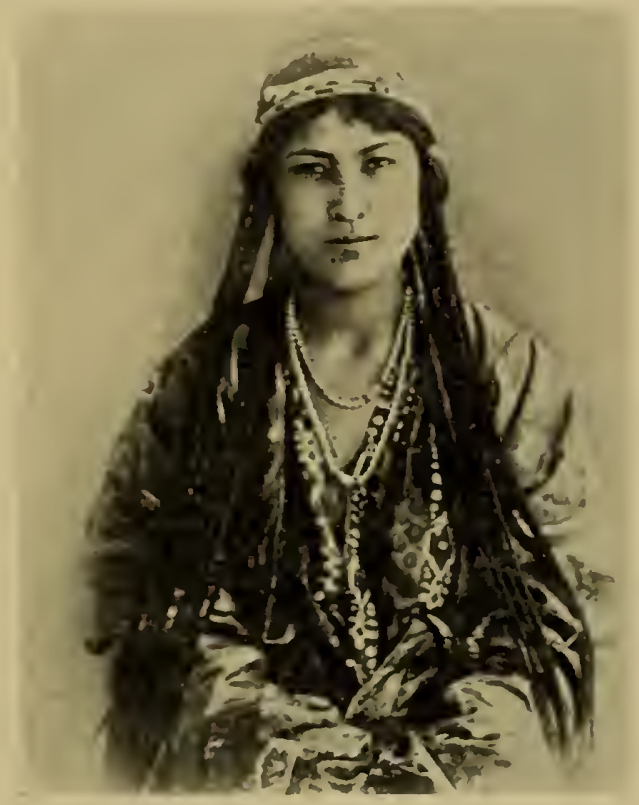

Fig. 20. Mountain Tadjik Woman resembling a European. Tadjik women, unlike other Turkestan Mussulman women, do not veil their faces. Long woollen braids are attached to their hair, and metallic pendants, rings, necklaces, beads, and other ornaments decorate their dresses.

the Afghan, the first place among the peoples of Afghanistan. But Professor Andreev, ${ }^{1}$ based on the calculations of Mr. Tate ${ }^{2}$ estimates the number of the Afghanistan Tadjik at about 2,000,000. Thus, the total number of Tadjik may be regarded as exceeding 3,000,000.

Under the name Tadjik (from the Persian word, Tadj, crown), is usually included the sedentary population of Turkestan and Bokhara which is not included among the Turkic peoples. But, as we have 
previously seen, a large part of the population of Afghanistan also consists of Tadjik. They speak different Persian dialects and other Iranian idioms. Most of these Tadjik dialects are differentiated to such a degree that representatives of the various Tadjik tribes do not understand each other and must have recourse to Persian in communicating with each other, being thus bilingual.

The Tadjik may be divided into plains and mountain dwellers. The Plains people were greatly influenced by their Turkic conquerors. Strong centers of Plains Tadjik are still preserved in the large towns of Samarkand and Bokhara and in some localities of Fergana.

The Mountain Tadjik (including those of Pamir) are usually called Galchas meaning "mountain people" (from an old Bactrian word, gar, meaning mountain). ${ }^{1}$ With the present Tadjik are also included the descendants of Persian immigrants, particularly the slaves who were brought into Turkestan in great numbers by its Turkish conquerors. But this Tadjik element, having interbred profusely with Turkic tribes, is losing its Aryan characteristics, a statement equally applicable to the Tadjik living with Turkic inhabitants in towns. Thus, in the Tashkent District, the Tadjik have become more and more Sarticized, and are forgetting their native tongue.

The Tadjik are of medium or high stature $(167$ to $170 \mathrm{cms}$.). They are broad-shouldered, usually with black hair, bushy black beards, dark eyes, and clear-cut features, have dark complexions, high foreheads, strong chins, and prominent noses. Were it not for their dark complexions, many of them would pass for Europeans. Some are of lighter complexion with light hair and blue eyes, indicating perhaps a mixture with a blond pcoplc. Among the mountaineers, according to Pumpelly, the dark type is more common. ${ }^{2}$ Andreev, however, expresses another opinion, saying:-

"Thanks to the better preservation of their Iranian blood by the Tadjik Mountaineers they resemble European types more than do the Plains Tadjiks. Among the Mountaineers one mects types resembling the Caucasian Ossetines. Tall and well-shaped, they have frequently reddish or blond beards, brown eyes, and light skin."'3

According to Sarubin ${ }^{4}$ they have an average cephalic index of 84 .

The Tadjik living in cities, on the plains, and on the mountain slopes are Mohammedans of the Sunnite faith. The Mountaineers adhere

1.According to Andreev (157) the Tadjik mountaineers do not eall themselves Galcha, but apply this name only to the Yagnob people, descendants of the ancient Sogdians, living in the valley of the Yaguob, a tributary of the Zarafshan River.

Pumpelly, 312

3 Andreev, 158

4Sarubin, (a), 97-14S. 


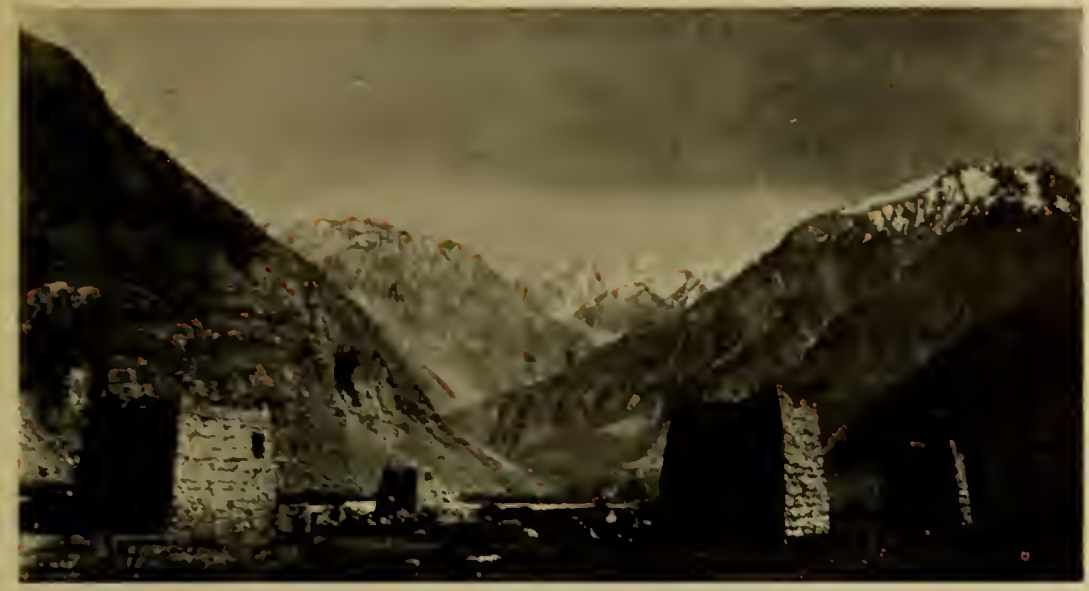

Fig. 21. Ruins of Fortified Tadjik Dwellings on the Upper Course of the Oksus River (Amu Daria).

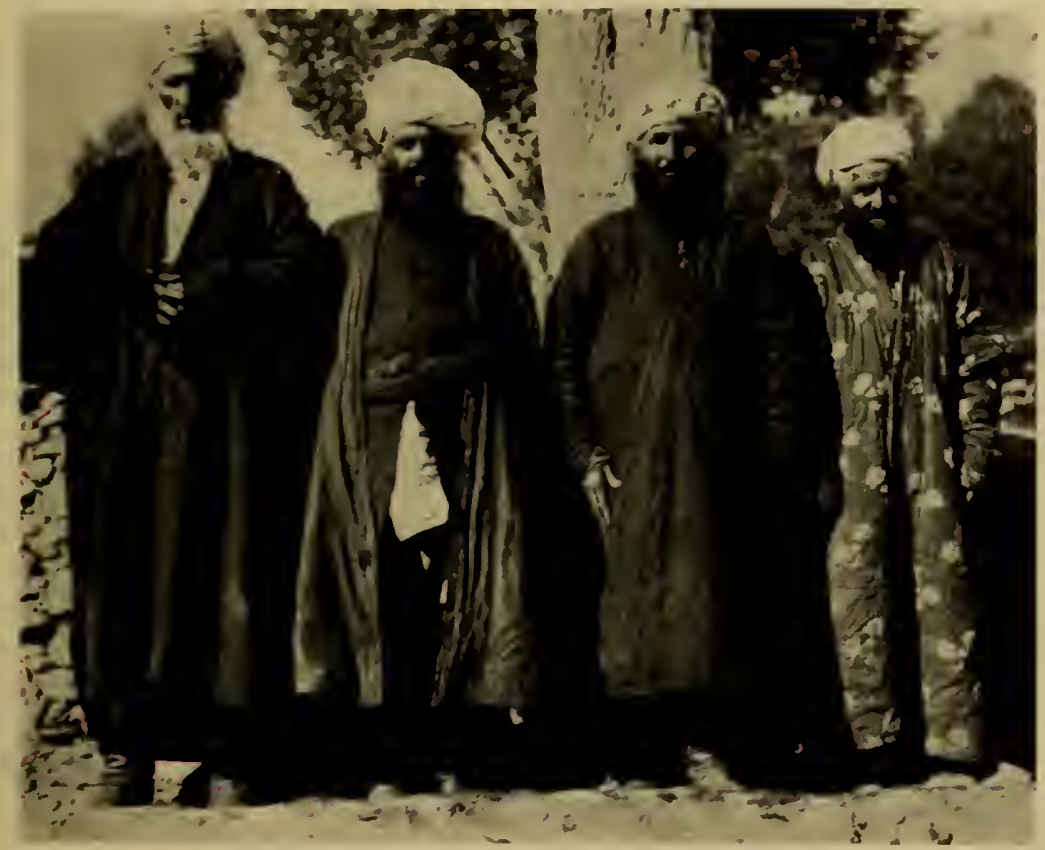

Fig. 22. Types of Tadjik of the Cpper Course of the Oksus (Amu Daria). As mountain dwellers they were little influenced by their Turkic conquerors and have preserved their Iranian type. They speak a Persian dialect and wear turbans. 


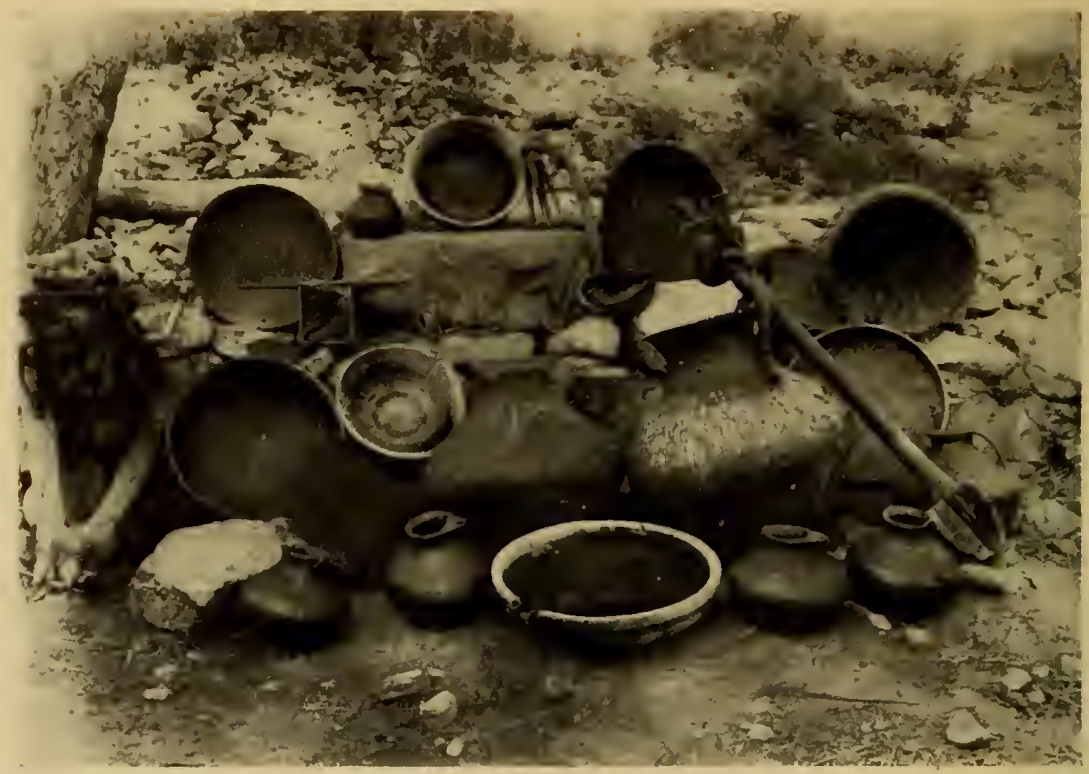

Fig. 23. Tadjik Pottery and Wooden Vessels, and a Stick for churning Butter. The Tadjik are the most industrious agriculturists of Central Asia, also rearing several kinds of domestic animals, as sheep, camels, cattle, etc.

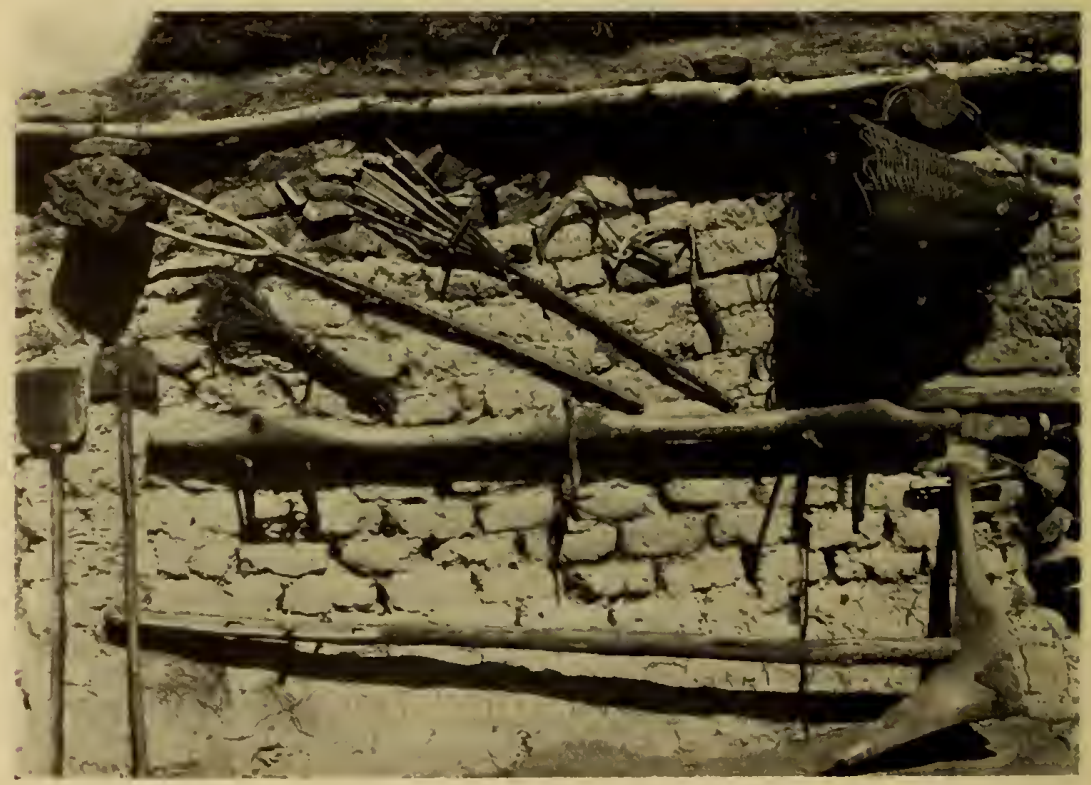

Fig. 24. Agricultural Implements and Tools of the Tadjik. Though living in the mountains these people maintain gardens and orchards among barren rocks. 
partly to the Shiite doctrine and partly to the Ismailite sect. ${ }^{1}$ The Tadjik are particulary fanatic in theil religious observances, but despite this, their belief in pre-Mohammedan superstitions has not lessened. They recognize two kinds of spirits-evil (dev) and benevolent ones (pare). The det's cause all kinds of maladies, death, and other calamities; the pares protect and defend man against the evil deeds of the devs. If the pares prove inefficient, incantations, amulets, prayers, and a special diet may afford relief.

Marriage among the Tadjik is, as a rule, with their own kin and that between cousins of different degrees is regarded as the most proper. A man may also marry his brother's or sister's daughter, but is not allowed to marry an aunt. There is practically no polygamy among them at present. The bride price is divided between her father and her mother's brother.

As a result of long submission to alien races the Tadjik seem to be reserved, distrustful, and timid, but they are noted for their industry and sobriety. From time immemorial, they have been the most typical and industrious agriculturists, representing an old and highly developed agricultural civilization. Their skillfully constructed systems of irrigation transformed deserts into flourishing fields and gardens and evoked the admiration of European and American explorers.

The Mountain Tadjik live in houses grouped into villages in oases of the high valley type, where the waters from streams may be diverted for irrigation. In contrast to the desolate slopes of barren rock that surround them, these oases, with their gardens, apricot orchards, and grain fields are a welcome sight to the traveler who has struggled over miles of the rough trails that wind up the desert gorges.

The houses are rectangular in groundplan, about eight feet high, with a courtyard containing the stalls for horses. Their roofs are flat, ordinarily of about six inches of clay, covering a foundation of brush laid on split saplings and hewn timbers. Higher in the mountains, houses are built of cobbles cemented with clay. Near the glaciers, the dwellings, usually only summer settlements (yailok) are mere squalid huts, with rounded corners, and brush roofs usually protected with felt, but without fireplaces, as there is no fuel. Situated as they are, the settlements are isolated from each other, and are necessarily self-supporting. One may

Ismsilism is an Islamic sect originated anong the Shiites. Its adepts may be found all over Central Asia, in lndia, Syria, F.gypt, and porthern Africs. The main feature of its doctrine eonsists in a liberal attitude toward the Koran, ad nitting its free interpretation by their imam, ealled Aga-Khas, after the name of their leader who, a century ago, emigrated from l'ersia to India with a group of his diaciples. Aga-Khan quides the sect by the right of succession and is regarded by the arases as an inesrnation of the deity. The present Aga-Khan is the forty-eighth imam. The sect is called lsmailite after Ismail, the seventh imam of the Shiites. 
be separated from its nearest neighbor by miles of dangerous trail, with their long rock-hewn flights of steps up which pack animals must struggle. Sometimes these cuts in the cliffs are so narrow and steep that freight must be carried by men. To acquire buoyancy in swimming across deep streams, inflated goat skins are used, a method also known to the ancient Assyrians.

The domestic animals of the Tadjik are cattle, horses, sheep, goats, asses, and camels (in the plains and valleys), but by far the most important occupation is sheep breeding, which is best adapted to the scanty pasturage afforded by the mountain envircnment.

Tadjik food consists chiefly of bread, flour made from different grains, fruits, various kinds of melons, and milk products. Meat is rarely consumed. Because of religious prohibitions they do not eat horse meat nor drink mare's milk. ${ }^{1}$

Tadjik women enjoy more freedom than do Sart women. They seldom veil their faces, the women of the mountains never using the veil. The man's costume consists of wide trousers and a robe. During the winter sheepskin coats are worn over their robes. Footwear consists of woolen stockings and soft leather boots. The head is covered with a skull cap of the Sart type or a woolen cap. Turbans are rarely worn. Women dress in the same manner as men. They cover their heads with cotton handkerchiefs and ornament their dresses with beads, necklaces, and bracelets. Their hair does not grow long and they attach long woolen braids with pendent metallic tassels to their tresses. Finger rings are worn by women and men, but not so often as earrings. Men and boys often wear silver earrings, not as ornaments, but as amulets.

Metallic ornaments are made by local smiths, who are honored by their fellow tribesmen and their trade is regarded as a supernatural gift. There is a tradition of a pious man, who in his sleep heard a voice telling him to go to a certain place. He went, and there found a golden anvil, hammer, and tongs which had fallen from the sky. It was he who became the first smith who taught other people to work metal.

The position of an embroiderer ${ }^{2}$ and lathe turner is not so honored. There are also special knife grinders and circumcisors. The last evoke as much respect as the mullahs, those who know how to read and write

ISarubin, (a). This observation is made with particular reference to the fact that many Islamic tribes, like the Tatar, are particularly fond of and consume horse meat and mare's milk as well as kumiss. Mr. Sarubin, ethnographer of the Russian Academy of Sciences, accompanied the French Professor R. Gauthiot, on his Turkestan expedition of 1914 in order to study the Iranian population. With the outbreak of the World War Gauthiot hastened to enlist and in 1916 died of wounds received in a battle, during the first offensive at Artois in the spring of 1915. Gauthiot was one of the greatest Iranian scholars. Doctor Laufer dedicated to his memory his volume, "Sino-Iranica."

2Embroidery is practised chiefly by men. 
Persian. Besides cooking and other housework, basket and rug weaving, and cropping of sheep, are considered women's occupations.

In conclusion, it should be pointed out that the Tadjik have no tradition of their arrival in their present territory, but boast of having always been there, which may be evidence of the presence of a very ancient Aryan civilization in Turkestan. Ruins of fortresses (gala) in which the Tadjik repelled the attacks of Kirghiz and Afghan are numerous. The mazars or stone monuments placed on the graves of pious or saintly men should also receive mention. The Tadjik traveler usually pauses when passing a grave to recite a prayer and leave an offering.

\section{PERSIANS}

Some of the Persians of Turkestan, as has been stated before, are included anong the Tadjik who are related to them, but the census of 1897 lists Persians separately. In the Russian provinces there were 12,$964 ; 1$ in Khiva they formed 0.6 percent of the whole population. Their number in Bokhara is unknown. A small percentage of the Persians in Turkestan are former slaves who were kidnapped and sold by Turkoman brigands. When the Russians conquered Turkestan the Persian slaves were freed and returned to Persia, only a small number remaining. But many of these released Persians were attacked on their homeward journey and killed by the Turkoman. According to the treaties of 1873 with the Amirs of Bokhara and Khiva, slave trade in these countries was abolished. In Khiva alone 35,000 Persian slaves were found.

Most of the Persians at present in Turkestan are newcomers from Persia who came to aid in the construction of the Central Asiatic railroad, all the embankments being constructed by Persian laborers. Because they are followers of the Shiite doctrine the Persians are disliked by the Sunnites of Turkestan. In Khiva and Bokhara they may not even pray in public.

THE HINDOOS

In the Russian provinces of Fergana, Syr Daria, and Semirechye there were recorded only 250 Hindoo males, but they are more numerous in Bokhara. The Hindoos come temporarily from Shikarpur or Peshawu and live in towns, mainly in special Indian caravansaries, partly to be near the business centers of the towns, and partly for safety. Their chief occupation is usury, although lending money at interest is forbidden by Mussulman law. Their tight trousers, peculiar coats, and red or

'According to the Report of the Turkestan Soviet Republic there were 25,000 Persians in 1922. 
black caste marks on their foreheads, in addition to their other race characteristics, make them easily distinguishable. They shave the tops of their heads, letting the hair at the back of the head grow long. Their mustaches and beards remain untouched.

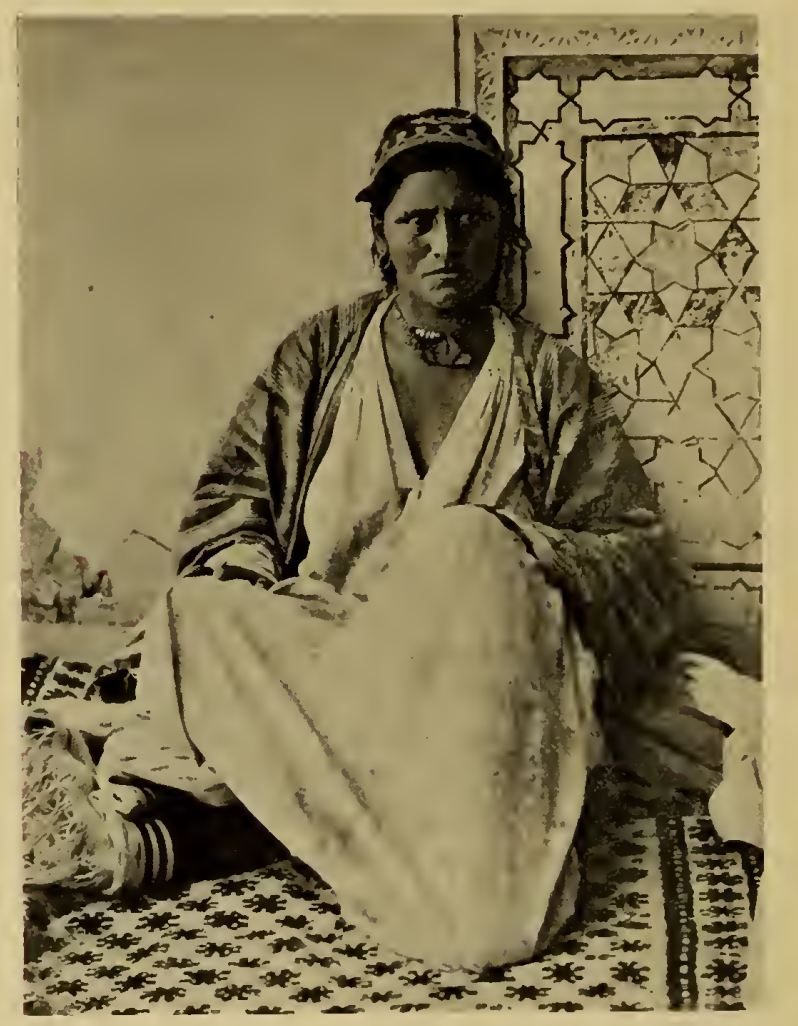

Fig. 25. Gypsy Woman, Samarkand. During the winter the Turkestan Gypsies live in Sart villages; in summer, they live in tents, moving from place to place. Their women engage in basket making, fortune-telling, and begging.

GYPSIES

Something over 600 Gypsies, called liuli, are scattered over Turkestan ${ }^{1}$. In the winter, they live in Sart villages; in summer, in tents, moving from place to place. They are constantly seen in the bazaars and streets. They make sieves, shovels, troughs, spoons, and

1According to Sarubin, (a), in 1917 there were in Turkestan about 2700 Gypsies speaking Tadjik. 
carry on petty trade. The women make baskets, tell fortunes, and take alms, when they can get them. They are more active than the men. The Turkestan gypsies speak Sart and Tadjik and are Mohammedans, but because of their dishonesty, are disliked by the local population. Their women go about with unveiled faces.

To these Turkestan gypsies evidently belong the so-called Karaliuli (black gypsies), Industani-liuli (Indian gypsies), or Maimunyliuli (monkey gypsies), who roam about in small groups, carrying on petty trade, chiefly selling cosmetics, and training bears, monkeys, and goats.

\section{Semites of Turkestan}

JENS

Of the Senitic inhabitants of Turkestan, the most important are the Jews, usually called Bokharan Jews, who live in all the towns. They believe themselves to be descendants of those Israelites who were taken prisoner by the kings of Assyria and Babylon, and brought to Central Asia between six and seven hundred years before the time of Christ. Under the successive Mohammedan conquerors their position was not an enviable one. In ancient times, they were obliged to live in separate quarters, were forbidden to ride within the city walls, to ride on horses or mules (they were restricted to donkeys), and to wear a turban and any girdle other than a rope.

The Mohammedans despised their Jewish neighbors and forbade them to enter their houses. If a Jew, mounted on his donkey, met a Mussulman in the street, he was expected to dismount and make way for him. The only people the Turkoman did not kidnap were the Jews, their reason for passing them over being that no Mohammedan would buy a Jewish slave.

All these restrictions and humiliations were abolished by the Russian conquerors and the Bokharan Jew, being well aware of what Russia has done for him, has shown himself an honest and friendly citizen of the new country. Besides, the Russian Government granterl him the right of "domicile" over all Russia, a privilege accorded only to a small class of Russian Jews. Learing the despicable practice of usury to the Hindoo settlers, the Jews of Turkestan devoted themselves principally to the dyeing of native silk, in eonsequence of which a Hebrew can be distinguished from the Sart, who have a inonopoly of the cotton trade, by the purple stains upon his hands, as well as by his distinctive features. So good a reputation have they won by their honorable and upright dealings 
that the Russian merchants rely implicitly on their word. They also carry on considerable trade with other countries. The Bokhara Jewish women may be distinguished by their beauty. In their own homes they mingle with the men as freely as they would in Europe, but, out-of-doors, for their own safety, they wear the Sart woman's coat (parandja) and horsehair veil, so that they may not be distinguished from the Mohammedan women.

The Turkestan Jew speaks Sart and, at present, wears the same costume as the other natives, but substitutes a high fur-trimmed cap for the turban. He shaves his head, leaving thick curls on the temples. In the Russian provinces there were about 6,000 Jews, very few in Khiva, and a considerable number in Bokhara, but the exact figure is not available. ${ }^{1}$

\section{ARABS}

The Arabs who, in former times, conquered Turkestan, where they forcibly introduced Mohammedanism, have become almost entirely assimilated with the Uzbeg population. The census of 1897 recorded 634 Arabs in Syr Daria Province, but it is assumed that this number is not high enough. The same reservation applies to the other provinces. In the district of Zarafshan there are estimated to be 2,000 Arab families.

\section{AFGHANS}

A few Afghan may be found in all the provinces of Russian Turkestan, as well as in Bokhara. Near Kokand there is a whole settlement of Afghans. The census of 1897 gives the number of Afghans (600) only for Samarkand and Transcaspia. The Afghans are Mussulmen, following the Sunnite doctrine, and are disliked by the native Mohammedans. In contrast to the latter they do not shave their heads, but wear long hair. Their clothing, however, is like that of the local population. They are merchants and speak an Afghan language with Semitic elements.

The Afghans have been included among the Semitic tribes of Turkestan, first, because the term. Afghan, applies only to one division of the conglomeration of peoples in Afghanistan, but this is the dominant section and is known as the Durani. The Durani Afghan claim to be Ben-iIsrael, and insist on their descent from the tribes who were carried away as captives from Palestine to Media by Nebuchadnezzar. The other less numerous division of Afghans, is called Ghilzai, and claims Turkic origin.

1 According to Sarubin the Central Asiatic Jew's speak a Persian dialect. He estimates the number of Jews in Turkestan provinces at about 16,000 and several thousand in Bokhara. He mentions alsn a small group of Jews converted to Islam and known as Chala 


\section{Administrative Changes under the Soviets}

The administrative changes through which the provinces and vassal states of Turkestan have passed naturally cannot affect its ethnical composition, but from a socio-historical point of view, they have a very farreaching importance.

After the revolution of October, 1917, the general government of Turkestan was overthrown and a Soviet government proclaimed. By a decree dated April 20, 1921, the Moscow Government recognized Turkestan as an Autonomous Socialist Soviet Republic. The Turkestan Republic enjoyed a somewhat larger measure of independence than did the other federal states, since it had its own legislative body, resembling the Moscow Congress of Soviets. When this body was not in session, its legislative functions were exercised by a Central Executive Committee. However, a special "Turkestan Commission" appointed by the Moscow Soviets, had its headquarters in Tashkent, and represented the central authority. Instead of five provinces the Turkestan Republic was divided into six, namely: Amu Daria, Djetisuinsk, Samarkandsk, Syr Daria, Turkmensk, and Fergansk. Amu Daria is actually a part of the former Semirechye, and Turkmensk is the former Transcaspia.

The Amir of Bokhara and the Khan of Khiva were driven out after the revolution of 1919 and Soviet governments were set up.

The Khanate Khiva was renamed the Republic of Khorezm ${ }^{1}$ and in September, 1920, the Moscow Government concluded a treaty with it, which affirmed the complete independence of the Republic of Khorezm. It annulled all agreements made between former Russian governments and the Khanate, agreed upon the previously existing frontiers, prohibited both sides from allowing their territory to be used as a base for hostile movements directed against either party, and promised assistance to Khorezm in the matter of education, technical instructions, and a subsidy. It stipulated also that Khorezm shall give concessions to no states other than the Soviet republics for industrial, mining, agricultural, transportation, or similar enterprises within its boundaries. Khorezm, like all the other independent States, had a plenipotentiary representative in Moscow.

In March, 1921, a treaty between Russia and the Soviet Republic of Bokhara was concluded in Moseow. It affirmed the complete independence of Bokhara and renounced all rights acquired by the Imperial Russian government. The treaty was styled a "Military Political Agreement" and its chief clauses were:-

'Khorezm is the ancient Turkic name for liviva. 
1. That neither contracting party shall allow its territory to be used as a base for military movements against any other Soviet republic, or permit the passage of armies intended for the furtherance of such movements, and that mutual assistance shall be rendered in order to protect the independence of either country against attacks from the world bourgeoisie or its agents.

2. The previously existing frontiers were confirmed.

3. An economic agreenent was to be concluded under which Russia is to assist Bokhara, by providing materials, machinery, specialists, and financial aid necessary to the country's industrial needs.

The representative of the Russian Government, who had his headquarters in Tashkent, also dealt with the Republics of Bokhara and Khiva.

In the beginning, both republics were called "soviet," but not "socialist," being named People's Soviet Republic, and occupied a middle position between capitalistic and communistic countries. Bokhara particularly held to the institutions of modern democracies, such as universal suffrage, the individual's right to own property, freedom of specch, press meetings and unions; liberty of trade and commerce; personal security and protection of private domiciles. Little by little, however, both republics were deprived of their privileges. Bokhara held out longer than Khiva (Khorezm). After four years of relative independence Bokhara too was reorganized into a Soviet Socialist Republic and becane a member of the Union of Soviet Republics.

According to a decree of November, 1924, Khorezm and Bokhara ceased to exist as separate administrative units, and were incorporated under different government divisions according to the principle of ethnical majorities. So that we now have the following reorganized administrative divisions, the data for which have been taken by the author from the paper "Pravda Vostoka" (The Truth of the Orient) for November 25, 1924 , which is responsible for the correctness of the report.

\section{UZBEKISTAN}

The Uzbeg Socialist Soviet Republic, or Uzbekistan, occupies 193,365 square miles and consists of seven provinces: Tashkent, Samarkand, Fergana, Zarafshan, Suzakhan, Kashka Daria, and Khorezm.

Tashkent appears to be a part of the former province of Syr Daria, occupies 6,008 square miles, and has a population of 282,455 . It is dividerl into two districts-Tashkent and Mirza-chul.

The appended map, "The latest administrative divisions of Central Asia under the Soviets" is copied from the same source (p. 117). 
The province of Samarkand occupies 11,529 square miles, has a population of 580,408 , and is divided into four districts: Dshidak, KattaKurgan, Khodjent, and Samarkand. The ancient city, Samarkand, the center of the province, is the capital of the Uzbekistan republic.

Fergana is divided into four districts: Kokand, Andijan, Namangan, and Fergana. It occupies 7,620 square miles and has a population of $1,293,385$. The center and chief city of the province is Kokand.

Zarafshan, Kashka Daria, and Surakhan provinces represent three districts of the former Republic of Bokhara which were incorporated into the Uzbeg Socialist Soviet Republic. Zeravshan Province includes three former vilayets ${ }^{1}$ of Bokhara: Nurat, Kezınin, and Bokhara, having as their center the city of Staraya Bokhara.

Kashka Daria includes the former vilayets of Bokhara: Karshin, Kitab-Shakhrizyab, and Guzar, with a central city, Begbudy (former Karshi).

Surakhan Province includes the following former Bokhara vilayets: Baisun, Shirabad, and a part of Sary-Assiisk. The central city is Shirabad.

The total number of inhabitants of the three last-named provinces is 958,686 .

The total population of the Uzbeg Socialist Soviet Republic is estimated at 3,725,326. The national composition of Uzbekistan includes representatives of different races. The Uzbeg, however, form the majority of the population and total 2,578,786 individuals. Then in order of their number follow the Tadjik $(594,986)$, the Russians $(159,845)$, the Kirghiz-Kaisak $(89,834)$, the Kara-Kirghiz $(81,762)$, and the Kipchak. It should be noted, however, that the Sart are classed with the Uzbeg by the Soviet Government and the name Sarts ${ }^{2}$ is no longer mentioned in the official records.

The population is largely rural: of the $3,725,326$ inhabitants only 613,772 are town dwellers.

\section{THE TURKOMAN SOVIET SOCIALIST REPUBLIC}

In extent of territory and number of inhabitants the Turkoman Soviet Socialist Republic, otherwise known as Turkmanistan, takes second place among the Soviet republics of Central Asia. It occupies

1 ilayet is a Turkish name for an administrative division of the first class governed by a vali (governor).

"Sarubin and Andreev, the latest investigators of Turkestan, regard the Sarts as Iranians (Tadjik) who adopted the Turkic dialect of their conquerors, the Uzbeg. In their Turkic speech they gave up, however, the Turkic harmony of vowels preserving to a certain degree the lranian phonetics. The wellknown Russian student of the Turks, Professor A. N. Samoilovich, regards the word Sart, not as an ethnological, but as a vocational term, deriving it, according to the linguistic research of the late Professor W. Radlof, from a Sanskrit word meaning, "merchant." 
170,650 square miles and has $\$ 50,000$ inhabitants. Turkmanistan is divided into five districts:-

1. Poltoratzk with a principal city of the same name.

2. Merv with a chief city of the same name.

3. Tashaun includes the former bek district ${ }^{2}$ of Khiva Tashaun, and some other districts of the former Khiva Khanate. The chief city is Tashaun.

4. Chardjui was formed from the Chardjui vilayet of the former Bokhara on the banks of the Amu Daria River. The chief town is Chardjui.

5. Kerkinsk was formerly the Bokhara vilayet, Kerkin, and the Kelif District of the former Turkestan Republic.

Until Chardjui is rebuilt as a capital, the administrative center is temporarily located in Poltoratzk, a large trading station, with 303,492 inhabitants.

The national composition of Turkmanistan includes different tribal elements, but the Turkoman are the dominating people, numbering 660,007. Then follow the Uzbeg, 92,782; the Russians, 47,341; the Tadjik, $1 \overline{7}, 622$; the Persians, 17,589 ; and others.

\section{THE KARA-KIRGHIZ AUTONOMOUS PROVINCE}

The Kara-Kirghiz autonomous province occupies the whole southeastern corner of Central Asia bordering on the foreign territories of China and Afghanistan. It occupies $\$ 9,048$ square miles, with a popula-

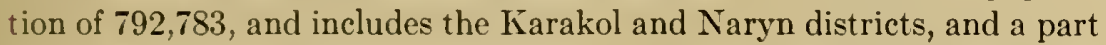
of the Aulie-Atin District of the former Province of Semirechye (later Djetisuinsk), fifty-two rural districts of the former Fergana Province and the eastern part of the Pamir region. For administrative purposes the province is divided into two districts: 1, Pishpek, with a center in a town of the same name; 2, Djalal-abad, with a center in a town of the same name. The population consists of nomadic, semi-nomadic, and. sedentary people. Only 73,000 live in towns; ninety percent of the population is rural. The Kara-Kirghiz, numbering 504,858, form the majority of the population, then follow the Russians, 135,784; the Uzbeg, 118,170; the Kirghiz, 14,324; and others.

THE TADJIK ACTONOMOUS REPUBLIC

The Tadjik Autonomous Republic, which enters into the composition of the Uzbeg Soviet Socialist Republic, occupies 33,436 square miles

'Bek is the Turkish name for the governor of a district. 
and has a population of about 600,000 . It consists of five vilayets of the former Bokhara, of one district of the former Samarkand Province, and of a district of western Pamir.

The whole of the Tadjik Autonomous Republic consists of high rocky mountains. It is watered by the upper Amu Daria River and its tributaries. The chief town and administrative center is Dyushambe on the Varzob River. The bulk of the population which is found in the rural districts of the more fertile western part of the republic is composed of Tadjik (65.4 percent), Uzbeg (32.4 percent), and Kirghiz (2.2 percent.)

THE KARA-KALPAK AUTONOMOUS PROTINCE

The Kara-Kalpak Autonomous Province occupies a territory of 30,572 square miles, with a population of 273,684 . It.is located between the Aral Sea, Kirghiz Republic, Uzbekistan, and Turkmanistan, and is composed of the Khodjel and Kugrad districts of the former Khiva (later Khorezm Republic) and of the Chimbai and Turtkul districts of the former Amu Daria Province. It is divided into four administrative Districts: Turtkul, Chimbai, Kugrad, and Khodjeibi, with principal towns of the same names. The chief occupations of the inhabitants are agriculture (the settled Kara-Kalpak) and cattle breeding (the nomadic Kirghiz). They form the major part of the Kara-Kalpak population (72.5 percent). The Kirghiz represent 21 percent.

STATISTICAL DATA ON THE TURKESTAN REPUBLIC

The following statistical data concerning the Turkestan Republic are based on the census of 1920 made before the reorganization of the Turkestan states. 


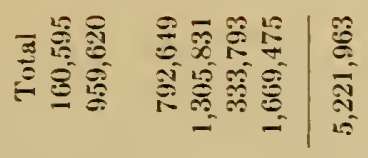

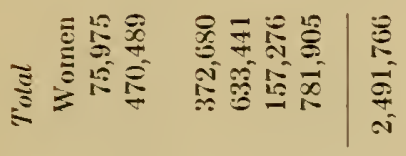

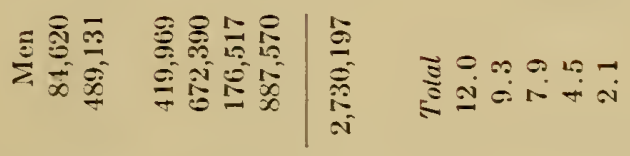

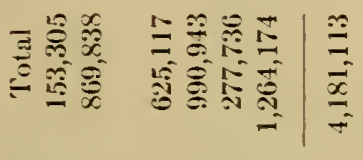

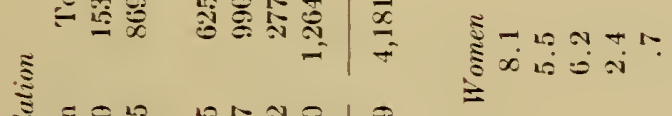

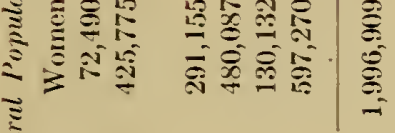

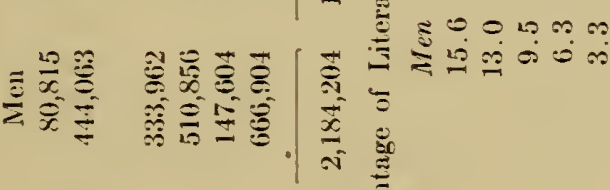

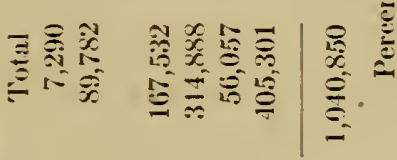

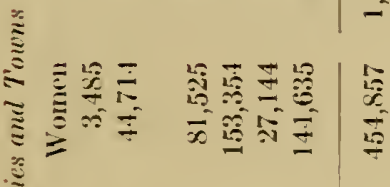

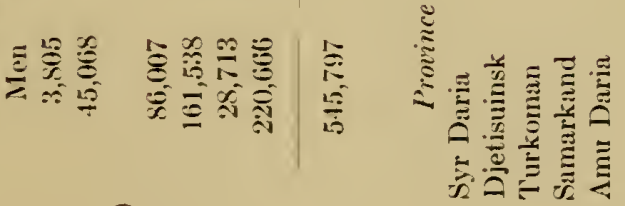

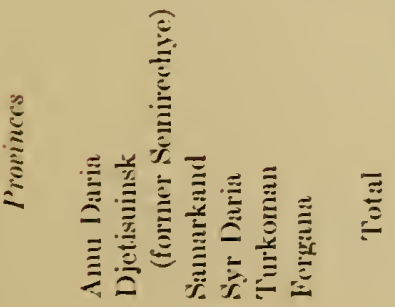


Domestic Animals Owned by the Natives of Turkestan in 1914, 1917, and 1920

Provinces
Djetisuinsk
Horses
Horned cattle
Shcep and goats
Syr Daria
Horses
Horned cattle
Sheep and goats
Turkoman
Horses
Horned cattle
Sheep and goats
Samarkand
Horses
Horned cattle
Sheep and goats
Fergana
Horses
Horned cattle
Sheep and goats

1914
$1,112,000$
860,000
$7,126,000$

678,000
798,000
$5,870,000$

81,000
63,000
$2,001,000$

115,000
230,000
$1,147,000$

338,000
415,000
978,000

1917

726,000

682,000

$6,233,000$

471,000
607,000
$4,538,000$

$4,538,000$

29,000
90,000
$1,275,000$

20,000

39,000

603,000

$\begin{array}{rr}75,000 & 56,000 \\ 239,000 & 166,000 \\ 960,000 & 288,000\end{array}$

We see from this table how much the war and the revolution affected the rural economy of the natives of Turkestan. The civil war particularly impoverished the Turkestan breeder of domestic animals. But in some cases (in the provinces of Turkoman, Samarkand, and Fergana) the number of horned cattle increased in 1917, as compared with the figures of 1914. 


\section{CHAPTER V}

\section{THE ASHATIC STEPPE PROVINCES}

The Steppe Provinces under old Russia included Uralsk, Turgai, Akmolinsk, and Semipalatinsk. This region is also known as the Kirghiz country, since the people of this name form the bulk of the population. Under the soviets, these steppe provinces are known as the Kirghiz Republic.

\section{THe KIHGHiz}

The local Kirghiz were included in the description of the inhabitants of Turkestan (p. $7 \overline{7}$ ), but in this section will be presented a survey of the whole tribe.

The total number of Kirghiz, according to statistical data published in 1911 , was $4,692,384$. Of these, $2,480,443$, or a little more than one half of both branches of Kirghiz lived in Turkestan (p. 77) and 37,982 in Siberia of whom there were about 33,000 in western Siberia (p. 33). A small part of the Kirghiz-Kaisak, called Bukeyef, numbering about 150,000 (see p. 128) live in Europe between the Ural and the Volga. Thus, there remain for the Steppe Provinces, 2,173,959. Sedelnikoff, ${ }^{1}$ however, gives $1,929,5 \pi 2$ for the Steppe Kirghiz. In the Steppe Provinces only the Kirghiz-Kaisak are nomadic.?

\section{HISTORICAL DATA}

The general region of the steppe provinces has been called "the historical gateway" of Asiatic peoples. From the remotest times, until the end of the nincteenth century, the country has served as the stage for numerous movements, struggles, and contests of different nations. Remains of the Stone, Bronze, and Iron Ages are numerous. Burial mounds called, kurgans, stone figures called baby (plural, from baba, woman) or kamenniya baby (stone woman), stone memorial tablets, and pictographic writings on cliffs and rocks have been encountered all over this region, as well as in southern Siberia. The memorial tablets are covered with inscriptions in the ancient Turkic language, called Uigur. Many of these inscriptions have been deciphered, but the pictographs are, as yet, uninterpreted. Russian investigators call the old Turkic characters "runic inscriptions" and the pictographs, "pisanitzy" from the word pisat (to write).

All these antiquities, dating from the Metal Ages and found in the Steppe region and in southern Siberia are known by the Russians under

'Sedelnikofi. Chapt. I:

'For the Kara-hirqhiz, who are mainly mountain dwellers in Turkestan, sce p. 77. 
the vague appellation, Chude, or remains of the mythical peoplc. The honor of being the first to decipher the old Turkic inscriptions belongs to the Danish scholar, Professor Vilhelm Thomsen ${ }^{1}$ of Copenhagen, who studied them in 1893, and to a member of the Russian Academy of Sciences in Leningrad, Professor Wilhelm Radloff, ${ }^{2}$ who began his investigations in 1894 . The racial affiliations are still undetermined, but some skulls excavated and ascribed to the Chudes appear to be dolichocephalic.

According to the Chinese annals of two centuries B.C., a blond and blue-eyed people named Usun, moved to Lake Balkash through the "historical gateway" formed by the Ili Valley, a route followed by all subsequent migrating peoples. The Usun continued to live there until the beginning of the new era, when, disrupted by internal dissension and forced out by pressure from new immigrants, they moved farther to the north and northwest into the steppes, where they were either exterminated or assimilated by Mongolo-Turkic tribes.

The Huns, coming from China in 177 A.D., the Uigur descending from the Altai in the seventh century, the Pechenyeg in the same century, and the Polovtzy in the eleventh century passed through the steppes in their westward migrations. About the same time the Kirghiz-Kaisak appeared from the Tyan-Shan Mountains. The Chinese historians of the seventh century, to whom they were known as Khakas or Khagas, describe them as fair-skinned and light-haired, and possessed of a civilization higher than that of most Central Asiatic tribes. Some authors are inclined to assume that they had a common origin with the Finns, or even the white race, but now most of them are dark-skinned and blackhaired, showing that their intermixture was with Turks and Mongols. The few words of their original language known to us show that it belonged with the Turkic group.

In the middle of the fifteenth century the Kirghiz-Kaisak wandered back, under pressure of kindred Turkic tribes (Uzbeg) from the Aral Sea to the region of the Balkash Sea. In the sixteenth century when the Uzbeg left for Amu Daria, a part of the Kirghiz migrated to the north and northeast of the Aral Sea and by the end of the century they had bccome powerful rulers in Turkestan and Tashkent.

In the seventeenth century, they became divided into three parts or 
hordes: the great horde (Ulu-juz), the middle horde (Urta-juz), and the small horde (Kitchi-juz). ${ }^{1}$

Turkestan and Tashkent remained the chief seat of the Middle Horde, while the Great Horde went to the east and the Small Horde to the north and west. Inner dissensions weakened the power of the Hordes, so that the Kalmuck in the southwest, the Russians on the north, and the Jungarians on the east, embarrassed them. The Khan of the Small Horde, Abul Khair, was compelled to offer his allegiance to Peter the Great. However, this was not accepted, because of lack of accord among the Kirghiz. When the Jungarians (1723) conquered Turkestan and Tashkent, the Middle and Small Hordes moved to the west, expelled the Bashkir from their habitat and occupied all the territory between the Aral and Caspian Seas and the Ural River. Thus the small Horde became a neighbor of Russia.

Soon the clever and crafty Abul Khair was named Khan of the Great Horde, again conquered Turkestan, and subjugated Khiva. But the Shah Nadir of Persia drove him out of Turkestan. In $1730 \mathrm{Abul}$ Khair repeated his offer of allegiance to Russia and this time it was accepted, the Russian Government having a mistaken idea of his power. It turned out that he could not fulfill his obligations to guarantee the safety of the Russian merchants and other travelers passing through Kirghiz territory. They were plundered and assaulted, the Russians were compelled to build fortresses, and to advance into Central Asia until they reached Pamir.

The Middle Horde came under Russian control in 1781, and the Great Horde in $154 \bar{i}$. After conquering Turkestan the Russians established (1S67) a government of the Steppe Provinces of the Kirghiz territory. The nomads were divided into administrative units called auls or volosty which elected their own elders (aksakals) and judges (bii) and taxes were imposed on them at the rate of three roubles from each tent for the state and half a rouble for internal expenses.

The boundaries of the territories of the three hordes are not fixed. Some families of the Middle and Great Hordes roam in Chinese territory, not far from Zaisan Lake, near the Tarbagatai Mountains, in the Sergiopol District.

The word, horde, Russian orda, is derived from the Turkic ordu, a camp. Orda is now commonly used by the Russians as a contemptuous term for the Asiaticy. LIu and Kitchi are not properly translated by grest and small, as the exact meaning of Llu is elder or older, and the word has no quantitative significance. Actually, the Clu-juz horde has fewer people than the two others. In the same way. Kitchi-juz should be iranslated as the younger and not the small horde. Juz is the Gernan transcription and should be pronounced like the English. Iuz. 
A fourth horde, the Bukeyef or Inner Horde, living in European Russia, between the Ural and the Volga, numbers about 150,000. This horde was formed in the early years of the nineteenth century from a part of the Small Horde, which, led by Bukeyef, a grandson of Abul Khair Khan, crossed the Urals to occupy the land vacated by the Kalmuck. Bukeyef was confirmed Khan in 1811. After his death his eldest son was given the Russian title, Prince Jenghiz, in honor of his illustrious ancestor, the famous Jenghis Khan, and of the services of his father.

\section{SOMATOLOGY}

The heterogeneous physical type of the Kirghiz-Kaisak reveals the mixed origin of the tribe. The average stature of the tribe is $164 \mathrm{cms}$., but taken separately, the different divisions have the following a verages:-

Bukeyef Horde

Middle Horde

Syr Daria

Semirechye
$162.9 \mathrm{cms}$.

$165.1 \mathrm{cms}$. $166.9 \mathrm{cms}$. $168.8 \mathrm{cms}$.

The general average for the cephalic index is 87.1 , but when divided into groups, the Kirghiz-Kaisak have the following averages: Kuldja Kirghiz, 83.2; Middle Horde, 87.4; Bukeyef Horde, 86.28; Syr Daria, 87.91; Semirechye, 85.18. The average for the transverse cephalo-facial index is 70.34, with the following variations for the various groups: Syr Daria Kirghiz, 67.43; Kuldja Kirghiz, 68.71; Bukeyef Horde Kirghiz, 71.32; Middle Horde Kirghiz, 71.35; Small Horde Kirghiz, 73.14. The total average for the nasal index is 68.50 , with variations for the Kuldja Kirghiz, 52.39; Middle Horde Kirghiz, 71.78; Small Horde Kirghiz, 74.13 .

The physical data on the different divisions of Kirghiz show their complex composition which may also be noted from the names of the tribes composing the various hordes. The most important tribes belonging to the largest, the Middle Horde, are the Kirei, Naiman, Argyn, and Kipchak. They are supposed to have originated from a mixture of Turkic peoples with the original inhabitants of the country, the Usun, and some Mongolic elements.

The Kipchak, identified with the Polovtzy and Kuman, were formerly the most numerous and powerful Kirghiz tribe, but, beginning with the twelfth century, some divisions separated from the parent stock and migrated to the west where they were mixed with the Bashkir, Nogai, and the Tatars of the Volga, Kazan, and Crimea. Some of them moved 
to the southwest and formed the bulk of the Uzbeg of Fergana, Khiva, and Zarafshan.

The chief divisions of the Great Horde are the Kangli and the Dulat. The Kangli nray be identified with the Pechenyeg, Turkic invaders of Southern Russia between the ninth and thirteenth centuries, who were known to the Chinese as the Kan-giu. The Alchin tribe was the most important in the Small or Younger Horde. According to some ethnologists the Alchin represent a mixture of Turks with the Dinlin of the Chinese Annals and Ugro-Finnic tribes.

\section{ETHNOGRAPHY}

The tribal and clan organization of the Kirghiz-Kaisak is very complicated. The Kirghiz ethnologist, Mustafa Chokayeff gave the following explanation of his own standing in the Kirghiz-Kaisak nation. ${ }^{1} \mathrm{He}$ belongs to the Turkic race, Kaisak nation, Middle Orda, Kipchak tribe, Toru-aibghyz clan,. Shashli subclan, Boshai branch (or generation, Russian kolyeno) and Janay sub-branch (Russian, podkolyeno).

Like that of most Turkic tribes, the social structure of the KirghizKaisak is based upon a patriarchal system. It is difficult to decide when the term clan should be used. ${ }^{2}$ There seems to be a conception of a political group, called among both the Kirghiz-Kaisak and the KaraKirghiz uruk or ru, with its head, bey, bi, or serdar. A group of families affiliated by blood is called by the Kaisak taypas or tayfa and the KaraKirghiz, kyrk. The head of such a subclan, based on blood relationship, is called ak-sakal. An amalgamation of several subclans forms a $s \ddot{k} k$ (clan).

The subclan crest or tamga may be regarded as its symbol. The crest is used as a property mark and is branded on the left side of the animal, i.e., the side from which the rider mounts, or cut on various belongings, as well as on the graves of deceased members of the clan. The tamga, represented by geometric designs, may correspond to a totem. Sone of the Kirghiz of the Middle Horde have tamgas representing a "bird's rib" (urdas bii), a comb (tarak), and a forked stick (salak). The antiquity of these symbols can be judged from the fact that they may be seen on the old Nestorian monuments and on the monument to

'Samoilovich. (b), 162

We have used the term clan in the same way as most Russian investigators. It should be pointed out, however, that it would be more appropriate to apply the term gens to certain units of Kirghiz social organization, as they reckon kinship in the male line only. However, the Kirghiz terms of relationship have not yet been adequately investigated. A thorough stury of the terms of relationship and marital customs of some other Turkic peoples, for instance the Yakut and Altaians, may lead to the proof of the former existencc of matriarchy among them. 
Khan Kul-Jegi in the valley of the Orkhon, on which the inscriptions are in old Turkic characters, dating from 732 A.D. ${ }^{1}$

SOCIAL LIFE

The social organization of the local Kirghiz-Kaisak was sketched in the chapter on Turkestan. The nomadic peoples of the steppes are more democratic than their Turkestan kin. Although the descendants of the old sultan-clans and the hodjas (the alleged descendants of Mohammed) are still regarded as secular and clerical nobility, their influence on the masses is quite insignificant. The more powerful clans were those possessing more land, usually commandeered from the common domain. The clan heads were the owners of large herds. Slavery flourished among the Kirghiz, until the middle of the nineteenth century, and at the end of the eighteenth century received official sanction from the Russian Government. But in 1822 the Russian Government made its first attempt to limit the slave trade. The retention of old slaves ( $k u l ' s)$ was allowed, but the acquisition of new ones was proscribed. In 1859, according to the proposal of the governor general, the sultans, biis, and elders of all the Kirghiz districts freed their slaves, but there remained a class of djetaks, poor people with no cattle, who were exploited by the rich cattle owners.

Under the Soviets these social relations have considerably changed, but to the detriment of the continued breeding of domestic animals. On the other hand, the development of agriculture which began long ago, under the influence of Russian immigrants, who occupied Kirghiz pasture lands, is increasing, the recent years of famine having furthered this process.

\section{RELIGION}

Like the Turkestan peoples, the Kirghiz of the Steppes are Mohammedans of the Sunnite faith. It is a curious fact that the Kirghiz were converted to Mohammedanism through the mistaken efforts of the Russian Government, which had no faith in the capacity of ignorant Russian missionaries to propagate Christianity among the Kirghiz pagans and preferred Mohammedanism to shamanism. In the same way, during the eighteenth century, the Buryat who were also shamanists, were converted to Buddhism by Mongolian lamas with the cooperation of Russian officials. A part of the Kirghiz, however, were converted to Islam in the beginning of the fourteenth century by the Mohammedan mullahs of Khiva, Bokhara, and Tashkent. They are, however, not very ardent Mohammedans.

Ar stoff, (b), 391-486. 
At the beginning their religious heads were hodjas, descendants of the first adherents to Mohammedanism. Later, the Kasan Tatars acted as mullahs. Now they have their own mullahs who receive their religious education in the theological colleges (medresses) of Petropavlovsk and Semipalatinsk. During the nineteenth century Kirghiz Mohammedanism • was strengthened through intercourse with their co-religionists of Central Asia.

Of the religious festivals, the following may be mentioned. In the offering festival (kurbanais), symbolizing the offering of Isaac by Abraham, the best male horses were sacrificed. The Kirghiz believe, that on the spirit of the sacrificial horse, sinners may safely drive through 'the infernal regions and not be forced to ride on a thin cord, sharp as a sword's blade. The hides of the horses sacrificed are given to the mullahs and the poor invited to consume the meat. The festival is accompanied by plays and contests. Horse races are run, girls faking part, and the youths overtaking them are privileged to kiss them.

A thirty dav fast (uraza) was established to commemorate Mohammed's fast. The month of fasting is called ramshan, during which food may be taken only during the night. From early dawn (when one is able to see a thread) until sunset, both food and drink are prohibited. This is a peculiar form of diet, but the Kirghiz accommodate themselves to it very well. They eat and drink throughout the night and sleep in the dastime.

The Ramazanait (or Uzazait) festival which follows the Ramazan fast is spent in the abundant consumption of meat (horse meat and nutton) and kumiss and in various contests, races, etc.

Besides the three festivals mentioned the Kirghiz also have feasts in the memory of honored dead.

\section{DWELLINGS}

There are two kinds of dwellings, the summer tent, ui, and the winter house -kstau, the $u i$ is the more characteristic and important in the history and nomadic life of the Kirghiz. The kstau is a necessity because of local climatic conditions. There are two types of $u i$, the conical tent of the Kirghiz proper and the dome-shaped tent of the Torgout. The first form is more widely used. Both forms have wooden frames and a felt cover. In the interior the place opposite the entrance is occupied by trunks corered with rugs and serves as the sitting and sleeping place for honored guests. At the right of the entrance is the living room of the 
master. It is partitioned from the rest of the tent by a curtain or screen made of stalks of a shrub (Lasiagrostis splendens). Behind the curtain are stored food, kitchen utensils, and other household belongings. To the left of the entrance is the place for married sons and grown children. On the same side, but near the entrance, the dogs, lambs, and falcons trained for hunting are kept. There also are seated needy or poor visitors. The fireplace (otbossy) is in the center of the tent. The Kirghiz are fond of sitting cross-legged around it, not only at meal times, but also to gossip. The tent (kibitka) is regarded as a sanctified shelter, under the protection of which all life proceeds. All clan deliberations and gatherings take place in the tent by which the Kirghiz swear. "I swear upon my tent," or "A man's tent is like a god's temple," the Kirghiz say.

The permanent winter dwelling, kstau, is regarded as imperfect and uncomfortable and is not liked by the Kirghiz. The character and type of this house varies with local conditions. In the mountains, it is of stones; in the river valleys, of wood; in the southern treeless region, of sod and turf; in the northern forest region, of sod or logs. However, the most characteristic winter dwelling is the sod hut, the walls of which are about a yard thick. The roof is flat.' Between the ceiling rafters are closely packed small willow branches. This roof foundation is then thatched with reeds over which is placed a layer of clay and sod. It is necessary to renew the clay and sod every year to render the roof waterproof to any degree. Leading to the court is a low door, opposite which are one or two windows, or, more exactly, holes covered with glass or the membrane of a bladder or guts.

The interior is divided in two sections. At the front is a stove of beaten clay with a cooking kettle set in it. Newly born lambs and calves are kept there and harness and household utensils. At the rear near the walls are the sleeping quarters. Wooden pegs are set in the wall on which are hung clothing and the more valuable harness. The walls are usually covered with felt rugs fastened on with pegs.

Close to the dwelling are stalls for sheep. These are similar in form to the dwelling, but without stove and windows. Nearby are two additional huts, one for laborers and the other used as a storeroom. Each dwelling and its accompanying structures is surrounded by a wall of earth, dung, and reed; a reed shed resting on the wall and on posts covers the whole court, protecting it from heavy winds and storms. The covered yard is divided into several sections of which the warmer ones are occupied by horned and small cattle and the others by horses. Well-to-do 
Kirghiz of the forest region build theil winter houses of logs like those of Russian peasints.

The clothing, food, and family customs of the Steppe-Kirghiz do not differ from those of the Turkestan Kirghiz-Kaisak (see p. 77).

\section{The Russiax Popclation of the Steppes}

The Kirghiz form 73.6 percent of the Steppe population and the Russians about 25.8 percent. The remaining .6 percent include Esthonians, Lethonians, Poles, Jews, Kalmuck, Sarts, Bokharans, and other Central Asiatic people. Most of the Russian population of the Steppes must be regarded as a variety of the Great Russians, although Little and other Russians, as well as some Poles, entered into its composition. The Russian population may also be divided into peasants and Cossacks.

The Russian colonization of Asiatic Russia began long before its conquest by the Russian Government. Beginning with the sixteenth century, or even earlier, adventurers, military deserters, fugitive serfs, criminals, dissidents, and others, who had escaped from the difficult conditions of life in Russia or were roused by the desire to enrich themselves by exploitation of the natives, appeared to the east of the Ural Mountains. One wave of this immigration reached the Kirghiz steppes and much later was followed by Government troops.

As these deserters, adventurers, and peasants were unaccompanied by women, they married Kirghiz women. The Cossacks adopted the Kirghiz custom of polygamy. These unions resulted in the partial Mongolization of the Slavic type. The Russians of the Steppes are of medium stature, stocky build, with rounded faces, dark skin color, straight black hair, dark brown eyes, and are slow of movement. They all speak Kirghiz as well as Russian, and their Russian pronunciation has lost the original softness of the Slavic sounds.

Their intellectual abilities correspond with their physical peculiarities. They think slowly, talk little, have a materialistic disposition, and idealistic motives are quite submerged by things utilitarian. They are far less religious than their kin in European Russia.

The natural environment influenced them as much as anthropological inixture and historical events. The new kind of life was unknown in their native country. The natural riches and spaciousness of their new environment gave an impetus to individualistic aspirations. On the other hand, the absence of restrictions and individual freedom tended to create independent and restless characters. Had the first Russian 
settlers been on a higher cultural plane, they might have initiated superior forms of economic and social life, as did the European settlers of North America. But the Russian immigrants were strongly dominated by predatory instincts and they oppressed and exploited the natives rather than make an attempt to profit by the riches of the country through their own labor.

Under Soviet rule the Russian settlers have been cruelly repaid by the Kirghiz. Acquiring power, the Kirghiz took their farms from the Russians, nationalizing all the land, under the pretext of distributing it among the needy Kirghiz. Thus, many of the Russian settlers were obliged to return to European Russia. Dr. R. Asmis, the councilor of the German Department of State, on his way through Russia, met many caravans of Russian peasants returning to their former home with a small number of cattle left to them after the rest were confiscated. ${ }^{1}$

\section{THE COSSACKS}

There are in the steppes two divisions of Cossacks: the so-called Siberian and the Ural Cossacks. The Siberian Cossacks came into the country together with other Russian settlers from southeastern European Russia. They were organized into irregular light cavalry (sotnyas, hundreds) whose duty it was to maintain order in the steppes and to guard the frontier. Service was compulsory and every male Cossack had to serve till the age of thirty-three. Their military duties occupied most of their time and they began to look down on the field work of the peasants and to despise the natives. The cultivation of the land assigned to them by the government was left to the women and hired Kirghiz laborers and therefore the harvests were not so good as those of the peasants. The Cossacks also traded with the Kirghiz, even monopolizing the grain trade. It is very profitable to carry on commerce with a people so easily exploited as the Kirghiz. There were also among the Siberian Cossacks many rich cattle breeders, but among them the cattle were cared for by the women.

About 96 percent of the Siberian Cossacks belong to the Greek Catholic Church, but they are not very religious. The small Steppes settlements rarely have their own churches and the inhabitants see the priest only on important occasions. It is interesting to note that 3 percent of the Siberian Cossacks in the Kokchetaf District are Mohammedans. A sinall number are "old believers" (dissenters). The Cossacks are less superstitious than the peasants.

ISee Doctor Asmis' very interesting book, p. 203. 
In tribal composition the Siberian Cossacks include about $\$ 4$ percent Great Russians, 6 percent Little Russians, 3 percent White Russians, 5 percent Mordva, 1 percent Kirghiz, and 1 percent Tatars. There are also a small number of Cheremiss, Churash, Votyak, Zyryan, and others who were assimilated with the great Russian bulk of the Cossacks.

The historical conditions of the life of the Ural Cossacks were similar to those of the Siberian Cossacks; therefore, they have many traits in common with the Siberian Cossacks. The nucleus of the Ural Cossack stock was formed by the Volnitza (freedom seekers), deserters, escaped serfs, dissidents, Don and Volga Cossacks, Poles, and a small number of Tatars and Kalmuck. They originally aspired to create a free and independent life for themselves, far from any oppressive government. They take their name from the Cral River where they first settled. Originally, they were called Yaik Cossacks after the river of the same name, but after the rebellion under Pugachoff in $\mathbf{1 7 7 4}$, in which the Yaik Cossacks took part, the Empress Catherine ordered the name Yaik changed to Ural.

Fishing is the chief occupation of the Ural Cossacks. Two physical types may be distinguished among them. One is of medium stature stockily built, round-faced, blond-haired, short and heavily bearded, and of somewhat rude.appearance: the other is of high stature, good looking, dark-complexioned, long-bearded, and with dark brown eyes.

LITTLE RUSSIANS

In the latter part of the nineteenth century there appeared in the Steppes (chiefly in the Akmolinsk and Atbazarsk districts), Ukrainian peasant immigrants. They settled apart from the Great Russians. Their villages can be easily distinguished by their white painted clay houses with straw roofs.

\section{GERMAX COLONISTS}

German settlers (Mennonites. Baptists, and other sects) came to the province of Akmolinsk in the nineties of the nineteenth century. Their villages are on leased land near Omsk, or on portions granted by the government of Akmolinsk District. The general appearance of their villages is very similar to that of the Little Russians, but these settlers differ in their European dress and their vehicles drawn by two horses and two-wheeled carts. Their relations with the Russians were rather unfriendly, so that in some cases the Administration had to interfere and the colonists were given other sections of land, which are even better cultivated than among the Russian peasants. They have their own schools and houses of prayer. 


\section{OTHER PEOPLES}

'Poles, Jews, Bokharans, and Sarts live in towns only. The Sarts are chiefly merchants. A small number of Bashkir and Kalmuck live in rural districts in Ural and Turgai provinces, where they cultivate the land. 


\section{CHAPTER VI}

\section{THE PEOPLES OF THE CAUCASUS}

The Caucasus region comprises the isthmus separating the Black Sea and the Sea of Azof from the Caspian Sea and the southeastern part of European Russia from Persia and Turkey in Asia. Under the Russian Empire, it was divided into two districts, Trans-Caucasia and North or Cis-Caucasia, with an area of 181,173 square miles and a population of $13,500,000$ with a density of about seventy to the square mile. In its territorial extent the Caucasus exceeds Sweden, and in density of population, European Russia. For administrative purposes Transcaucasia was divided into eleven parts. Six of these were called governments: Baku, Cbornomor, i.e., Black Sea, Erivan, Kutais, Tiflis, and Yelizavetpol; three were provinces: Batum, Kars, and Daghestan; and two territories: Sukhum or Abkhasia and Zakataly. Cis-Caucasia was divided into one government, Stavropol, and two provinces, Terek and liuban.

Nowhere else in the world do we find such a heterogeneous confusion of peoples, languages, and religions gathered in one area. The peoples of the Caucasus may be divided into three groups: first, newcomers like the Russian conquerors and other recent immigrants; second, aborigines with tribal affiliations outside the Caucasus; and third, abcrigines indigenous to the Caucasus.

The languages of the Caucasian aborigines are, according to Professor Marr, called Japhetic, ${ }^{1}$ a designation in accord neither with the biblical nor with the present scientific use of the term Japheth. Biblical anthropology, as interpreted by theologists, divides mankind into the descendants of Shem (the white race), Ham (black race), and Japheth (the yellow race). This identical terminology is used in quite a different sense by modern anthropologists. These three terms refer to Caucasians only: The Indo-European tribes are Japhetic, while the Semites and the Hamites (the African subdivisions of the semitic race) are regarded as having a common origin. Whether Professor Marr used the term Japheth correctly or not, the question lies chiefly in the meaning he attributed to it and in this respect his classification can be of great assistance in classifying the Caucasian peoples. ${ }^{2}$ Marr's theory of what he terms Japhetism, was much criticised by European philologists, but among his ardent adherents Professor Braun of Leipzig may be named. ${ }^{3}$

\footnotetext{
1.Mars.

It may be added that the use of the name Japhetides to designate the earliest inhabitants of the Caucasus might clear up the ambiguous meaning of the word Caucasian as a meographical (native of Caucasus) and an anthropologieal (representative of the white race) term. 'Braun.
} 
A brief résumé of the Japhetic theory may be worth while. The two primary elements of Mediterranean civilization, according to Marr, are the languages and culture of the Indo-Europeans and the SemitoHamites, the Japhetic languages and culture comprising the third ele-

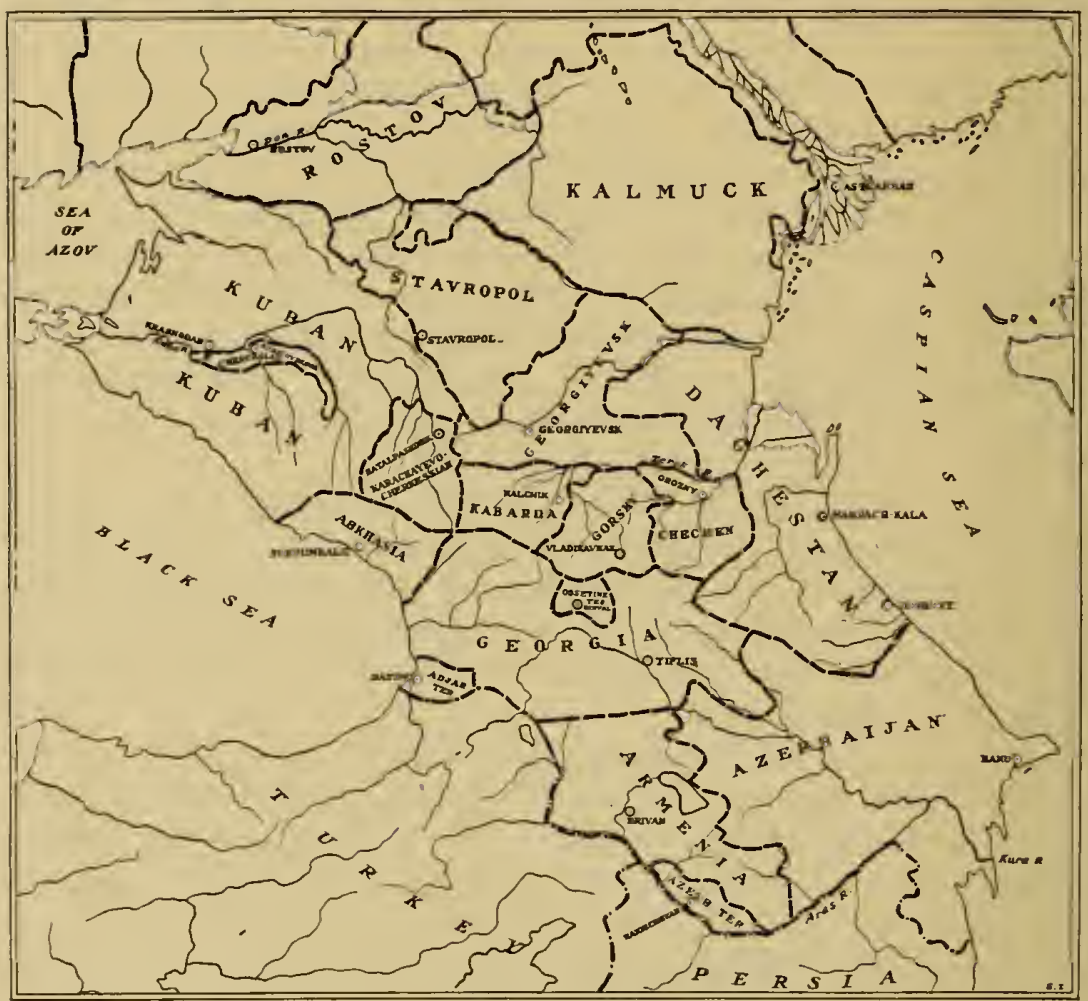

Map 4. Administrative Divisions of the Caucasus under the Soviets.

ment. Properly speaking, the Japhetic languages and culture should be designated the first or fundamental element, which, being mixed with Indo-European, Semito-Hamitic or Turkic elements, produced hybridism of different kinds, to which the present Indo-European, SemitoHamitic, and some Turkic languages belong. The Basques of the Pyrennees and the Bureshki, Burishaski, or Vershiki ${ }^{1}$ tribe of Pamir still retain remnants of Japhetic languages. The extinct languages of the

Marr, 36, 52. He regards this tribe as emigrants from the Caucasus, Dixon (303) mentions an "isolated and peculiar little group of the Burusheski just under the Pamirs." Although brachycephalic, these people are very light, almost fair, and occasionally have hazel or even gray-blue eyes. Professor Dixon gives no bibliographical reference to this group. 
prehistoric Etruscans, Pelasgians, and Iberians, also shows affinities with the Japhetic languages. The great variety of Japhetic languages in the Caucasus forces Marr to assume that their place of origin must be sought outside of the Caucasus Mountains. These languages are more closely

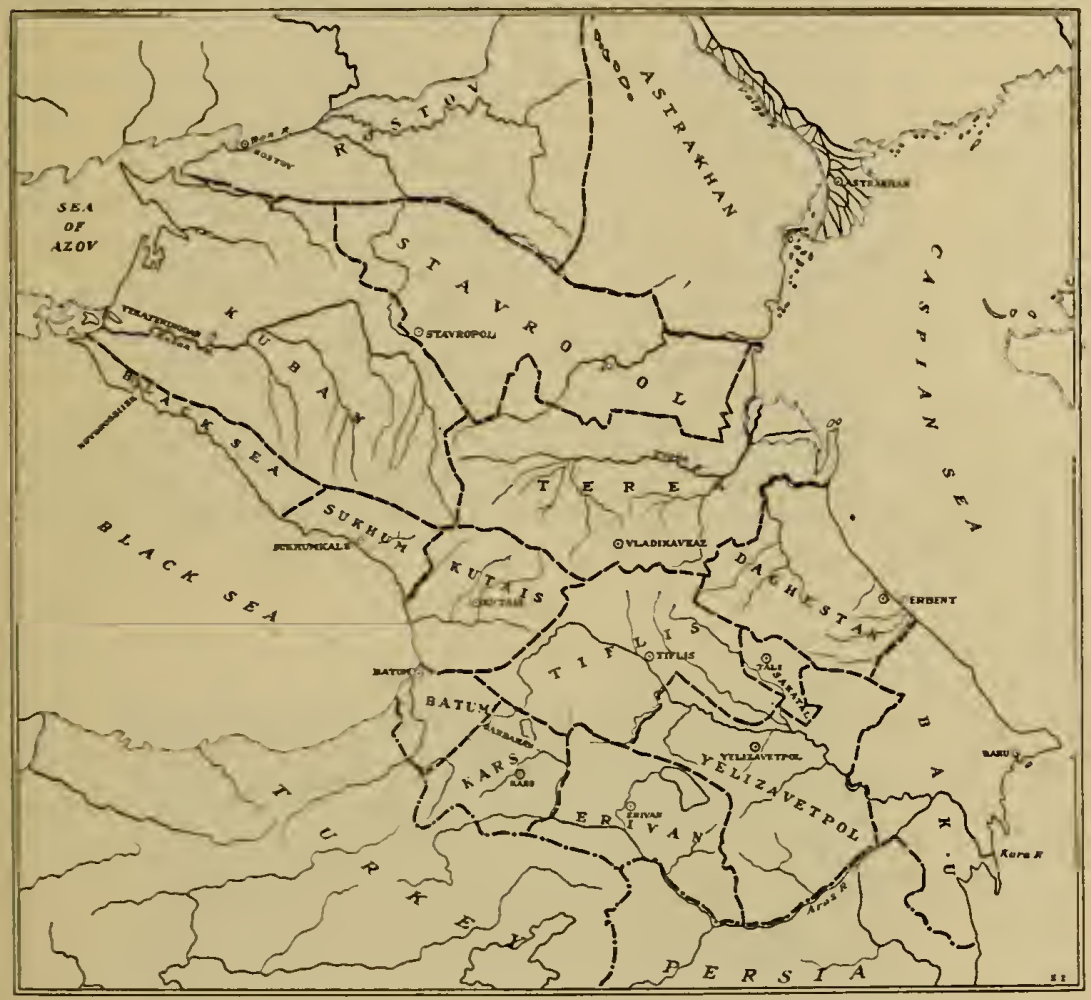

Map 5. The Former Administrative Divisions of the Caucasus.

related to the Semitic-Hamitic than to the Indo-European stocks. Regarding the different types of language structure (monosyllabic, agglutinative, and inflective) not as parallel types, but as three chronological phases in the development of language, Professor Marr assumes that Semitic and Japhetide peoples parted after reaching the inflective phase in the development of their languages. Japhetic elements may be found in the vocabulary, structure, and phonetics of all the Mediterranean languages. As no physical type is absolutely pure, so no languages are pure. The Mediterranean languages consist of a compound of original 
and borrowed elements, the sources of the latter being partly known. The elements of unknown origin are ascribed to Japhetic influence. This is true not only of the Mediterranean cycle of languages. The role played by the Caucasus in the formation of human speech and culture is shown by the Hebrew traditions of the flood and Noah's ark, borrowed from Assyro-Babylonian sources, and Greek myths of Prometheus, the fire-giver. In 1922 the Russian Academy founded a Japhetic Institute for the study of Japhetic languages and Japhetic survivals in other languages and publishes a "Japhetic Magazine."

With this brief summary of Japhetism we may pass to the description of the peoples of the Caucasus, beginning with those living exclusively in the Caucasus, whom Professor Marr regards as Japhetides.

\section{The Georgians}

The Georgians or Kartveliens belong to the southern Japhetides of the Caucasus. Traditionally, their origin may be traced to Thorgomos, a greatgrandson of Japheth. They were Christianized during the fourth century and at various times were under the domination of various conquerors. In 302 they were freed from Alexander the Great. The Sussanide dynasty controlled Georgia from 205 to 571 ; in 787 the Arabs over-ran the country; and in the eleventh century it was temporarily brought under the yoke of the Seljuk Turks, but regained independence under King David (1090-1125). In the thirteenth century Jenghis Khan conquered Georgia and toward the end of the following century Timur overthrew the country, but the beginning of the fifteenth century saw his expulsion by the Georgian king, George VII, under whose reign Georgia became a flourishing state. His son divided the kingdom among his three sons and three states (Guria, Mingrelia, and Imeretia) were formed, thus weakening the country in the event of foreign aggression. From 1798 to 1810 these states were surrendered to Russia.

I. The Georgians include the following stocks:-

1. The Georgians proper or Grusians. To these may be added the Inghilois, of a mixed Georgian-Lesghian origin. Mohammedans of the Sunnite faith may be included with the Georgians proper, who number about 480,000 .

2. The Khevsur, Pshav, and Tushin of the northern part of Tiflis Province, about 25,000.

3. The Imeretins, living chiefly in the eastern part of Kutais Province, numbering 505,000. 


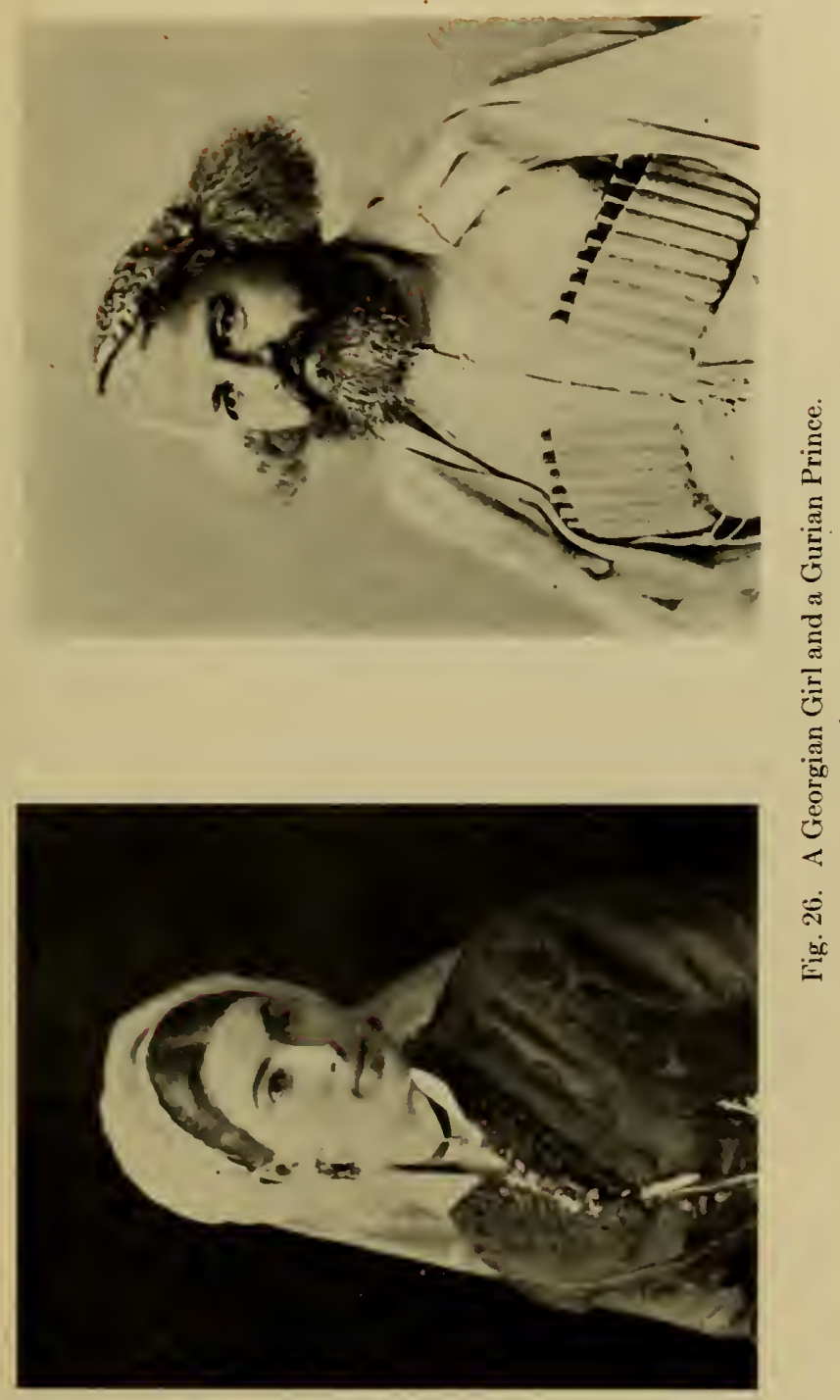


4. The Gurians, living chiefly in the Osurghet District of Kutais Province. The population is about 93,000 .

5. The Adshar, are according to Marr, Gursinized Megrels. They were converted to the Sunnite faith of Islam. In their religious services they used Arabic, but in ordinary speech Turkic (Azerbaijan) and the Georgian languages. They number about 70,000.

Some Georgian groups have preserved ancient local names which have, however, a geographical rather than an ethnographical meaning, like the Ratcha inhabitants of the Ratcha District or Kakhetins, the inhabitants of Kakhetia.

II. The Megrel or Mingrel living in the western part of the province of Kutais, numbering about 253,000.

III. The Lazes or Chan. The bulk of the stock lives in Turkey, adjacent to Russian territory and on the shores of the Black Sea. Only a small number (about 3,000) live in Batum Province. They are Mohammedans of the Sunnite faith. Their written languages are Holy Arabic (extinct) and literary Osmanic. Their own Chan language is spoken in two dialects and the popular Osman-Turkic.

IV. The Swan or Swanet, numbering about 23,000, live on the banks of the upper course of the Ingur River. Most of them are Greek Catholics, but a small number are Roman Catholics. They use the now extinct Georgian language in their church services, the present literary Georgian in writing, and the Swan dialect in conversation.

\section{The Abkhas-Cherkess Group}

The Abkhas, numbering 61,000, living chiefly in the Sukhum District, are called the Coast Pontine group, and consist of three divisions: Samurrakan, Abjui, and Bzyby. Part of them belong to the Greek Catholic Church and part to the Mohammedan (Sunnite doctrine). A Caucasian tribe called Ubykh, which occupied an intermediary ethnographic position between the Abkhas and the Cherkess, immigrated into Turkey and now lives in Ismid, Asia Minor.

The Cherkess, also called Adighe, numbers about 200,000, and is a Japhetic division consisting of many differently named tribes. - After the Russians conquered the Caucasus many Cherkess migrated to Turkey. The Kabardin who live in the former province of Daghestan are the chief Cherkessian tribe. They are Mohammedans of the Sunnite faith. Old Arabic is used as a church and literary language and Adighe in ordinary communication. 


\section{The Chechen Group}

The Chechen belong to the North Caucasian Japhetides, number about 305,000 , and include a group of tribes speaking different dialects of the Chechen language. The chief and most numerous people are the Chechen proper, or Nakhchi (in the district of Groznyi); the Mountain Chechen (in the former Argun District); the Ingush or Galga (in the districts of Vladikavkaz and Terek); the Kist (to the north of Tiflis); and the Thushi and Khevsur (to the north of the Kist). Among the Thushis there lives a small Chechen tribe called Tsova-Thushi (in

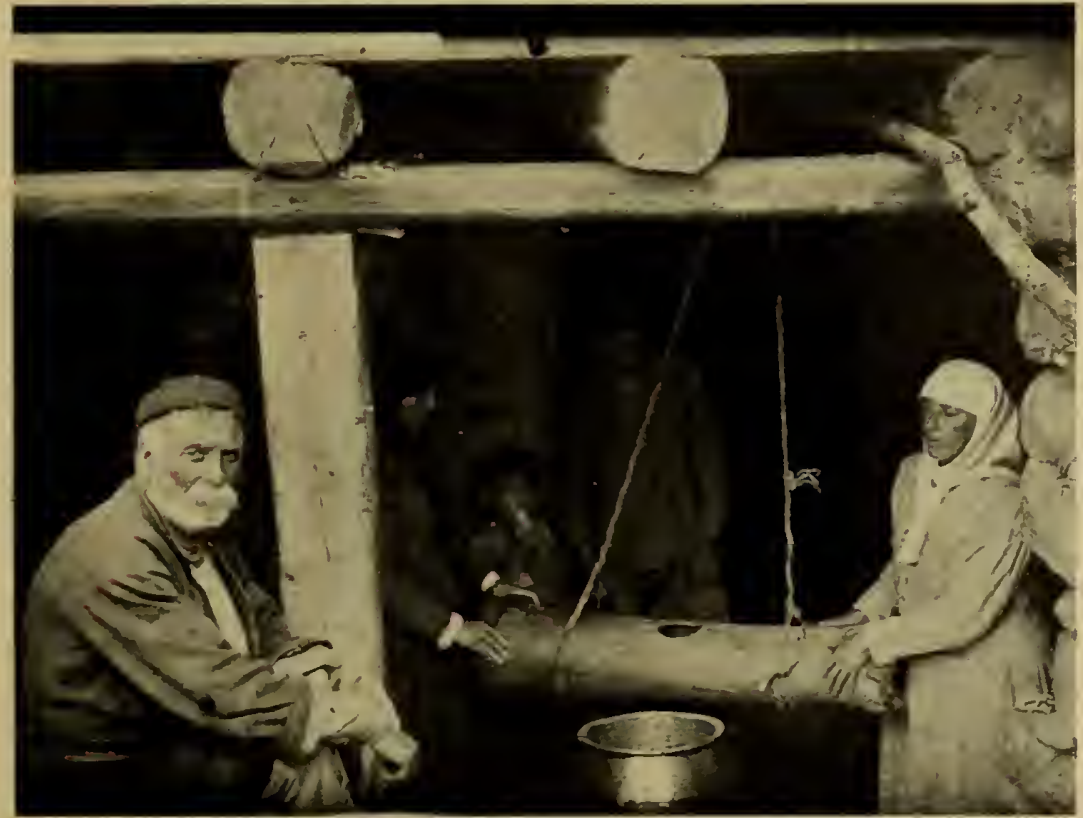

Fig. 27. Georgian Women churning Butter.

Tiflis Province). All the Chechen tribes occupy the region to the northwest of Daghestan, in the corner formed by the upper and middle course of the Terek River and its right tributaries, the Argun and Assa. Most of them are Greek Catholics, but there are also some Roman Catholics and Mohammedans of the Sunnite doctrine.

\section{The Lesghin Group}

The present population of Daghestan is known by the name, Lesghin. However, there is in Daghestan only one tribe which calls itself Lesghin and its name was transferred to other Daghestan tribes and 


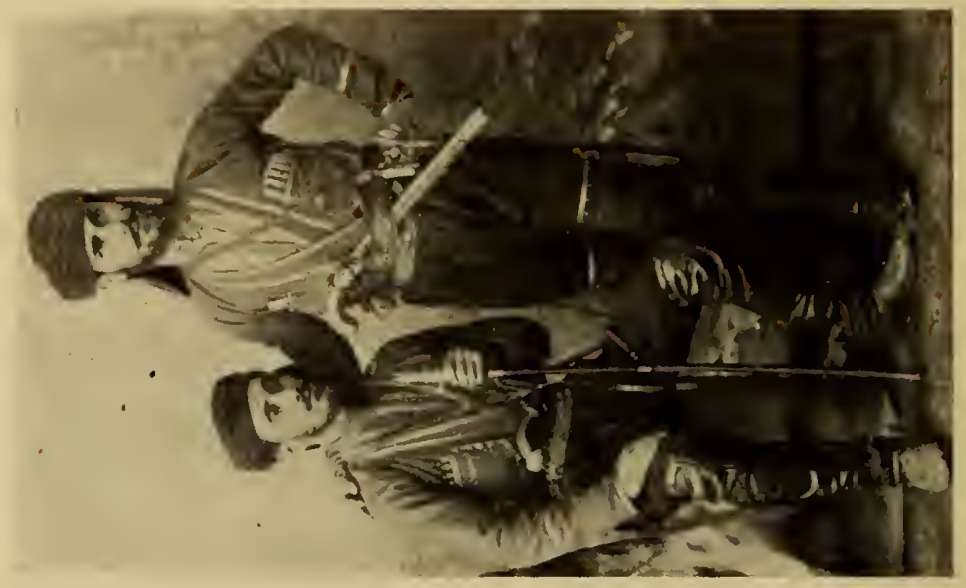

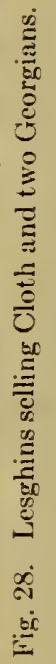

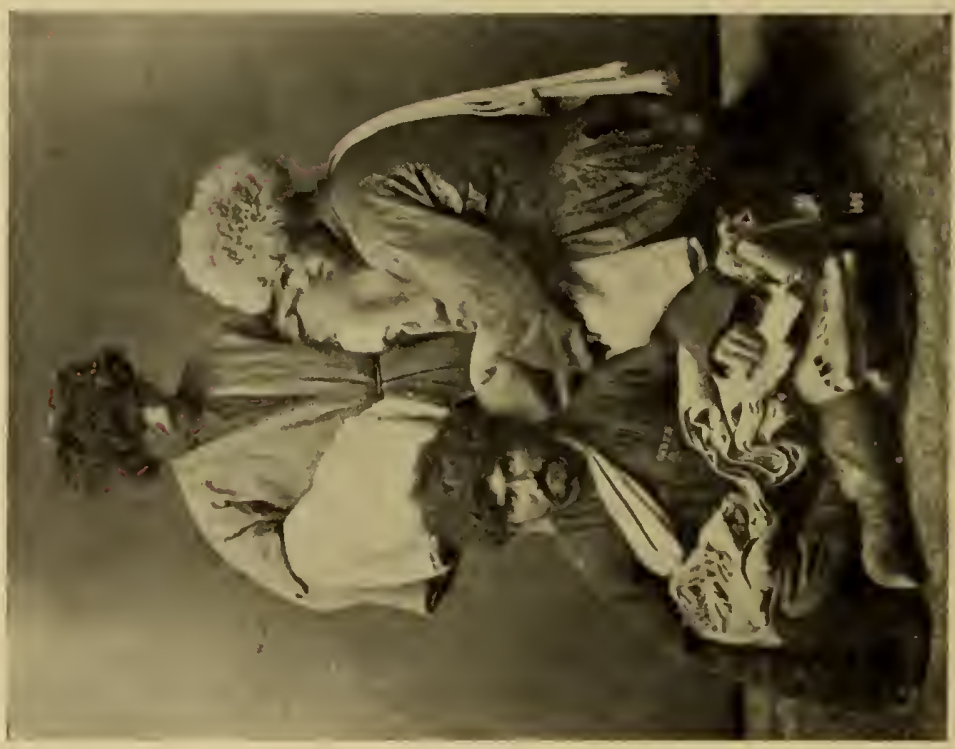


even to some living in the Sakatal District of Baku Province and in some sections of Yelizavetpol Province. Marr ranks the Lesghin among the North Caucasian Japhetides of the Pontine-Caspian branch. The following are the Lesghin divisions:-

1. The Avar. This is the strongest and most numerous Lesghin tribe, living in central Daghestan, from its northernmost part to the main ridge. Some of the Avar crossed the mountain ridge and penetrated into the Sakatal District. The Avar played an important part in the preRussian period of Daghestan, and consequently, their language, which has several dialects, became the common means of intercourse over a considerable part of the northeast and west of Daghestan. At present, their language is being supplanted in some localities by the KumykTatar dialect. The population is about 234,000 .

2. The Darghin live in the eastern part of Daghestan. Their language has three dialects. The population is about 148,000.

3. The Lak or Kazi-Kumuk live in Central Daghestan, numbering more than 45,000 .

The following Lesghin divisions belong to the eastern or Kurin group.

4. The Kurin proper live along the Samur River, penetrating partly into Baku Province. They number about 158,000.

5. The Tabsaran, numbering about 20,000 , live to the north of the Iivrin.

6. The Agul live to the west of the Tabasaran and number about 8,000 .

7. The Archin live in a single village of Central Daghestan and number about 800 .

S. The Rutul (or Mykhad), numbering about 14,000 , live on the banks of the upper course of the Samur River.

9. The Oudin, numbering about 10,000 live in two villages of Trans-Caucasia, not far from Nukka. In contrast to the Daghestan peoples who are Mohammedans of the Sunnite faith, the Oudin are Christians of the Armenian-Gregorian or Greek Catholic faith.

10-13. The Khinalug, Djek, Budukha, and Khaput together, number 14,000 .

The following Lesghin divisions belong to the western group.

14. The Andi live in sixty-two villages and form eight tribes, numbering about 28,000 .

15. The Didol live in fifty-three villages, form eight tribes, and number about 11,000 . 
The Andi and Didoi are Mohammedans of the Sunnite faith. Their church language is old Arabic, but for ordinary intercourse they employ Avar.

\section{Anthropological Characters of the Japhetides}

THE GEORGIANS

We find two physical types among the Georgians: brunette and blond. The first has black hair and dark eyes, the second has blond hair and blue eyes, probably indicating a mixed physical origin. While skulls found in Caucasian excavations are mostly dolichocephalic, the present Georgians are brachycephalic, and in many cases, hyperbrachycephalic. They are of medium stature $(165 \mathrm{cms}$.$) .$

THE ARMENIANS

From the standpoint of language, the Armenians were regarded as belonging to the Indo-European division of mankind. Professor Marr, however, believes their language to be a hybrid and calls it Japhetic-Aryan. Somatically, Professor von Luschan regarded them as a comparatively homogenous people. There are, of course, various alien physical elements, but on the whole, the great mass of the Armenians form a somatic unit. More frequently than any other group in western Asia and the Caucasus they show the "plano-occipital" form of the profile curve, great brachycephaly (with the maximum of frequency of the cephalic index falling at 88 and an average of 87.5), extreme height of head, and a particularly narrow and high nose. They are generally dark, yet a small number of Armenians have reddish hair and gray or greenish eyes, which may indicate racial mixture. They call themselves Haikan and their country, Haiastan, from Haik, the grandson of Japheth, from whom they traditionally trace their descent.

Armenian territory embraces the northeast corner of Asiatic Turkey, the southern part of Transcaucasia, and the northwest corner of Persia. The principal portion belongs to Turkey. The Russian portion was acquired in part from Persia, in 1828, and in part from Turkey, in 1878. Persian Armenia forms a part of the Persian province of Azerbaijan.

Professor von Luschan believed that the Armenians may be descendants of the Hittites. The Hittite inscriptions have not yet been deciphered, but orientalists are unanimous in assuming that there is not the slightest doubt that the Hittite language was not of the Semitic type.

The tragic history of the Armenians shows that they were unable to uphold their independence. Greeks, Persians, Arabs, Egyptians, 


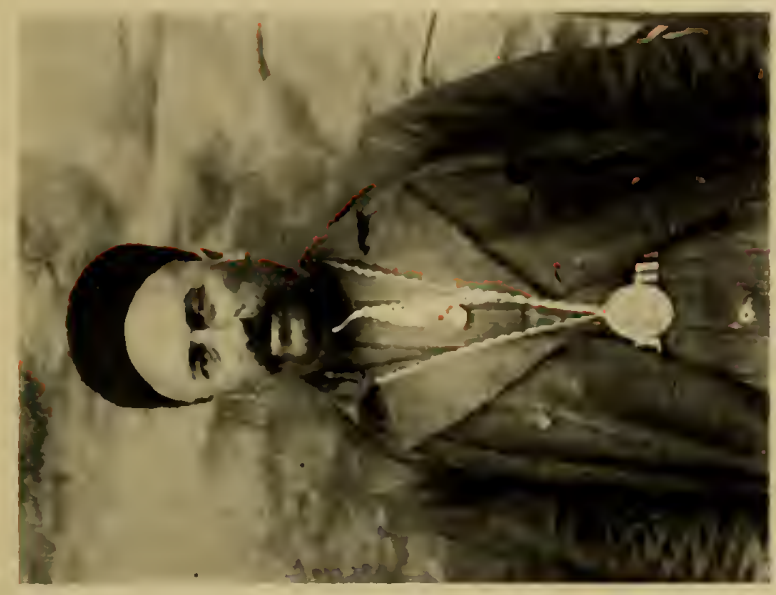

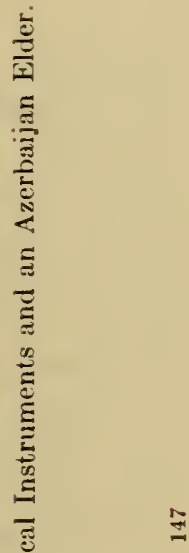

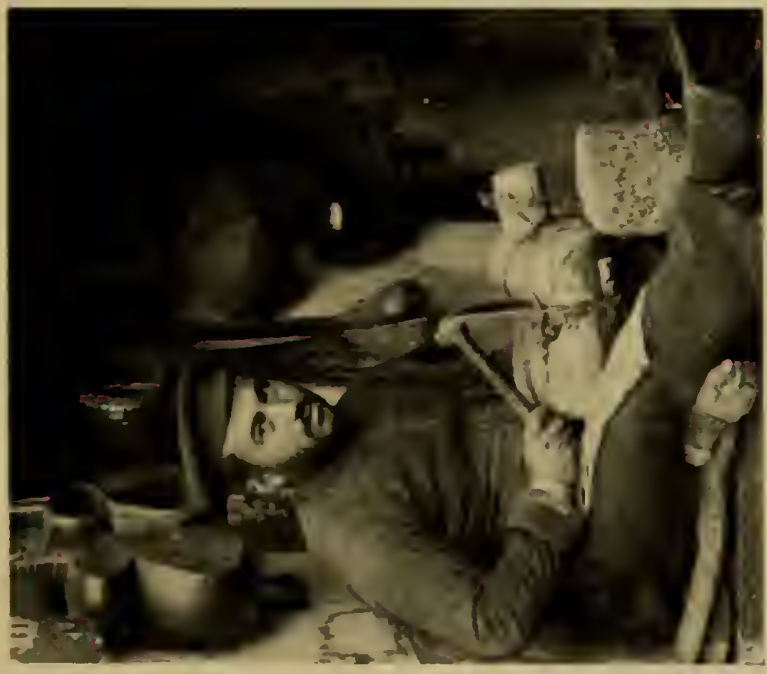

$\pm$ 
Mongols, and Turks alternately oppressed and governed them. Internal troubles and their inability to maintain their own government may account for their becoming the prey of alien rulers, so that they have succeeded in achieving independent existence only for short intervals. From 885 to the end of the tenth century they maintained an independent kingdom under the dynasty of "the Bagratides, descendants of ancient Jews. In 1198 a local prince was made king under the name of Leo II, but his dynasty was overthrown by the Egyptians in 1374. In the sixteenth century, Armenia was divided between Persia and Turkey and in the nineteenth century Russia also became, a partner in possessing Armenia.

It is well known that the Kurds, encouraged in their assaults by the Turkish Government, repeatedly massacred large numbers of Armenians. It is said that during the World War, one million out of $1,850,000$ Turkish Armenians were slaughtered. The present total number of Armenians is not exactly known. It is, however, estimated at about 5,000,000, of whom only half live in their original diaspora, while the other half is distributed over the world. They have large colonies in all the great cities and a special quarter in New York. In the Caucasus and other parts of Russia there were 1,490,000 Armenians.

About the end of the third century, Christianity began to displace the old religion of the Armenians, the Persian doctrine of Zoroaster. Now the mass of Armenians belongs to the Armeno-Gregorian church and a small number to the Russian Orthodox, Roman Catholic, or Protestant church. A few Armenians, called Hemshin, are Moslems of the Sunnite faith.

In its historical development the Armenian language may be divided into the classical or church language, the present literary language of the educated classes, and the language of the common people. Beside those the Armenians speak one or two of the languages of their neighbors, but a few living among the Georgians speak only Georgian. The Hemshin speak Osmanly and also popular Armenian, which is, however, on the verge of extinction. Extinct holy Arabic is their church language.

Although there are families among the Armenians pretending to be of princely descent, they are as a whole, a democratic nation, without nobles, differing greatly from the Georgians with their numerous princes and nobles.

The Armenians are a business-like people; most Caucasian merchants and capitalists are Armenians. Georgian agrarians were always dependent on Armenian capitalists. The Armenians are despised 
by the Georgian upper classes. A Georgian may marry an Armenian woman, but a Georgian girl will never wed an Armenian. Of all the Caueasian peoples the Armenians show the greatest percent of urban population: about 22 pereent of the Armenians live in towns; 9 pereent of the Georgians: about 11 pereent of the Turko-Tatars; and about 1 pereent, of the Cherkess.

\section{INDO-EL'ROPEAXS}

The Kurd. Certain parts of Turkey in Asia and Persia have been named Kurdistan. Kurdistan is a vast mountainous territory to the southeast of the Armenian mountains. The greater or northwestern part is under Ottoman, the southeastern, under Persian control. The Kurds number about $2,300,000$. Of these, about $1,500,000$ are supposed to live in Asiatie Turkey, 750,000 in Persia, and 60,000 (aecording to Marr, 100,000 ) in the Caucasus. These figures eannot be regarded as exact, as the nomadie hurds avoid being reeorded in order to eseape taxation. The speak several dialeets of an Aryan language, related to new Persian. The Caueasian Kurd speaks two dialeets, Kurmandshi and Zaza.

The western Kurd are doliehocephalie, with an average cephalie index of 75 , and more than 50 percent of the adults have fair hair and blue eyes. The eastern Kurd have shorter heads and darker hair and eyes, resembling the Persians among whom they live.

Professor Marr regards the Kurd as Japhetie-Aryan hybrids. They profess the Sunnite doetrine of Islam, which has brought them into antagonism with the surrounding Armenians and other Christians and made them the agents of Turkish oppression. They are of small stature, shrewd, and bad neighbors. Most of them are nomadie eattle breeders, but there are also some agriculturists.

A group of Kurds ealled Yezidis form a religious seet of fire and devil worshippers. It is believed that Yezidism is an offshoot of Mazdeism and is regarded as an effort to bring unity in dualism. The Yezidis recognize the old testamental, Christian and Moslem reformers and practise baptismal and eireumeision rites. They are seattered all over Kurdistan, Armenia, and Caueasus. Their total number is estimated at about 50,000 , of whom 12,000 are believed to dwell in the Caucasus. The average stature of 40 Caueasian Yezide men was 163.3 ems., eephalie index, 77.86; length-height index, 74.21 ; and nasal index, 61.59 .

The Ossete. There appears to be no agreement as to the number of Ossete. Thus Erekert gives their population as 120,000 and Ischehanian, as 165,494 , while Dirr and Marr give 224,000 . The bulk of the people 
(about 127,000) live in central Caucasus to the south of Kazbek. About 86,000 Ossete live in the government of Tiflis. On the Kuban River is a small colony of 1,600 Ossete and in the Ratcha District of Kutais Province about 5,000 .

Their traditions give their place of origin in the region of the Don. Some writers believe them to be a part of the Alan who were forced into the Caucasus by the Huns. Ripley is inclined to regard them as immigrants from Iran. They call themselves Irons. Marr, regarding them as a a Japhetized Indo-European people, divided them, first, into eastern (Iron) Ossete, to whom the Tagaur belong; second, western Ossete, called Digor; and third, southern, called Tual.

The Ossetic language belongs to the Indo-European stock. The greater number of Ossete are Christians (of the orthodox faith), the remainder are Sunnites. Both Christians and Moslem have, however, preserved much of their former pagan beliefs. They have but a scanty literature, but have a rich folklore. They are becoming Russianized or Gruzinized. Somatically, they are related to the southern Aryan. The average stature of the men is 1,692 , of the women, $1,573 \mathrm{mms}$; the cephalic index is 81.95 ; height-length index, 71.58 ; facial index, 78 .

The Tate. As with the Ossete, there is a discrepancy in the population figures of the Tate. Erckert gives 90,000; Ischchanian, 94,302; Dirr, 74,000; Marr, 125,000; and Kurdoff, 135,000. The Tate villages are scattered all over Transcaucasia but the majority live in Baku Province. The name, Tate, has no ethnological significance since the Turkic conquerors applied it to all the sedentary tribes subdued by them, and means a subject, slave, or attendant of a lord.

The language of the Tate is a somewhat corrupt dialect of New Persian. Therefore some scholars regard then as Iranians who were driven from Persia to colonize the conquered Caspian provinces, while others consider them Turks, who, being conquered by the Persians, adopted the language and religion of the latter. The Tate, like the Persians, are followers of the Shiite faith. According to Tate tradition, however, they are Persian emigrants who were exiled after a revolt against the Sassanides. Marr simply ranks them with the Persians and regards them as a Japhetized Iranian tribe. The average stature of Tate men is 1,701 mms., the cephalic index, 78.62 .

The Talysh. The Talysh, numbering about 91,000 , live in the Lenkoran District close to the Persian frontier. The Talysh language is a New Persian dialect containing, however, many elements of Zend, the language of the Avesta, or ancient sacred writings of the Persians. 
In physical type and mode of life, they form, according to Erckert, two sharply differentiated groups: the inhabitants of the mountains are of Iranian descent, while the Talysh of the plains are descendants of the Tatars. Marr ranks them with the Japhetized Aryans.

Persians. Dirr gives the population for Caucasian Persians as 50,000; Marr, 16,000, and Erckert, 10,000. But the actual number of Persians in the Caucasus is not known, since all Persian subjects were recorded under this name at different times. The greater part of them speak Azerbaijan and may be of Tatar descent.

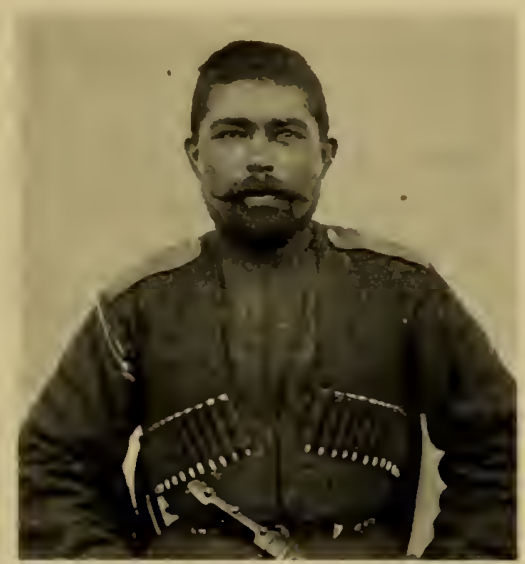

Fig. 30. A Terek Cossack. A distinct division of Cossacks in Cis-Caucasia named after the Terek River, believed to be descendants of the Russian conquerors of the Caucasus.

Gypsies. There are about 2,500 gypsies in the Caucasus. They are nomadic. Those who live among the Armenians are called Boshas and speak a kind of Armenian jargon.

Europeans. Russians (Great, Little, and White Russians) in the Caucasus number $3,900,000$. They form the majority of the population in Cis-Caucasia, particularly in the region of Kuban $(2,135,460)$. In Transcaucasia there are about 280,000 Russians and about 35,000 scattered Poles who do not form colonies. There are 103,000 Greeks, 4S,000 Germans, 8,700 Italians, French, and Rumanians, and an insignificant number of other Europeans.

\section{Semitic Peoples JEWS}

According to the census of 1897 there were 56,783 Jews in the Caucasus, but Dirr and Marr give the figure, 119,000, of whom 53,000 live in 
Transcaucasia and are known as Gruzian Jews and 64,000 live in Terek and Daghestan provinces, and are known as Gorsky (i.e., Mountain) Jews. With the exception of 3,500 European Jews who recently immigrated into the Caucasus from European Russia, the Jewish aborigines there are believed to be ancient inhabitants of the country. They regard themselves as descendants of the ten lost tribes of Israel.

While somatologically, both the Gruzian and Gorsky Jews form one unit, they are ethnographically quite different. Both groups are of medium stature $(163.6 \mathrm{~cm}$. and $164 \mathrm{~cm}$.), brachycephalic, and, with rare exception, have dark hair, complexions, and eyes. Anthropological students of the Caucasian population find a certain similarity between the physical type of the Armenians, Aissor, and the Caucasian Jews. On the other hand, the Jews of Yemen, being dolichocephalic, represent the original semitic type. The brachycephaly of the Caucasian Jews may be caused both by mixture with Armenians and others and the influence of. environment.

Ethnographically the Gruzian Jews are Georgians. They have adopted the Georgian language, dress, and manners, but preserved their religion. This is true also of the Gorsky Jews. They speak the language of the Tate, a dialect of New Persian, and neither in dress nor manners can they be distinguished from the local Islamic population. Wherever they come into contact with the Caucasian Tatars they speak Azerbaijan. Marr calls the Caucasian Jews, "Caucasian colonists of the ancient world's peoples."

\section{THE AISSOR}

The total number of Aissor or Assur is estimated at 150,000 but the prevalent opinion is that actually their number is considerably larger. They are descendants of the old Chaldeans and call themselves Syrians. They live in Persia and partly in Asiatic Turkey. After the end of the Russian-Persian war of 1827 , a few Aissor emigrated into the Caucasus and settled in some villages in Erivan Province. Now their number in that province is about 1,250 .

The Persian and Turkic Aissor are Nestorians. Some of them were converted to Catholicism or Protestantism, but the Caucasian Aissor belong to the Greek Catholic church, though they are not strict observers of baptismal, marriage, and burial customs, and under the influence of their Mohammedan neighbors, often practise polygamy. In intercourse with their neighbors, they use the Armenian and Tatar languages.

Their stature (173.7 cms. after Chantre and $168.3 \mathrm{cms}$. after Pant- 
Iukhoff) exceeds medium height. Their cephalic index (average of different investigators) is S7.2. The Mongoloid evefold is not present; the iris is light or dark brown. The skin color is dark brown, the hair is dark and slightly wavy.

They are agriculturists and cattle breeders. In the cities they are day laborers, carters, water carriers, brick layers, ete.

\section{ARABS}

There are a small number of Arabs in the Caucasus, bat the exact figure is not a vailable.

\section{Catcasian Mongoloids}

THE AZERBAIJAN

The Azerbaijan are a Turkish-speaking people so named after the Persian province, Azerbaijan, which is inhabited mostly by a tribe of the same name. In order to colonize Transcaucasia the Persian rulers of ancient times directed the Azerbaijan Turks to move into the Caucasus, so the Azerbaijan occupied the southeastern part of Transcaucasia. At present, their settlements or camps are met in all the provinces of Transcaucasia.

The greatest number (about 70,000) live in the former province of Baku. Their total number in the Caucasus is estimated by Dirr and Narr at about 2,000,000. The number of the Persian Azerbaijan is not exactly known. Vambery gives the figure for Persian Turks as 2,000,000. According to Rasul-Zade, ${ }^{1}$ the Azerbaijan author, there were $2,500,000$ Azerbaijan in Persia. Marr estimates them at about 3,000,000.

Like the Persians, they are Mohammedans of the Shiite doctrine. Their language is a Turkic dialect which was adopted from them by other Turkic tribes of Transcaucasia and also by the Islamic population of southern Daghestan.

In somatic characters they differ from other Turkic tribes, except the Turkoman, and show some affinities with the Persians. They are of medium stature, $168.5 \mathrm{cms}$. (men); have a cephalic index of 77.6 ; a length-height index of 70.9 ; a facial index of 75.9 ; and a nasal index of 63.2. The eye fissure is wide; the eye is dark brown in color; the hair is of dark tints. We may say that physically, the Azerbaijan are of mixed Turkic-Iranian origin. Marr characterizes them as JapheticTurkic hybrids. 
The Azerbaijan are mostly semi-nomadic herders; they rear horned cattle, sheep, buffalo, some camels, and but few horses, and for this reason, oxen are often used as pack and riding animals. They use the arba, a two-wheeled cart. For the summer, they migrate by villages, to the mountains, and return for the winter to the plains and valleys. They carry on some agriculture in order to protect the land from Russian intruders.

Their dwellings are of two kinds: a permanent house and a tent. The house used in winter is a hut built of clay or of stones cemented and covered with clay. The roof is flat and covered with clay. Frequently, the permanent dwelling is a two-storied house; the lower floor serves as a stall for animals. On the flat roof, hay is stored for the winter. Wellto-do people have three rooms. The largest one is the cleanest; the floor is covered with carpets and rugs, and has some furniture. In the walls are niches with bedding, which serve as sleeping places for guests. The host and his family live in the two smaller rooms, which are far from clean. They sit, eat, and sleep on the clayey floor. The summer dwelling is a tent consisting of a felt-covered frame. The tent is not quite circular in groundplan.

The staple food of the Azerbaijan consists of milk products (cheese, fresh and sour milk), bread, and pancakes. Hot and meat dishes (soup with balls of dough, roasted mutton, or fowl) are not eaten every day.

As compared with their neighbors, Azerbaijan culture has remained at a low stage. Among the Armenians there is about 10 percent of illiteracy, but among the Azerbaijan, 95 percent are illiterate. Ancient Arabic is the church language, Osmanli the literary language, and that for ordinary intercourse is the Azerbaijan dialect of Turkish.

\section{THE KUMYK}

The Kumyk, numbering 112,000 (after Marr and Dirr), live in the northeastern part of Daghestan, to the north of Derbent, and on the lower course of the Terek River. Erckert is inclined to regard the Kumyk as the remnants and descendants of the ancient Khazar. But it is questionable how much support can be brought to bear out "this hypothesis. Even the language of the Khazar is not known, though it is assumed to be a Finnic or a Turkic one. The Kumyk language is akin to that of the Nogais, who came to the Caucasus in the twelfth century together with other hordes of Jenghis Khan. The Kumyk are more civilized than the Azerbaijan and other Turkic neighbors. They are Mohammedans. They breed cattle, are fishermen, and are becoming agriculturists. They 

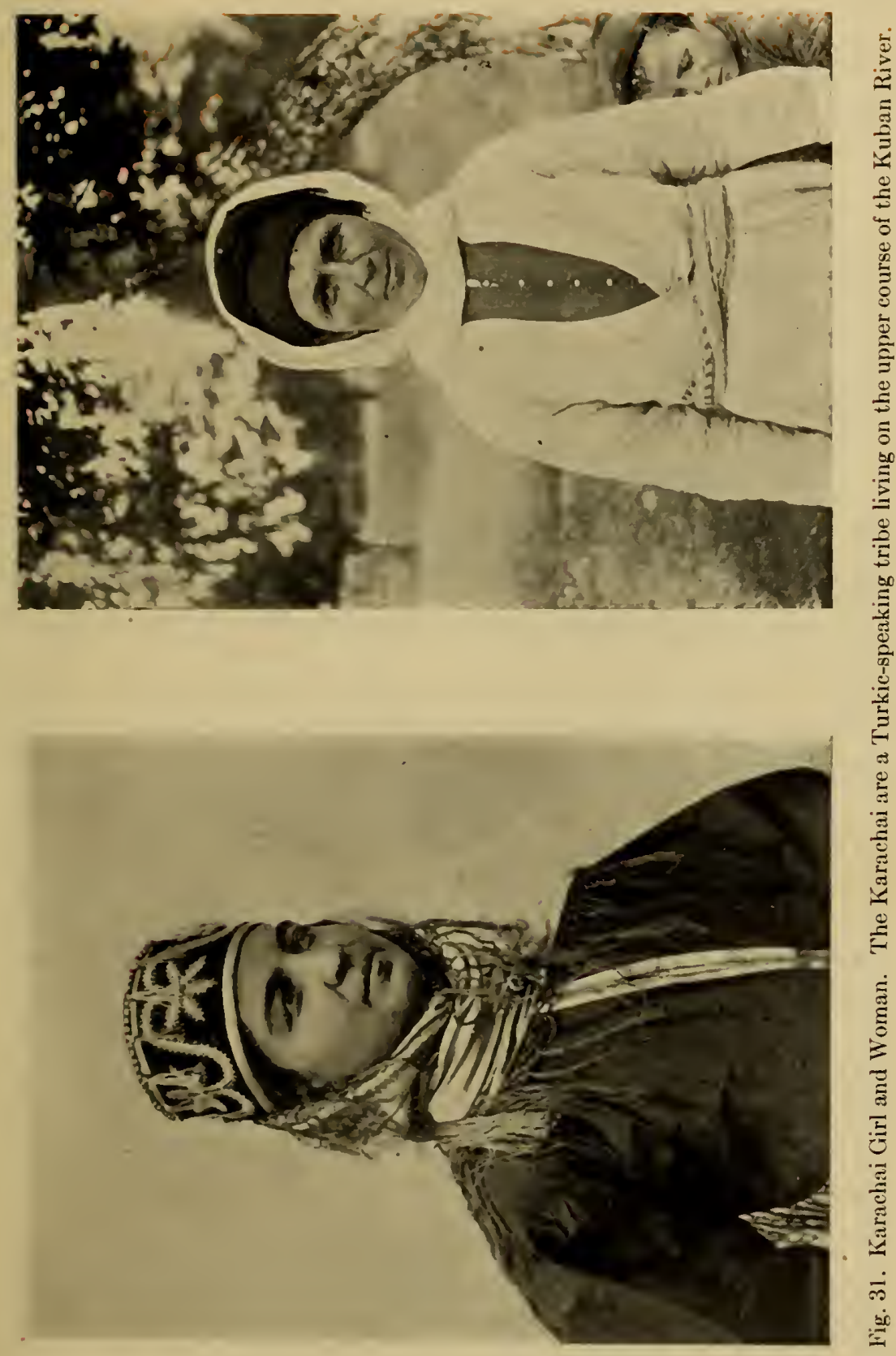

| 
lead a very simple life. They are divided into two social classes; the common people or "black bone," and nobles, or "white bone." Marr calls them Japhetic-Turkic hybrids.

THE BALKAR AND KARACHAI

According to Marr, the Balkar or Tauli and the Karachai people also belong with the Japhetic-Turkic hybrids. The Balkar, numbering 25,000 , live in the mountains of the Naltchik District of Terek Province and are called by the Russians, "Mountain Tatars." The Karachai, numbering 30,000, live on the upper course of the Kuban River and its tributaries. The dialects of both tribes are akin to the language of the Kumyk.

\section{THE CAUCASIAN OSMANLI}

The Osmanli, who remained in the provinces of Kars and Batun, acquired through conquest by the Russians from Turkey, belong to the Southern Turks. They number about 140,000. After the last war, Turkey regained from Russia the districts of Ardahan and Kars in which the Turkic population is estimated at about 80,000. (Compare Maps 4 and 5).

With the more or less recently immigrated Turkic tribes should be included the Nogais, Bashkir, Chuvash, Sarts, Kirghiz-Kaisak, Karapapak, and Turkoman.

\section{THE NOGAIS}

The Nogais entered Cis-Caucasia in the twelfth century, together with the other Turco-Mongolic hordes of the invasion of Jenghis-Khan. At present, they live on the Steppes between the Kuma and Terek rivers and at the mouth of the Sulak River. Some small Nogais villages are located near Piatigorsk, at the mouth of the Selentchuk River, a tributary of the Kuban, and on the upper course of the Kuban. They number about 58,000. About 48,000 nomadic Nogais wander in the eastern part of Stavropol Province, 4,000 sedentary Nogais in Terek Province, and about 6,000 live on the banks of the upper Kuban.

The Bashkir (about 1,000), the Chuvash (about 400), the Sarts (150), and Kirghiz-Kaisak (80) are recent immigrants to Cis-Caucasia.

THE KARAPAPAK

The Karapapak are a Turkic tribe, numbering about 39,000, and live in Kars Province, at present under Turkish dominion. This tribe is mentioned by Dirr and Marr who give no particulars, except its number and lccation. 
THE TLRKOMAN

The Turkoman, numbering about 15,000 , according to Marr, and about 23,000 , according to Dirr, are nomads who wander in the lower courses of the Kalaus and Kuma rivers. They are immigrants from the Transcaspian steppes.

\section{MoNgolic Tribes}

\section{THE KALMUCK}

The Kalmuck belong to the western branch of the Mongols. They live in eastern Tibet, eastern Turkestan, the western part of Astrakhan Province, and the province of the Don Cossacks. In 1703 a branch of the Kalmuck (otherwise called Oirat) and known as Torgout crossed the Ural Mountains, because of constant feuds among the heirs of Jenghiz Khan, and settled in the lower region of the Volga River. The Chinese Government, profiting by the internal dissensions of the Mongols, succeeded in destroying the power of the descendants of Jenghis Khan and subjugated all the Mongolic peoples of Jungaria, Mongolia, and Eastern Turkestan. Soon after the final emigration of the Oirat tribes to the Volga, the Chinese Emperor Kiang-hi sent a mission to the Kalmuck Khan on the lower Volga, inviting him to Jungaria. The Volga Kalmuck decided to return to Jungaria and set out from the Volga in the beginning of $17 i 1$. Only a small number preferred to remain. After an eight months' march, attended by much suffering, being harassed by the Kirghiz and pursued by the Russians, they arrived in Jungaria to find the Chinese in full possession of the country. They were allowed, however, to settle on the Kunges and Tekes rivers in Ili Province, where nearly half a million still live, under the name of Torgout. According to the census of 1897 , the Kalmuck in Russia numbered 190,648. The Kirghiz forced the Kalmuck to occupy the right bank of the Volga and a part of them, about 14,000 , wander in the steppes on the left bank of the Terek, in the former Groznyi District of Cis-Caucasia. The mass of the Russian Kialmuck now form, according to a decree of November 4, 1920, an autonomous Kalmuck Province, occupying portions of former Astrakhan, Tsaritsyn, and Stavropol governments, and of Don and Terek provinces. The capital is Astrakhan. While Turkic tribes, as a rule, are adherents of one of the doctrines of Islam, the Mongol, including the Kalmuck, are Buddhists. The Russian Kalmuck have preserved their Mongolic type and language and, to some degree, their nomadic mode of life. 


\section{THE KAITAK}

Marr mentions another Mongolic tribe, the Kaitak, which is being Turkicized, but gives no estimate of its population.

The Administrative Divisions of the Caucasus under the Soviets

Transcaucasia is divided into three republics: Georgia, Armenia, and Azerbaijan. In 1918 they set up an Independent Transcaucasian Republic and refused to recognize the Russian Soviet Government. The three component states soon split off into independent republics.

\section{GEORGIA}

Georgia, occupying an area about 35,000 square miles, and including the former provinces of Tiflis and Kutais and the districts of Batum and Artvin, and the portion of Sukhum Province known as Abkhasia, has a population of $3,053,345$, according to the census of 1915 . The Georgians form the greatest percentage of the population (82 percent) and are in Kutais Province; the Russians compose only 1.27 percent of the local population, the remainder being divided among other peoples. In Tiflis Province, the Georgians constitute 44.5 percent of the whole population, the Russians 8.2 percent, and other Caucasian peoples 47.3 percent. In both provinces the Georgians constitute 61.5 percent of the whole population, thus forming a majority.

The constituent assembly of Georgia ratified its independence March 12, 1919; the Allies recognized the government de jure, January 21,1921 , but in the course of that year the Soviet troops occupied the country. The state was termed Fraternal Soviet Republic of Georgia and a treaty between Russia and Georgia was signed in Moscow, August 7, 1921. Arrangements were concluded regarding communications, finances, and commerce. Foreign affairs remained in the hands of the Georgia Government, while the Georgian military forces passed over to Russian control. The territory was administered by a temporary Revolutionary Committee.

Commercially, Georgia, with Armenia and Azarbaijan, enjoyed an exceptional position, for the three states formed their own Department of Foreign Trade, independent of Moscow. Internal trade in Georgia remained free, as it was before the invasion of Moscow troops.

The capital of Georgia is Tiflis. An uprising in Georgia in 1924 which was suppressed with the utmost severity by the Moscow army and the changes that have taken place in Georgia after this rebellion are not known. As far as can be judged from the new administrative map of the 



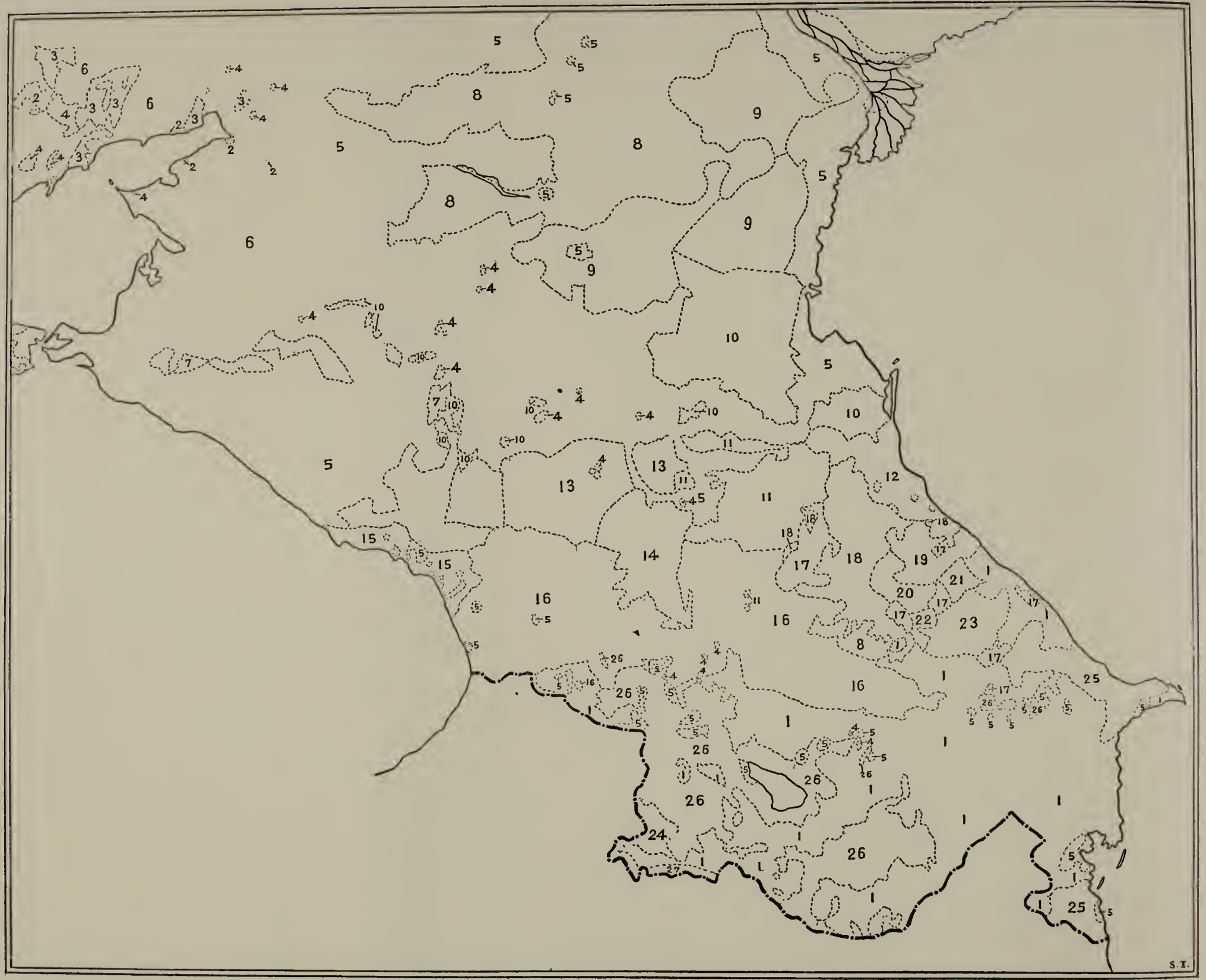

Map 6. The Distribution of the Peoples in the Caucasus

[Re-arranged by the author after A. von Petermann's "Ethnographische Karte von Russland" (S:idliches Blatt), Mittheilungen aus Justus Perthes Gcographisches Anstalt. Erganzungsband XII (1878)].
1. Azerbaijan
6. Little Russians
2. Jews
7. Cherkess (Adighe)
3. Greeks
8. Kalmuck
4. Germans
5. Great Russians
10. Nogais

11. Chechen

12. Kumyk

13. Kabardine

14. Ossete

15. Abkhasian
16. Georgian

17-23. Lesghin Tribes

24. Kurd

25. Tate

26. Armenian 
Caucasus recently received, Georgia is now called Georgian Socialist Soviet Republic, with adjoining states as follows: 1, the Autonomous Abkhasian Socialist Soviet Republic with the capital at Sukhum-Kale; 2, the Autonomous Adjar Territory with the capital at Batum; 3, the Autonomous Ossetine Province, with the capital at Dinval. (Map 4, p. 13S).

\section{ARMENIA}

The situation of Armenia is very similar to that of Georgia. It occupies the former provinces of Erivan and Kars, an area of 17,500 square miles, with a population of $1,510,000$, among whom are 795,000 Armenians, 575,000 Moslems, and 140,000 of other races. A part of the Moslens are Armenian-Themshins. The capital is Erivan $(90,000$ population). The country is administered by a Central Executive Committee.

\section{AZERBAIJAN}

Azerbaijan occupies the former Russian provinces of Baku and Yelizaretpol, and a small portion of Erivan Province. The present Caucasian Azerbaijan occupies the same territory as the original Persian Azerbaijan Province ceded to Russia in 1813. When the provinces of Baku and Yelizavetpol declared themselves independent, the Persian name was adopted for the infant state, for political motives. It was hoped thus to attract to the new republic the Persian remainder of the old province of Azerbaijan, peopled chiefly of the same stock.

Caucasian Azerbaijan occupies an area of 33,970 square miles with a population of $4,615,000$ of whom $3,482,000$ are Moslems and 795,000 Armenians. The capital is Baku (250,000 inhabitants).

\section{Actonomous States in Cis-Caucasia}

According to the recently published administrative map of the Caucasus the following autonomous states were created in Cis-Caucasia.

1. The Autonomous Daghestan Socialist Soviet Republic created by a decree of January 20,1921. It occupies the territory of the former Daghestan Province. The capital is Makhach-Kala.

2. The Chechen Autonomous Province, the former Chechniya. The capital is Groznyi.

3. The Gorsky (Mountain) Autonomous Socialist Soviet Republic created by a decree of January 20,1921, occupies the former Terek Province. The capital is Vladikarkaz. 
4. The Autonomous Kabarda Province, with the capital at Nalchik.

5. The Autonomous Karachayevo-Cherkessian Province, with the capital at Batalpashinsk.

The following Soviet states may be added to those mentioned above.

1. The Russian Province, Rostov, with a capital of the same name.

2. The Cossack Province, Kuban, with the capital at Krasnodar (former Yekaterinodar). ${ }^{1}$

3. The Russian Province, Stavropol, capital of the same name.

4. The Russian Province, Georgievsk, capital of the same name. A small number of Chechen and other Caucasian natives live in this province.

5. The Kalmuck Autonomous Province (former Astrakhan Province). The capital, Astrakhan, as an administrative center, is located outside the borders of the Kalmuck state.

6. Azerbaijan Territory, with the capital at Nakhichevan, is a small Tatar state, separated from the main Azerbaijan Republic by the Armenian Soviet Republic.

7. Cherkasian Territory, located in the middle of Kuban Province, capital, Adamovskaya, is occupied by a remnant of a Cherkessian tribe, the bulk of which emigrated to Turkey after the Russians conquered their country. The territory is called Cherkasian after the Russian terminology.

In order to afford a clear view of the present and former administrative divisions of the Caucasus, two maps are appended, each accompanied by two lists of former provinces and present states. (See pp. 138 and 139).

Yekaterinodar means a gift from Catharine (Empress) and Krasnodar, a red gift. 


\section{CHAPTER IIII}

\section{THE IRANIAN PEOPLES}

The history and development of the Iranian peoples is still to be recorered. Doctor Laufer says:-

If we know as much about the culture of ancient Iran as about ancient Egypt, or even as much as about India or Chin:l, our notions of cultural developments in Asia would probably be widely different from what they are at present. ${ }^{1}$

It is related in the Avesta, the sacred book of the Zoroastrian religion, that Thraetono had three sons, Tura, to whom fell the Oriental lands; Sairima, who received the western lands; and Airya (Arya), who received Iran as his portion. Tuirya or Turya in the Avesta applies to the countries now called Turanian, and the people of Tuirya are spoken of as enemies of the people of Airya. ${ }^{2}$ In the epic poem by the Persian poet, Firdousi, the Shâh Naméh ${ }^{3}$ dating from the tenth century, A.D., Iran is placed to the south of Turan. A prominent figure in this poem, the Turkic Khan Afrâsiyâb, is said to have reigned over Turo in the sixth century B.C., and to have been the great foe of Iran. ${ }^{4}$

The inhabitants of Persia call their country, Iran, while the name Persia is applied only to the small province, Farsistan. But according to historians, ethnologists, and geographers, Iranian territory included the region from the Caucasus, the Caspian Sea, and Russian Turkestan on the north, to the Tigris, the Persian Gulf and the Arabian Sea on the west and south, and extended to the Indus on the east, including modern Afghanistan and the territory to the north of it, as far as the Jaxartes River (Syr Daria)

The ancient and modern peoples included in the Iranian stock are: the Sogdians and Khorezmians, the old Medes and Bactrians, the Persians, Tadjik, Galcha, Kurd, Ossete, Baluchi, Afghan, and the inhabitants of the Pamir districts. Within the Iranian area there are now many mixed groups. Mongolian, Turkic, and Arabian conquerors influenced the physical type of the Iranians to some degree, while Jews, Armenians, and natives of the Caucasus and India, who were in contact with the Iranians, as merchants and colonists, also contributed their share to the mixture.

On the other hand, Iranian blood and culture have been diffused eastward to China, to the west, as far as westernmost Turkey, to the

IL.aufer, (e

:Blorhet. 30.5-3009

'Firrlousi (Abul Casim).

stirine. 115. 
north into Cis-Caucasia, and to the south into India. The chief tribes of Russian Turkestan are regarded as Turkicized Iranians.

Ethnologically, the Iranian peoples are members of the Aryan or Indo-Germanic family. The question of their place of origin is therefore closely connected with the problem of the earliest abode and dispersion of the Aryan race as a whole. Since philologists have discarded the view that Sanskrit represents the most archaic form of Indo-European languages, the theory of the Asiatic origin of the Aryan peoples has lost the support of many students. Various places in Europe were assumed to have been the original home of the Indo-Europeans and the Asiatic branches of the stock, located in Iran and India, are regarded as having emigrated from Europe. But this hypothesis can hardly serve as the final solution of the Aryan problem. A brief résumé of the Iranian peoples, beginning with the Persians, the most prominent member of the family follows.

The name Persia is derived from the classical "Persis" which referred to the province of Parsa (now Fars). The word farsi is employed by the Persians to describe their own language, although when applied to an individual it is restricted to an inhabitant of Fars Province. Parsi is the Persian word, and Farsi its Arabic form, there being no $p$ in the Arabic language. ${ }^{1}$ Persians call their country, Iran, or Eran and themselves, Irani, a word which is the Airyiya of the Avesta, and signifies "the land of the Aryans." Thus, Iran, when used in a political sense, applies to modern Persia only. When used geographically Iran includes all the Iranian countries.

Modern Persian, as well as the other Iranic languages, is written in Arabic script. Pahlavi, the Persian language of the middle Iranian period and the language of the Avesta, is recorded in a script based on Semitic writing, and is read from right to left. The middle Iranian period lasted from the fifth century B.C., until the tenth century of our era. The ancient Iranian inscriptions were in wedge-shaped letters based on Babylonian characters.

The Persians appear to be rather homogeneous. However, our knowledge of the physical anthropology of Persia is still extremely limited. Of its ten million inhabitants hardly thirty individuals have been measured and no authentic Persian skulls are as yet available in our scientific collections. We know, however, that omitting about 300,000 people, Kurd, Arab, Armenian, and others (Lori, Gypsies, etc.) the bulk of the Persian population consists of two elements: the Tadjik, the 
original settlers of the country, and the Ihlat, the descendants of the Turkoman conquerors. The first have been agriculturists since ancient times; the second were originally nomadic herders and now most of them have also become tillers of the soil. They are Mohammedans, following the Sunnite doctrine.

The Tadjik embraced the Shiite faith about 1520 A.D. They do not recognize the three successors of Mohammed, Abubekr, Omar, and Othman, but honor the fourth, Mohammed's son-in-law, Ali, like a god. The hatred between the followers of these two Islamic doctrines is so great that a Shiite, after treating a Sunnite as a guest, ostentatiously breaks the plates on which the guest has eaten in the open street while the visitor is mounting his horse to leave. But in spite of this mutual enmity, narriages between adherents of both religious faiths are frequent.

In some remote districts, as, for instance, in Jesd, despite the persecution of the followers of Zoroaster (or Zarathustra) by the Persian governnent, a small number of Parsis have preserved their old faith, which became the State religion about 520 B.C. under the reign of Darius I. It is said that among these Parsis the ancient Persian physical type has been preserved in quite a pure form. But this does not refer to those Parsis whose ancestors in order not to be converted to Islam, when the Arabian conquerors destroyed the kingdom of the Sassanides, 640 A.D., migrated to northwestern India. Up to the present time, they adhere closely to their old religion. They expose their dead on high towers. that they may be devoured by rapacious birds and that the earth or fire may not be polluted by their uncleanliness. On the other hand, the Indian Parsis have lost their original physical traits and with their dark eyes and skin closely resemble their Indian neighbors.

The above characterization of the Persians is based on the work of von Luschan. ${ }^{1}$ We wish, however, to cite other investigators on the subject, particularly Russian explorers. In Constantinople and Asia Minor von Luschan himself measured fifteen pure Persians who were temporarily sojourning there. Three of these had a dolichocephalic index $(\mathbf{7} 3, \mathbf{7} 4, \mathbf{7})$, one was a mesocephal $(80)$, and eleven individuals were brachycephalic and hyperbrachycephalic (from 81 to 90 ).

Russian investigators (Daniloff, Maslorsky, Pantyukhoff, and Bogdanoff $)^{2}$ measured 1.23 Persians, with an average cephalic index of $\mathbf{7 8 . 7 2}$ (mininum, 69.20; maximum, 88.40). Thus, 45 percent were dolichocephals, 24 percent mesocephals; and 31 percent brachycephals. It will

Ivon Luschan, (b), 110-112.

:Daniloff: Pantyukhoff: Bogdanoff: Maslovsky's material was utilized by Ivanovsky. 
be noted that these data differ considerably from von Luschan's figures. According to these Russian authorities, the hair and eye color are almost exclusively dark. Thus, the present Persians differ physically from the primitive Iranians, who are said to have been blue-eyed and blond dolichocephals. According to Ujfalvy, the present sedentary inhabitants of Persia, known as Tadjik, are a blend of Persians, Uzbeg, and Kirghiz. ${ }^{1}$ The northern Persians were also influenced by the Turkoman and the Persian language contains many Turkic elements.

\section{The Kurd}

The problem of the Kurd has been discussed in the chapter on the population of the Caucasus (p. 149), but we may present some additional data here. Kurdistan, the present territory of the Kurd is a mountainous region, almost as large as Greece, lying to the southeast of the Armenian mountain range. Geographically, the home of the Kurd may be regarded as the upper part of Mesopotamia and the region of the upper courses of the Euphrates and Tigris. The banks of the Chabur River, an important tributary of the Euphrates, are inhabited mostly by the Kurd. However, the exact boundaries of their territory are quite uncertain. The bulk of them are still nomads and their camel caravans reach Mersin and Alexandrette on the Mediterranean Sea and Bassora on the Persian Gulf. How far the Kurd penetrate into southeastern Persia is not well known, nor the exact number living in Afghanistan and Beluchistan.

Kurd history is still veiled in darkness. The Armenians claim that they are of Medean origin. Although both are Sunnites, the western Kurds have an unconquerable aversion toward their Turkish "oppressors." After sanguinary wars in 1837 and 1847 they were subdued by the Turks, under the command of the well-known Moltke. More recently, the Turks were confronted by a Kurd uprising.

The eastern Kurds fanatically hate their Persian rulers as heretic Shiites, although both are Iranian. In Turkey, as well as in Persia, the Kurds are feared as plunderers and robbers. They kidnapped the women of the Christian Armenians, their rivals for the mastery of eastern Asia Minor, and have more than once, at the instigation of the Turks, their hated masters, perpetrated cruel massacres of Armenians.

The Kurd language is related to New Persian, thus belonging to the Indo-European stock. It has not yet been sufficiently studied and contains words borrowed from Turkic, Chaldaic, Persian, Arabic, and 
Russian, according to the peoples with whom they have been in contact. The eastern dialects are better known than the western ones from which they differ considerably. The hurd have no writing of their own, but the few of the m who know how to write their own language and Turkic use Arabic ch aracters. Their literature, insignificant as it is, is also recorded in Arabic script.

Physically also their position still remains in doubt. The Eastern Kurd are dark-skinned and short-headed like the Persians, among whom they live, while the somatological traits of western ones are quite different. Professor von Luschan investigated three groups of western Kurds: 115 adult men of the district of Karakush, 26 at Nemrud-Dagh, and 80 in the environs of Sendschirli, the ancient capital of the Hittites. Of the 115 Karakush men, 71 were pronounced xanthochroics, of the 26 men of Nemrud-Dagh there were 15 and of 115 Sendschirli men only 31 were fair. Thus, of blond-haired and light-eyed there were: in Karakush, 62 percent; on Nemrud-Dagh, 58 percent; and in Sendschirli, 39 percent. The head index in Karakush ranged between 71.3 and 78.5 ; at NemrudDagh between 72.3 and 78.3 ; and in Sendschirli between 74.4 and 80.9 . The arithme tical averages were $74.9,75.2$, and 76.9 . There were no essential differences in nasal and facial indices in these groups. All three groups have almost identical facial indices, ranging between 76 and 96 , with the greatest distribution at 87 and 93 .

The Kurd at Karakush and of the Mountains of Nemrud-Dagh have no alien neighbors although an occasional Armenian retail merchant may be met. In Sendschirli, with its unhealthy swampy plains, the Kurd set up their tents only in winter, and live in Turkish and Armenian villages, and very often marry Turkic women and kidnap Armenian girls. We can thus explain why the hill Kurd are inainly a xanthochroic and longheaded people while the Kurd of Sendschirli are in the main dark and have broad heads.

We have previously seen that the Eastern Kurd living among the Persians do not differ from them somatologically: they are brachycephals and brunettes. From these data we may conclude, as von Luschan contends, that originally all the Kurd were blond, long-headed, and blueeyed, and only as a result of blending with Turks, Armenians, and Persians have they become more or less dark-complexioned and shortheaded. Where then is the actual home of the blond, blue-eyed, and longheaded Kurd? Professor von Luschan's reply to this query is that Northern Europe is the only region in the world where we now find blond, blueeyed, and long-headed people. He rejects the opinion of some philol- 
ogists that the Kurd were originally Persians; in order to accept their conclusions he believed that the questions as to where the pure Kurd acquired the Northern European somatological traits and whether it is compatible with the latest theories as to the European origins of Aryan peoples in general, to admit an Asiatic origin for the Kurds, must be answered.

If we answer these queries in accordance with Professor von Luschan's theories, another question arises. What language did they speak before they came into contact with the Persians? The Persians themselves, as Aryans, may also claim a European origin. Thus the study of the Kurd involves important historico-anthropological problems, particularly as to the actual history of the migrations between Europe and Asia.

\section{The Ossete}

Another Aryan tribe, the history of which is lost in the remote past, is the Ossete. They call themselves Iron, a name which has been identified with Iran. Ripley is inclined to regard the Ossete as immigrants from the direction of Iran. ${ }^{1}$ According to their own traditions, however, they came from the region of the Don River in southern Russia. Moreover, as Vsevolod Miller ${ }^{2}$ has shown, the Ossetian language alone explains a great many South Russian place names. The Ossete occupation of territory in the Caucasus along the Pass of Dariel, according to Ripley, gives tenability to the hypothesis that they came from the south. But as the Ossete occupy both slopes of the pass there is some doubt as to the direction from which they may have come to the Caucasus, whether from south or north. On the other hand, linguistic investigations have shown that the Ossete must have had a direct connection with the Scythians and Sarmatians of Europe (southeastern Russia). In the third century B.C., the Scythians were overcome by the Sarmatians, who spoke a Scythian dialect. $^{3}$ Remains of Sarmatians have been found in the burial mounds of their former habitat. The greater number of the barbarian names occurring in the inscriptions of Olbei, Tanais, and Panticopæum are supposed to be Sarmatian, and as these have been well explained from the Iranian language, now spoken by the Ossete of the Caucasus, these are supposed to be the descendants of Sarmatians. The latter are also regarded as the ancestors of the Slavs. The Russian anthropologist, Pantyukhoff, regards the Ossete as the latest European immigrants among

1Ripley, 436.

2Miller.

${ }^{3}$ Zaborowski (36) identifies the Ossete with the Alan who were Scythians of Iranian speech. 
the peoples of the Caucasus. Judging by the considerable percent of blue eves and long heads he is inclined to regard the Ossete as a blend of North Europeans (Celts, Slavic tribes) with Caucasian and Middle Asiatic brachycephals. The somatology of the Ossetes was studied by several Russian investigators, all of whom came to the same conclusion. Fifty-five percent of the Ossete have dark hair and eyes; 30 percent are of a mixed type, while only 15 percent have light eyes and blond hair. The average height of 500 Ossete was 169.2 cms. (minimum, 154.2; maxinum, 190.0). The head index is moderately sub-brachycephalic, in average, $S 1.95 ; 11$ percent were dolichocephalic and .22 percent mesocephalic. Their facial index is 54 percent chamæprosopic; as to nasal index, 69 percent were leptorrhin.

\section{Sogdiaxs axd Khorezmians}

The well known authority on the history of the Orient, the Russian Professor and Academician V. V. Barthold, ${ }^{1}$ gives some data concerning the original population of the country now called Turkestan. During more than 1500 years, since the sixth century B.C., the names of two civilized Iranian nations, the Sogdians and Khorezmians, have been mentioned. Figures of a Sogdian and a Khorezmian are preserved on the tomb monument of Darius (522-486 B.C.), near the ruins of Persepol, among representations of other peoples who composed the empire of this monarch. Authentic information on the languages of these two peoples is a vailable only for the period of their disappearance and may be found in a work written in Arabic by a Khorezmian, Biruni, in the year 1000 of our era. Describing the Sogdian and Kihorezmian calendars, he refers to names of days, months, and holidays, thus giving an idea of the dialectic peculiarities of both languages.

Of these two agricultural and civilized Iranian nations, the Khoreznians had an independent political existence for a long period and were politically dominant in Central Asia before the formation of the Persian empire of the Achæmenid dynasty. They were subjugated for a short period by the Persians, but soon freed themselves. During the Central Asiatic campaigns of Alexander the Great (330-327 B.C.), Khorezm had its own king, while the country of the Sogdians, the center of which was the region of the Zarafshan River, remained a Persian province. As far as is now known, Khorezin was never conquered either by Alexander the Great or by the Greco-Bactrian kings, or the pre-MIussulman nomadic peoples of Central Asia. Only the Mussulman conquest in the seventh to 
eighth centuries of our era put an end to the political, and later, the ethnographical independence of Khorezm; but even the Mohammedan rulers retained the title of the pre-Mussulman rulers of Khorezm, or Khorezmshah.

The country of the Sogdians was a part of the empire of Alexander the Great and later of the Greco-Bactrian dominions, and was many times subjected to invasions of nomadic peoples, so there was no favorable basis for the creation of a tradition of political independence, as in Khorezm. On the other hand, the Sogdians, far more than the Khorezmians, influenced the course of cultural history and were the chief diffusers of Anterior Asiatic culture in the countries of Turkestan and eastward, as far as China. The oldest Turkic alphabet known from the Yenisei-Orkhon inscriptions is said to have originated in the most ancient form of Sogdian. The derivation from the Sogdian of the much later Turkic alphabet, that of the Uigur, is more evident.

The Arabian invasion of the seventh to the eighth centuries changed the ethnographic composition of the Iranian population of Turkestan. At the end of the tenth century when the political power was definitely vested in the Turks, the remainder of the Iranian population, under the influence of their Turkic rulers, began to call themselves Tadjik. When the Turkic nomadic Uzbeg began to settle themselves as agriculturists, the Tadjik were gradually forced out of the valleys to the mountainous regions. The Russian conquest of Turkestan saved them from the predatory invasions of Turkic nomads and further displacements. However, in the course of intertribal relations, the Iranian dialects became more and more often displaced by the Turkic.

The Sogdian language is still spoken by a small group of Iranians called Yagnobtzy (about 1500-2000) living in the mountains of Yagnob, a tributary of the upper Zarafshan River. They are surrounded by Tadjik who speak Persian dialects. The Yagnobtzy are also called Galcha, but all the Tadjik inountaineers are known by this name.

\section{Medians and Bactrians}

Media and Bactria were ancient Iranian kingdoms. The Medians were fire worshipers. Among their priests, called Magi, rose Zoroaster, or more correctly, Zarathustra, the founder of the religion known under his name. Bactria was still independent in 1000 B.C. The Persian king, Cyrus, subjugated both countries and made them Persian provinces. Alexander the Great conquered them in 327 B.C. The descendants of the old Bactrians, together with the partly civilized Kurd, are said to speak purer Persian than that in vogue in Persia itself. 


\section{The Tate and Azerbaijan}

These two tribes are regarded as Iranians who adopted the Turkish language and therefore linguists class them as Turks. For a more detailed description see pp. 150, 159.

\section{The Sarts}

Some ethnologists are inclined to regard the Sarts as Turkicized Iranians, but as we have previously seen, they are somatologically a mixed population and have been recorded by the Soviets with the Turkic Uzbeg.

\section{The Arghay and Baluchi}

A certain portion of the populations of Afghanistan and Baluchistan is physically Persian, speaking more or less Turkic dialects. The Afghan (36 individuals) were measured by the Russian anthropologists, Poyarkoff, Matzeyevsky, and Maslovsky. ${ }^{1}$ Their average stature was 165.7 cm.; cephalic index, 80.24; facial index, 73.18; and nasal index, 50.93. We have no measurements for the Baluchi.

\section{The Tadjik and Galcha}

The Galcha are Mountain Tadjik. We have previously noted that these two Iranian divisions form one people. They speak Persian and other Iranian dialects. However, the Plains Tadjik and the Mountain Tadjik are unlike in some of their somatological characters. Taking the average figures for descriptive characters of the Tadjik recorded by Maslovsky, ${ }^{2}$ Yavorsky, and Ujfalvy, we have (of 393 persons examined) 41 individuals, or 11 percent who are blond; 66 or 17 percent who are mixed; and 285 or 72 percent who are dark. The chief measurements recorded were stature, 169.3; head index, 84.85 ; facial index, 73.33 .

For the Galcha ( 58 individuals) we have only the measurements by Ujfalvy." Their stature is $166.7 \mathrm{cms}$; head index, 85 . The number of blond persons ( 8.6 percent) is less than among the Tadjik.

Thus, we see that both branches of the Iranian Tadjik somatologically tend to resemble the Alpine type of Europeans. The Galcha may be regarded as a primitive population which preserved its relative purity perhaps by reason of its isolation in the mountains. If we compare the somatology of the Tadjik and other Asiatic Iranians (Persians, Hindoos, Kurds, and others) we must conclude that in tracing the European racial 
types to Asia in the search for a common stock, we find at least two of the types present in Central Europe.

\section{Armenians}

Earlier authorities classed the Armenians with the Iranians, but later investigators regard them as an independent Aryan branch.

\section{The Hindoos and Gypsies}

To complete our survey of the Iranians or the Asiatic Aryans, some space should be devoted to the Hindoos and Gypsies. Some Hindoos may be found outside of India on the right banks of the Indus, among the Baluchi and Afghan. Crossing the Indus we enter into the actual country of the Hindoo division of the Aryan race. From the left bank of the Indus the Hindoos spread over all of northern India and over the western Dekhan (or Deccan). Their distribution boundary lies somewhat to the south of the Narbada and Mahanadi rivers. The country farther to the south and east, to the shores of Bengal Bay and the Indian Ocean, is occupied by the Dravidians. They were regarded as the ancient inhabitants of India who were driven back by an Aryan invasion. The invasion was not quite complete and was effected gradually, so that numerous mixtures of both races had taken place. Then a Mongolian current, which carried Mohammedanism with it, engulfed this medley of peoples, and was, on one hand, the cause for the splitting of the Indian inhabitants into different religious denominations, and on the other, served further to entangle the various factors entering into the racial mixture, so that at present it has become exceedingly difficult to disentangle the various components.

The Indian population comprises not only Dravidians, Hindoos, Mongols, and Arabs, but also the supposed more ancient inhabitants who lived there long before the arrival of the Dravidians. These descendants of the older inhabitants live in the mountains, leading a very primitive life. More recently came the Parsis, Jews, and Europeans.

The Aryan Hindoos came to their present home about 2000 B.C. from their former habitat in the high steppes of Pamir. In India they first appeared as herders, and occupied the Punjab where they developed their high culture, which became more complicated the farther they penetrated into the provinces of Deccan and Hindustan with their more favorable climatic conditions.

The physical type of the Indian Aryans is not in any way homogeneous. Intermixture with the native aborigines, in spite of the caste system, 
and later, with the Mongolian invaders has effaced the original Aryan physical characters. The Hindoos are of medium stature, have an olive brown skin, straight black hair, oval face, large almond-shaped eyes, and small chin. There are individuals of lighter complexion, of whom they are proud, as they offer evidence of their Aryan origin. Hindoo women are said to be very beautiful. The Hindoos speak a Neo-Sanskrit idiom. The phonetic changes which old Sanskrit passed through are regarded by philologists to be similar to the development of New Persian from the Avesta. Like Persian, Sanskrit also had three periods of development: 1, Classic Sanskrit, the ancient Veddic dialect; 2, Middle Indian, the Prakrit; 3 , New Indian dialects.

About 210,000,000 people speak Aryan dialects, most closely related to Persian and Kurd, and like the European Aryan branches, may be regarded as members of the Indo-Germanic family. But no inference should be made as to physical affinity from this linguistic relationship. We refer here only to an Aryan language. The study of the physical anthropology of India is still in its infancy. We gave above some descriptive characters of the Indian Aryans and here add some figures for average measurements. The average stature of 6,423 Hindoos measured by different investigators is 162.3 ; the cephalic index, 75.2 ; the average facial index of 161 individuals is 70.22 ; the average nasal index of 5,924 individuals is $\$ 2.37$.

The most prominent social phenomenon in India is the caste system. These castes are: priests (Brahmans), warriors (Kshatriyas), traders (Vaisya), and peasants and craftsmen (Sudra). Later a fifth caste, that of savages or out casts was added. The Aryans in India never conquered the land through mere force of numbers. Their social and religious influence upon the pre-Hindoo population was far nore important than their racial influence. Nevertheless, the racial element affected the position of the priest caste to a certain degree. The Brahmans are distinguished from the other castes by a lighter complexion, considered a reminder of superior descent.

The Buddhist doctrine, which, like Christianity, was preached not to a selected people, but to all mankind, enjoyed many centuries (from about 500 B.C. to 599 A.D.) of undisputed sovereignity. Buddhism has, however, almost disappeared from India, in spite of the fact that Buddha himself was a Hindoo, according to tradition, the son of Cuddhodana, the King of Kapilavastu, the house of Sakya. The militant Mohammedanism introduced into India by the Arabic conquerors was much more successful and the Islamic period lasted from 1000 until 1757 A.D., but it was not strong enough to supplant Brahmanism. Neither was 
Christianity capable of taking the place of the original Hindoo beliefs. The Indian census of 1911 gives an exact idea of the relation of Buddhism, Mohammedanism, and Christianity to Brahmanism, which still dominates the minds of the Hindoos: Brahamanism, with its ideas of castes, was professed by $217,586,900$ people; Mohammedanism, by $66,000,000$; Buddhism, by 10,721,500; Christianity by $3,000,000$.

The Gypsies should be ranked with the Hindoos. Their origin was unknown for a long time, but scientific investigations recently made by Pott, M. L. Goje, and Bataillard' lead to the belief that their original home must have been somewhere in northwestern India. There is no doubt that the language of the Gypsies is closely related to old Prakrit, and that for some time before they migrated to the northwest, they lived on the middle course of the Indus. There are a considerable number of Gypsy dialects as they adopted lexical elements from the languages of the countries they inhabited. The Slavic linguist, Miklosich, ${ }^{2}$ was the first to call attention to the fact that the migration routes of a Gypsy band can be determined by the borrowed foreign elements in its language. In Germany, Gypsies first appeared in 1417 and in Poland and Russia in 1500.

We do not know the exact number of Gypsies in Asia or Europe, but according to superficial estimates there are 500,000 in Asiatic Turkey, about the same number in the Balkan countries, and in other European countries, scarcely 200,000 altogether. This small European population may be explained by the fact that European legislation had prohibited the immigration of Gypsies. They call themselves Rom which term corresponds to the name of a dark caste in India. They are differently named by different peoples. The Persians call them Luri or Karachi; the Syrians, Nawars; the Hindoos, Jat or Sinti; the Germans, Zigeuner; the Russians, Tzygany.

Very little is known of the physical characters of the Gypsies. In Anterior Asia they are long-headed (75.29); the average facial index is 84.23; the average statue is 170.1 . The Gypsies of southern Russia (Taurida) according to the measurements of Lyshin ${ }^{3}$ have an average cephalic index of 82.93 .

The Gypsies are rarely sedentary, but roam from place to place with their wagons and tents. The men are mostly blacksmiths and shrewd horse dealers, curing sick horses and cattle, and have an inclination to theft and larceny. The women make baskets and sieves and are known as fortune tellers.

'von Luschan, (b), 78.

2Miklosich.

syshin. 


\section{CHAPTER VIII}

\section{SOMATOLOGY}

We now turn to a general anthropological survey of the affinities and peculiarities of the peoples noted in the preceding pages. In such a study one must deal with anthropometric data and should be reminded that arithmetic averages for bodily measurements do not of themselves give an accurate idea of the extent of individual variation in the group nor do such averages taken alone enable one to make satisfactory comparisons as between groups, modern statistical methods demanding in addition to the average, the standard deviation, the coefficient of variation, and the probable errors for these. Unfortunately, these requirements cannot be fully met with respect to many of the ethnic groups considered herein, the published data giving only arithmetical averages. Nevertheless, these are of value and we shall make the best possible use of them.

Taking into consideration the large number of peoples reviewed and their different racial affiliations, we had necessarily to limit ourselves to the examination of but a few physical characters, namely: stature, cephalic index, facial index, height-length-breadth head index, the cephalic module, stature index, and their distributions.

$\mathrm{By}$ their statures we can differentiate arctic and southern tribes, mountaineers, and plains dwellers. The cephalic and facial indices are generally regarded as the most important racial indices, and while these indices give us the relation of $t$ wo measurements, the height-lengthbreadth head index, or the cephalic module $\left(\frac{1+b+h}{3}\right)$ will give an idea of the absolute size of the head.

\section{The Distribution of Stature}

We turn, first, to stature about which a great deal has been written, but concerning which there is no definite insight as to the factors that increase or decrease bodily length. It is customary to say that the environment, natural or artificial selection, habits of life, race, etc., are all determining factors in size, but so far no one has been able to isolate any one of these and the assumed resulting stature increment. It is even asserted that topographical factors are important determiners, as when we are told that northern peoples are shorter than southern; yet, the northwestern extremity of Europe (Scandinavia and the British Isles) is occupied by very tall peoples, while in some parts of Italy stature is very low. The same contradictions are met with in mountain and plains 


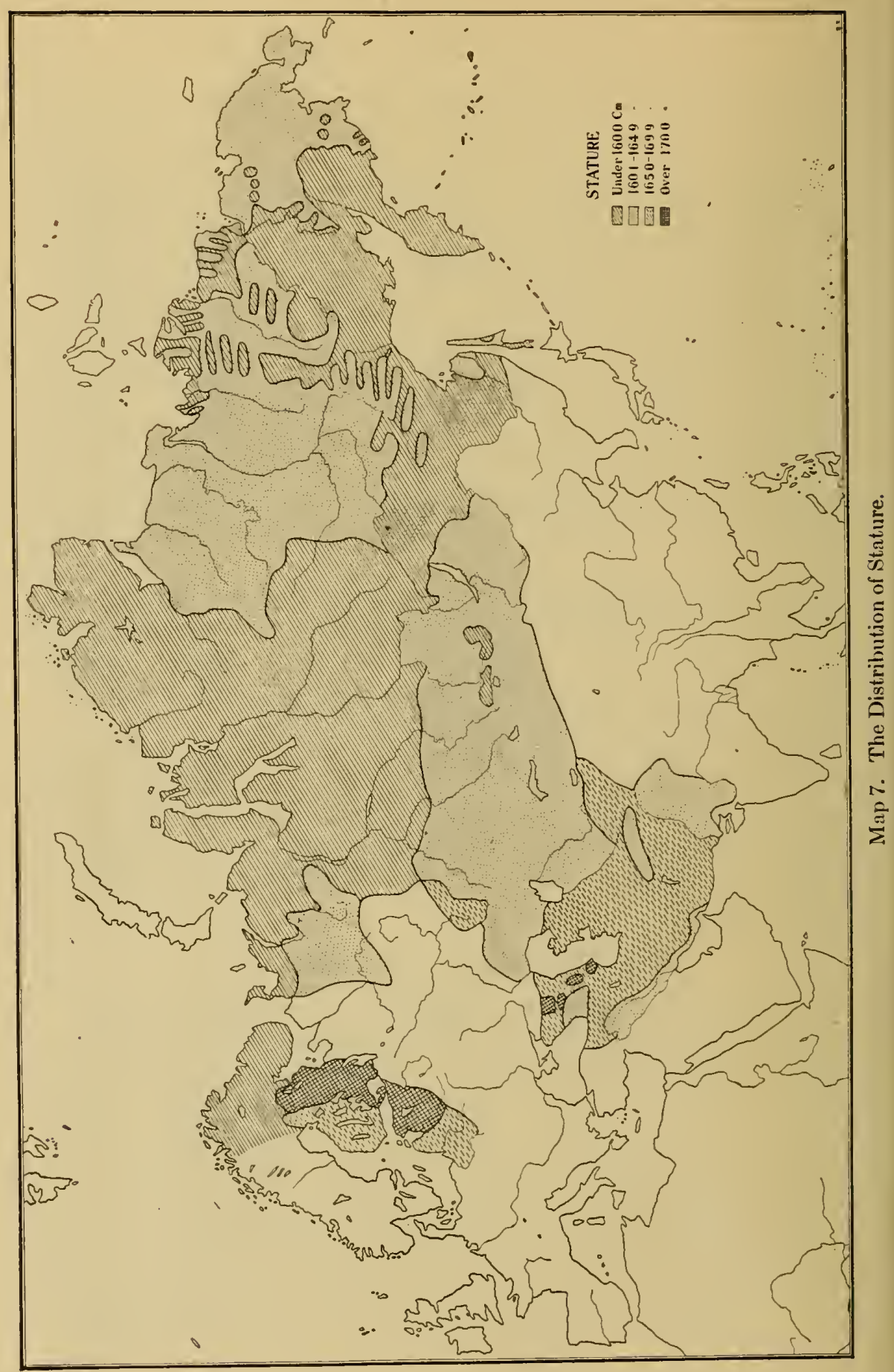


dwellers, for while it is true that the Swiss of the Bernese Oberland are short in contrast to their brothers dwelling in the valleys below, the highlands of Scotland, Dalmatia, and Bosnia-Herzogovinia are the homes of very tall men. Hence, we can do no more than present the facts for Siberia as we find them.

From the variations in stature shown in the table below and graphically represented in Map 7 , the following conclusions may be drawn. As a rule, the shortest people of Eurasia occupy the most northerly portions of the continent (Lapps, Samoyed, Ostyak, Yukaghir), but in the northeastern extremity of Asia are people falling below the average (Chukchee, Asiatic Eskimo), while to the south of them (Koryak, Kamchadal, and some of the Tungus tribes) are again peoples of low stature. The Yakut are also of sub-average stature, but they are newcomers in the Polar region.

With regard to occupation we see that fishermen are low statured, while reindeer and cattle breeders and tillers of the soil are of average or high stature. Samoyed, Ostyak, Lapp, and some other reindeer breeders are exceptions to this rule, but most of them are largely dependent on fishing for their living.

It is of interest to draw attention to geographical distribution of stature. In Eurasia, the stature of the Polar tribes increases from west to east, beginning with the Lapps and Samoyed, while in Arctic America the reverse is true: the Eastern Eskimo have the lowest stature; the Eskimo of Alaska and the Chukchee Peninsula have the highest. If, then, we regard the whole Arctic and Sub-Arctic belt extending from Lapland to Greenland, a border of low statures tends to surround a central trans-Bering area of higher statures.

The Distribution of Statere

Low Stature (under $1600 \mathrm{~mm}$.)

$\begin{array}{llll}\text { Orochi } & 1545 & \text { Japanese } & 1578 \\ \text { Samoyed } & 1550 & \text { Ostyak } & 1579 \\ \text { Yukaghir } & 1559 & \text { Vogul } & 1580 \\ \text { Lapps } & 1559 & \text { Chuvantzy } & 1581 \\ \text { Ainu } & 1567 & \text { Aleut } & 1584 \\ \text { Northern Tungus } & 1570 & \text { Karagas } & 1589 \\ \text { Labrador Eskimo } & 1575 & \text { Koryak } & 1596 \\ & & \text { Kamchadal } & 1597\end{array}$


Stature below the Average (1601-1649 mm.)

$\begin{array}{llll}\text { Eastern Eskimo }^{1} & 1606 & \text { Yezides } & 1633 \\ \text { Point Barrow Eskimo } & 1615 & \text { Torgout } & 1636 \\ \text { Yakut } & 1617 & \text { Telengit } & 1636 \\ \text { Permiak } & 1618 & \text { Jews (Georgian) } & 1636 \\ \text { Votyak } & 1619 & \text { Black Tatars (Altai) } & 1639 \\ \text { Chukchee } & 1620 & \text { Kirghiz } & 1640 \\ \text { Asiatic Eskimo } & 1623 & \text { Kalmuck } & 1640 \\ \text { Hindoo } & 1623 & \text { Udine } & 1643 \\ \text { Jews (Russian) } & 1626 & \text { Kumyk } & 1644 \\ \text { Tungus } & 1627 & \text { Tatars (Kazan) } & 1645 \\ \text { Cheremiss } & 1628 & \text { Georgians } & 1646 \\ \text { Zyryan } & 1629 & \text { Gypsies (Europe) } & 1646 \\ \text { Buryat } & 1631 & \text { Mingrelian } & 1647\end{array}$

Stature above the Average (1650-1699 mm.)

\begin{tabular}{|c|c|c|c|}
\hline & & & \\
\hline Mestcheryak & 1650 & Armenians & 1673 \\
\hline Chinese & 1653 & Kara-Kirghiz & 1673 \\
\hline Poles & 1654 & Karachaevtzy & 1675 \\
\hline Bashkir & 1655 & Persians & 1677 \\
\hline Great Russians & 1657 & Kabardine & 1678 \\
\hline Lithuanians & 1659 & Uzbeg & 1679 \\
\hline Afghan & 1659 & Lesghin & 1681 \\
\hline Dungan & 1659 & Kurd & 1684 \\
\hline Gorsky Jews & 1659 & Azerbaijan & 1685 \\
\hline Tatars of Crimea & 1661 & Ossete & 1692 \\
\hline Turks & 1668 & Tadjik & 1693 \\
\hline White Russians & 1668 & Sarts & 1695 \\
\hline Galcha & 1669 & Imeretine & 1696 \\
\hline Little Russians & 1670 & Turkoman & 1696 \\
\hline Aissor & 1671 & & \\
\hline Finn & 1671 & & \\
\hline $\mathrm{Hig}$ & h Stat & $0 \mathrm{~mm}$. and up) & \\
\hline Svanets & 1700 & Lett & 1705 \\
\hline Gypsies (Anterior Asia) & 1701 & Ingush & 1713 \\
\hline Tate & 1701 & Karelian & 1720 \\
\hline Esthonians & 1703 & Livonian & 1736 \\
\hline
\end{tabular}

\section{Distribution of the Cephalic Index}

- The cephalic index, i.e., the breadth of the head expressed in percentage of its length is regarded as one of the best means to detect racial affinities. In most cases our list of cephalic indices corroborates this contention. The Iranian nations (Persians, Yezide, Kurd), and the 


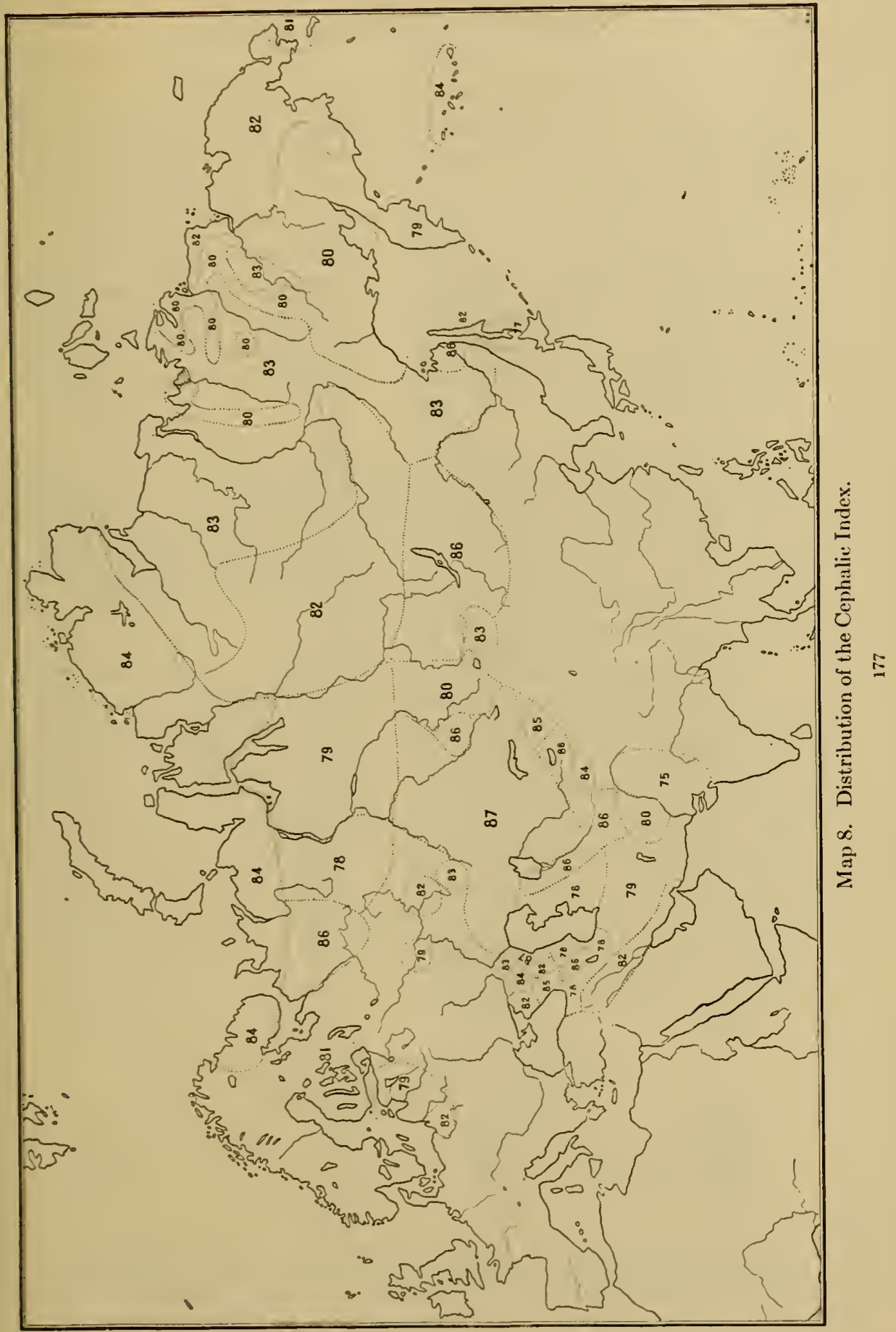


linguistically Turkicized Iranians (the Tate, Azerbaijan, and Afghan) are mesocephals. The Hindoos and Gypsies (of interior Asia) are also mesocephals. If we take the Finnic group of peoples, independent of culture stage, we see that with a few exceptions, they are mesocephals. These are: the Vogul, Ostyak, Esthonians, Livonians, and Finns of Finland.

Turks and Mongols are pronounced brachycephals or hyperbrachycephals. The Mongols are usually regarded as typically broad-headed, but our list of indices shows that some Turkic tribes have wider heads than the Mongols. While the chief Mongolic divisions, Kalmuck, Torgout, and Buryat are brachycephals, the Turkic, Kara-Kirghiz, Kumyk, and Kirghiz are hyperbrachycephals.

Some exceptions to this may be pointed out. Thus, the dolichocephalic Turkoman are a Turkic tribe (75.63), which may be explained by the fact that the Turkoman before their subjugation by the Russians, were robbers, slave dealers, and kidnappers of Persian men and women, and were consequently mixed with Persians. The Persians themselves are, however, mesocephals. ${ }^{1}$ Also, it should be noted that Turkoman women have a distinctly Mongol type of face.

The Dungan are also dolichocephalic (76.05). Some writers regard them as Chinecised Turks, while others believe them to be Chinese Mohammedans. The average cephalic index for all Chinese is 79.61, for those of Kuldja, 78.41, and for northern China, 77.0. There are still other puzzling questions regarding the cephalic index, as the Finnic Lapps with a brachycephalic index of 84 , and the hyperbrachycephalic Zyryan (86.36). The Americanoid Gilyak also have a hyperbrachycephalic index, while their nearest neighbors, the Ainu and Tungus, have indices of 79 and 83 or 80 , respectively. The hyperbrachycephalic index of the Armenians bears witness against the contention of some writers that they belong to the Iranian group of Aryans.

Distribution of the Cephalic Index

Dolichocephals (below 76.4)

$\begin{array}{llll}\text { Hindoos } & 75.2 & \text { Turkoman } & 75.63 \\ \text { Gypsies (Anterior Asia) } & \mathbf{7 5 . 2} & \text { Dungan } & \mathbf{7 6 . 0 5} \\ \text { Labrador Eskimo } & \mathbf{7 5 . 5 3} & & \end{array}$

1The ancient Persians [Aristoff, (a), 451] had light hair and long heads. Their present mesocephaly and dark hair were acquired through mixture with Semites and Turks. Thus, the dolichocephaly of the Turkoman might be explained by their mixture with old Persian and other lranian dolichocephals. 
Distribetion of the Cephalic Index (Continued)

Mesocephals (75.6- 80.9$)$

\begin{tabular}{|c|c|c|c|}
\hline Ainu & $77.3^{1}$ & Cheremiss & 79.20 \\
\hline Eastern Eskimo & 77.3 & Ostyak & 79.23 \\
\hline Azerbaijan & 77.57 & Esthonian & 79.26 \\
\hline Yezide & 77.86 & Lett & 79.52 \\
\hline Vogul & 77.90 & Northern Tungus & 79.6 \\
\hline Japanese & 78.15 & Altai Tatar & 79.64 \\
\hline Furd & 78.29 & Livonian & 79.9 \\
\hline Chinese (Kuldja) & 78.41 & Chuvantzy & 79.9 \\
\hline Tate & $7 S .62$ & Koryak & 80.0 \\
\hline Persian & 78.72 & Afghan & 80.24 \\
\hline Kamchadal & 78.90 & Yukaghir & 80.4 \\
\hline Alaskan Eskimo & 79.20 & Finn & 80.67 \\
\hline \multicolumn{4}{|c|}{ Brachycephals (81.0-85.9) } \\
\hline Luli & 81.16 & Jews (Russian) & 82.56 \\
\hline Karelian & $\$ 1.19$ & Kalmuck & 82.57 \\
\hline Asiatic Eskimo & $\$ 1.20$ & Yakut & 82.60 \\
\hline Mestcheryak & 81.64 & Orochi & 82.81 \\
\hline Lithuanian & 81.88 & Gypsies (Tauride) & 82.93 \\
\hline White Russians & 81.87 & Soyot & 83.03 \\
\hline Chukchee & 81.90 & Imeretine & 83.09 \\
\hline Votyak & 81.94 & Mordva & 83.21 \\
\hline Ossetines & 81.95 & Tatar (Caucasus) & 83.49 \\
\hline Abkhastzy & 82.02 & Kabardine & 83.73 \\
\hline Tatar (Kazan) & 82.08 & Aleut & 83.80 \\
\hline Arab & 82.10 & Karachayevtzy & 83.88 \\
\hline Pole & 82.13 & Samoyed & 83.95 \\
\hline Ingush & 82.14 & Lapp (Russia) & 84.00 \\
\hline Little Russians & 82.31 & Sarts & 84.22 \\
\hline Chechen & 82.37 & Afghan & 84.24 \\
\hline Great Russians & 82.39 & Tatar (Crimea) & 84.49 \\
\hline Permiak & 82.40 & Turk & 84.70 \\
\hline Sibo (Manchu) & 82.42 & Torgout & 84.73 \\
\hline Mingrelian & 82.44 & Karaites & 84.80 \\
\hline Tungus & 82.46 & Tadjik & 84.85 \\
\hline \multirow[t]{2}{*}{ Bashkir } & 82.53 & Georgian & 85.303 \\
\hline & & Buryat & 85.87 \\
\hline \multicolumn{4}{|c|}{ Hyperbrachycephals ( $86.0-$ and upwards) } \\
\hline Telengit & 86.14 & Udine & 86.86 \\
\hline Kara-Kirghiz & 86.17 & Kalmuck (Kuldja) & 86.98 \\
\hline Uzbeg & 86.26 & Kumyk & 87.04 \\
\hline Gilyak & 86.30 & Kirghiz & 87.10 \\
\hline Zyryan & 86.36 & Laze & 87.48 \\
\hline Armenian & $86.46^{2}$ & Lesghin & 87.74 \\
\hline Taranchi & 86.46 & Aissor & 87.89 \\
\hline
\end{tabular}

1.Average for $9 y$ males from Hudson Bay, Greenland, and Coronation Gulf measured by Birket-Smith. According to von Luschan, 87.5 . 


\section{Facial Index}

There is usually some relation between the proportion of the head and the form of the face: a relatively broad head is accompanied by a round face. We know that there are exceptions to this rule. For instance, the Greenland Eskimo head and face is remarkably disharmonic. These Eskimo are very long-headed, yet they resemble the Lapps in extreme width of face. The accompanying table of the available physiognomic facial indices brings out the correlation of the head and facial indices of the tribes reviewed. Unfortunately, the facial indices for many of these tribes were not available. For instance, no where in the literature could we find data on the facial indices of the narrow-headed Turkoman and Dungan.

The Ainu (78.07 facial and 77.03 head index), the Mongolic Tourgout (85.2 and 84.73), the European Gypsies (79.26 and 78.36), the Anterior Asiatic Gypsies (84.23 and 75.20), and the Finnic Ostyak (79.6 and 79.23) have large facial indices. All the other peoples have narrower faces as compared with the width of their heads. The differences between the two indices mentioned ranges from 1 to 12 units. The Mongolic tribes show less difference than the Turkic tribes. Thus, the head indices of the Buryat and Kalmuck are larger than their face indices by 6 and 3 units respectively, while the head indices of the Turkic Kirghiz and Uzbeg are larger than their face indices by 7 and 9 units, respectively. The greatest differences are shown by some of the Asiatic Japhetides and Aryans. The face indices of the Caucasian Lazes and of the Turkestan Tadjik are smaller than their head indices by 11 and 12 units, respectively.

\section{Facial Index}

Leptoprosopic (below 70)

Mesoprosopic (70.01-80.00)

$\begin{array}{llll}\text { Japanese } & 71.35 & \text { Taranchi } & 77.26 \\ \text { Arab } & 72.46 & \text { Uzbeg } & 77.41 \\ \text { Afghan } & 73.19 & \text { Ainu } & 78.07 \\ \text { Tadjik } & 73.33 & \text { Little Russians } & 78.12 \\ \text { Karelian } & 73.68 & \text { Armenian } & 78.31 \\ \text { Persian } & 74.31 & \text { Ingush } & 78.37 \\ \text { Mezleghantzy } & 74.70 & \text { Imeretine } & 78.33 \\ \text { Lithuanian } & 75.16 & \text { Tatar (Kazan) } & 78.64 \\ \text { Kurd } & 75.32 & \text { Votyak } & 78.70 \\ \text { Jew } & 75.50 & \text { Aissor } & 78.73 \\ \text { Vogul } & 75.77 & \text { Luli } & 79.09 \\ \text { Azerbaijan } & 75.88 & \text { Yakut } & 79.25\end{array}$




\section{Facial IxDEx (Continued)}

$\begin{array}{llll}\text { Laze } & 76.14 & \text { Georgian } & 79.43 \\ \text { White Russians } & 76.22 & \text { Kumyk } & 79.47 \\ \text { Pole } & 76.32 & \text { Ostyak } & 79.60 \\ \text { Zyrran } & 76.45 & \text { Ossetine } & 79.63 \\ \text { Khalkas } & 76.50 & \text { Udine } & 79.65 \\ \text { Great Rusians } & 76.73 & \text { Buryat } & 79.72 \\ \text { Tatar (Crimea) } & 76.97 & \text { Kabardine } & 79.79 \\ \text { Basnkir } & 77.50 & \text { Kalmuck } & 79.87 \\ \text { Finn } & 77.15 & & \end{array}$

Chamaeprosopic (80.01 and upwards)

$\begin{array}{llll}\text { Mingrelian } & \text { S0.0s } & \text { Permiak } & 81.00 \\ \text { Telengit } & \text { S0.32 } & \text { Tungus } & 81.26 \\ \text { Kirghiz (Middle Horde) } & 80.43 & \text { Lesghin } & 81.77 \\ \text { Ossetine } & \text { S0.82 } & \text { Gypsies (Anterior Asia) } & 84.23 \\ & & \text { Torgout (Tarlag) } & 85.20\end{array}$

A Comparative Table

Gypsies (Anterior Asia)
Ainu
Azerbaijan
Vogul
Japanese
Gypsies (Europe)
Kurd
Persian
Chinese
Afghan
Finn
Asiatic Eskimo
Luli
Karelian
Mesteheryak
Lithuanians
White Russians
Chukchee
Votyak
Ossetine
Abkhastzy
Tatar (Kazan)
Arab
Pole
Ingush
Little Russians
Chechen

Cephalic Index

72.20
77.3
77.57
77.90
78.15
78.36
78.29
78.72
79.66
80.24
80.67
81.00
81.16
81.19
81.64
81.88
81.87
81.9
81.94
81.95
82.02
82.08
82.10
82.13
82.14
82.31
82.37

\section{Facial Index}

84.23

78.07

75.88

75.77

71.35

79.21

75.32

74.31

73.74

73.19

77.25

79.09

73.66

75.16

76.22

78.70

80.82

7864

72.46

76.32

78.37

78.12 
A Comparative Table (Continued)

Great Russians
Permiak
Mingrelian
Tungus
Bashkir
Jews (Russian)
Kalmuck
Yakut
Imeretine
Kabardine
Tatar (Crimea)
Torgout
Tadjik
Georgians
Buryat
Telengit
Uzbeg
Zyryan
Armenian
Taranchi
Udine
Kumyk
Kirghiz
Laze
Lesghin
Aissor

Cephalic Index

82.39

82.40

82.44

82.46

82.53

82.56

82.57

82.60

83.09

83.73

84.49

84.73

84.85

85.36

85.87

86.14

86.26

86.36

86.46

86.46

86.86

87.04

87.10

87.48

87.74

87.89
Facial Index

78.73

81.00

80.08

81.26

77.80

75.50

79.87

79.25

78.38

79.79

76.97

85.20

73.33

79.43

79.72

80.32

77.41

76.45

78.31

77.26

77.55

79.47

80.43

76.14

81.77

78.73

\section{The Cephalic Module}

While the cephalic index (as well as the height-length and heightwidth head indices) give us a relative idea of the form of the head, the height-length-breadth head index or the cephalic module will give us an idea of absolute size of the head which may be compared with the head sizes of other ethnic groups. Although anthropologists attach little importance to the absolute size of head as a means of establishing intellectual superiority or inferiority, it may be of importance as a racial character.

The following list shows that the cephalic module ranges between 147.3 and 162 .

The Cephalic Module

Hindoo

$$
\left(\frac{\mathrm{L}+\mathrm{B}+\mathrm{H}}{3}\right)
$$

Chinese 
The Cephalic Module (Continued)

\begin{tabular}{|c|c|}
\hline \multicolumn{2}{|l|}{ Kamehadal } \\
\hline Lithuanian & 150.6 \\
\hline Chuvantzy & 150.7 \\
\hline Aleut & 152 \\
\hline Lett & 152 \\
\hline Koryak & 152.7 \\
\hline Asiatic Eskimo & 152.7 \\
\hline Livonian & 152.7 \\
\hline Jews (Russian) & 152.7 \\
\hline Gypsies (Europe) & 153 \\
\hline Lapps (Russian) & 153 \\
\hline Bashkir & 153.3 \\
\hline Chukchee & 154 \\
\hline Georgian & 154 \\
\hline Little Russians & 155 \\
\hline White Russians & 155.3 \\
\hline Aissor & 155.3 \\
\hline Tatar (Kazan) & 155.3 \\
\hline Dungan & 155.3 \\
\hline Kabardine & 155.3 \\
\hline Great Russians & 155.6 \\
\hline Gruzine (Guria) & 155.6 \\
\hline Kumyk & 155.7 \\
\hline Yukaghir & 156 \\
\hline Turkoman & 156 \\
\hline Kalmuck & 156 \\
\hline Sart & 156 \\
\hline Tadjik & 156.3 \\
\hline Japanese & 156.3 \\
\hline Tatar (Altai) & 156.6 \\
\hline Ainu & 156.6 \\
\hline Jews (Mountainous) & 157 \\
\hline Zyryan & 157 \\
\hline Kurd & 157.3 \\
\hline Armenian & 157.3 \\
\hline Persian & 157.6 \\
\hline Eskimo (Labrador) & 158 \\
\hline Little Russians & 158 \\
\hline Chinese (Kuldja) & 158.3 \\
\hline Buryat & 158.3 \\
\hline Udine & 158.3 \\
\hline Tungus & 158.3 \\
\hline Ingush & 158.6 \\
\hline Tate & 158.6 \\
\hline Afghan & 158.6 \\
\hline Jews (Georgians) & 159 \\
\hline
\end{tabular}




\begin{tabular}{lc}
\multicolumn{2}{c}{ The Cephalic Modole (Continued) } \\
Torgout & 159 \\
Mingrelian & 159.3 \\
Kara-Kirghiz & 159.7 \\
Yezide & 159.7 \\
Yakut & 160.3 \\
Ossetine & 160.7 \\
Kirghiz & 161 \\
Ostyak & 161 \\
Samoyed & 161.3 \\
Azerbaijan & 161.5
\end{tabular}

We see from the table of cephalic modules that no definite somatological conclusions can be drawn from the array of these indices. Only such closely related ethnical groups as the Great, White, and Little Russians have similar cephalic modules $(155.6,155.3$, and 155). The Mongolians (Kumyk, Kalmuck, Buryat, and Torgout) have approximately similar cephalic modules $(155.7,156,158.3,159)$. This is not the case with the Finnic, Turkic, and Iranic nations. Of the Iranians, the Kurd and Persians have almost the same cephalic module. The Ostyak have the same cephalic module as the Samoyed.

\section{The Cephalic Module Stature Index}

The cephalic module stature index (cephalic module by 100, divided by the stature) shows the relation of the size of the head to stature. Taking the available data concerning the peoples mentioned in the preceding table we can compile the following list.

$\begin{array}{lccc}\text { Mean } & \begin{array}{c}\text { Mean } \\ \text { Sephalic } \\ \text { Module }\end{array} & \begin{array}{c}\text { Cephalic } \\ \text { Module } \\ \text { Stature Index }\end{array} \\ \text { Chinese } & 1653 & 149.7 & 9.0 \\ \text { Lett } & 1705 & 152 & 9.0 \\ \text { Livonian } & 1736 & 152.7 & 9.0 \\ \text { Hindoo } & 1623 & 147.3 & 9.1 \\ \text { Lithuanian } & 1659 & 159.6 & 9.1 \\ \text { Kabardine } & 1678 & 155.3 & 9.2 \\ \text { Turkoman } & 1696 & 156 & 9.2 \\ \text { Sarts } & 1695 & 156 & 9.2 \\ \text { Tadjik } & 1693 & 156.3 & 9.2 \\ \text { Ingush } & 1713 & 158.6 & 9.2 \\ \text { Tate } & 1701 & 158.6 & 9.2 . \\ \text { Gypsies (Europe) } & 1646 & 153 & 93 \\ \text { Lapp (Russian) } & 1559 & 153 & 9.3 \\ \text { Bashkir } & 1655 & 153.3 & 9.3\end{array}$




\begin{tabular}{|c|c|c|c|}
\hline & $\begin{array}{l}\text { Mean } \\
\text { Stature }\end{array}$ & $\begin{array}{l}\text { Mean } \\
\text { Cephalie } \\
\text { Module }\end{array}$ & $\begin{array}{c}\text { Cephalic } \\
\text { Module } \\
\text { Stature Index }\end{array}$ \\
\hline Little Russian & 1670 & 155 & 9.3 \\
\hline Aissor & 1671 & 155.3 & 9.3 \\
\hline Dungan & 1659 & 155.3 & 9.3 \\
\hline Kamehadal & 1597 & 150 & 9.4 \\
\hline Asiatic Eskimo & 1623 & 152.7 & 9.4 \\
\hline Jew's (Russian) & 1626 & 152.7 & 9.4 \\
\hline Georgian & 1646 & 154 & 9.4 \\
\hline Tatar (Kasan) & 1645 & 155.3 & 9.4 \\
\hline Great Russian & 1657 & 155.6 & 9.4 \\
\hline Gruzine (Guria) & 1646 & 155.6 & 9.4 \\
\hline Kumvk & 1644 & 155.7 & 9.4 \\
\hline Kurd & 1684 & 157.3 & 9.4 \\
\hline Armenian & 1673 & 157.3 & 9.4 \\
\hline Little Russian & 1670 & 158 & 9.4 \\
\hline Chuvantzy & 1581 & 150.7 & 9.5 \\
\hline Chukchee & 1620 & 154 & 9.5 \\
\hline Kalmuek & 1640 & 156 & 9.5 \\
\hline Jews (Gorsky) & 1659 & 157 & 9.5 \\
\hline Kara Kirghiz & 1673 & 159.7 & 9.5 \\
\hline Ossetine & 1692 & 160.7 & 9.5 \\
\hline Azerbaijan & 1684 & 161.5 & 9.5 \\
\hline Aleut & 1584 & 152 & 9.6 \\
\hline Koryak & 1596 & 152.7 & 9.6 \\
\hline Altai Tatar & 1639 & 156.6 & 9.6 \\
\hline Zyryan & 1629 & 157 & 9.6 \\
\hline Idine & 1643 & 158.3 & 9.6 \\
\hline Afghan & 1659 & 158.6 & 9.6 \\
\hline Buryat & 1631 & 158.3 & 9.7 \\
\hline Tungus & 1627 & 158.3 & 9.7 \\
\hline Georgian Jews & 1636 & 159 & 9.7 \\
\hline Torgout & 1636 & 159 & 9.7 \\
\hline Mingrelian & 1647 & 159.3 & 9.7 \\
\hline Yezide & 1633 & 159.7 & 9.7 \\
\hline Japanese & 1578 & 156.3 & 9.8 \\
\hline Kirghiz & 1640 & 161 & 9.8 \\
\hline Ainu & 1567 & 156.6 & 9.9 \\
\hline Yakut & 1617 & 160.3 & 9.9 \\
\hline Yukaghir & 1559 & 156 & 10.0 \\
\hline Labrador Eskimo & 1575 & 158 & 10.0 \\
\hline Ostyak & 1579 & 161 & 10.2 \\
\hline Samoyed & 1550 & 161.3 & 10.4 \\
\hline
\end{tabular}

The cephalic module stature index ranges between 9.0 and 10.4 units. It is difficult to draw conclusions from this index concerning the 
relation between the size of the brain and stature, but the above table may be of some value for future investigators of the subject. It is worth noting that the tallest peoples of the list (Lett, Livonian) show the smallest index (9.0) while the shortest peoples (Ostyak, Samoyed) show the greatest indices (10.2 and 10).

In concluding this chapter on somatology we may point out that all the absolute measurements given refer to males only. There are very few measurements of women and in many cases these are altogether lacking. The relative measurements shown in our tables also refer mostly to men. Yet, in some cases average indices of men and women are available. The indices of both sexes are usually parallel, but we submit what data we have.

\begin{tabular}{llccc} 
& \multicolumn{2}{c}{ Head Index } & \multicolumn{2}{c}{ Facial Index } \\
Mrmenian & Male & Female & Male & Female \\
Ainu & 86.46 & 84.12 & $\ldots \ldots$ & $\ldots \ldots$ \\
Buryat & 77.3 & 78.4 & 78.7 & 79.98 \\
Georgians & 85.87 & 80.7 & $\ldots \ldots$ & $\ldots \ldots$ \\
Kalmuck & 85.36 & 83.56 & $\ldots \ldots$ & $\ldots \ldots$ \\
Kurd & 82.57 & 86.83 & 79.87 & 80.0 \\
Lithuanians & 78.29 & 77.68 & 75.32 & 76.05 \\
Ossetine & 81.88 & 83.47 & 75.16 & 77.68 \\
Soyot & $\ldots \ldots$ & $\ldots \ldots$ & 79.63 & 77.68 \\
Tadjik & 84.42 & 82.57 & $\ldots \ldots$ & $\ldots$. \\
Uzbeg & 84.84 & 82.89 & $\ldots \ldots$ & $\ldots$ \\
Yakut & 86.26 & 81.15 & $\ldots \ldots$ & $\ldots$ \\
\hline
\end{tabular}

We see that in some cases men have larger indices, while in others the reverse may be noticed. 


$$
\begin{aligned}
& \text { central } \\
& \text { c, semi- } \\
& \text {-revolu- } \\
& \text { yratory, } \\
& \text { to draw } \\
& \text { groups, } \\
& \text { I of the } \\
& \text { ) set up } \\
& \text { avel on } \\
& \text { rell as a } \\
& \text { deer, to } \\
& \text { pon the } \\
& \text { dkaghir } \\
& \text { ndra or } \\
& \text { r, even } \\
& \text { he fish- } \\
& \text { undless } \\
& \text { various } \\
& \text { scality, } \\
& \text { Upper } \\
& \text { of the } \\
& \text { re they } \\
& \text { [undra } \\
& \text { ast, of } \\
& \text { ith the } \\
& \text { to the } \\
& \text { ər, the } \\
& \text { gratis } \\
& \text { their } \\
& \text { : place } \\
& \text { e their } \\
& \text { iumed } \\
& \text { rstem. } \\
& \text { I Asia }
\end{aligned}
$$




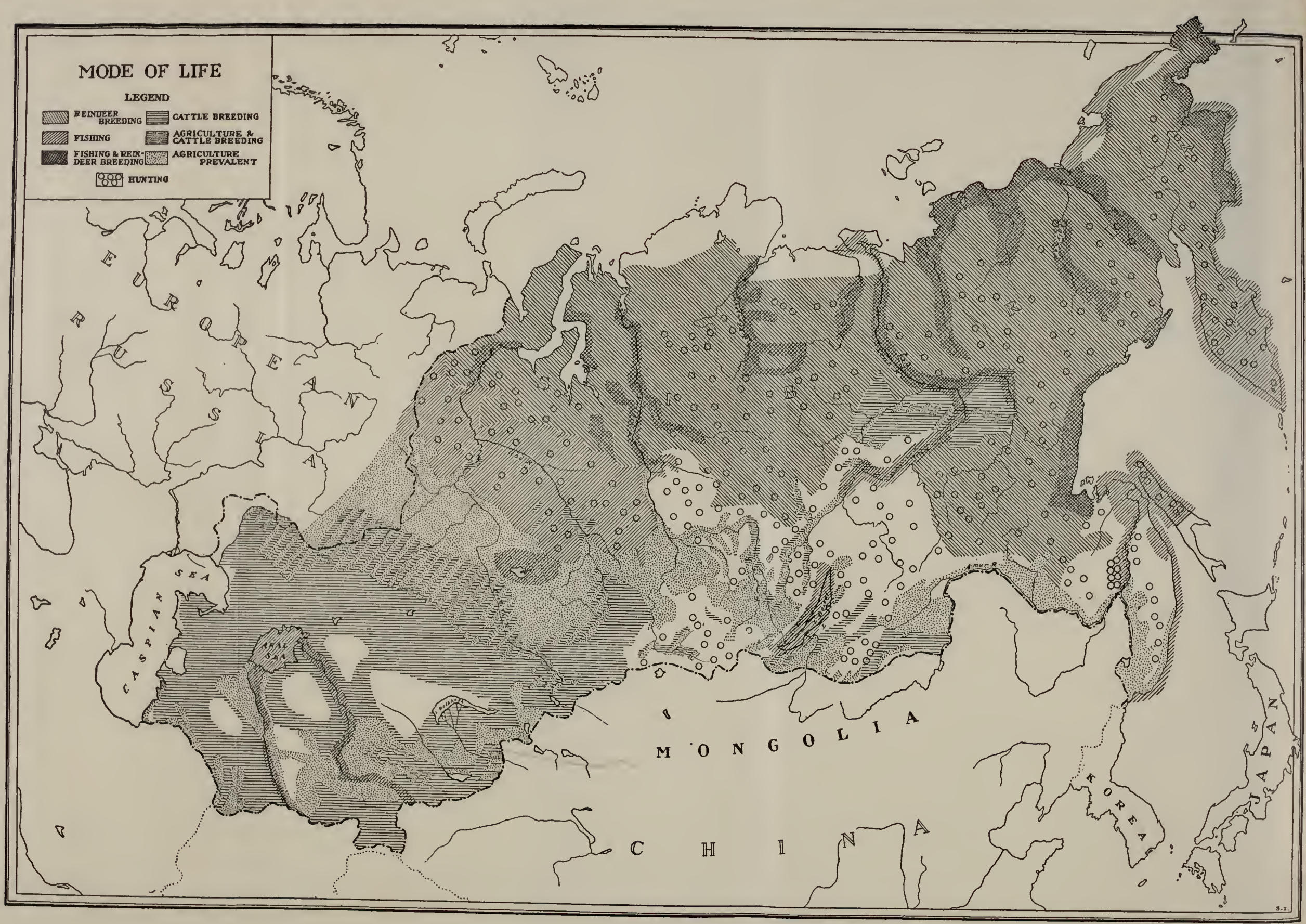




\section{CHAPTER IA}

\section{IIODE OF LIFE}

Russian ethnologists classify the natives of northern and central Asia according to their mode of life, into migratory, nomadic, seminomadic, and sedentary peoples. For taxation purposes, the pre-revolutionary Russian government distinguished three divisions: migratory, nomadic, and sedentary: In both classifications, it is difficult to draw definite boundary lines since each tribe may represent different groups, and each group may migrate or lead a nomadic life in one season of the year and be settled in the other. We will endeavor, however, to set up definitions for these terms.

Migratory people are exclusively hunters, whether they travel on foot, by dog sledges, or mounted upon reindeer. A nonradic as well as a semi-nomadic people may also hunt, and may breed dogs or reindeer, to transport them when on the hunt, but are not wholly dependent upon the hunt for sustenance.

As representative migratory people, we may mention the Yukaghir and some of the Tungus clans who roam over the vast polar tundra or through the immense forest inmediately to the south. However, even these nomads remain near the river banks or lake shores during the fishing season. The hunting groups wander over a vast, but not boundless area. To avert conflicts, which formerly took place between various tribes, the Russian government assigned each group to a certain locality, but this arrangement is not faithfully observed. For instance the Upper Kolyma lukaghir complain that the Tungus reindeer breeders of the Okhotsk region come to their territory and kill the squirrels before they themselves can do it, since they are "walking hunters." The Tundra Yukaghir accuse the Chukchee, who recently came from the east, of driving off the wild reindeer with their domesticated herds. Both the Tungus and the Chukchee contend that since all the land belongs to the State, they may use it as hunting ground or pasture. However, the Chukchee have tried to appease the Yukaghir, giving them meat gratis or presenting them with reindeer for killing.

Nomadic tribes may be defined as those who move with their domesticated herds from one pasture to another. This may take place infrequently or many times a year. The Koryak or Chukchee move their herds of reindeer as soon as the lichens in any pasture are consumed The cattle and horse breeders of the steppes follow the same system. The nomadism of the Mongolic and Turkic peoples of Central Asia 
differs, however, from that of the north, in that the migrations are seasonal.

Tribes who change their abode twice a year are called semi-nomadic. The Yakut and Buryat are typical tribes falling under this category, maintaining permanent dwellings in both their habitats. Fishing people, like the Maritime Koryak, the Kamchadal, and River Ostyak, may also be called semi-nomadic, as they live in settlements in winter and have summer huts on the seacoast or river banks during the fishing season.

Those people or divisions living in permanent villages or cities are called sedentary. These are mostly agriculturists, merchants, and artisans, as the Tadjik, Sarts, Persians, and others.

\section{DwELlings}

Natural shelters, like caverns, overhanging rocks, holes in the ground, hollow tree trunks, etc., are still occasionally used by primitive hunters and travelers. These shelters undoubtedly served as a model for the first man-made habitation. The ideal dwelling should protect its inhabitants from wet ground, rain, snow, cold, sun, and other inclemencies of the weather, but not every type of dwelling fills all these requirements. The full history of the development of house types has not yet been recovered. We will here review the numerous types of dwelling as they now exist in northwestern Asia, their use, and dependency upon climatic and topographic conditions, mode of life, and stage of culture.

These dwellings may be distinguished according to their outer form, material, and method of construction. According to form, dwellings may be classified as follows:-

1. Shades and screens.

2. Conical.

3. Cylindro-conical.

4. Cylindro-dome or cupola- shaped.

5. Pyramidal.

6. Truncated pyramidal.

7. Flat-roofed, square.

8. Flat-roofed, rectangular.

9. Flat-roofed, polygonal.

10. Sloping-roofed, square.

11. Sloping-roofed, rectangular.

12. Sloping-roofed, polygonal.

13. Underground or half underground.

14. Pile dwelling.

15. Tents on boats. 


\section{MATERIAL AND CONSTIRUTION}

Dwellings are built of the following: snow, rods, poles, wattle, logs, hide, leather, birchbark, thatch, earth, sod, clay, stone, and brick. The type of construction depends on the form and building material. All the morable dwellings are set up by women, while the fixed habitations are built by men.

Shades and screens. This primitive type of temporary abode is used by Siberian hunters and fishermen when moving about unaccompanied by women. In winter, sticks or rods are set up in the ground or in the snow in a sloping position against the wind and two or three reindeer skins sewn together are tied to the sticks. The people place themselves under the slope of the screen and build a fire in front. In winter the outer side of the hide shelter is banked with snow. When a skin cover is not available a snow wall is built, with or without a thatch of twigs. Yakut drivers with whom the author traveled over sparsely populated places used to erect such shelters as sleeping places. When sleeping in such a shelter the Siberian natives lie with their feet toward the shade and head toward the fireplace. the fire being kept up during the night.

Conical Tents. The conical tent of circular groundplan is the simplest kind of temporary dwelling. It is used, in the main, by hunting and fshing, nomadic, or semi-nomadic tribes. It consists of a framework of rods, the upper ends of which are bound together by a bast rope, thong, or a willow ring, while the lower ends are set up in a regular circle in the earth or snow. In northern Siberia, the frame is covered with soft tanned reindeer skins. The cover consists of three separate strips of skin fastened to the rods by leather straps. The apex of the tent frame is left uncovered and serves as a vent for the smoke. Through the same hole the sunlight may penetrate. The hide cover is also not wholly impermeable to the daylight.

The size of the tent depends on the number of its occupants. Inside, in the center of the floor, is a fireplace encircled with stones. Over the fireplace is set up a wooden tripod with hooks for hanging kettles and teapots. Under the slope of the conical tent, all around the wall, are seats made of soft willow twigs covered with reindeer skins. These serve also as sleeping places and for grown-up girls and married couples, sleeping tents in the form of rectangular boxes placed upside down are hung over the sleeping places. The sleeping tents are sewn of dressed reindeer skin or of some cotton material. Unmarried men, boys, small girls, and old people have no sleeping tents. The lower strip of the tent cover docs not cover the entire frame and an entrance is left between two poles. 


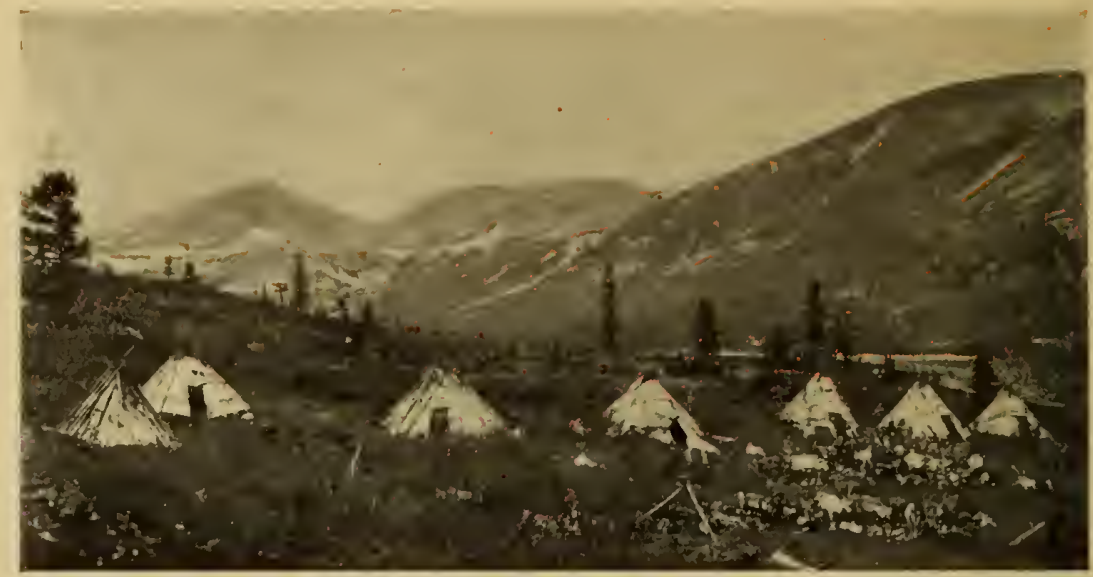

Fig. 32. Birchbark Tents of the Soyot.

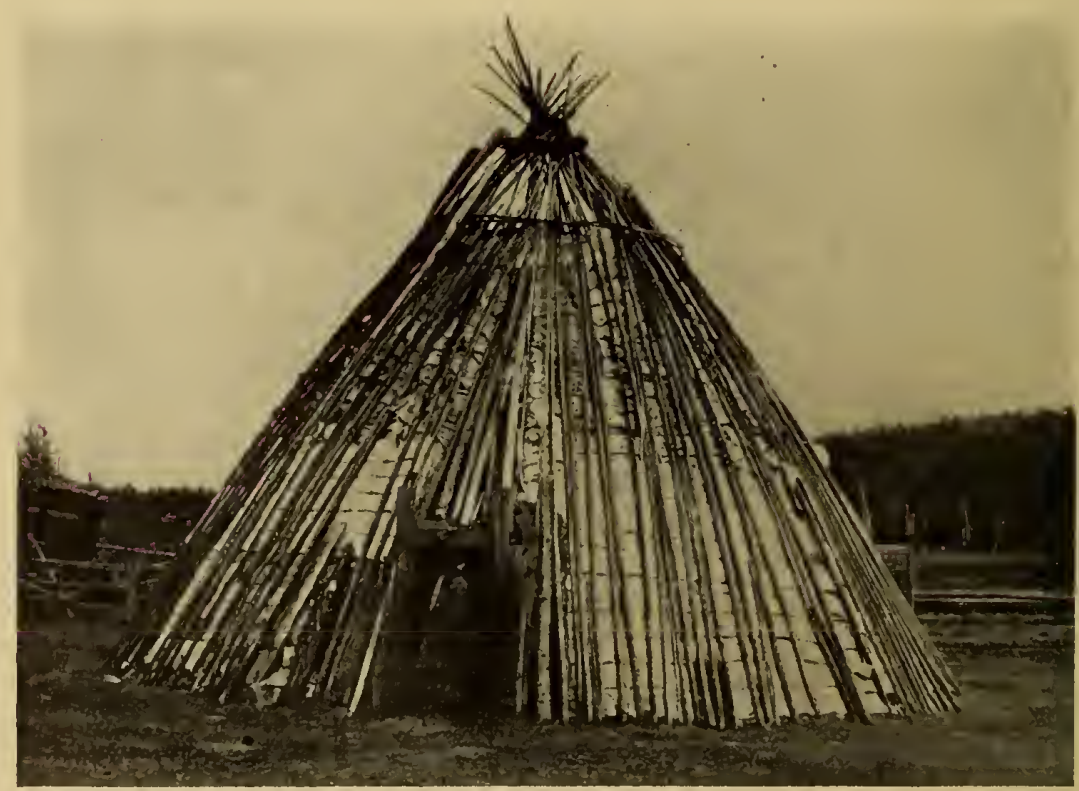

Fig. 33. Summer Dwelling of the Ancient Yakut. These were large conical tents, covered with birchbark, often elaborately decorated, but now seldom seen. 
This is covered by a flap of reindeer skin which serves as a door. Honored guests do not raise the entrance flap for themselves. This is done for them by boys or girls. The same mark of respect is given to old people.

It is the woman's duty to care for the tent. She sews the skins for the tent cover, sets up the frame, covers it, and arranges the fireplace and sleeping places. When the family moves, as to another hunting or fishing place, the women take down the tent, and load it on the sledge or in a boat.

In southern Siberia and in the Amur River region, the conical tent is covered with birchbark. To prepare the tent cover, strips of birchbark are first softened by boiling and then sewn together.

The conical tent witl a skin cover is distributed anong the following tribes: the Kolyma Yukaghir, the northern Tungus, the Ostyak, Samoved, and Lapps. The conical tent with a birchbark cover is used by the Amur River Tungus, the reindeer-breeding Soyot and Karagas, and the southern Ostyak.

The writcr met poor Yakut at the mouths of the Yana and Lena rivers who lived in conical dwellings, the frames of which were covered with earth and sod. But this should be regarded as a seasonal dwelling, since it was used only during the summer fishing season.

As a summer drelling, the ancient Yakut used a conical tent covered with birchbark. It differs from other types of tents in its size and heavy and solid construction of the wooden frame so that it cannot be easily transported. These large tent-like dwellings were located far from the winter earthen huts of the Yakut and were occupied during the summer in order that their horses and cattle might not injure the meadows on which hay is made for the winter and near which the winter dwellings are situated.

The fireplace in a Yakut birchbark tent is a large wooden bottomless box filled with beaten clay. The tent was ornamented with engravings, wood and birchbark carvings, sinew thread and horsehair embroidery and with slivers of colored mica and pieces of bright cloth. This type of dwelling is no longer in use, though twenty-five years ago it was occasionally observed. A complete tent, such as is described above, was brought to the museum by the author. At present, the Yakut build log houses instead of tents for the suinmer.

The following types of conical tents also deserve mention. The Altai Tatar, living in the forest, cover their conical tents with the bark of pines and larches, but in open country they use felt covers. Some of these dwellings have the entrance framed in wood and a door of boards. 


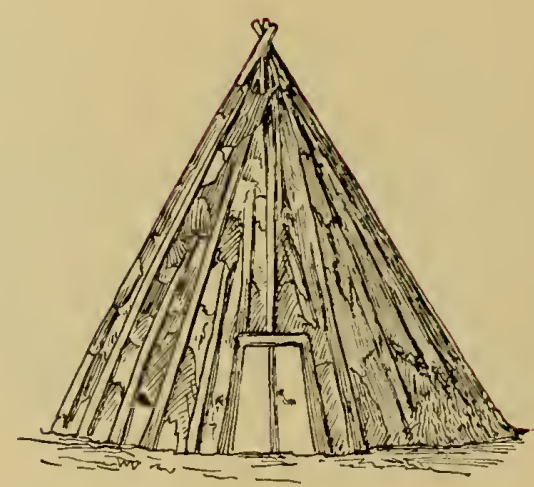

Fig. 34. Conical Tent of the Forest Altai Tatar. The cover is of bark from the larch tree; the entrance is framed in wood and the door is of boards. The outer poles keep the bark cover in place.

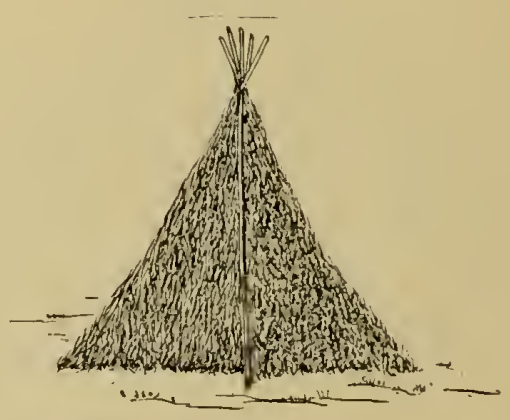

Fig. 35. A Sod and Grass-Covered Conical Tent of the Yakut from the Mouth of the Yana River. Some of the Altai Tatar also cover their conical tents with reeds. 


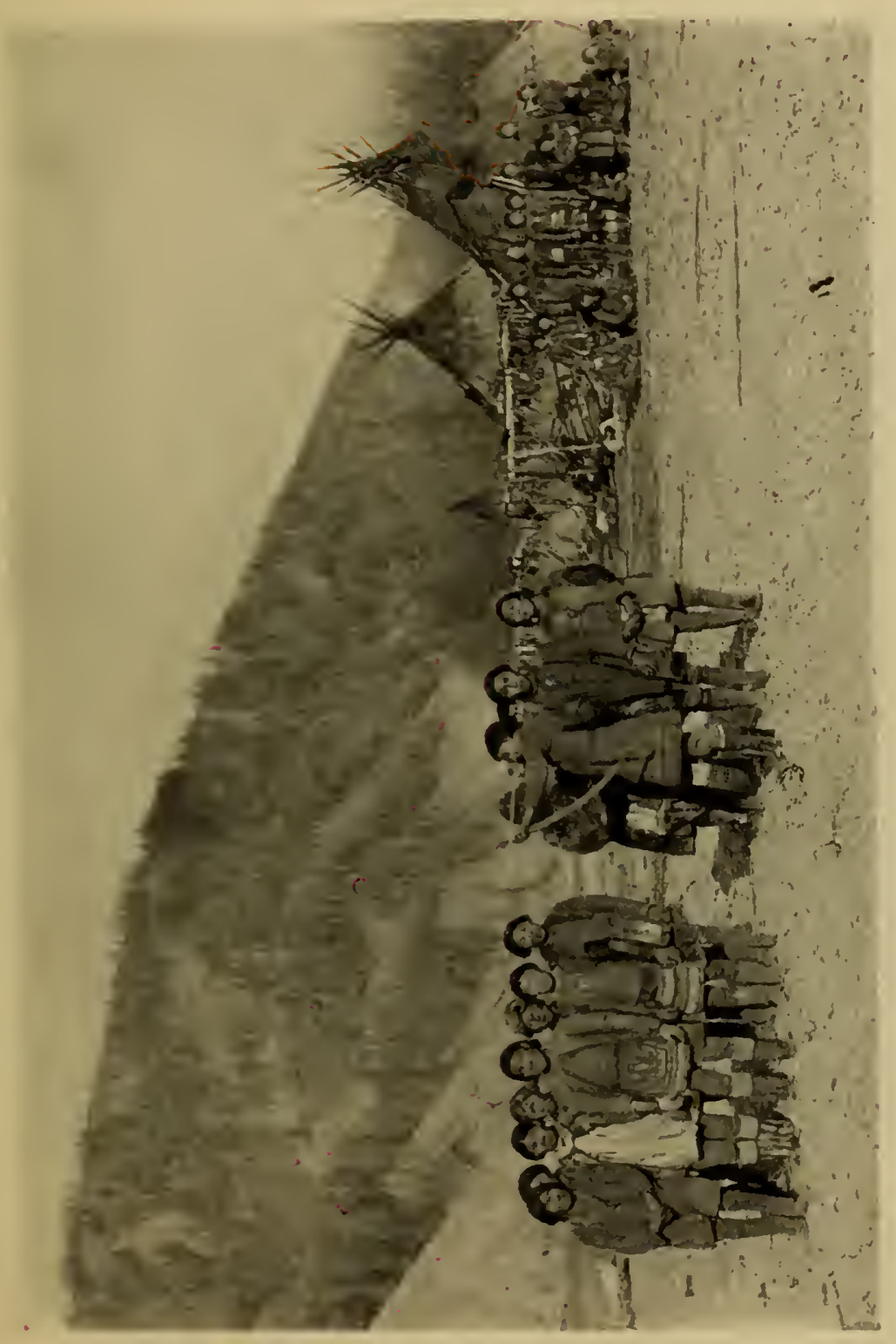

อ

.

.$\Xi \stackrel{\infty}{\Xi}$

ए

है क्ष

車

○

ฮี อ

일

(1)

$\stackrel{\Xi}{\Xi}$

동

ช્ฮ

需

\&

ธ. ज్

\%

$\stackrel{80}{=}$

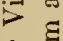

ष्]

छ

के 2

릉용

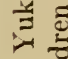

$<$ :

ल)

क्ष 


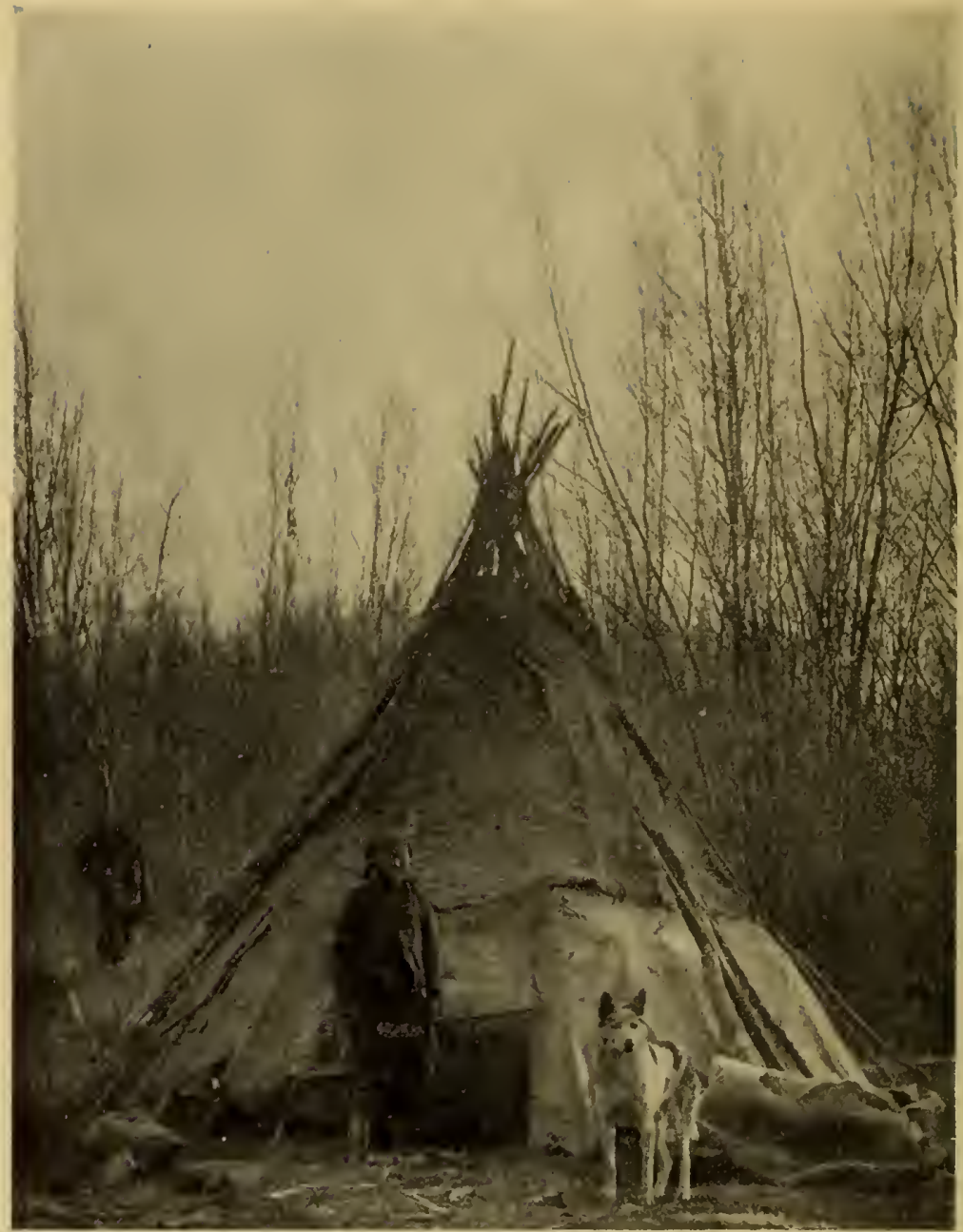

Fig. 37. Conical Summer Tent of the Upper Kolyma Yukaghir. The cover consists of three separate strips of soft tanned reindeer skin fastened to the frame. 
In winter, the bark as well as the felt conical tent, is banked with earth and snow to half its height. The length of the tent poles is from 6 to 8 meters. The Altai Tatars cover their tents with birchbark. In some districts the Altai Tatars as well as the Teleut use tent covers of mats made from the bark of the acacia (Robinia Carganata L.) or of reed grasses.

According to Khangaloff, ${ }^{1}$ the northern Buryat formerly used to cover their conical tents with skins in winter and with pine branches in summer. At present they do not use the conical tent. The Selenga Buryat, according to Erman, ${ }^{2}$ used conical tents covered with double sheets of felt.

The Bashkir of Ufa Province still use conical tents with a framework of rods plastered with dung and covered with straw.

The Mongols of northern Mongolia, according to Potanin ${ }^{3}$ use feltcovered conical tents. Shitetzky also reports that the Mongolic Kalmuck of Astrakhan use such tents. The Kirghiz also continue the use of the conical felt-covered tent as a temporary dwelling.

The construction of the pole framework of these tents falls into the following types:-

1. The upper ends of the poles are tied by a thong or cord.

2. The poles are held by a ring of plaited willows.

3. The upper ends of the poles are held in the holes of a wooden hoop.

4. Several willow rings are tied to the poles at certain distances. In forested areas the framework is of heavier poles and it is usually abandoned to aroicl its transportation when moving. In the open steppes the frame consists of light poles and is always transported, together with the cover, when moving.

The conical tent may be regarded as a primitive typc of dwelling associated with the hunting stage of culture. However, it is retained, chiefly as a summer dwelling, by many nomadic or semi-nomadic herders and even by some sedentary agricultural tribes.

Cylindro-Conical Tents. This type of tent consists of a frame of poles and a skin cover, but it is constructed in two parts, a lower, cylindrical, and an upper, conical one. The cylindro-conical tent may be regardecl as a natural development from the conical one, and accordingly it constitutes a higher type of dwelling. We do not know exactly how the process of transition from the conical to the cylindro-conical tent was effected, but we may assume that a casually bent rod may have suggested

'Khangaloff.

Erman.

'Potanin, (b). 


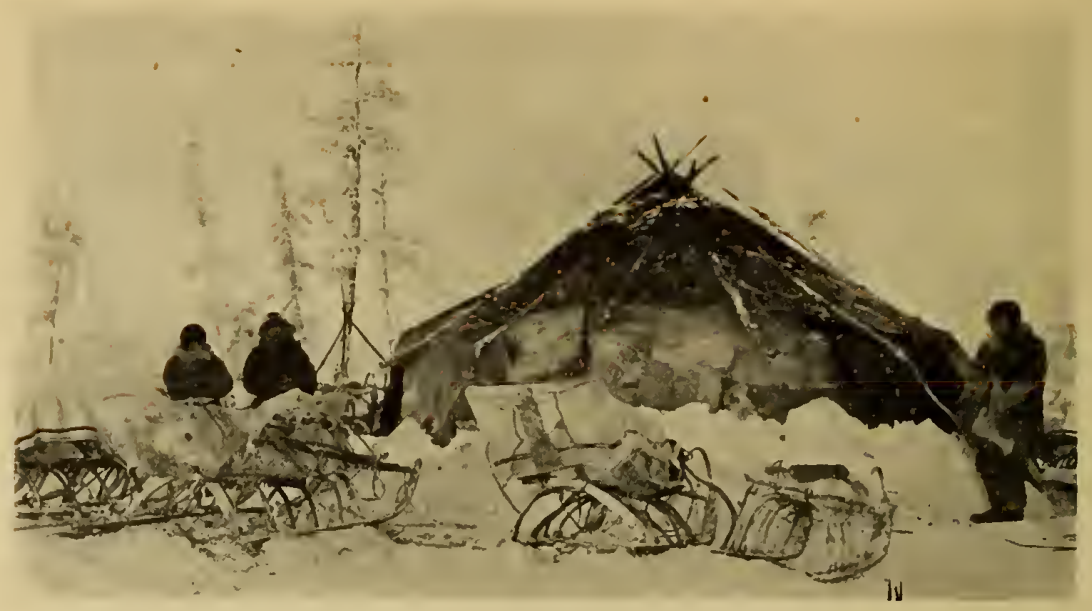

Fig. 38. A Cylindro-Conical Tent of the Tundra Yukaghir. It is eovered with reindeer skins; in the winter, with the hair on; in summer, without the hair. In winter the lower part of the tent is banked with snow for warmth. The photograph is from the rear, where covered freight sledges serve as storage places for clothing and household belongings.

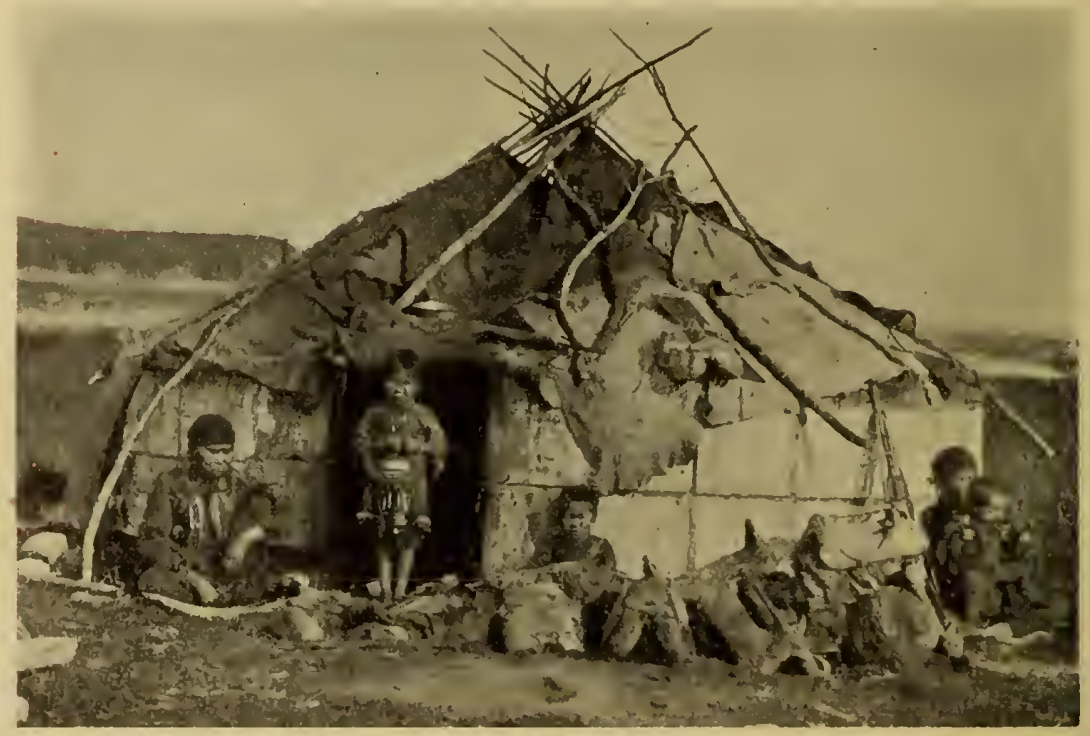

Fig. 39. A Cylindro-Conieal Tent of the Okhotsk Tungus. The upper, eonical portion, is covered with reindeer skins; the lower, cylindrical section, is of reetangular shects of birchbark sewed together with thongs. 
the idea of allowing the lower part of the poles to remain vertical and the upper part to slope toward the center of the tent. The cylindrical part

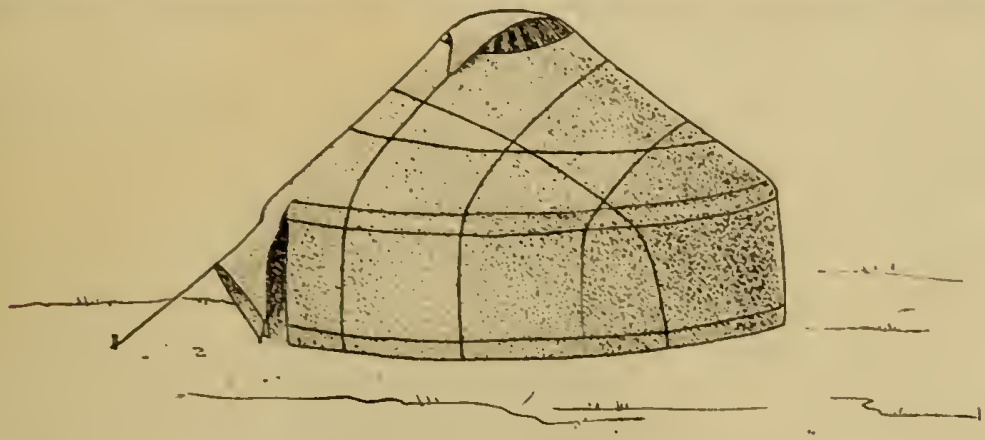

- Fig. 40. A Felt-Corered Cỵlindro-Conical Tent used chiefy by Mongoloid Tribes and usually known as the Kalnuck Tent. This type is used by the Kalmuck, Buryat, and other Mongoloid tribes.

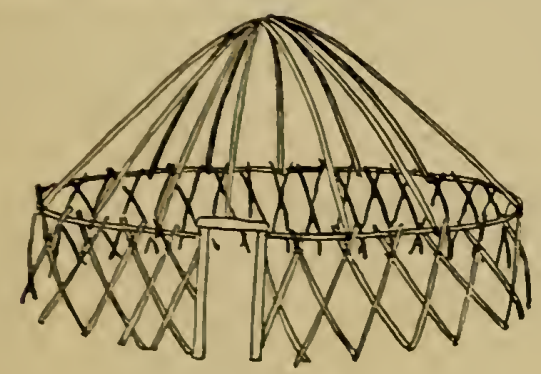

C

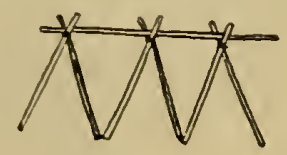

万

Fig. 41. Framework for a Felt Tent. $a$, The upper part consists of straight or bent rods; $b$. A variation in the side frame.

is about one meter high, the top of the tent in the center is from 3.5 to 8 meters high. The framework of the lower part is composed of short light stakes, tied in pairs with cross bars to form a wide circle. The conical. upper part consists of poles, the lower ends of which are tied to the cross bars of the cylindrical section. Thongs hold the upper ends of the slanting poles together and they are supported in turn by a high tripod of heavier poles, the lower ends of which are dug into the ground on three sides of the fireplace.

This form of dwelling is in use all over Siberia and partly among the nomads of northern Europe. The framework is usually covered with reindeer skins dressed without the hair. Though the compound tents of 
the Chukchee and Koryak are similar in plan, their lower sections are heavier, clumsier, and less regular in shape than other similar tents. Furthermore, in winter, the Chukchee and Koryak cover their tents with heavy reindeer skins with the hair on.

In the district of Okhotsk and in the Amur River region, the Tungus cover the lower, cylindrical parts with rectangular pieces of birchbark sewed together with thongs.

The interior arrangement of the compound tent is the same as for the conical form. The compound tent cliffers, however, from the conical in being larger and higher, that is, high enough for a person to stand erect not only in the center of the dwelling, but in other places as well.

Felt-Covered Tents. The felt-covered tents are of two shapes-a cylindro-conical, like the skin tents described above, and a cylindrodome-shaped. The first is called the Kalmuck type, and the second, the Kirghiz type, because the former is used by the Kalmuck and the latter by the Kirghiz. But as most Mongolian tribes use the cylindroconical tent and the Turkic tribes use the cylindro-dome-shaped, they may be designated as Mongolian and Turkic types. . The difference is mainly in the shape of the upper framework. In the Mongolian type the rods are straight, while in the Turkic type they are curved.

We have previously assumed that the cylindro-conical tent was derived from the conical form, but we cannot state that the cylindrodome form was in turn evolved from the cylindro-conical. We believe, however, that the dome form is a further development from the cylindroconical.

Cylindro-Coniral Felt Tents. This form of tent is in use among the Mongol tribes, the Kalmuck, Northern and Transbaikalia Buryat, and the Mongols proper. However, some of the Turkic tribes also use the cylindro-conical tent, namely, the Bukei-Kirghiz, Altai-Tatar, KachinTatar, Kara-Nogai, and Sarts of northwestern Mongolia.

Cylindro-Dome or Cupola-Shaped Felt Tents. This form of tent is used by the following Turkic tribes: the Kirghiz, (both branches), Kara-Kalpak, Kipchak, Uzbeg, Turkoman, Nogais, and the Bashkir.

The cylindrical portions of both types of felt tent are of light wattle, fastened together, in a circle, with cords of horse, bull, or camel hair. The upper poles, either straight or curved, are tied at their lower ends to the upper wattle slats while the upper ends are fastened in the holes of a large wooden ring. The whole frame is fastened all around with thongs or cords and covered with wide strips of felt attached to the frame and held down on the outside with cords. The wooden ring serves as a vent 
and is covered by a piece of felt when there is no fire. The wooden door at the side of the cylindrical section is sometimes two-paneled and is covered with a reed mat or a felt rug. The floor is covered with felt rugs

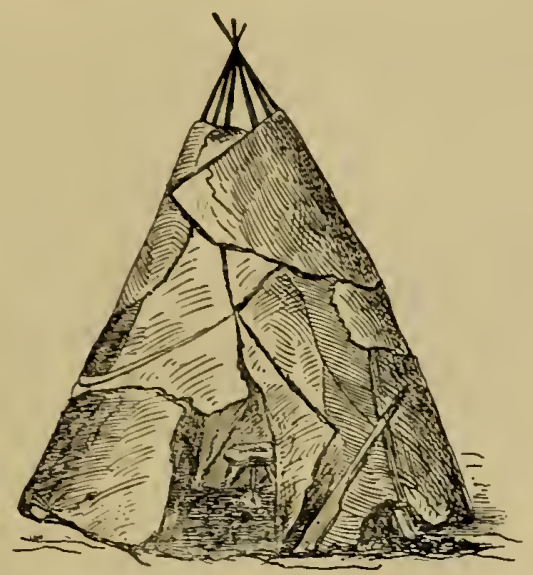

Fig. 42. A Felt-Covered Conical Tent of the Northern Mongols. The Kalmuck of Astrakhan and the Kirghiz use it as a temporary dwelling.

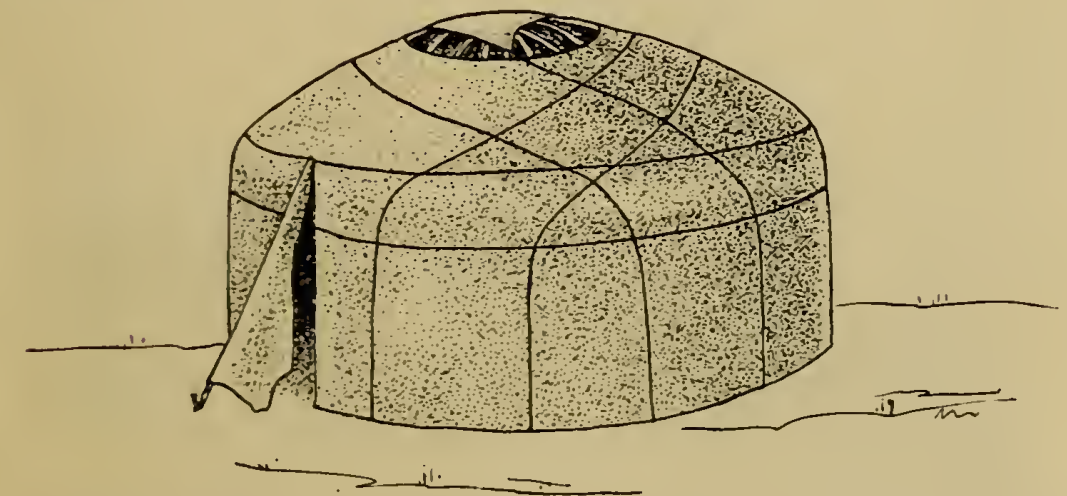

Fig. 43. A Cylindro-Dome-Shaped Felt Tent used by Turkic Tribes and called a Kirghiz or Turkic Tent.

and, among rich people, with tapestry carpets. The interior arrangement of the tent has been previously described. It is set up by the women, but the men assist, holding the heavy wooden ring while the women attach the upper poles. For the winter, the felt cover is usually doubled, nevertheless it is not a warm dwelling for the steppes, where it originated. 


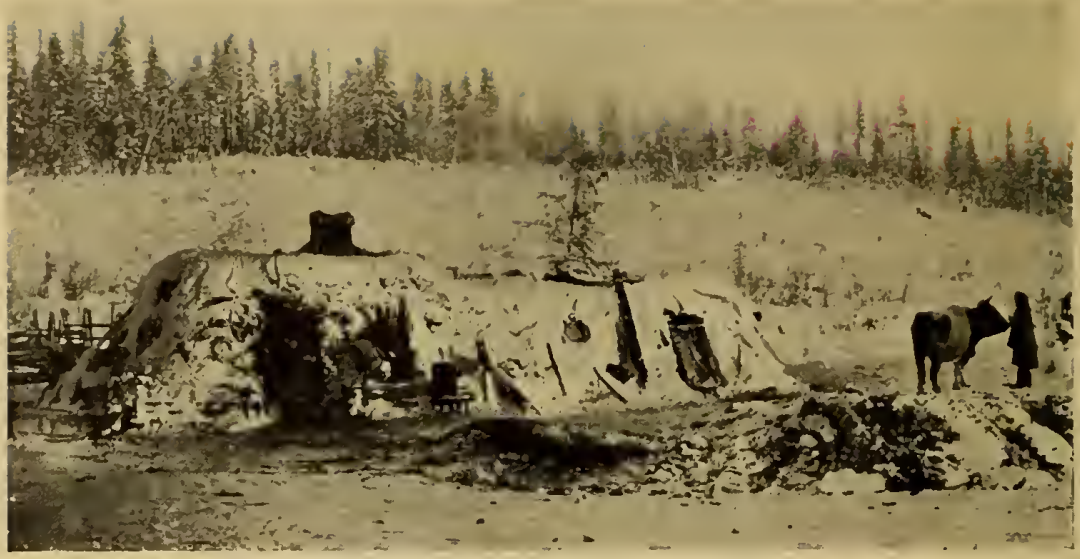

Fig. 44. A Yakut Dwelling. A double structure is shown, a dwelling with chimney, and a cattle stable, adjoining. Inside the dwelling a door leads to the stable. New-born calves are kept in the dwelling behind the chimney.

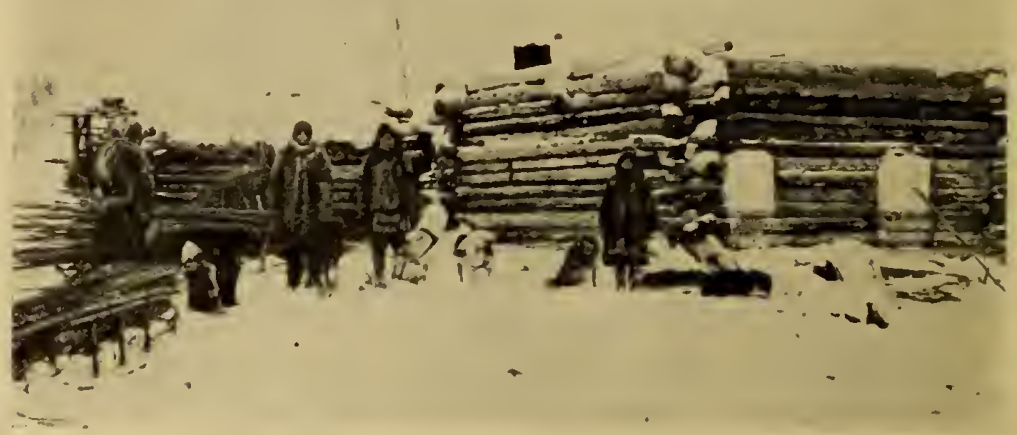

Fig. 45. A Flat-Roofed Blockhouse of the Upper Kolyma Yukaghir which serves as a Winter Dwelling. The windows are covered with thick panes of river ice. 
Pyramidal Dwellings. Dwellings of pyramid al form are found only among some of the northern Yakut, who set up a four-poled frame and cover it with sod, leaving the top of the pyramid open as a vent hole.

Truncated Pyramidal Duelling. This form of dwelling is in use among the lakut and Yakutized Tungus. We may assume that it was invented by the Yakut after their arrival in their present territory from a more southerly habitat. Indeed the present Yakut house is far more fitted to the harsh sub-polar or polar climate than all the types of tents described above.

The Yakut house is built as follows: Four posts, driven into the ground, are joined by four cross-beams, on which rest the upper ends of poles or roughly hewn boards, set up in slanting position. The cross beams are covered with branches, poles, or boards, over which bark is spread, thus forming the ceiling and roof. Then the roof and sloping walls are covered with mud, earth, and clay mixed with cow dung. In winter, a laver of snow is added.

The floor, generally of beaten mud, is sunk two or three feet below the ground; rich people, however, have it level with the ground and covered with boards. A few small squared openings, admitting scant light, are covered by sheets of ice in winter, and, in summer, with fish membrane, mica, oiled paper, or dense horsehair nets, which ventilate the dwelling and shut out mosquitoes. Around the walls are partitioned off wide permanent benches which serve as seats in the daytime and as sleeping places at night.

The bench opposite the door, usually on the southern wall, is reserved for honored guests. The right side is occupied by the master of the house, his children, and married sons; the left by grown girls. Less honored guests occupy the lower ends of the right and left sides, nearest the door. The sleeping places of married people and grown girls are set off with a curtain. The slanting board door is covered by cow or horseskins. In the corner, to the right of the entrance, but not close to the walls, is a kind of open hearth, made of beaten clay in a wooden box, from which a chimney made of poles tied together with willow rings and coated inside with a layer of clay rises to the roof. A fire burns constantly on the hearth, but during the night the temperature drops very low despite the fact that the chimney hole is covered with a piece of skin. There is usually a shed over the entrance which faces the east. Some Yakut dwellings have an elongated form and they are divided by an inside wall of thin boards, to form a living room and a stall for cows, with a communicating door. The cows 


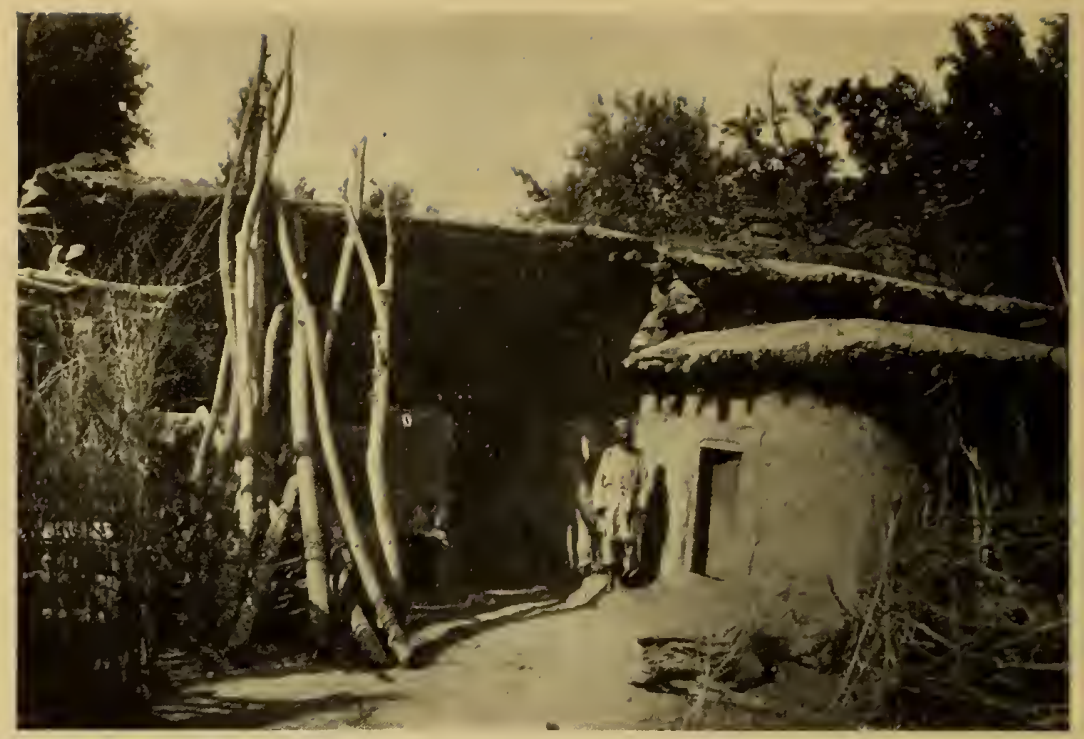

Fig. 46. Inner Court of a Tadjik Dwelling, Eastern Rokharn. The house is a flat-roofed structure made of mud and clay.

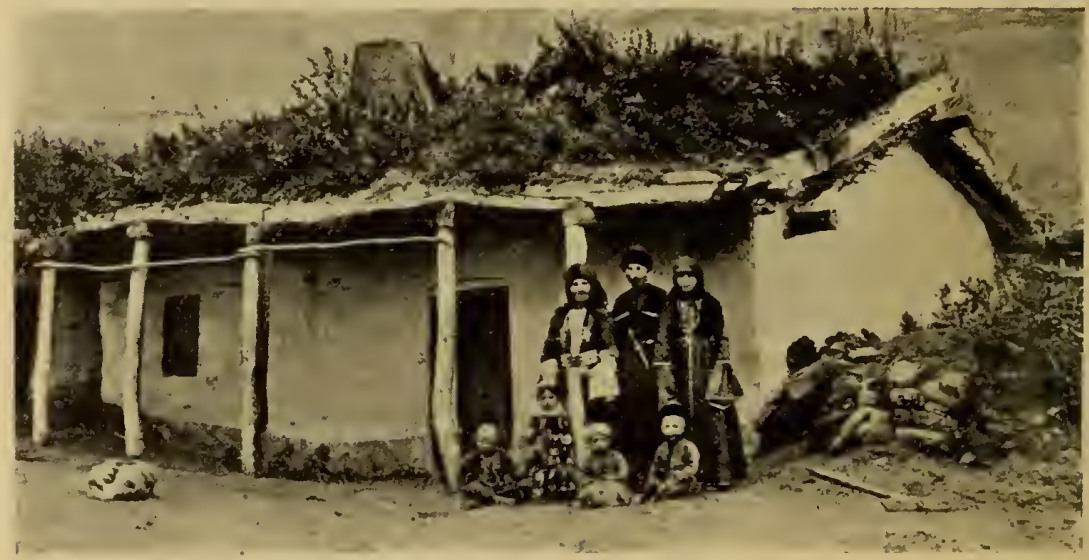

Fig. 47. A Karachai House. The Karachai, a Cis-Caucasian Turkic tribe live on the upper course of the Kuban River. The dwelling is made of clay-covered willows. 
enter and leave their stalls through the living room where newborn calves are kept behind the hearth. Rich people, however, build separate stalls, called khoton, with a separate hearth for their cattle.

This truncated pyramidal dwelling of the Yakut is a typical winter dwelling for a semi-nomadic life. Their summer dwelling is the large conical birchbark tent, described above (p. 190). At present, most Yakut have two earth huts, one for the winter, the other for the summer, but when living near cities or Russian settlements they have abandoned their old type of dwelling and live in $\log$ houses.

Flat-Roofed Block Houses. The further evolution of the material culture of the cattle-breeding tribes of Siberia and Central Asia led them to substitute log houses of the type used by Russians for their tent-like dwellings. These log houses may be square, rectangular, or polygonal. The flat roof has a foundation of rods overlaid by grass, bark, earth, clay, and sod. This type of dwelling is found among the Bashkir, Kirghiz, Buryat, Dolgan, Yakut, and many other Siberian Turkic tribes. The polygonal house of the Altai Tatars may be regarded as an imitation of the cylindrical skin tent. The block house usually served as a winter dwelling, while the tent remains a summer dwelling; but in some districts the cattle breeders have two wooden houses in different places.

Pent-Roofed Duellings. The author has never seen pent-roofed log houses in use among the Siberian natives. Neither are they mentioned by other investigators. However, the late Yadrintzev, in his book on the Altaian natives mentions a log house with a sloping roof.

Sloping-Roofed Block Houses. The block house is the highest type of dwelling of the Asiatic natives who have partly or entirely abandoned their nomadic life. Tent-like dwellings are usually used in the summer, but for those who have become agriculturists the block house is a permanent dwelling. The sloping-roofed block house may be square, rectangular, or polygonal in form. The latter is in some respects a reminder of the cylindro-conical tent from which it was probably derived.

The richer and more civilized Siberian and Central Asiatic natives now live in wooden houses. The polygonal sloping-roofed block house of the Altaians was described by Radloff ${ }^{1}$ and Yadrintzev. ${ }^{2}$ Like tents they have no windows. We have observed such block houses on the Kolyma River, used by the local Yakut and Russian settlers as storehouses and summer dwellings during the fishing season. 
Underground Dwellings or Earth Huts. Although underground dwellings are usually characteristic of a lower stage of culture, we are describing them after the block houses, since we wish to show the transitional culture processes from the lower to higher forms of habitations, beginning with the conical tent. It can be demonstrated, for example, that the underground dwellings found in different latitudes have evolved into superterrene habitations, and into $\log$ houses.

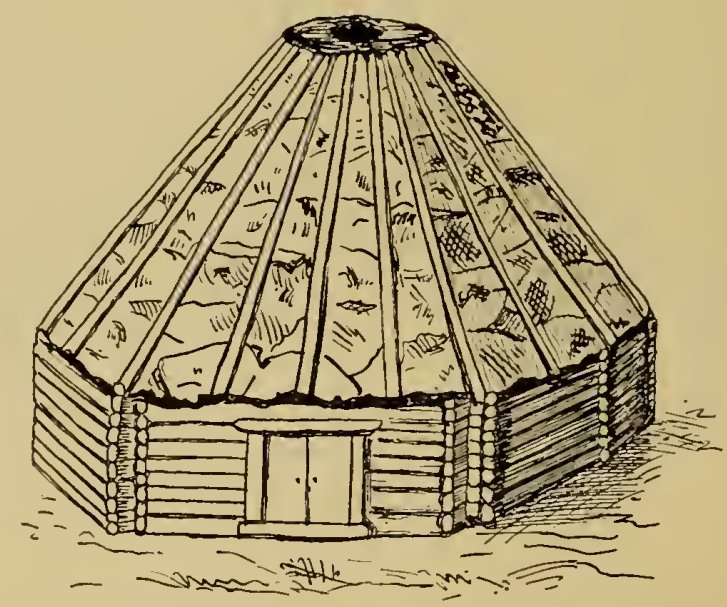

Fig. 48. A Polygonal Altaian Sloping-Roofed Blockhouse. The author saw such blockhouses among the Yakut fishermen of the Upper Kolyma River. They resemble in form the cylindro-conical tents.

The designation "subterranean" is not always correct, for few of this type are entirely underground; others are situated under the ground to a greater or less degree (about a half or less), while their superterrene portion is covered with earth taken from the pit in which the dwelling is placed. Therefore, all these dwellings should perhaps be considered under the general name, earth huts.

The earth hut is built to protect its inhabitants from climatic extremes, against frosts or heat, and therefore it is found in the north as well as in the south, though it occurs more frequently in the polar region. Ireland.

For instance, the remains of ancient subterranean dwellings that have been found in Scotland and 
The following are the general characteristics of the earth hut.

1. The round, rectangular, or irregular pit is dug in the ground to a depth of from three to six feet. It is generally dug at some altitude, to allow adequate drainage.

2. The timber walls are set in the pit vertically. They form a rectangle, or an irregular octagon, about half or a third of them above ground.

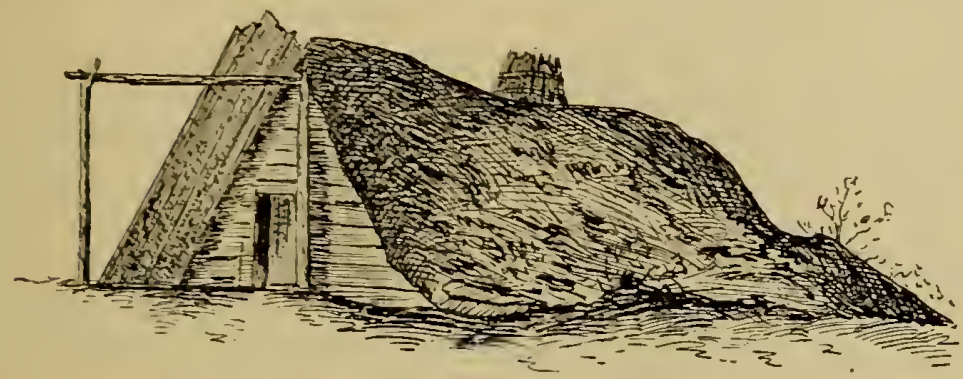

Fig. 49. An Earth-Covered Blockhouse of the Altai-Tatar Kumandintzy, Biisk District of Tomsk Province.

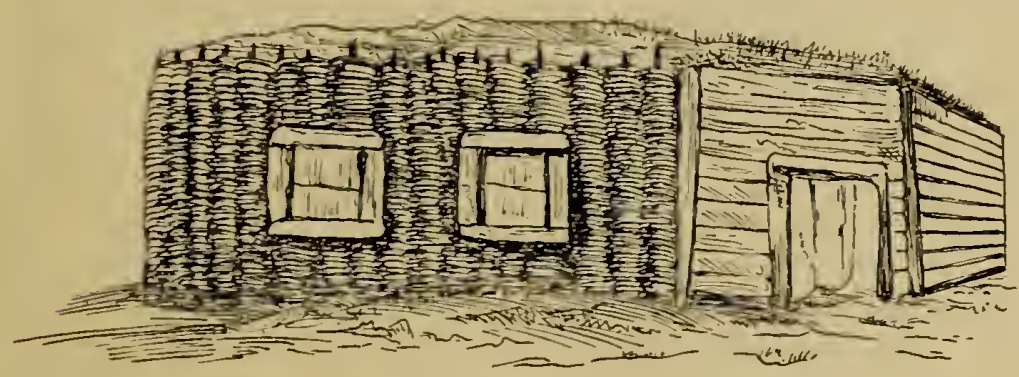

Fig. 50. A Teleut (or Telengit) Dwelling. This has a flat roof of clay and reeds and sides of plaited willow branches covered with clay outside and inside. The Teleut live in the Tomsk, Kusnetzk, and Biisk districts of Tomsk Province.

3. The flat roof is supported by four or more pillars, and slopes from these to the outer walls.

4. A square aperture in the roof serves as an outlet for the smoke, as a window, and a door. For entering and leaving the house a notched $\log$ ladder is placed within the opening.

There are many deviations from these general characteristics. It should be added, however, that some forms of the earth hut have not yet been sufficiently studied. 
In Europe, the earth hut was known to the Scythians, ancient Germans, and the Swiss. In southern Bavaria it was round, with a kettle-like widening at the bottom, from eleven to fifteen meters in diameter, and from two to four meters in depth. In the winter, the Slavs, Finns, and Laplanders lived in earth huts. They were also used in the last century by Hungarian gypsies, who dug holes in the ground ten or twelve feet deep for their winter huts. Their roofs were of rafters covered with straw and sod.

In Asia, Armenia may be mentioned first of all. According to Xenophontes, the pit of the Armenian earth huts was wide at the bottom and the huts were entered by a stairway. The Phrygians overlaid their stone dwellings with earth. The Ostyak earth hut, which has now almost disappeared, was built in a quadrangular pit lined with wood. The roof was of poles covered with turf and earth. It had no windows. An opening in the roof served to let in the light and allowed the smoke from the hearth to escape. The hut was entered through a side door from which steps led down into it. The earth hut of the present Ainu is also entered by a lateral door. Whether the earth huts of the ancient Ainu, numerous remains of which have been found on the Islands of Yezo and Sakhalin, were entered through a lateral door or through the roof cannot be ascertained. The earth hut of the modern Gilyak, who have not yet acquired the superterrene Manchurian structure, is entered through a narrow sloping passageway to the lateral door. Sternberg surmises that in ancient times the smoke hole of the Gilyak earth hut also served as an entrance, as with the Kamchadal.

The Kamchadal are now Russianized and no longer live in earth huts in winter, but have replaced these with Russian block houses. In summer they lived in pile dwellings. The smoke hole of their ancient earth hut served also as a window and a door.

Among the Maritime Koryak the earth hut is still in use. As among the Gilyak it has a sloping passage leading to the lateral door of the house, but this is only open in the summer. For the winter, the lateral passage is fenced with logs, grass, earth, and snow and only the smoke hole is used as an entrance. One peculiarity of the Koryak earth hut is presented by its storm roof which resembles an inverted umbrella in shape and protects the smoke hole entrance from the wind, and the house itself against snowdrifts.

The Chukchee, even the Maritime branch, now live in reindeer skin tents, but the ancient Maritime Chukchee lived in earth huts. According to Bogoras's description, the Maritime Chukchee earth hut, called walkar 
(jawbone housc), also had two entrances, but, contrary to the Koryak house, the upper entrance at the top of the wall was reserved for the summer, while in winter they used a narrow underground passage which, in summer, was filled with water. The floor of the inner room being on a higher level than that of the underground passage, the water could do no damage. The walkar had a whalebone frame, heary pieces of bone were set upright in the ground, at intervals, and were held in place by earth and stones. Large pieces of jawbone or of whales' ribs were superposed as rafters.

The Yukaghir, as reported by the first Russian invaders of the country, lived in earth huts. The first Russian travelers refer to the remains of earth huts, which were formerly inhabited by the Yukaghir. This leaves no doubt that the houses of the Yukaghir, at any rate, of those who dwelt on the seacoast and on the river banks, were earth huts, though we lack a detailed description of them.

The dwelling of the ancient Aleut was similar to the Kamchadal earth hut. Its frame was built up of driftwood and jawbones and ribs of whales. The roof opening served as a smoke hole, window, and entrance, and one descended into it by means of a notched log. Beyond the main living room, as has been ascertained by the author's excavations, and as related in folk tales, there were other and smaller lateral rooms, but it is not known whether they had individual means of exit. The present earth huts of the Aleut are of two types. The Attu hut has the entrance at the side and a window in the roof. The Umnak hut has a door and windows in the walls and the roof is covered with long grass. The dwellings of the Aleut of Unalaska and Pribilof Islands are modern board block houses.

For comparative purposes a description of the Eskimo earth huts may be of interest. There are varieties in type. To judge by the descriptions of travelers, earth huts of the Aleut type were encountered in southern Alaska with this difference, however, that besides the small earth hut, one might find large subterranean public houses (kashim) designed for festivals, entertainments, or sweatbaths. In some places remnants of earth huts of the Gilyak type were found. At Bering Strait, the Eskimo were found to possess underground houses of the walkar type described above (p. 206). On the shore of the Aretic Ocean we find small earth huts of the Kamchatka type, with the entrance through the smoke hole, but with a frame marle of jaw bones and ribs of whales. Farther east, we find the remains of stone walls of earth huts, similar to the old Scotch and Armenian subterranean dwellings. The easternmost huts had roofs of whales' bones. The stone walls frequently penetrate but very slightly 
into the ground, or are erected on the surface of the soil, being banked with earth.

Snow Dwellings. The well known vaulted snowhouse, built by the Arctic Eskimo of North America, because of the absence of driftwood and timber, has never been observed in Asia, but almost all the northern earth huts described above are covered with snow in the winter. The winter dwelling of the Kerek, a northeastern division of the Koryak tribe, may be called a snowhouse. The Kerek, who have an insufficient supply of wood or skins to construct adequate winter houses, utilize snow as building material. Their half underground house has a roughly constructed framework of such poles and pieces of wood as they can find on the shore. Crooked branches of stunted willow and birch trees are used to fill in the spaces in the frame. The interior is lined with such skins as they can scrape together, and the exterior is covered with sod and loose earth. A long, low, narrow passage made of similar material forms the entrance. This structure is used in this form in spring and summer; but in the fall it is covered with a layer of snow several feet deep, and fashioned into a well-defined round or rectangular form which gives it, outwardly at least, the appearance of an Eskimo snowhouse. Like the latter, the Kerek house lacks the roof entrance with its characteristic notched log ladder.

In winter the joint mortises of block houses in the polar region are covered with wet snow which freezes and protects the house against cold winds.

Flat-Roofed Dwellings of Mud, Clay, Unbaked Bricks, and Stones. These types of dwellings are used by Central Asiatic natives, usually as winter houses.

The Kirghiz dwelling, called kstau, has already been described ( $\mathrm{p}$.

The Uzbeg, Turkoman, Kara-Kalpak, Sarts, and other Turkic tribes live in winter or sometimes permanently in houses of mud, clay, or unbaked bricks. Some of these, as in Tashkent, are covered with plaster and painted with some light color. They are seldom more than one story high. The flat roof has a foundation of rafters and pieces of sinall willow branches closely fitted together. The whole is then thatched with reeds and covered with a layer of clay and sod.

The Dungan have similar clay dwellings, the roofs of which are covered with straw.

In winter, the Azerbaijan live in huts made of clay or cemented stones covered with clay. 


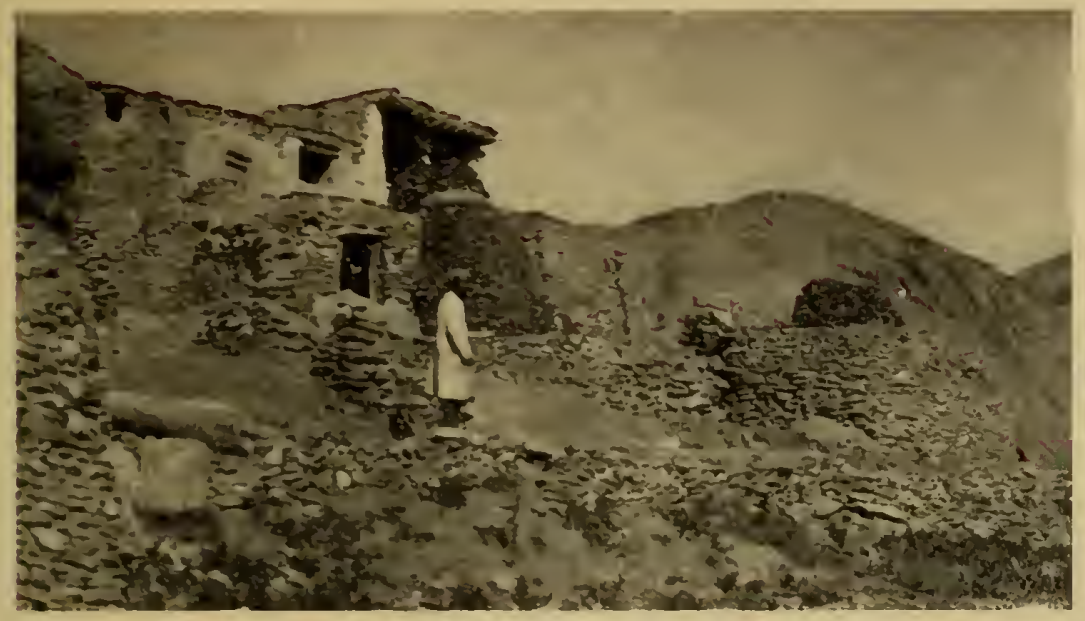

Fig. 51. Galcha Summer Dwelling in the Mountains of the Yagnob, a Tributary of the Zarafshan River. The two-storied house is built of cobbles cemented with clay, the lower for cattle, the upper for the family.

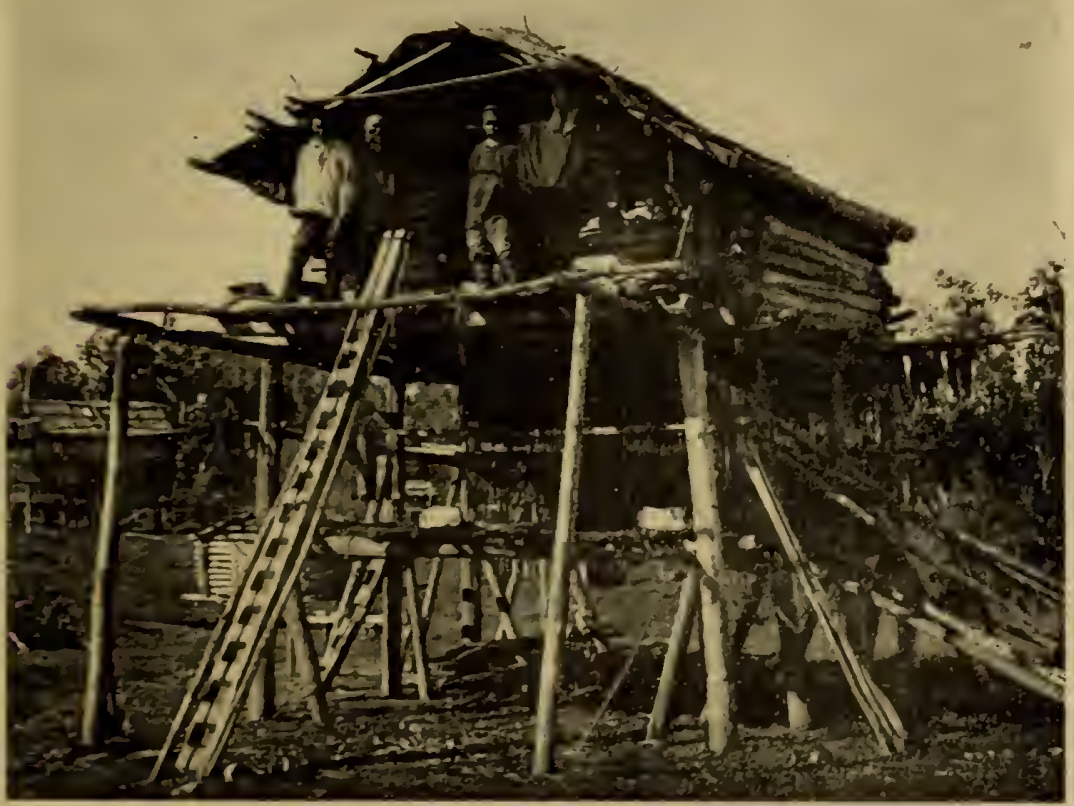

Fig. 52. A Kamchadal Storchouse which also serves as a Summer Dwelling. Such houses have two or three floors aul in the upper one food is storcd out of reach of the dozs. The lower floors are used for storing clothes and household belongings. 
The Tarljik of Turkestan have similar houses. In the plains and valleys they are of clay; in the mountains of cobblestones cemented with clay.

Pile Dwellings. The Kamchadal and the Gilyak are the only Siberian tribes who formerly used and in part still use houses built on piles in the summer. The Kamchadal pile dwelling is built on a platform supported by posts two fathoms, or more, high. The Gilyak pile dwelling is considerably lower, about a fathom above the ground. The Kamchadal and Gilyak now living in block houses instead of earth huts use these houses in winter as well as in summer, but in many cases the pile dwelling has not been completely abandoned. Both the Kamchadal and Gilyak use their pile structures as storehouses in summer as well as in winter, but almost all the Siberian natives use pile storehouses.

\section{Dress and ORNament}

\section{PERSONAL DECORATION}

Painting. Body painting is not practised by any of the tribes under consideration since the northern primitive tribes as well as the Central Asiatic peoples are completely clothed, at least, out-of-doors. Face painting was practised by the Kamchadal, Ainu, and Koryak. Men, women, and children in Turkestan paint their eyebrows and the intervening space with surma, a black powder made from antimony. The eyelashes are painted by the man in the belief that the painting will relieve inflammation of the eyes caused by dust and wind. The women use white lead rice powder for whitening their faces. They also color their nails, perfume themselves, and carry sweet-smelling plants. Men like to carry a rose or a bunch of roses tucked under the turban. Formerly, it was customary for elderly women to paint their teeth black, as Japanese married women still do, but now it is out of fashion. The Hindoo usually have a red or black caste mark in the form of a circle painted on their foreheads, but this can hardly be regarded as an ornament.

Tattooing. While painting is a transitory decoration, which must be constantly renewed, tattooing is a permanent cosmetic modification of the body. The art of tattooing has spread only among the fairer peoples; the dark-skinned peoples practise scarification. All the northern inhabitants of Eurasia practised tattooing, chiefly of the face, but, under the influence of contact with civilized nations, this type of personal decoration is becoming less and less prevalent. It is still retained by the Chukchee and Koryak who have had contact with the Russians less 
frequently than other Siberian natives. Their tattooing may be regarded as a privilege of the wolnen.

Piercing Parts of the Face. Lip, nose, and cheek plugs are not worn by the Siberian natives and probably were unknown in the past. The Chukchee, for instance, ridicule the labrets of their Eskimo neighbors, calling them "mouthed people." Piercing the ear lobes and earrings were apparently known to them prior to the aequisition of metal ornaments. Koryak and Chukchee women still wear earrings of polished stone and fasten stone pendants to their braided hair.

Hair Dressing. The women of the Tundra Yukaghir, Kioryak, Chukchee, and Asiatic Eskimo part their hair in the middle, from the forehead to the neck, and braid it behind in two braids, so that each braid begins quite close to the ear. The back of the head is thus left free for the attachment of an ornamented leather strip, which extends almost from one ear to the other. The ends of the braids are usually tied with a thong or sinew thread on which beads are strung. The braids rest on the ehest or back, though oftener on the chest. The women of Turkestan tie their braids at the occiput.

Men dress their hair in various ways. The Mussulmen of Siberia, Turkestan, and Caucasus shave their heads, allowing their beards to grow: The beards of Turko-Mongolic tribes are usually very sparse, but the Iranian tribes are quite hirsute. According to Pallas, ${ }^{1}$ the aneient Ostyak used to shave their heads. The Koryak, Chukchee, and Asiatic Eskimo men use a sharp knife to cut or shave the hair from the top of the head, leaving a thick fringe of short hair around it, produeing a tonsure like that of a Roman Catholic priest. The forehead is free; the hair is removed from the nape of the neck and the region about and under the ears. This ring of hair is often supported by a small thong with which the Kioryak tie their hair when fighting, running raees, tending herds. or engaging in other activities.

The Yukaghir, Tungus, and Ostyak-Vogul wear their hair long. In the love songs of the Yukaghir, the hair of a lover is pictured as squirrel tails falling over the neck. The Yakut and other non-Mussulman natives of Siberia cut their hair short. Some Vogul wear their hair in two braids hanging from the neck near the ears.

The non-Mussulman tribes of Northeastern Siberia, the Chukchee, Koryak, Yukaghir, Chuvantzy, Tungus, Yakut, and in part, the Buryat, peoples of different racial origin. pull out their faeial hair which is generally a short, scanty growth, with iron tweezers. Pubic hair is pulled

Pallas, vol 4, 91. 
out with tweezers or shaved with the tailoring knife by Yukaghir, Tungus, and Yakut women.

Costume. While the southern hunting and other primitive tribes are not troubled by the necessity for clothing, the northern, and particularly the polar natives must, before all, provide themselves with a costume that will afford protection from the cold. The winter dress of these tribes is of fur; for the short summer, of leather. Yet, despitc the primary necessity for protection from the elements, the northern tribes do not forget ornament. They trim their fur garments with variously colored strips of fur and hide, embroidered with painted hair, sinew, cotton thread, or silk. At the front, sides, and especially at the seams, leather tassels and fringes, bone and metal pendants, and similar objects are attached.

The women's dresses are ornamented with circlets of silver and pendants like bronze bells, human figures in brass, and metallic rattles. Silver and bronze circlets are attached to the breast part of the leather apron of Yukaghir and Tungus womcn. Some of these metallic ornaments are regarded as amulets, thus obscuring the question as to whether their original significance, was religious or æsthetic.

The tail-like prolongation of the back of the fur coat of the Tundra Yukaghir, Tungus, and the ancient Koryak and Kamchadal, an adornment used by the Eskimo, should be mentioned.

The ornamental designs used in the decoration of fur clothing by the northern peoples are very variable. Here we find both the most primitive motives, consisting of dots, dashes, and rings, together with geometrical patterns in the shape of triangles, rhombi, and squares. In one style of ornamentation, for instance, nets and checker-work patterns are represented; 'in another, the realistic representation of animals and human beings, or of groups of both of a pictographic nature, is dominant. Finally, realistic or conventionalized plant motives are often used.

The methods of ornamentation used for clothing are also employed in the making of fur rugs which are frequently of high artistic value. All these achicvements in decoration are the results of the artistic cfforts of the women. Of particular excellence arc the fur clothing and skin mosaic rugs made by Koryak and Kamchadal women. The technique of ornamental embroidery with colored sinew, yarn, or silk is quite varied.

Whilc the clothing and rugs of the reindeer-brecding peoples are madc of reindeer skins, the northern horse and cattle-breeding tribes, like the Yakut and Buryat, use horse and eattle skins. Their workmanship is, however, inferior. For trimming, skins of other fur-bearing animals are used. Sea-hunting people use sealskins for clothing and rugs, 
to some degree, particularly for summer clothing. The Ainu, Gilyak, and some of the Amur Tungus make clothing of fish skins which they ornament by rarious methods. The Aleut and Asiatic Eskimo make rainproof clothing from the guts of sea and land mammals and ornament the seams with rariously colored birds' down, or, at present, with gayly colored yarns.

The motives employed in the decoration of clothing represent, on the one hand, a rhythmic repetition of ornamental elements, and, on the other, a symmetrical composition of the whole decoration, both combining into a single rsthetically pleasing unit. The bead embroidery on belts, caps, mittens, and the borders of coats deserves mention. Silk enbroidery in Turkestan is mostly executed by men.

The patterns of carpets and rugs woven in Persia and in Central Asia consist of geometric and conventionalized motives rather than of realistic and pictographic designs. This is also true of the rugs from Daghestan, Caucasus, and those made by the Turkoman of the Steppes. Although they are inferior in beauty, as compared with Persian rugs, they surpass the latter in their closeness of weave and in the dyes. The reason for this absence of realistic motives will be discussed later.

\section{Graphic Art}

Few discoveries have attracted such general attention as the representative art of the Reindeer Age, brought to light in the caves of southern France and Spain. None the less interesting are the so-called pisanitzy, the prehistoric pictographs on rocks in Siberia. P. P. Khoroshikh, in a recently published description of the pisanitzy in the Irkutsk country, ${ }^{1}$ illustrates two kinds of writing, represented by conventional and realistic figures. Some of the conventional signs are regarded as old Turkish, or the so-called Uigur letters. The realistic figures represent men and animals (horses, reindeer, elk, goats, bulls, and birds). Some archæologists connect these drawings and engravings on the rocks with magical practices, but it seems impossible that figures drawn or engraved with such great feeling for form were produced by the artists for any other reason than for the mere love of the task.

\section{DRAWING AND ENGRAVIXG}

The present Aretic peoples, from the Lapp to the Eskimo, draw and engrave, mostly in miniature, on wood, bone, and ivory. Many of these engravings are representations of a single man or animal; in others,

'Khoroshikh. 
human and animal figures are grouped to tell a story, or, in other words, make a picture. Houses, implements, and even vegetation are frequently associated with animals and men. The bulk of these pictures are representations of hunting scenes and incidents in the life of the Arctic peoples and are useful as illustrations of native life and industry. The grouping of figures is mainly linear; no attempts are made to place them in perspective. The lines of the engravings are filled in with black and red paint.

Picture writing is most developed anong the Yukaghir who incise their realistic and symbolic figures on birchbark with a knife point. The former are used in letters and maps, the latter in love letters. ${ }^{1}$

Carving. Sculpture, which like drawing, is found even among the remains of Quaternary man in Europe, attains little development among uncultured peoples in general. However, anong the Arctic peoples of Eurasia, we find a great development of sculpture or carving in miniature, chiefly executed in bone. This sculptured art is most highly developed among the Koryak whose accomplishments are worthy of some detailed attention.

The Koryak carvings are realistic, representing human beings, animals, and birds. Some carved figures ornament household articles, tools, instruments, and pipes, while others serve no practical purpose and aim to afford pleasure only. These carvings of animal and human figures, when applied to household articles, follow the rule of modern ornamental carving, embellishing the ornamented object without obscuring it. For this reason, Koryak ornamental carving retains the realistic character of pure art.

Their non-utilitarian sculptural carvings not only surpass the art of the European cave dwellers but of the modern Eskimo. The vivacity and artistic execution of some specimens is remarkable. The fine technique and great artistic merit may be seen in a figure of a man holding a drum. ${ }^{2}$ The plastic curves of the back and the sides are rendered with anatomical accuracy and realistic vividness. The characteristic postures and movements of animals are carved with such realism as to call forth a vivid image in the mind of the spectator and testify to the great skill and æsthetic taste of the artist.

That these Koryak carvings are objects of pure art, independent of religion, may be seen from the fact that the Koryak idols and amulets usually bear but a crude likeness to human or animal forms and serve,

Jochelson, (d), part 3.

Jochelson, (a), 654. 
not as expressions of real sense-impressions, but of vague ideas of invisible biomorphic beings. Frequently, part of a human figure or an animal is substituted for the whole and serves as a guardian.

The carvings of the western neighbors of the Koryak, the Yakut, Tungus, Yukaghir, and others, lack all artistic merit, and can in no wise be compared with their own. The human and animal carvings are rigid figures bearing only scant resemblance to their originals. The artists are unable to put life and motion into them.

\section{RELIGioN AND ART}

Religious ideas have always influenced the character of art and, generally, this influence has been detrimental. Taking our illustrations from the history of sculpture and painting of civilized nations, we see that anong the ancient Greeks religious ideas corresponded to the requirements of realistic art, while we find an opposite effect in Judaism. The prophetic attack on idolatry carried with it an objection to images and the representation of any form of animal life was forbidden in the Decalogue. The old dislike of animal representation is continued in the Talnud. There is still a reluctance to admit animal or human forms in the decoration of present day synagogues.

Realism in art is forbidden by Islam owing to the Prophet's injunction against depicting human and animal forms. Ornamentation of Mohammedan sacred buildings embraces no representation of living objects. Buddhism introduced a great deal of conventionalization into sculpture and drawings and Christianity also adopted a certain kind of conventionalization in the representation of saints and icons.

The art of uncivilized peoples is likewise influenced by their religious beliefs. The Yakut ornamental designs include the representation of neither human nor animal figures. Only the dress of the shanan may be decorated with figures of men and animals which represent his guardians and benevolent and evil spirits, since it is feared that any biomorphic representation may become a harmful spirit. Even representations of the horse, which is regarded as a benevolent being and almost worshiped, is avoided. Only the bases of the large wooden goblets for drinking kumiss represent horse's legs and hoofs. All other carved ornamentations of the goblets consist of geometric, skewomorphic, and conrentionalized designs. This applies also to Yakut weaving and the manufact ure of fur rugs which have no biomorphic decorations. In the Yakut collection in the American. Museun there are sone crude and rigid figures of men and animals made from inammoth tusks. There are also combs 
and boxes of mammoth ivory, ornamented in filigree. But these articles are products of the Yakut living near Yakutsk and were made to meet the demands of the Russians and are not works of art.

Among the Tungus, as among the Yakut, ceremonial objects are decorated with more or less realistic designs;, while geometric motives are applied to ordinary garments. Professor Boas has called attention to the difference in the realistic decoration of ceremonial objects and the geometrical designs on objects in common use among the Indians and Eskimo. ${ }^{1}$ Among the Koryak the reverse is true. Their funeral and ceremonial dancing garments are covered with geometrical designs, while realistic motives are found only on ordinary clothing and fur rugs.

\section{Music and Dancing}

\section{MUSIC}

The Drum. Some writers consider the drum the most ancient musical instrument, but archæological evidence has shown that the flute antedates the drum. It is also possible that the musical bow may precede the flute. The drum is the most complicated of primitive musical instruments. However, drumming is regarded as the first attempt at music, or rather, time-keeping.

The drum is distributed all over Asia and is used both for amusement and ritual purposes. The Siberian drum is single headed and consists of a wooden rim, covered with a membrane held in place by cords, a crosspiece of metal, or a wooden bar, inside the drum. The Chukchee drum, like that of the Eskimo, has a wooden handle, like that on a hand mirror attached to the rim. The drumstick is covered with skin.

Two-headed drums, covered with hide, are used in Siberia only by Buddhists (for instance, the Buryat) in their divine services and by Tibetan lamas in their temples. These are cylindrical and have leather handles attached to the outer edge of the rim.

In Turkestan a large goatskin-covered tambourine which is tossed up in both lrands and struck with the flat of the fingers is in use for dance music. The edge is fitted with jingling bits of metal. The player constantly holds the instrument over a pan of hot coals to make it more resonant. It is called tchilmanda. In Persia the same instrument is called daira.

Other drums called nagora are also used in Turkestan. These consist of two differently sized drums made of small earthenware vessels covered with skins fastened on by a network of little straps. The smaller

'Boas, 484, 48.5. 
drum has a thicker skin: its sound is called zic, or wooden; the larger, with a thinner skin, produces a more prolonged sound called bum. The drums are beaten in turn with two sticks.

The Jew's Harp. ${ }^{1}$ This prinitive musical instrument has spread almost all over the world. It is found among all the peoples of Asiatic Russia. It consists of a small frame (of wood, bone, or metal) with a metal tongue, moved by the finger. The narrow end of the instrument is held between the teeth, so that the mouth acts as a sounding board. It is a wind instrument combined with the principle of a string instrument (of the vibrating string). The Germans call it Maultrommol; the Koryak, cogged drum (raniyayai): the Yakut, khomus; the Soyot, komus; the Buryat, khur: the Kirghiz, tchang.

Wind Instruments. The flute is the most primitive wind instrument, but the author has never seen it among the Siberian natives. It is told of the Hindoo that they used a nose flute like that of some Malayan people. The use of this type of flute may be explained as the result of prejudice, since no Hindoo of higher caste would touch with his lips a flute which a low caste man had made and put to his mouth.

The Gypsies play the bagpipe and reed-pipe, which they brought presumably from India. The Turkestan musicians play the surnai, a pipe-like clarinet made of apricot wood, about two feet long, in the small opening of which there is a brass pipe called nil. It has a reed mouthpiece close to which is a brass clisk serving as a support for the lips of the player. When not in use, the farther end of the pipe is stopped up with a brass rod, to which two small wooden disks which cover the mouthpiece are attached by a chain.

Turkestan musicians also use the kurnai, a large brass trumpet six to seven feet long, swelling greatly at the farther end, and when blown, producing only one unearthly deep bass note. Two trumpets of different keys are generally used at the same time. The Mongol and Tibetan Buddhists use trumpets and trombones in their temples.

Stringed Instruments. Stringed instruments may be divided into those plucked with the fingers, struck with a stick, or played with a bow. The Sarts sing or recite half chanted poems to the accompaniment of a two-stringed guitar. They also have a kind of violincello named ridschak. In the cities of Turkestan the chief stringed instrument played is called dutara (a Persian word, from $d u$, two, and tara, string), and is of the same general shape as a guitar. It is played with the hand, the strings are usually of fine wire. The sitara (Persian, si, three, and tara, string) has, as its name indicates, three strings, and is usually played with a bow, like

IPennant, vol, $3,95$. 
a violin. The tchetara, or four-stringed instrument is also used. Another stringed instrument, called kemangeh is known. The strings proceed from a long metal foot and are drawn over a sounding board made of a coconut with about one-third cut off. This is also played with a bow. The Vogul have a five-stringed instrument like the dombra of the Ostyak.

The Ostyak have three stringed instruments of their own invention, one called dombra (the name seems to be akin to the tombora of the Magyar) with five strings, another with eight strings called chotuing which means swan, and a third, a two-stringed violin.

The Kamchadal have a three-cornered guitar with two or three strings and rude violins which are undoubtedly adopted from Russian settlers. The triangular guitar is the Russian balalaika.

The Kara-Kirghiz have a two-stringed instrument called kobys. The horsehair strings are drawn over a bowl-like sounding board and are played by plucking with the finger or with a horsehair bow.

The Mongol have a two-stringed violincello. The Sarts of East Turkestan and the Taranchi have a guitar. The Ainu also use a guitar and the Gilyak have a kind of two-stringed violin.

\section{DANCING}

In the first place, dancing is intended to provoke pleasure and æsthetic feeling, both in the dancer and the spectator. Its chief characteristic is the rhythmical order of the movements. In its most primitive form dancing is closely associated with music, that is, beating time by clapping the hands. On the other hand, primitive dances are mainly mass dances and have a social influence, the dancing group feeling and acting as a single organism.

Circle Dance. The circle dance was observed by the author among the Tungus, Yukaghir, and Yakut. It appears that the Yukaghir and Yakut adopted it from the Tungus among whom the sexes frequently dance separately, as the author has observed in the Okhotsk country.

Among the Yukaghir and Yakut the sexes dance together. The men and women dancers, arm in arm, but in no definite order, form a circle, and, tramping with their feet, move slowly from right to left in a sunwise direction. The entire dance consists of four kinds of steps. First, the left foot is moved along the ground to the left; then the right foot is brought up near the left, in the same fashion; and finally, the dancers stamp twice, with both heels held together, standing on their toes, and without moving from the spot. At the same time, the dancers bend and unbend their knees, sway their bodies to and fro, raise and lower their 
shoulders, and bend their heads first to one side, and then to the other. All these movements are performed by all the dancers simultaneously and with the same rhythm. The grace thus displayed by some of the dancers is admirable.

The motions of the Tungus seemed less pleasing. The circle dance of the Yakut is still more clumsy, the movements are slow, at first, but become faster and faster as the dancers become more excited, and the circle revolves with greater speed. Gradually, other persons present begin to be affected by the dance; old men and women join the circle, and children and infirm persons who usually stand aside, begin to stamp the ground, imitating the dancers.

On holidays the Yukaghir whirl around in this fashion all day long; they dance to exhaustion, nay, to intoxication. Some leave the circle to rest, while others having regained their strength, break in and join the dancers, again closing the circle. The dance is accompanied by a song consisting of four notes, corresponding to the four steps. The words sung: ho-yoi-he-yui, or, he-ke-ha-ka, are Tungus. The Yukaghir believe them to be pure interjections. No drum or other musical instrument is used in this dance.

Pantomine or Primitive Drama. The singing during the performance of the circle dance is interrupted from time to time by a guttural rattle, and by other sounds imitating the cries of various animals. At times, the singing recalls the cries of sea animals and sea birds.

One mimic dance of the Yukaghir, with its accompanying onomotopoetic sounds is performed with great vivacity and grace and refers to the swan. It is called the "dance of the long-necked one," as the Yukaghir call the swan. The dance is performed in combination with a circle dance. Girls and youths form a circle and revolve from right to left around a couple representing a male swan making love to a female. The male circles the female alternately lifting the left, then the right wing (that is, arm), while the female tries to evade his approaches. At the same time, the dancing couple skillfully imitates the sounds by which the male and female swans call each other in the mating season. This dance discloses how carefully the Yukaghir observe the ways of animals.

Among the Koryak and the Chukchee, both children and adults perform similar dramatic dances, consisting in the imitation of the movements and sounds of animals. A row of Koryak men faces a row of women, and men and women in turn produce guttural rattling sounds in imitation of seals, tramp on one spot, bend and unbend their knees, and move their shoulders. 
Young Chukchee girls have dances of their own which are meant to imitate the motions of various animals or certain human actions. They are accompanied by peculiar songs, or rather, rhythmical guttural sounds produced by alternately drawing in and letting out the breath. To make these sounds is termed "to call with the throat." Two or more girls take positions opposite each other or in a circle and produce the sounds in succession, carefully kecping time and quickly taking their turns one after the other. The singing is begun with low hoarse notes. Imitative sounds are introduced later in a much higher key. While singing, the girls sway the upper parts of their bodies back and forth and then go through various imitative motions in connection with the sounds uttered. Young boys taking part in the dance, hold up their hands and snap their fingers, at the same time, producing a peculiar clicking sound with their tongues. Each song, with its accompanying dance, is named after the animal represented.

The Raven dance is the one most frequently performed. The imitative sounds represent the croaking of the raven. While dancing, the girls hop around, pretend to search for something, peck at the ground, etc.

Among other songs may be mentioned "the song of the fox," a kind of dialogue between the fox and the bear, reproducing a widely known tale in which the fox pretends to heal the bear's wounds with red hot stones, and finally kills him. The fox speaks in a thin treble voice which gradually weakens.

In the dance and song of the geese, the motions and cackling of the white-breasted goose (Anser obbigrans) are imitated. In "the song of the fighting sandpiper" (Totanus pugnax) are imitated the quaint motions of those birds in their social gatherings during the early nesting season. Songs of the long-tailed duck (Fuligula glacialis), swan, walrus, seal, and of reindeer rutting, are either imitative, or accompanied by imitative dances.

The dances of the Kamchadal are pantomimic, accompanied by songs, with always increasing passion. Langsdorf ${ }^{1}$ mentions the sea dog dance and the bear dance of the Kamchadal, during which they begin with the gentlest, softest motions of the head and shoulders and close with very violent motions of the whole body. Lesseps ${ }^{2}$ mentions the partridge dance. Krebs ${ }^{3}$ saw similar dances among the Ainu of the Kurile Islands. Choris ${ }^{4}$ writing of the Aleut, mentions a pantomime in which a hunter

'Langsdorf, vol. 2, 302

2. esseps, 105-106.

Krebs, 355.

'Choris, 9. 
shoots a beautiful bird which is suddenly transformed into a beautiful woman with whom he at once falls in love.

Caucasian Lesghinka Dance. Although this dance is named after the Lesghin of Daghestan it is regarded in the Caucasus as a common national dance. It is accompanied by the beating on a drum or tambourrine, playing on a kind of clarinet, and beating time by hand clapping. Sometines a harmonica is used. The spectators, mostly men, form a circle, either standing or sit ting. Outside the circle stands a small group of women dancers, dressed in their picturesque national costume, with faces half hidden by their head covering. Suddenly, one of the women dancers leaps into the circle, holding in her left hand a handkerchief with which she conceals the lower part of her face. Forthwith, one of the men dancers follows her and with his right hand held flatly over his heart and the left resting on his hip, or, with graciously outstretched arms, he tries to approach the shy and coquettishly erading lady. He displays a manly self-consciousness and dignity: she, with rhythmic, short, fast, and sidewise steps, swiftly glides away, giving her body the appearance of a puppet, the movements of which are controlled by a wire. On the whole, the lesghinka, representing as it does a courting pantomime, makes a pleasing and æsthetic impression.

The Trading Dance of the Chukchee. While the purpose of most primitive dances is purely æsthetic, they often go far beyond the bounds of what may be termed æsthetic. Dances in which both men and women take part, or even in which men dance alone and women are mere onlookers and vice versa, are, for the most part, calculated to excite sexual passion. In many cases, the sexual element predominates. We have previously noted (p. 101) the lascivious character of the dances of the batchas or dancing boys in Turkestan. The sexual element in some horyak and Chukchee dances is even more conspicuous. Georgi, writing of the dances of the Ostyak, states that the gestures in them are frequently immodest. ${ }^{1}$

The trading or bartering dance of the Chukchee is not in itself, but because of its consequences, placed in this class. On the second day of the festival consecrated to the sea god, keretkun (p. 223), an exchange of presents takes place. This brings us to another variety of ceremonial exchange, the exchange of wives. It takes place between members of a "compound marriage," beginning with a dance in which a male member of the group has one of the women for his partner. Frequently, the man merely looks on, while the woman clances before him. He must, however,

¿Georsi, so. 
provide a reingleer skin to spread on the ground under her feet while she dances. While the dance is performed, the other dancers remain quiet, and join the other spectators. After the dance, the man must give a present to the woman and the following night they sleep together, leaving their respective mates to arrange matters between themselves. The next day, the husband of the woman and the wife of the man perform a similar dance in which the man gives an equivalent of the present of the preceding day, and each newly mated couple sleeps together for another night. Such dances are arranged chiefly among cousins or other relatives, who, among the Chukchee, frequently assume the bond of compound marriage. Conversely, a new bond of compound marriage may be concluded through a trading dance. The third day of the keretkun ceremonial is the women's day. This time it is they who act as drummers and dancers.

Religious Dances. In most religions, ritual dances play a large part and are a means of excitement in the desire to approach or to unite with the deity. King David danced before the Ark; the Levites had their sacred dances. Even as late as the eighth century early Christianity retained the dance in its religious rites, a partial survival of which may be seen in the proceedings in the Cathedral at Seville during the Easter Festival and in what has recently taken place in one of the American Methodist churches. The masked ballets performed by the Buddhist, Lamaist priests are a part of religious worship. The Brahmins, Hindoo, and Japanese Buddhists require dancing girls in their temples for religious feasts. Human sacrifices of the Aztec to the god, Huitzilopochtli, were also accompanied by dances by men and women.

In primitive religions, also, the dance is a part of worship. The well known bear festival of the Ainu and Gilyak is accompanied by dances before and after the killing of the bear that has been reared from a cub. According to Sternberg, the dead bear is regarded as a messenger to the sky who will secure prosperity for the men below. Ainu girls and women dance round the bear's cage before it is killed. Among the Gilyak, men also participate in the dancing. Dances also accompany the ritual after the eating of the bear meat, which is regarded as a communion with the worshipped bear.

A similar cult of the bear is found among the Goldi, a Tungus tribe, which believes the bear about to be killed is their kin. Eating the bear is a form of communion with the ancestor animal. The Ostyak, Vogul, and Samoyed have similar ceremonies.

On many occasions the Koryak perform ritual dances. They greet dead whales, white whales, and other sea and land animals with songs 
and dances. The men and women dancers wear special richly embroidered dancing coats and grass masks. The second act of the ceremony is performed several days later, when the Koryak feign to send the dead animals home as honorable guests who were well treated. This part of the festival is also accompanied by songs, dances, and drum beating. At the beginning of the winter the Koryak, wearing wooden masks, dance and enact different scenes of winter life. Launching the skin boat in the spring and storing it for the winter are celebrated by a feast and dances. The Reindeer Koryak have some festivals of their own in connection with the herd: the ceremony on the return of the herd from summer pastures; the fawn festival. The bear, wolf, and fox festivals are common to both branches of the Koryak.

The usual ceremonies of the Reindeer Chukchee are those connected with the herd. The most regular festivals are: the autumn slaughtering; the winter slaughtering; the ceremonial of antlers; the sacrifice to the new moon; the sacrifice to the fire; the sacrifice for luck in hunting; and a ceremonial connected with the killing of wild reindeer bucks. Besides these seasonal cerenonials there is also a thanksgiving ceremonial which each family must perform once or twice a year, on different successful occasions.

The ceremonial cycle of the Maritime Chukchee opens in the beginning of the autumn with two short ceremonies which are often combined. One of these is a commemorative sacrifice to the dead, the other is a sa crifice to the sea, to ensure good fortune in subsequent sealing on the sea ice. Late in the autumn, or rather, early in the winter, the chief ceremonial of the year is performed. It is consecrated to the sea god, keretkun, or is made a thanksgiving ceremonial to the spirits of sea mammals killed since fall. Early in the spring the ceremonial of boats is held. In the iniddle of summer, the ceremonial of heads is performed; this is a thanksgiving to the spirits of sea animals killed since early in the spring. These four ceremonials are performed with varying similarity by both the Maritime Chukchee and Asiatic Fskino. Some minor festivals are observed during the year by the Maritime Chukchee and Asiatic Eskimo which are accompanied by songs and dances.

The Yukaghir, as a genuine hunting tribe, invest the hunt with religious coloring. In olden times before starting on the spring hunt, clan groups celebrated their departure from winter quarters by shamanistic perforinances, sacrifices, and minetic dances to gain the favor of the animals' guardian spirits.

All the shamanistic performances of the Siberian peoples are accompanied by the shaman's dances. 


\section{POETRY}

Poetry is a verbal representation of subjective and objective phenomena and thus it embraces the lyric, which affords expression to the inner world, and the epic, which expresses the outer world. In both cases, the expression serves an æsthetic purpose; the poet invokes feeling rather than action. The expression of joy and suffering in love belongs to lyric poetry. The high development of poetry, lyric and epic, among the Mussulman people of Central Asia and Caucasus is well known, so we will give attention to the poetry of primitive Siberian tribes, not unmindful that most authorities deny primitive tribes the sense of poetry. It is also said that primitive tribes have no true love songs.

We will take, first of all, the Yukaghir, a poor hunting tribe. All their poetry consists of improvisations or is handed down from narrator to narrator and from singer to singer through generations. In the last case the context is subjected to slight individual alterations.

The Song of an Old Man

Oh, old age came to me.

It threw me down like a rotten tree.

A scorched stump I am looking, see.

The Song of an Amorous Lad

She is white as snow

Her eyebrows are black as ink

Her hair is soft as silk

She shines like the sun

I am hurrying to her

Never to part with her

The Song of a Girl

When our camps separated

I looked after him

He is tall like a mountain ash

His hair covered his shoulders

Like black squirrels' tails.

When he disappeared

I lay down in the tent.

Oh, how long is a spring day?

But the evening came

And through a hole in the tent cover

I saw my love coming

When he came in

And looked at me

My heart melted

Like snow in the sun 
The following is the love song of a Russianized Yukaghir of the Omolon River.

\author{
There stood a handsome fir \\ Vasya ${ }^{2}$ fell it there, \\ Meadow green was their bed, \\ Moving clouds their coverlet \\ Soft bush of a willow \\ Served them as a pillow \\ And the firmament \\ Was their upper tent
}

Of course, all this is a free translation, but the originals, although not in verse, have a peculiar beauty.

The cpic narratives of the lukaghir, dealing with wars with alien tribes, struggles between their clans, and the first meeting with the Russians, are distinguished by a majestic simplicity combined with deep feeling.

The poetic dramatizations of shamanistic performances also deserve mention. An example is given below, a part of a Yukaghir shaman's address to his spirits:-

You, owners of the green and trees, help me

Sea mother, who has as cover seven snow mounds,

As bed, eight ice layers,

As collar, black foxes,

As foam, arctic foxes,

As waves, cub foxes.

Help me, sea-mother-owner.

The following is the song of a Buryat shaman while making a libation at the ceremony connected with the birth of a child:-

The boys, like the rushes

The maids, like the mushrooms

From the grass of the steppe

They have made a scourge;

With the water of the spring

They have made ablution

With the nine silken threads

They have made a scourge

The following is an extract from a Buryat epic tale about KhanGuzhir (Gesser) showing the verbosity, eloquence, and richness of epithets of this Mongolic tribe.

Wasya, caressive of Vasilii (Basil), is the $\mathrm{n}$ ame of the author. 
"Khan Guzhir drove to the blue sea, turned into a golden birch, which grows there, throwing a cool shade upon the sea by its early leaves."'

Patkanoff gave us material through which we may appreciate the epic lore of the Ostyak ${ }^{2}$ and Potanin of the Mongol ${ }^{3}$. The author recalls how his Yakut guides and drivers sitting on horseback or sledge would hum or sing, praising the green wood, the blue sky, the flying birds, and the whole world around.

In concluding this chapter we wish to cite a Yakut epic poem called "The White Youth" in which there appears a beautiful fairy who asks the White Youth, a knight of divine origin, for protection against the designs of a powerful monster. The heroine is thus described:-

"Just when he (the White Youth) was asleep, between sleep and waking, he heard above him a voice, gentle and kind, the voice of a woman whispering like the sound of the light breeze which rustles in the leaves of the poplar trees by the river."

The exalted language and poetical similes are commendable. The opening section of the poem is erotic in character; but in spite of its utter frankness, it is clothed in poetical form. The monster of devilish origin appeals to the White Youth, requesting him to assist him in getting possession of the beautiful woman:-

"We shall ride very fast, very speedily," says the monster, "Go and make the bed softer for the mistress, for the lady. Tonight I have a mind to go to my mistress, to take her, the clean one, the transparent one, ... Thou, I suppose, wilt support and help me. . . . Dost thou hear? Well, then, go on.

"Upon this, the man grew terribly angry, awfully wrathful; the blood rushed to his cheeks, and the blood of his nose became smoking hot. His daring thought came leaping from his side; his boastful thought came flying from the nape of his neck; his proud thought arrived, smoking like a blue cloud. Then he commenced to speak in his wrath, like the sound of a rifle-shot.

"What insulting words. What a venom of mouth. What a caustic beak. Foulness of the lips of such a piece of nothingness; the lowest of man eaters, profligate among the devils. A devil from the very worst place. Thou'dst better tell thy will instead of that. Say, instead of that, thy last word of farewell to the earth and place. I shall break the crown

'Khangalofi and Satoplaef.

2Patkanoff, (b).

3Patanin, (a), (b), (c). 
of thy head into four pieces; the upper part of thy body into three; the remainder of thy body into five parts." 1

All this is a preliminary dialogue before a combat between the divine and devilish hero. The wealth of allegory, the solemn character, impressive style, poetic fancy, and the archaic expression of this poem are peculiar to all Yakut heroic epics. 



\section{CHAPTER X \\ MIGRATIONS AND HISTORY}

Anthropologists recognize that the whole of mankind consists of a single species: Homo Sapiens, and that distinct racial characters were produced by climatic, social, and other environmental factors. Therc have been many theories concerning the place of man's origin, and though most of the remains of fossil man have been discovered in Europe, he is believed to have had his origin in Asia. Palæographical reasons, says Professor Martin, ${ }^{1}$ lead us to believe that the Hominidx originated in interior Asia. Matthew ${ }^{2}$ is inclined to regard the great Central Asiatic plateau as the center of dispersal for mankind. But concrete facts as to the prehistoric dispersion and differentiation of human groups are still scarce, particularly with reference to Asia, where both archæological and palæontological dat a are meager. We have some knowledge of stone artifacts in isolated localities, but know little of fossil man himself.

\section{Prehistory and Prehistoric Migrations}

Cultural remains of prehistoric man in the Caucasus were discovered (1579) in a cave near Kutais. Also, traces of a palæolithic station were found (1S14) in the central Caucasus between Kutais and Oni. When excavating near Tomsk, Siberia, Professor N. F. Kastchenko discovered the bones of a young mammoth that had been killed and eaten by palæolithic hunters. At this site were also found ashes, charcoal, fragments of stone knives, and the burnt leg bones of the mammoth that had been split to obtain the marrow. This station has been assigned to the upper palæolithic period.

Forty years ago, another palæolithic site was discovered near Krasnoyarsk by the archæologist, I. T. Savenkov. Here he found stone scrapers, cutting implements, flakes, and nuclei comparable to those of the upper palæolithic period of Europe. Few bone implements were found. This palæolithic deposit described by Savenkov was on a high terrace, fifteen to eighteen meters above the Yenisei River. The gravels of this terrace, used for ballast, are overlaid by a deposit of silt or loess containing a rich Pleistocene fauna, including the woolly rhinoceros, mammoth, and reindeer. Worked stones were found in abundance at the bottom of the silt deposits where they lay upon the gravels. These included implements fashioned of quartzite pebbles, dressed on one or

Martin, 19.

'Matthew.

'Kastchenko, (a): (b), 64-70; (c), 4.j 
\| both surfaces, in the Mousterian or Chellean manner. With these stone objects were others of bone, reindeer antler, and mammoth ivory.

This layer, essentially palæolithic in character, and geologically similar to European alluvial beds, is quite distinct from the neolithic of that region, of which characteristic evidences may be found in the layers of vegetable soil covering the loess. Irasnoyarsk, situated at about $56^{\circ}$ north latitude, seems to be the most northerly Pleistocene palæolithic site known. Here the great ice sheets did not spread as far south as in Europe. Noteworthy among the animals hunted by prehistoric man is the argali, or great mountain sheep, the present habitat of which is now four hundred miles to the south.

Savenkov recorded the occurrence, on rocks in western Siberia, of curious engravings and paintings which are sometimes of fine workmanship, recalling the products of European Palæolithic art. ${ }^{1}$ Since 1919 Savenkov's work has been continued by G. P. Sosnovsky, G. von Merhart, and others who have considerably extended the investigations. Von Merhart, a German scientist, spent considerable time in Siberia as a prisoner of war. ${ }^{2}$ These archæologists have excavated in the Yenisei Valley to the south of Krasnoyarsk and discovered microlithic artifacts characteristic of the end of the palæolithic period. However, on the same level were found artifacts which may belong to epochs of the lower as well as of the upper palæolithic period, so von Merhart, for the present, defines the Old Stone Age culture of the Yenisei as a Siberian variation of the upper palæolithic period.

Within a radius of 330 miles in the Yenisei Valley twenty palæolithic stations are at present known.

In the Angara Valley, palæolithic finds were made by Chersky ${ }^{3}$ and Chekanovsky, ${ }^{4}$ but the artifacts were probably lost in the fire (1879) which destroyed the museum of the Geographical Society of Irkutsk, where the specimens were deposited. In the vicinity of Irkutsk M. P. Ovchinnikov ${ }^{\bar{x}}$ found many palæolithic objects which are on exhibition in the museum of Irkutsk.

Professor B. E. Petri ${ }^{6}$ recently made excavations on Verkholensk Mountain near Irkutsk and discovered typical stations on the loess belonging to the upper palæolithic epoch. He is convinced that these are similar to Magdalenian artifacts, but with many special characteristics.

\footnotetext{
ISavenkov, (a), (b).

${ }^{2}$ Von Merhart, 21-5.5.

${ }^{3}$ Chersky, 108-116.

"Chekanovsky.

sOvchinnikov.

SOvchinnikov.
${ }^{\text {Petri, }}$ (a), (b).
} 
The numerous artifacts of stone, bone, horn, and tusk found in Siberian palæolithic stations, are lacking in ornanentation, with one exception-a horn awl bearing engraved lines. This dearth of decorated objects may bear witness to a lesser development of artistic skill on the part of palæolithic peoples of Siberia as compared with those of western Europe, who left so many examples of skilled sculpture and painting. Materials for painting, such as graphite, hematite, and lime, were found on Verkholensk Mountain, but there were no traces of their use. Aurignacian and Mousterian scrapers, laurel leaf-like stone blades typical of the Solutrean Period and nicely made harpoons like those of the Magdalenian Period of Western Europe were represented in the palæolithic cultural remains from Verkholensk Mountain. This diversity of forms, belonging to different culture stages and occurring together, appears to reveal the specific peculiarity of the Siberian palæolith since the mixture of ancient and new styles is clearly demonstrated in the excavations of different investigators. ${ }^{1}$

Palæolithic man in Siberia knew the art of fire-making and produced stone, and later, bone implements.

Neolithic man was distributed from the Urals to the Pacific, but his culture is as little known as the more ancient cultures.

Traces of an ancient station in the far north of Siberia were discovered in Obdorsk Village, on the Ob River, where pottery was found. However, the present inhabitants of the district, the Samoyed, do not make pottery. We do not know whether they abandoned pottery making after acquiring metal wares, as did many other Siberian peoples, or whether this pottery should be ascribed to a pre-Samoyed tribe. It should be noted that Obdorsk pottery resembles, on the one hand, the prehistoric pottery of Ladoga Sea in the north of European Russia, and on the other, the ceramics found near Krasnoyarsk and Irkutsk.

In southern Siberia neolithic stations are known as far south as the borders of Mongolia. In the Minusinsk region they were discovered by Savenkov; in the Irkutsk country on the shores of the Baikal Sea, by Petri; in the Orkhon country by P. P. Khoroshikh $;^{2}$ in western Transbaikalia by Talko-Hrynceviz, ${ }^{3}$ who found stone implements together with some human skeletal remains. Farther to the east, neolithic stations were discovered on the dunes of the banks of the Patkha River where it flows into the Amur.

'See also Doctor Vishnievsky's chapter "Fossil Man in Russia" appended to his Russian translation of Osborn"s "Men of the Old Stone Age."

Khoroshikh.

Talko-Hrynceviz. 
In western Siberia neolithic stations are known on the shores of the Transuralian lakes and on the eastern slopes of the Ural ridge. Siberian neolithic man knew the art of polishing and drilling stone, making pottery, and carving in wood.

In Irkutsk Province, Vitkovsky ${ }^{1}$ has excavated tombs containing neolithic relics of an archaic character, where human skeletons were covered with red ocher, like those of the reindeer age in western Europe. Farther north, near Olekminsk, deposits bordering the Lena River contain arrowheads and implements of mammoth ivory, simple objects representing a Stone Age culture which still exists or formerly existed among the circumpolar population. ${ }^{2}$

In the far northeast of Siberia, neolithic artifacts were discovered by the author in excavations in the Koryak and Kamchadal region. At the Koryak sites (1900) remains of elaborate pottery and polished stone implements were uncovered. On the Kamchatka Peninsula polished stone axes, arrowheads, etc., were collected (1911) in abundance, together with a particular type of pottery influenced by the culture of the preJapanese population of the Japanese islands. This material has been analyzed by the author for the Carnegie Institution of Washington. ${ }^{3}$

Returning to the middle of the Asiatic continent, we must record the researches of Doctor and Mrs. Torii in eastern Mongolia, a region covered with incredible quantities of remains and ruins. Here the stone objects, axes, knives, scrapers, and arrows, are neolithic. According to these authors, this region, as well as Manchuria, Korea, Japan, and even China, seems to have no palæolithic remains. ${ }^{4}$ In Asia, according to Boule, ${ }^{5}$ the age of polished stone seems to be less clearly separated from the older age of dressed stone, than it is in Europe.

All these countries are rich in prehistoric relics, ranging from the Stone to the Iron Age. The coast of Manchuria (Port Arthur), the banks of the Amur, and the coast of Japan have many shellmounds and kitchen middens similar to those of Denmark. Sometimes, raised high above the present sea level, these mounds contain neolithic implements. These countries, as well as Korea, are dotted with many megalithic monuments. The Chinese prehistoric period is still unknown; but we are aware that it includes a neolithic phase. ${ }^{6}$

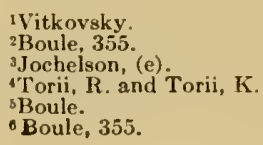


In Turkestan, Pumpelly has traced five successive civilizations, ranging from neolithic times to the present. The most ancient culture dated from $\$ 000$ years before our era. ${ }^{1}$ The mountains and high plateaus of Asia Minor and Persia which, during the Pleistocene period, were covered to a large extent with ice and snow, are very poor in palæolithic remains.?

Migrations are determined by two main factors: by the attractiveness of other localities and by an expulsion caused by invaders. Increase in population, clinatic changes, the aspiration for freedom from social, political, or religious bondage, or the enthusiasm to spread a new religious doctrine, may be regarded as secondary causes, but these also may be reduced to the first two factors. Two periods, a prehistoric and a historic, nay be distinguished in the course of a people's migrations. Information concerning the first period is ordinarily based on traditions and archæological evidence; concerning the second, on written records.

We have seen how fragmentary and uncertain is our knowledge of the stone age in the countries we have been discussing. The data on the metal age are equally unsatisfactory. Traditions, as a source of information, are significant only when supported by archæological evidence, and corroborated by known historical facts. Archæology, unaccompanied by historical records may be compared to a book from which a great many pages are lacking. We will try, however, to coordinate the disjointed fragments of archæological evidence as far as possible.

Archæological evidences of prehistoric migrations in Asiatic Russia are very scanty. Osteological remains of the neolithic period have shown that there were probably several narrow-headed peoples in Asia. These were further differentiated in the beginning of the metal age. The prehistoric dolichocephalic Chud of southern Transbaikalia, the narrowheaded builders of the tumuli (kurgans) of southern Siberia, and the dolichocephalic kurgan builders of South Russia probably belonged to one stock, which may be identified with the blue-eyed and blond Usun or Wusun of the Chinese annals, who lived on the northern slopes of the Tyan-Shan in Chinese Turkestan, with the Sacae, the western Scythians, and the Nordics of northern Eurnpe. These are believed to have been nomadic peoples, mostly pastoral.

Craniometric measurements of the kurgan skulls, made by the Siberian anthropologist, Gorostchenk $0^{3}$ produced evidence of a single long-headed type which does not correspond to the modern population of the region,

1 Pumpelly.

Boule. 3.3

Gorostchenko. 
either Mongol or Turk. The present Ainu and Yeniseians may be regarded as present representatives of this prehistoric dolichocephalic race. Further archæological evidences are too fragmentary. We know from Petri's excavations in the Baikal country that traces of the culture of the Yakut were found there.

\section{The Historic Period}

The early historical information on the movements of Siberian and Central Asiatic peoples found in the Chinese annals is far from reliable. The study of the runic inscriptions on stone memorial tablets, apparently written in the old Turkic language, is of some historical value. These memorial tablets belong to the Iron Age, and judging by the historical events, mentioned in the inscriptions, may be dated between the sixth and seventh centuries, A.D. The beginning of the Iron Age was undoubtedly much earlier. According to the Chinese annals in the second century B.C., the Hiung-nu (i.e., the Turk), then living to the north of the Chinese, used iron implements. ${ }^{1}$ Preceding the Iron Age there have been found remains of a Bronze Age, which also included copper and gold objects and traces of pictographic writings called by Russian archæologists, pisanitzy. The Bronze Age people are often set down as FinnoSamoyedic, or as Palæo-Yeniseian, but Tallgren justly rejects the idea that the primitive peoples who are still living in northern Siberia might have developed a comparatively high Bronze Age civilization. The people who developed the Bronze Age civilization of the Upper Yenisei may have been Turks or Indo-Europeans. ${ }^{2}$

The names of rivers in the forested regions of the Upper Yenisei are of Turkic origin. It has been established that the late Iron Age is to be ascribed to the Turks, but whether the people of the Bronze Age and of the early Iron Age belonged to the same stock as the people of the late Iron Age cannot be ascertained. If this be true, they must have been in contact with and influenced by Aryan culture since their methods of bronze working and the characters used in their inscriptions must have been borrowed from Semitic sources.

"The ability of the old Turks to develop these borrowed arts," says Miss Czaplicka, "is surprising, in view of the fact that no later Turks in Central Asia have reached so high a standard of civilization, but the explanation may possibly be that the Turks of that time were freer from Mongolian admixture than they have been since the thirteenth century 
and that the Aryan element in Central Asia was, at the time of this old culture very considerable." 1

The people of the Bronze Age are believed to have been peaceful, since there are hardly any weapons among the cultural remains of this period. From the abundant remains of agricultural and mining implements, it has been assumed that they were agriculturists and miners. Finally, they have been described as democratic, because we find Bronze Age communal graves and graves of ordinary individuals, while in the Iron Age, it was mainly the chiefs who enjoyed the privilege of burial in a mound. On the other hand, the Iron Age people were supposed to have been warlike nomads who lived on their horses, and who left behind them many weapons of war.

The late Siberian scholar, Yadrintzev, ${ }^{2}$ who made observations on the physical type of the Altaian Turks and the Chern Tatars was struck by their resemblance to the people of the Caucasus. Yet, the western Aryan are not known ever to have spread as far as the Altai Mountains; on the other hand, we know of the close association of the Turkic peoples with this region. The only plausible suggestion, therefore, is that the prehistoric contact between the Turks and Aryan affected the physical type of the Asiatic Turks as well as their nomadic life, leading them to settle down to agriculture.

\section{THE DINLIN}

We have stated that some Aryan tribe must have influenced the culture and physical type of the Turkic tribes of southern Siberia. Most of the Turkic tribes, according to Aristoff, ${ }^{3}$ originally occupied the Altai Mountains, Turkic traditions, tribal and place names bearing witness to this. Many centuries before Christ, Turkic tribes inhabited the Altai country and the adjacent parts of Mongolia. The most ancient Turkic tribe, the Hun-nu, was known to the Chinese as living in Central Mongolia and there are available reliable data about them, dated the third century B.C., when they conquered the whole of Mongolia. Before the invasion of the Hun-nu, northern Mongolia and a part of the Gobi desert was occupied, according to Chinese sources, by the Dinlin. ${ }^{4}$ Thus, in the Chinese inscription on a monument on the Orkhon River in northern Mongolia, erected in 732 to the memory of the Khan Kyul-Tegin, the territory which at that time belonged to the Tukiu Turks, and before

¿Czaplicks, (b), 79

Yadrintzev.

'Aristoff, (a). 17, 22. 
them to the Hun-nu, is named as an ancient country and the native region of the Dinlin. ${ }^{1}$ The earliest mention of the Dinlin in official Chinese history was in the years 209-201 B.C., when the conquests of the Hun-nu are included in enumerating the possessions of the Dinlin. ${ }^{2}$ About the year 100 B.C. the Hun-nu transferred the territory of the Dinlin to the Chinese military chief, Vei-Lui, to whom they were subjected. ${ }^{3}$ The latest authentic mention of the Dinlin was in the middle of the second century of our era in connection with their failure to subdue the Sian-bi in the north. ${ }^{4}$ In the Chinese annals on the Han dynasty, the Dinlin are described as having been of tall stature, considerably pilose, and with red hair, ruddy faces, and blue eyes. ${ }^{5}$ Another fair-complexioned division of the Dinlin who were engaged in agriculture, hunting, and fishing was also mentioned. ${ }^{6}$ They had utensils of clay and copper, very few of iron, and lived in block houses covered with birchbark. They were divided into communities headed by independent chiefs. They had thirty thousand warriors and were often at war with the Kirghiz. Of the two divisions of the Dinlin, one occupied the country between the Ural and Altai, the other the Yenisei to the north of the Kirghiz, approximately between the Obi River and Lake Baikal.

In the seventeenth century, the Russian conquerors of Siberia found the Dinlin in the localities previously mentioned, but largely Turkicized and subjugated by the Kirghiz, to whom they paid taxes in peltries, iron implements, and utensils, and who called their vassals, Kyshtym. At that time, of the descendants of the Dinlin only the Arines, Assan, Kotts, and the so-called Yeniseian Ostyak (p. 65) still retained their native language, but they were in a state of degradation. The first of the three tribes soon became extinct or were Turkicized and merged with the local Tatars, as the Turkic tribes of the region are called. The Yenisei Ostyak are still extant. They have preserved their language, but physically have become intermixed with Finno-Ugrian Ostyak and Samoye d. Klaproth, and following him, Ritter, believed the Dinlin belonged to the Aryan stock. If this theory be tenable, many puzzling problems in Asiatic archæology and ethnology may be satisfactorily solved.

The vestiges of the ancient civilization of southern Siberia and Mongolia as evidenced by monuments and burial mounds (kurgans), objects of bronze, copper, gold, and silver, as well as the remains of the

See p. 65 with reference to the Yeniseians who eall themselves, Din

Bichurin, 2.58, 259.

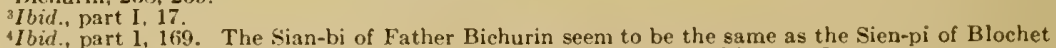
$(305-309)$ who believes the sien-pi to be of Tungus stock and identical with Jwen-Jwen.

Ibid., part 1,443 .

Ibid., part 1, 442; Deguignes, tome 1, part 2, lxii; Klaproth, (b), tome I, 129-131. 
oldest mining and ore smelting industries and agriculture should be ascribed to the Dinlin. The later Turkic metal workers of the Altai, called kuznietzy. i.e., smiths, by the Russians, may be regarded as successors of the Dinlin, with whom they were partly mixed and from whom they must have learned the art of metal working.

The dolichocephalic skulls found in the burial mounds of Transbaikalia, southern Siberia, and southern Russia may be the remains of a single race represented by the Dinlin, to which the blue-eyed and blond Usun, or Wisun of the Chinese annals, might have belonged and which might have been connected with the high statured, fair complexioned, longheaded, narrow-faced Europeans, who are at present represented by the so-called Nordics. In southern Russia and Central Europe this physical type was modified by the admixture of Scythian and Turco-Mongolic Asiatic invaders, and gave rise to two short-headed types: the Alpine (with narrow faces and narrow noses) and the Slavic (with wide faces and short, wide noses) types. The Dinlin were greatly Mongolo-Turkicized in Asia and only a few individuals of the Yenisei-Kirghiz have preserved the reddish hair and gray eyes of a primeval stock, possibly of the Dinlin. The so-called Yenisei-Ostyak and the Ainu may also be regarded as related to the Dinlin, the former because of their considerable percentage of light hair, eyes, and complexion, and the latter, because of their hairiness and cephalic index. The physical type of the original Yeniseians was influenced by the Samoyed and that of the Ainu by the Japanese.

\section{HISTORICAL WANDERINGS}

Data on historical migrations of the Asiatic peoples were given in the chapters dealing with separate tribes or groups of tribes. A brief summary will be added here.

Iranians. The question as to the place of origin of the Iranians, as a division of the Aryan, will be answered only when the entire Aryan problem is solved. As most authorities on the history of the Aryan peoples are inclined to believe their origin to have been European and not Asiatic, the Iranians too must have originated in Europe. The Persians are the chief Iranians, who have undergone considerable Turkic mixture and have, in their present abode, lost some Aryan somatological traits.

Professor ron Luschan ranges the Kurd with the peoples of northern Europe. The Ossete, according to their own traditions, came to the Caucasus from the region of the Don River, which traditions are corro- 
borated by linguistic evidence. The Sogdians, Khorezmians, Medians, and Bactrians were old Iranian peoples. The Afghan and Baluchi are regarded as Turkicized Persians, but when their place of origin is taken into account, they must be considered with the Persians. The Tadjik and the Mountaineer Tadjik, the Galcha, are also Iranian, but have been less influenced by Turkic culture than the Persians related to them and may, without doubt, be ranged with the Aryan, as remnants of the Sogdians. Somatologically, they resemble the European Alpines. The Aryan Hindoo came to India from the high steppes of Pamir about 2000 B.C., though some investigators do not consider this their original home, but believe them to have had a place of origin in common with other Aryan peoples. The Gypsies of India are ranked as Aryan with the Hindoo and wandered from their secondary home in northwestern India to the northwest in the beginning of our era, appearing in Germany in 1417.

The Caucasus Peoples. The Caucasus is not the original home of the peoples now dwelling there, even of those who live there exclusively.

The Georgian tribes may have come to the Caucasus from Western Asia in the earliest period of Asiatic history. A small number of Mohammedan Georgians migrated to Turkey after the Russian conquest of the Caucasus.

The history of the Abkhas-Cherkess group of tribes is identical with that of the Georgians and differs only in that a considerable number of them are Islamists, a part of whom, as noted above, migrated to Turkey in the nineteenth century.

The Chechen and Lesghin groups of the northern Caucasus and Daghestan were mentioned by Greek historians 2500 years ago. There is strong evidence that their habitat was thickly populated in neolithic times.

The origin of the Armenians is closely connected with that of the Hittites from whom they are believed to have descended. Von Luschan connects them with the Alpine race of Central Europe, but does not solve the problem as to whether the Hittites came from Central Europe, or the Alpine race from Western Asia, though he does incline to the latter view. ${ }^{1}$

In language and type the Kurd may be classed with the northern Europeans, but the time and routes of their migrations are unknown. The Ossete are an Aryan tribe whose original home was on the Don River, whence they were forced into the Caucasus by the Huns. The Tate

'von Luschan, (a), 212-243. 
migrated to the Caucasus from Persia, having been exiled after a revolt against the Sassanides. They are Persians both in language (speak a dialect of New Persian) and religion (Shiites). Somatologically, they are mixed with Turks.

The Talysh speak Persian, but somatologically, form two groups, Iranians in the Mountains and Tatar in the Plains.

The Jews are ancient dwellers of the country and regard themselves as descendants of the lost tribes of Israel. The Aissor are descendants of old Chaldeans. Some of them migrated into the Caucasus from Persia after the Russian-Persian war of 1827 .

The Azerbaijan are regarded as Iranians who adopted the Turkish language. The ancient Persian rulers directed the Azerbaijan to move into the Caucasus in order to take possession of Transcaucasia.

The Kumyk is a Turkic tribe that came to the Caucasus in the twelfth century from the north. Akin to Kumyk are two small Turkicspeaking tribes, the Balkar and the Karachai.

The Caucasian Osmanli are Turks who remained in the Caucasus after the Russian conquest.

The Nogais came into Cis-Caucasia from the east in the twelfth century, together with other Turco-MIongolic hordes of Jenghis Khan's invasion.

The Turkoman are immigrants from the Transcaspian steppes.

The Kalmuck of the Caucasus are a part of the Kalmuck who settled on the Volga River in 1703.

The Turkesian Peoples. The Kirghiz came into Turkestan from the Altai country with other Turkic invaders in the sixth century.

The Uzbeg, who are related to the Kirghiz, were also among the sixth century invaders of Turkestan. They were first called Uzbeg in the first half of the fourteenth century, after their khan, Uzbeg-Khan, a descendant of Jenghis-Khan.

The Turkoman, who are related to the Kirghiz and Uzbeg, came to their present abode in Transcaspian Province from the Ili River and Lake Issyk-kul in the third century of Mussulman chronology.

The Kara-Kalpak, a tribe related to the Kirghiz-Kaisak, came to western Turkestan with the followers of Jenghis-Khan. In the eleventh century, they formed the borderland population of southern Russia. It is assumed that they re-emigrated to Asia from European Russia in the eighteenth century. A part of them, accepting Christianity, settled in southern Russia and still another part, driven to the west by other Turkic invaders, now live in Bessarabia under the name of Gagauzy. 
The Tatar are Turks who migrated into Turkestan from the eastern provinces of European Russia before and after the Russian conquest of Turkestan.

The Taranchi, a Turkic tribe mixed with Iranians originally lived in Eastern Turkestan. In the nineteenth century the Taranchi left Chinese territory and settled in Russian Turkestan, chiefly in Semirechye Province.

The sedentary Sarts being a mixture of Iranian and Turkic elements, though mainly Uzbeg, may be regarded as a local ethnical compound and to recapitulate their migrations, one must refer to the ethnical components of which they were formed.

A part of the Dungan, a Chinese-Turkic blend, migrated into Russian Turkestan about 1890, after an uprising suppressed by the Chinese.

The Jews of Turkestan regard themselves as descendants of the Israelites who were captured by the kings of Assyria and Babylon and brought by them to Central Asia between six and seven hundred years B.C.

A small number of Arabs remained in Turkestan after they conquered the country and in the eighth century forcibly introduced Mohammedanism.

Siberia and the Amur Country. The supposed re-migration of the Americanoid tribes into Asia from America, after the last glaciation, took place in the prehistoric period. Their historical movements do not, represent large migrations.

The Chukchee occupied the northern tundra to the east of the Kolyma River until the middle of the nineteenth century. In 1859 a division of Reindeer Chukchee, with the permission of the Russian Government, crossed the Kolyma River and moved to the western tundra, where they found large reindeer pastures. Gradually, they moved farther to the west and reached the Indigirka River about the end of the nineteenth century. In their western movements they came in contact with the tundra Yukaghir, Tungus, and Yakut divisions. During the same period of the nineteenth century, some camps of Reindeer Chukchee moved to the south, wandering amid the Reindeer Koryak.

The Reindeer Koryak in their turn, under the pressure of the expansion of the Reindeer Chukchee, moved to the south, appearing as far south on the Kamchatka Peninsula as the upper valley of the Kamchatka River and the mountain slopes between Tighil and Sopochnoye villages. 
The Tungus are a striking example of a people whose language and ethnic unity are not closely connected with their material culture and they show particularly that culture is a question of environment and not of race. The Tungus are fishermen, liunters, dog, reindeer, cattle or horse breeders, agriculturists and town dwellers according to the natural resources and social conditions surrounding them. One of the Tungus tribes, the Manchu, after being Chinesized, became the rulers of China.

The original home of the Tungus ( $p .37$ ) appears to have been the uplands of Chan-alin, where they dwelt with the kindred Niu-chi of the Chinese annals, i.e., the Manchu, till the thirteenth century, when the disturbances brought about by the wars and conquests of JenghisKhan drove them to the north, west, and east. The Tungus migrations were slow, but constant. In their movement to the north and northeast they met a stubborn resistance from the Chukchee, Koryak, and Yukaghir. The Tungus wars with the last-named tribes are mentioned in their folklore. Finally, however, the Tungus succeeded in advancing to the north, to the coast of the Arctic tundra, to the west, as far as the Yenisei River, and to the east, as far as the Anadyr River region, and the Kamchatka Peninsula.

Reindeer Tungus first appeared on the Kamchatka Peninsula in 1850 , having come from the Amur Valley, along the shores of the Okhotsk Sea and its bays (Gishiga and Penshina Bays), fighting the Koryak while traversing their country. Some of the nomadic Tungus, after losing their reindeer, settled on the shores of the Okhotsk Sea, in the Maritime Koryak villages and became mixed with them. Now they have extended their territory as far south as the camps of the Reindeer Koryak (p. 47).

The Yakut, the most numerous Turkic tribe of Siberia, originally lived in the Altai Region, together with other Turkic tribes. The Mongol invasion of the thirteenth century found them in the region of the Baikal Sea. The Mongolic Buryat invasion from the banks of the Upper Amur forced the Yakut, with their horses and cattle, to move down the Lena River. On their way to their present places of habitation, they fought the war-like Tungus, who finally retreated to the mountainous portions of Yakut Province and the Yakut occupied the Lena River Valley to its mouth, and all its tributaries. After the occupation of the Lena River (1632) by the Russians and the foundation of the Fortress of Yakutsk, some Yakut divisions moved to the most distant parts of the country, and even crossed the Verkhoyansk Mountain Ridge to escape taxation. After curbing the resistance of the Tungus and Yukaghir, the Yakut settled the Yana, Indigirka, and Kolyma valleys, and in some localities 
between these rivers. About the same time, some Yakut crossed the Stanovoi Mountain Ridge and came to the shore of the Okhotsk Sea. Some trading and hunting Yakut went to the south of the Stanovoi Ridge and appeared in the valleys of the left tributaries of the Amur River.

The Western Siberians. In the historical movements and migrationd of the western Siberian peoples, three geographically distinct regions must be distinguished: the southwestern steppes, the western forestes country, and the northern tundra. At the dawn of history we find southwestern Siberia occupied mostly by Scythian peoples, originally of Iranian descent, belonging to the fair-complexioned, long-headed European stock. Later, they were mixed with Finno-Ugrian and MongolTatar elements. This is also true of the Alan who mixed with the Mongols to a greater degree. Although we have no exact knowledge of the original abode of the Magyar, numerous Turkic elements in their language show that they lived in southwestern Siberia a long time and occasionally were in contact with Turkic tribes. They were drawn along by the westward migration of Central Asiatic peoples, which continued many centuries after the Hun onslaught on Europe, until in 886 they established themselves on the Danube, in the country formerly occupied by the Avar. After the disappearance of the Hun and the Alan and the withdrawal of the Magyar from western Siberia, the nomadic Kirghiz ruled the country until they were subjugated by Russia in the beginning of the eighteenth century.

In the fifteenth century the forested country of western Siberia was occupied by several Tatar states the most powerful of which was the Sibir kingdom. From 1557 they paid tribute to Russia and remained undisturbed until the Russian Cossack leader, Yermak, took the residence of the Khan Kuchum Sibir, or Isker, and subjugated all other Tatar princes. Although Yermak fell in a battle in/584 and Kuchum's kingdom was restored, in 1588, Isker (present Tobolsk) was again occupied by the Russians and in $\mathbf{1 5 9 8}$ the Khan Kuchum suffered a decisive defeat.

The northern parts of western Siberia are now occupied by the Samoyed and Finno-Ugrian groups of the Ostyak and Votyak. Their place of origin is regarded as the Altai in close proximity with the localities whence Turks originated. The Samoyed drifted northward to the Arctic Ocean and a small group recently migrated westward into European Russia. The Finnic branches followed the course of the Istish to the Urals. Of the northwestern Siberian tribes, known in the Russian annals under the name of Yugria, the Samoyed, Ostyak, and Vogul, the 



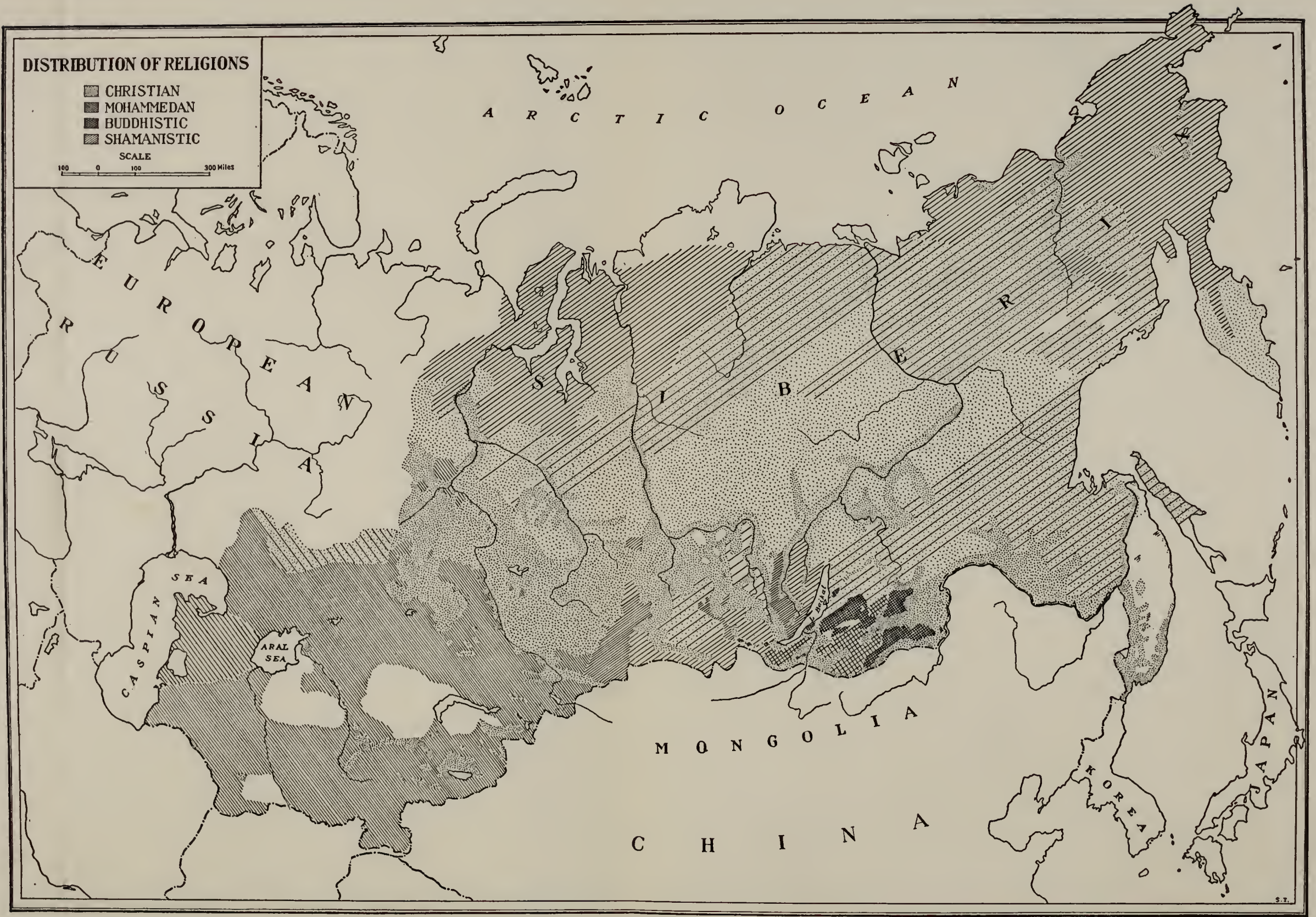

Map 10 
most southerly of them, the Ostyak had a military organization and fortified settlements. On the one hand, they had to resist the Tatar efforts to subdue them, and, on the other, they had to uphold their independence with Russian merchants who came to Yugria from the free state of Novgorod. In 1465 the Ostyak became tributary vassals of Russia and in 1499 the region of the lower Obi was included in the Russian dominions.

\section{Religiols Classification}

With very few exceptions Russian political domination in Asia had little influence on native religions. As has been previously noted, some of the aborigines of Siberia and Central Asia were converts to Mohammedanism or Buddhism after the Russian conquest. The official State religion of czarist Russia, Greek Catholicism, was adopted by many of the peoples of the Caucasus who had already been converted to Christianity before the conquest of the Caucasus by the Russians.

Greek Catholics. The following peoples belong to the Greek Catholic church:-

1. The Abkhasian belong in part to the Russian Church and, in part, are Sunnites.

2. Some Caucasian Aissor, descendants of ancient Syrians or Chaldeans, and not Assyrians, as many regard them, belong to the Nestorian church and to the Jacobites.

3. The Aleut of the Commander Islands (as well as of the Aleutian Islands) are Greek Catholics. Of the primitive tribes conquered by Russia, the Aleut are the most devoted Greek Catholics. The author observed many cases where Aleut children who had been brought up in the Methodist House of Unalaska, returned to the church of their parents after leaving the House.

4. The Armenians belong in part to the Greek Catholic Church. The bulk of the people belong to their own church, the ArmeniaGregorian, akin to the Greek Catholic Church, but with a separate head and organization. A small number of Armenians are Roman Catholics. The Hemshin, a small Armenian division, are Mohammedans of the Sunnite faith.

5. The Chechen belong to the Greek Catholic Church; a small number are Roman Catholics; some profess the Sunnite faith of Islam.

6. The Chuvantzy, a branch of the Yukaghir, are Greek Catholics, and, in part, shamanists.

7. A few Gilyak are Greek Catholics. The bulk of the tribe renain shamanists, or, as Sternberg characterizes them, pronounced animists. 
8. The Georgians of the Caucasus are Greek Catholics. A small number of Gruzians are Roman Catholies; the Adjar Gruzian and the Ingilois are Mohammedans of the Sunnite faith.

9. The Kamchadal are devoted Greek Catholics and their former shamanistic practices are almost entirely abandoned.

10. The Megrel or Migrelians of the Caucasus are Greek Catholics. A small number are Roman Catholics.

11. The bulk of the Ossetes or Ossetines are Greek Catholics. A small part of them are Islamists of the Sunnite doctrine.

12. The Swan of the Caucasus are Greek Catholies; a small number of them are Roman Catholics.

13. The Yakut are Greek Catholics, but shamanistic beliefs and practices are still maintained. Fifty years ago, there were no baptized individuals in the northern districts.

14. The Yeniseians on the Yenisei River are Greek Catholics, but continue their shamanistic practices.

15. The Yukaghir, like the Yakut, are Greek Catholics, but practise shamanism.

Roman Catholic. A small number of the following Caucasian peoples belong to the Roman Catholic church: 1, Armenians; 2, Gruzians; 3, Megrel; 4, Swan, or southern Chechen.

Protestants. Only a small number of Armenians are recorded as Protestants.

Buddhists. With few exceptions all the Mongolic tribes are Buddhists: the Mongol proper, the Kalmuck, and the Buryat of Transbaikalia. Of the other peoples reviewed, a small part of the Tungus in Transbaikalia, a part of the Ainu, and some of the Hindoo are Buddhists. From the account of Professor Petri, mentioned above (p. 24) one may draw the conclusion that the sinall tribe of Karagas, Turkicized Samoyed, are Buddhists.

Brahmanists. Some Hindoo and Hindoo Gypsies are recorded as Brahınanists.

Mohammedans. All the Turkic tribes (with few exceptions, as for instance, the Yakut), a part of the Caucasians and the greater part of Iranian peoples are Mohammedans. While the Turks are almost exclusively Sunnites, the Iranians are adherents of the Shiite faith.

The following peoples are adherents of the Sunnite doctrine:-

Turkic peoples: 1, Sarts; 2, Sart Kalmuck ; 3, Siberian Tatars; 4, Kumyk: 5, Nogai; 6, Kirghiz; 7, Uzbeg; 8, Turkoman; 9, Kara-Kalpak; 10, Kipchak; 11, Taranchi. 
Turkicized Mongol: Western Hazara or Aimak.

Caucasian peoples: 1, Laze or Chan; 2, Cherkess (Adighe); 3, Kabardine; 4, Adjar-Gruzian; 5, Ingiloi-Gruzian; 6, Abkhasian (a part); 7 , Chechen (a part).

Iranians: 1, Persians (a part); 2, Tadjik of the Plains; 3, Afghan, 4, Baluchi; 5, Kurd; 6, Hindoo of Turkestan; 7, Gypsies of Turkestan; 8, Ossete (a small part): 9, Hindoo (a part).

Other Aryan: Hemshin Armenians.

Other peoples: 1, Dungan; 2, Arab of Turkestan.

The followers of the Shiite doctrine are the Iranians: 1, Persians; 2, Mountaineer Tadjik or Galcha; 3, Azcrbaijan (Turkicized); 4, Tate; 5, Talysh; 6, the Eastern Hazar (Turkicized Mongol).

Some of the Persians, Tadjik, Afghan, and Hindoo are adherents of the Ismailite sect of Islam.

Shamanists. The following have been recorded as shamanists: 1, Chukchee; 2, Koryak; 3, Asiatic Eskimo; 4, Buryat of Irkutsk Provínce; 5, Ainu (nature worship and cult of bear); 6, Gilyak (like Ainu); 7 , Tungus of Irkutsk Province.

All the baptized Siberian natives practise shamanism. The Islamic Kirghiz and Tadjik have also retained some shamanistic beliefs.

\section{LANGUAGES}

I. Turkic Languages. The greater number of the inhabitants of Siberia and Central Asia speak Turkic or Tataric languages. In the following enumeration, those tribes that speak one or more languages in addition to Turkic are marked with an asterisk. Some of the Caucasians also speak Turkic languages.

1. *Aissor speak Azerbaijan Turkic (also Semitic-Syrian and Armenian).

2. Azerbaijan (Turkicized Iranians).

3. *Gorski or Mountain Jews speak Azerbaijan (also New Persian and use old Hebrew as the church language).

4. *Adjar-Gruzine (also Gruzinic).

5. *Ingiloi-Gruzine (also Gruzinic).

6. Hemshin (Turkicized Armenians, speak Osmanli).

7. Kaitak (Turkicized Mongol in Caucasus).

8. Caucasian Osmanli.

9. Kunyk.

10. Karachayev'tzy. 
11. Nogai.

12. Hazara (Turkicized Mongol in Afghanistan). ${ }^{1}$

13. Kirghiz-Kaisak.

14. Kara-Kirghiz.

15. Uzbeg.

16. Turkoman.

17. Kira-Kalpak.

18. Kipchak.

19. Taranchi.

20. Tatar of Turkestan.

21. Sarts.

22. *Turkestan Gypsies (also speak New Persian).

23. *Turkestan Jews (Old Hebrew as church language).

24. *Turkestan Arabs (also Arabic).

25. Bashkir.

26. Chuvash (Turkicized Finns).

27. Arin (Turkicized Yeniseians).

28-32. Baltir, Koibal, Karagas, Soyot, Uriankhai (Turkicized Samoyed).

33-34. Tatar of Tobolsk and Tomsk provinces.

35. Altaian or Cherneviye Tatar.

36. *Afghan.

37. *Baluchi.

38. Yakut.

39. Dolgan.

40. *Tungus living among or near the Yakut.

41. *Yukaghir.

42. *Russian settlers in Yakutsk Province (Some of them speak very poor Russian or have altogether abandoned their native speech).

II. Mongolic Languages. Mongolic dialects are spoken by the following peoples:-

1. Eastern or Mongol proper.

2. Western Mongol.

a. Astrakhan Kalmuck.

b. Caucasian Kalmuck.

c. Torgout of Jungaria and northwestern Mongolia.

IThere are contradictory accounts of the language spoken by the Hazara. Some travelers contend that they adopted the Persian dialect of the Tadjik, the former inhabitants of the present Hazara country. 
3. Buryat.

4. *Tungus living among the Buryat.

5. Sart-Ialmuck.

III. Finnic Languages.

A. Ugrian Dialects.

1. Ostyak.

2. Vogul.

3. Magyar.

B. Permian Dialects.

1. Votyak.

2. Zyryan.

C. Bulgarian Dialect.

1. *Mordvin.

2. *Cheremiss.

The Bulgarian branch of Finns is Russianized to a large degree.

D. The language of the Lapp.

IV. Samoyedic Dialects.

1. Samoyed.

2. Narym-Samoyed (usually called Ostyak-Samoyed).

V. Yeniseian Dialects.

1. Yeniseians (usually called Yenisei-Ostyak).

2. Kott (extinct).

3. Assan (extinct).

4. *Arin (Tatarized).

VI. Tungus-Manchu Languages.

1. Tungus proper.

2. Tungusic tribes of the Amur region.

3. The so-called Lamut clans.

4. The Manchu of the Amur River region.

5. *Buryat (a small part).

6. *Yukaghir.

VII. Ainu language (a distinct tongue)

VIII. Iranian Languages

A. New Persian

1. Persians

2. Tadjik

3. Galcha

4. Kurd.

5. Ossete. 
6. Yezide.

7. *Gorski Jews (and Azerbaijan).

8. *Turkestan Gypsies (and Turkic).

B. Archaic Persian.

1. Talysh.

C. Southern Aryan.

1. Hindoo.

2. Gypsies.

IX. Caucasian Languages.

A. Georgian proper or Gruzian Dialects.

1. Gruzian (Gruzian language).

a. *Adjara-Gruzian (Gruzian and Turkic).

b. *Ingiloi-Gruzian (Gruzian and Turkic).

2. Khevsur, Pshave, Tushin (Gruzian language).

3. Imeretine (Gruzian language).

4. Gurian (Gruzian language).

5. Georgian Jews (Gruzian language).

B. Megrel or Migrelian.

C. *Laze or Chan (Chan and Osmanli).

D. *Swan (Gruzian and Swan).

ii

\section{Abkhas-Cherkess Group}

1-2. The Abkhasian and the Abazin speak Abkhasian.

3-4. The Cherkess or Adighe and Kabardine speak Adighe. iii

*Lesghin (fifteen divisions) speak Avar and Kumyk Tatar. iv

1. Armenians.

2. Armenian Gypsies.

3. *Aissor (also Syrian and Azerbaijan).

$\mathrm{X}$. Chinese Language.

Armenian Language

Dungan.

XI. Americanoid Languages.

1. Chukchee. 
2. Koryak.

3. *Kamchadal (The greater number have abandoned their native language, having become Russianized).

4. * Yukaghir (Also speak Tungus, Yakut, and in some places, Russian).

5. *Chuvantzy (Have abandoned their native language of the Yukaghir stock and speak Chukchee, Koryak, or Russian).

6. Gilyak.

XII. Eskimo Dialects.

1. Asiatic Eskimo.

2. *Aleut of the Commander Island (also speak Russian)

XIII. Semitic Languages.

1. *Arabs (In Persia also speak New Persian; in Turkestan, Turkic).

2. *Turkestan Jews (Old Hebrew and Turkic).

3. ${ }^{*}$ Caucasian Jews (The so-called Gorski or Mountaineers speak Azerbaijan and New Persian and use old Hebrew as the church language; the Gruzian Jews speak Gruzian and old Hebrew as a church language; some Caucasian Jews speak Aissor, Iranian Tate, or one of the north Caucasian languages).

4. *Aissor (Speak a Syro-Chaldean language and one or two of the following: Armenian, Azerbaijan, Kurd, New Persian. Some Aissor know all these languages). 



\section{BIBLIOGR.APHY}

Abul-Ghazi-Bahadur Kihan. Histoire des Mongols et des Tartares. Publicé, traduite et annotée par le baron Désmaison. St. Petersburg, 1871-1874. English translation by Col. W. Miles. London, 1838.

Adrianoff, A. V. Sketehes of the Minusinsk Country. Tomsk, 1904. (In Russian). Andreev, M. S. On the Ethnography of the Tadjiks (The Tadjikistan Publication of the Society for the Study of Tadjikistan and the Iranian Peoples beyond its Borders, Tashkent, 1925). (In Russian).

Anuchin, $Y$. I. A Sketch of the Shamanism of the Yenisei Ostyak (Publications of the Mluseum for Anthropology and Ethnography of the Imperial Academy of Sciences, vol. 2, pp. 1-89, Petrograd, 1914).

Aristoff, X. A. (a) Notes on the Ethnic Composition of the Turkic Tribes and Peoples and Information about their Number (Shivaya Starina [The Old Living Times], Journal of the Ethnographical Division of the Imperial Russian Geographical Society, vol. 6, parts 3 and 4, pp. 277-446, St. Petersburg, 1896). (In Russian).

(b) Attempt at an Explanation of the Ethnic Composition of the Kirghiz-Kaisak of the Great Horde and of the Kara-Kirghiz, based on Clan Traditions and on the Existing Clan Divisions, on the Clan Ensigns (Tamga) and also on Historical Documents and on Anthropological Investigations (Shivaya Starina [The Old Living Times], Journal of the Ethnographical Division of the Imperial Russian Geographical Society, Parts 3-4, pp. 391-486, St. Petersburg, 1894). (In Russian).

Asmis, Rudolf. Als Wirtschaftspioner in Russisch-Asien. Tagebuchblätter. Berlin, 1924.

Baelz, E. Zur Vor und Urgeschichte Japans (Zeitschrift für Ethnologie, vol. 39, pp. 281-310, Berlin, . 1907).

Barthold, V. V. The Tadjik, an Historical Sketch (Articles on Tadjikstan of the Society for the Study of Tadjikistan [Soviet State of Tadjik] and of Iranian Peoples outside its Boundaries). Tashkent, 1925. (In Russian).

Batchelor, J. The Aino and their Folklore. London, 1901.

Bichurin, Father Yakinth. Collection of Information concerning Peoples living in Central Asia in Ancient Days. St. Petersburg, 1851. (In Russian).

Blochet, E. Le Nome de Ture dans l'Avesta (Journal of the Royal Asiatic Society, vol. 20, pp. 305-309, London, 1915).

Boas, Franz. The Decorative Art of the North American Indians (Popular Science .Ionthly, vol.63, pp. 451-493, October, 1903). 
Bogdanoff, A. P. Authropometrical Notes on the Natives of Turkestan (Bulletin of the Society of the Friends of Natural Science, Anthropology, and Ethnography, at the Imperial University of Moscow, vol. 34, part 5, Moscow, 1891). (In Russian).

Bogoras, W. The Chukchee (Memoirs, American Museum of Natural History, vol. XI, parts 1-3, 1904-1909).

Boule, M. Fossil Men. Elements of Human Palæontology. Translated from the French. Edinburgh, 1923.

Braun, F. F. Die Urbevölkerung Europas und die Herkunft der Germanen (Japhetische Studien zur Sprache und Kultur Eurasiens, vol. 1, Berlin-Stuttgart-Leipzig, 1922).

Castren, M. Alexander. (a) Reisserrinnerungen aus den Jahren 1838-1844 (In Nordische Reisen und Forschungen, Kaiserliche Akademie der Wissenschaften, St. Petersburg, 1853).

(b) Reiseberichte und Briefe aus den Jahren 1845-1849 (In Nordische Reisen und Forschungen, Kaiserliche Akademie der Wissenschaften, St. Petersburg, 1856).

(c) Versuch einer Jenissei-Ostjakischen und Kottischen Sprachlehre nebst Wörterverzeichnissen aus den genamiten Sprachen (In Nordische Reisen und Forschungen, Kaiserliche Akademie der Wissenschaften, St. Petersburg, 1858).

(d) Ethnologische Vorlesungen über die Altaischen Völker nebst Samojedischen Märchen u. Tatarischen Heldensagen. St. Petersburg, 1857.

Chekanovsky, A. Geological Investigation of Irkutsk Province. Irkutsk, 1874. (In Russian).

Chersky, I. D. Fossil Fauna in the Environs of Irkutsk (Bulletin of the Siberian Division of the Russian Geographical Society, vol. 5, no. 3-4, pp. 108-116, Moseow, 1892). (In Russian).

Choris, M. L. Voyage Pittoresque Autour du Mond, etc. Paris, 1822.

Czaplicka, M. A. (a) Aboriginal Siberia. A Study in Social Anthropology. Oxford, 1914.

(b) The Turks of Central Asia in History and at the Present Day. An Ethnological Inquiry into the Pan-Turanian Problem and Bibliographical Material relating to the Early Turks and the Present Turks of Central Asia. Oxford, 1918.

Daniloff, N. P. On the Characteristics of the Anthropological and Physiological. Traits of the Present Inhabitants of Persia (Memoirs of the Anthropological Division of the Society of the Friends of Natural Science, Anthropology and Ethnography, at the Imperial University of Moseow, vol. 17. 1894.) (In Russian). 
Dixon, Roland B. The Racial History of Man. New York, 1923.

Dyachkofi, G. The Country of the Anadyr. Vladivostok, 1893. (In Russian).

Erm:un, G. A. Reise um die Erde durch Nord-.Asien und die beiden Oceane in den Jahren, 1828-1830. Berlin, 1838.

Firdousi, Abul Casim. The Shath Nameh. Translated from P'ersian by J. Atkinson, London, 1S56; another edition, 1892. Other translations by A. S. Werner, 1905; by A. Rogers, 1907.

Georgi, J. G. Beschreibung aller Nationen des Russischen Reiches. St. Petersburg, 1776.

Golubowsky, P. The Pechenyegi, the Torki, and the Polovtzy before the Tatar Invasion. History of Southern Steppes of Russia in the Ninth to the Thirteenth Century. Kieff, 18St. (In Russian).

Gorostehenko, K. I. Skulls of the Kurgans in the Minusinsk District (Description of the Collections of the Minusinsk Museum, part 2, Minusunsk, 1900). (In Russian).

Guignes. J. de. Histoire générale des Tures, des Mongols et des autres Tartares oecilentaux. Paris, 1756-8.

Hall, H. L'. The Siherian Expedition University of Pennsylyania (The Museum Journal, vol. 7, pp. 27-45, Philadelphia, 1916).

Howorth, H. H. History of the Mongols from the Ninth to the Nineteenth Centuries. Part 1. The Mongols Proper and the Kalmueks (1876); Part II. The So-Called Tartars of Russia and Central Asia (1880); Part III, The Mongols of Persia (18ss). London.

Ivanorsky, A. A. (a) Anthropological Composition of the Population of Russia. Moseor, 1904. (In Russian).

(b) The Mongol Torgout. Moscow, 1891. (In Russian).

Jochelson, Waldemar. (a) The Koryak (Memoirs, American Museum of Natural History, vol. 10, 1905 1908).

(b) Kumiss Festivils of the Yakut (Boas Anniversary Volume, New York, 1906).

(c) Ethnological Problems of Bering Sea (Natural History, Journal of the American Museum of Natural History, vol. 26, no. 1, pp. 90-95, 1926).

(d) The Yukaghir (Memoirs, American Muscum of Natural History, vol. 13, 1910-1926).

(e) Archæologieal Investigations in Kamchatka (Publication No. 388, Carnegie Institution of Washington, 1928).

(f) Past and Present Subterranean Dwellings of the Tribes of Northeastern Asia and Northwestern Ameriea (International Congress of Americanists, Qurber, 1906).

Kastchenko, I. F. (a) The Skeleton of a Mammoth and Evidences that parts of its Body were eaten by Man (Memoirs, Russian Academy of Sciences, 8th series, vol. 11, no. 7, 1901). (In Russian). 
Kastchenko, N. F. (b) On the Question of the Synchronous Existence of Mammoth and Man (Memoirs, Tenth Archæological Congress in Riga, 1896, vol. 1, pp. 64-70, Moscow, 1899). (In Russian).

(c) Ein von Menschenverzehrtes Mammuth (Correspondenz Blatt der Deutschen Gesellschaf t für Anthropologie, Ethnologie, und Urgeschichte, XXVII Jahrgang, no. 6, p. 43, München, Juni, 1896).

Katanoff, N. F. Essay on an Investigation of the Uriankhai Language. Kazan, 1903. (In Russian).

Khangaloff, M. N. Some Data concerning the Mode of Life of the Northern Buryat (Ethnographical Review, Moscow, 1876). (In Russian).

Khangaloff, M. N. and Satoplaeff, N. Tales and Beliefs of the Buryat. Irkutsk, 1889. (In Russian).

Khanykoff, N. Description of the Khanate of Bokhara. St. Petersburg, 1843. (In Russian).

Kharuzin, N. History of the Development of the Dwellings of the Turkic and Mongolic Nomads of Russia. Moscow, 1896. (In Russian).

Khoroshikh, P. P. Investigations of the Stone and Iron Ages of the Irkutsk Country (Bulletin of the Biologico-Geographical Institute of Irkutsk University, part 1, Irkutsk, 1924). (In Russian).

Khoroshkhin, A. P. The Nations of Central Asia. Year-Book of the Turkestan. Country, pp. 303-330. Tashkent, 1874. (In Russian).

Khudyakoff, I. A. Verkhoyansk Collection of Yakut Tales, Songs, Riddles, and Proverbs (Published by the Eastern Siberian Division of the Imperial Russian Geographical Society, Irkutsk, 1891).

Klaproth, H. J. (a) Asia Polyglotta. 2 Parts. Paris, 1831.

(b) Mémoires relatifs à l'Asie. Vols. 1-2. Paris, 1824-1828.

Koganei, Yoshikiyo. (a) Ueber die Urbewohner Japans (Mittheilungen der Deutschen Gesellschaft für Natur. und Völkerkunde Ostasiens, vol. 9, Theil 3, pp. 297-330, Tokio, 1903).

(b) Beiträge zur Physischen Anthropologie der Aino (Mittheilungen aus der Medizinischen Facultät der Kaiserlich Japanischen Universität, Band 2, pp. 1-251, Tokio, 1894).

Krivoshapkin, P. The Yenisseisk District. St. Petersburg, 1863. (In Russian).

Langsdorf, G. H. von. Voyages and Travels in Various Parts of the World during the Years 1803-1807. Translated from German. 2 vols. London, 1813-1814.

Laufer, B. (a) Die angeblichen Urvölker von Yezo und Sakhalin (Central-blatt für Anthropologie, Ethnologie, und Urgeschichte, Band 5, Heft 6, Jena, 1900). 
Laufer, B. (b) The Reindeer and its Domestication (Memoirs, Anerican Anthropological Association, vol. 4, no. 2, 1917).

(c) Sino-Iranian, Introduction (Anthropological Series, Field Muscum of Natural History, vol. 15, no. 3, Chicago, 1919).

Lesseps, F. M. Travels in Kianchatka. Translated from the French. London, 1790. Isuschan, F. von. (a) The Early Inhabitants of Western Asia (Journal, Royal Anthropological Institute of Great Britain and Ireland, vol. 41, pp. 230-241, London, 1911).

(b) Völker, Rassen, Sprachen. Berlin, 1922.

Lyshin, X. I. An Anthropological Sketch of the Gypsies of Tauride Province (Sup- . plement to vol. 2, Bulletin of the Society of the Friends of Natural Science, Anthropology and Ethuography, at the Imperial University of Moscow, 1893). (In Russian).

Maksimoff, A. X. The Kara-Kialpak (Encyclopedie Dictionary edited by Jelesnoff, vol. 23, Mloscow, 1912). (In Russian).

Marr, X. The Japhetie Caucasus and the Third Ethnical Element in the Creation of Mediterranean Culture. Leipzig, 1920. (In Russian).

Martin, R. Lehrbuch der Anthropologie. Jena, 1914.

Massalsky, Prince V. I. The Turkestan Country (Vol. 19, of "Russia." Edited by P. P. Semenoff-Tyan-Shansky. St. Petersburg, 1913).

Matthew, W. D. Climate and Evolution (Annals, New York Academy of Sciences, vol. 24, pp. 171-318, 1915).

Merhart, G. von. The Palæolithic Period in Siberia: Contributions to the Prehistory of the Yenisei Region (American Anthropologist, N.S., vol. 25, pp. 21-55, 1923).

Miklosich, F. Zigeuner Europas, Wien, 1873.

Miller, V'sevelod F. Sketches on the Ossetines. vols. 1-2, Moscow, 1882; vols. 3-4, Moscow, 1887.

Moshkoff, V. The Gagauzy. Samples of the Folk-Literature of the Turkic Tribes, vol. 10. Edited by W. Radloff. St. Petersburg, 1904. (In Russian).

Muhammed-Emin, Rasul-Zade. The Iranian Turks (In the Stambul magazine, Turk-Yurdy, 1912).

Müller, Friedrich R. Allgemeine Ethnographie. Wien, 1873.

Müller, Max. Lectures on the Science of Language delivered at the Royal Institution of Great Britain in April, May, and June, 1861, and February, March, April, and May, 1863. London, 1866. Last edition, London, 1891.

Munro, N. G. (a) Primitive Culture in Japan (Transactions, Asiatic Society of Japan, vol. 34, pp. 1-212, Yokohama, 1906).

(b) Prehistoric Japan. Yokohama, 1911.

Nalivkin, V.P. and U. A Skctch of the Life of the Women of the Sedentary Population of Fergana. Kazan, 1886. (In Russian).

C̈ordenskiöld, A. E. Die Umseglung Asiens und Europas auf der Vego. Leipzig, 1882. 
Ovchinnikov, M. P. Material for the Study of Archæological Remains in the Environs of Irkutsk (Bulletin, Last Siberian Division of the Russian Geographical Society, vol. 35, no. 3, Irkutsk, 1904).

Pallas, M. P. S. Voyages en Différentes Provinces d l'Empire de Russie, et dans l'Asie Septentrionale. Traduite de l'Allemand. Tome Quatrième. Paris, 1793.

Pantyukoff, I. I. Anthropological Observations in the Caucasus (Bulletin of the Caucasus Division of the Imperial Russian Geographical Society, vol. 15, 1893). (In Russian).

Patkanoff, S. (a) Increase of the Native Population in Siberia. St. Petersburg, 1911. (In Russian).

(b) The Ancient Life of the Ostyak and their Heroes gathered from their Poems and Tales. St. Petersburg, 1891. (In Russian).

(c) Statistical Data on the Racial Composition of Siberia, its Languages and Tribes. St. Petersburg, 1912. (In Russian).

(d) Essay on the Geography and Statistics of the Tungusic Tribes of Siberia. Petrograd, 1906. (In Russian).

(e) Essai d'un Statistique et d'une Géographie des Peuples PaléoAsiatiques de la Sibćrie. St. Petersburg, 1903.

Pennant, Thomas. A Tour in Scotland, 1769. In John Pinkerton's Voyages and Travels, vol. 3, London, 1809.

Peschel, Oscar. The Races of Man and their Geographical Distribution. Translated from the German, New York, 1876.

Petri, B. E. (a) The Distant Past of the Buryat Country. Irkutsk, 1922. (In Russian).

(b) The Siberian Palæolith. Irkutsk, 1923. (In Russian).

(c) The Reindeer Breeding of the Karagas. Irkutsk, 1927. (In Russian).

Pilsudski, B. Die Urbewohner von Sachalin (Globus, Band 96, no. 20, pp. 325-330, December, 1907).

Potanin, G. N. (a) Eastern Motives in the Mediæval European Epic. Moscow, 1899.

(b) Sketches of Northwestern Mongolia (Publication of the Imperial Geographical Society, St. Petersburg, 1881-1885). (In Russian).

(c) The Tangut-Tibet Borderland of China and Central Mongolia. Travels in 1884-1886 (Publications of the Imperial Russian Geographical Society, St. Petersburg, 1893). (In Russian).

Pumpelly, R. Explorations in Turkestan, Expedition of 1904, Prehistoric Civilization of Anau. Origins, Growths and Influence of Environment. 2 vols. (Carnegie Institution of Washington, Washington, 1908).

Radloff, W. (a) Aus Siberien. 2 vols. Leipzig, 1853.

(b) Das Ili-Thal in Hoch Asien und Seine Bewohner (Petermann's Mitteilungen, vol. 12 , pp. 88-97, and 250-264, 1866). 
Radhof, II. (e) Siberian Antiquities, Materials for the Archarology of Russia (Published by the Imperial Areharologieal Commission st. Petershurg, 1sss, 1\$91, 1\$92, 1902). (In Russian).

(d) Die . Att.irkischen Inschriften der Mongolei. St. Petershurg, 1894, Neue Folge, 1897 .

(e) Die Jakutisehe Sprache in ihrem Verhültniss zu den Türksprachen (Memoirs, Imperial Russian Aeademy of seiences, Radloff, W: and Meliransky, P. M. rol. S, part 7,1907$)$.

(a) The Old Turkic Monuments in liosho-Tsaidam (Colleetion of Documents of the Orkhon Expedition. vol. 4 , st. P'etershurg, 1897). (In Russi:n).

(b) . Alnigurische Sprachproben aus Turfan. (Nachrichten ïber die von der Kaiserlichen Akademie der Wissenseluaften za st. P'etershurg im Jahre 1893 ausgerichtete Expedition naeh Turfan, St. Petersburg, 1599).

Rashid al-Din Tabib, Fazl Allah. Introduction a l'Ilistoire des Mongols. Translated by E. Blochet, E. J. W. Gihb Memorial, vol. 12, Leyden and London, 1910.

Ripley, W. Z. The Races of Europe. New lork, 1 S99.

Rostortzeff, M. Iranians and Greeks in South Russia. Oxford, 1922.

Ruclenko, S. I. Anthropological Investigation of the Natives of Northwestern Siberia (Memoirs, Imperial Aradeny of Sciences, vol. 33, no. 3. Petrograd, 1914). (In Russian).

sumoilovieh, A. X. (a) On the Question of the Suceessors of the Khazar and their Culture (Yerreiskaya starina [The Old Hebrew Times], vol. 11, 1p). 200-210, Leningrad. 1924). (In Russian).

(b) I'rohibited Words in the Voeabulary of a Married Woman among the Laisak (Shivara Starina [The Old Living Times], parts 1-2, [Petrograd, 1915). (In Russian).

Sarubin, I. I. (a) Notes and Material on the Ethnography of the MountainTacljiks (Memoirs, Muscum of Anthropology anel Ethnography, Russian Aeademy of siciences, vol. 5, part 1, p1). 97-148, Petrograd, 1918). (In Russian).

(b) A List of the Tribes of the Turkestan Country (The Russian Aearlemy of Siciences, Results of the Study of the Ethnical Composition of the Population of Russia, No. 9, Leningrad, 1925). (In Russian).

savenkov, I. T. (a) sur les Restes de I' Epoque Palcolithique daus les Environs de Krisnoiarsk (Congris Internationale d'Anthropologie at d'Archóologie de Moseow, vol. 1, 1892).

(b) The stone Age in the Minusinsk Country. Moseow, 1876. (In Russian). 
Schrenck, P. L. von. (a) Die Völker des Amur-Landes. Geographisch-Historischer und Anthropologisch-Ethnologischer Theil (Kaiserliche Akademie der Wissenschaft, St. Petersburg, 1891).

(b) Reisen und Forschungen im Amur Lande in den Jahren 1854-1856 (Kaiserliche Akademie der Wissen schaften, 4 vols., St. Petersburg, 1858-1881)

Schuyler, E. Turkestan. 2 vols. New York, 1871.

Schwarz, F. Turkestan die Wiege der Indo-Germanischen Völker. Freiburg, 1900. Sedelnikoff, A. P. Distribution of Population. (In "Russia," vol. 18, the Kirghiz Country, Chapter V). (In Russian).

Shirokogoroff, S. M. Anthropology of Northern China (North China Branch, Royal Asiatic Society, Extra vol. 2, Shanghai, 19:3).

Shitetzky, I. A. Sketches of the Astrakhan Kalmuck (Memoirs of the Society of the Fricnds of Natural Science, Anthropology and Ethnography, at the Imperial University of Moscow, vol. 57, pp. 110-123, Moscow, 1892). (In Russian).

Silinich, I. On the Question of the Anthropological Type of the Population of Northwestern Siberia (Russian Anthropological Journal, parts 3-4, pp. 43-45, Moscow, 1916). (In Russian).

Sinelnikoff, N. A. The Yenissei-Ostyak (Memoirs of the Society of the Friends of Natural Science, Anthropology, and Ethnography of the Imperial University of Moscow, vol. 28, part 1, Moscow, 1914). (In Russian).

Skrine, F. H. B. and Ross, E. D. The Heart of Asia, a History of Russian Turkestan and the Central Khanates from the Earliest Times. London, 1899.

Stepanoff, P. The Yenisseisk Province. St. Petersburg, 1835. (In Russian).

Sternberg, L. J. The Gilyak (Ethnographical Review, vols. 60-63, pp. 1-131, Moscow, 1905). (In Russian).

Sushkin, Peter P. Outlines of the History of the Fauna of Palæarctic Asia (Science, vol. 61, pp. 522-523, May 15, 1925).

Sykes, P. M. History of Persia. 2 vols. New York, 1915.

Szinnyei, Joseph. Finnisch-Ugrische Sprachwissenschaft. Leipzig, 1910.

Talko-Hrynceviz, J. D. The Ancient Inhabitants of Central Asia (Russian Anthropological Journal, Vol. 1, pp. 1-11, no. 2, Moscow, 1900). (In Russian).

Tallgren, A. M. Collection Tovostine des Antiquités Préhistoriques de Minoussinsk conservées chez le Dr. Karl Hedman à Vasa. Chapitres d'Archéologie Sibérienne (Société Finlandaise d'Archćologie, Helsingfors, 1917).

Tate, C. P. The Kingdom of Afghanistan. Bombay, 1911.

Thomsen, V. (a) Déchiffrement des Inscriptions de l'Orkhon et de l'Jénisséi. Notice Préliminaire (Bulletin de l'Académie Royale des Sciences et des Lettres de Danemark, 1893, pp. 285-299, Copenhagen, 1894). 
Thomsen, l. (b) Inscriptions d l'Orkhon déchiffrées, I, 1894 (Mémoirs, de la Socićtć Finno-Ougricnne, vol. 1, p. 224, and vol. 5, p. 54, Hclsingfors, 1894, 1896).

Torii, R. and Torii, Limico. Etude Archcologiques et Ethnologiques (Journal, Collcge of Science, vol. 36, Tokyo, 1914).

Tretyakoff, S. The Turukhansk Country. St. Petersburg, 1871. (In Russian).

Tsuboi, S Toḳu Jinruigaku Zasshi (Anthropological Magazine, no. 90, Tokyo, 1894). Ujalvy, C. dc. Les Aryans au Nord et au Sud l'Hindou-Kouch. Paris, 1896.

Vishniersky, B. N. Fossil Man in Russia (Appended to the Russian translation of Henry Fairfield Osborn's Men of the Old Stone Age, Leningrad, 1924).

Vitkorsky, X. I. Results of Excavations of Stonc Agc Burials in Irkutsk Province; Account of the Excavation of Stone Age Burials on the Banks of the Angara River (Bulletin, East Sibcrian Section of the Imperial Russian Geographical Society, vol. 12, no. 1, 1881, vol. 13, nos. 1-2, 1882).

Winkler, H. Die Altaische Völker und Sprachenwelt. Leipzig, 1921.

Wissler, Clark. The Ameriean Indian. An Introduction to the Anthropology of the New World. New York, 1922 (Second Edition).

Yadrintzev, X. M. (a) The Altai and its Natives. Petrograd, 1885.

(b) The Altaians and the Chern Tatars (Bulletin, Imperial Russian Geographical Society, vol. 17, pp. 228-254, 1881).

Yavorsky, I. L. (a) A Brief Review of a Scientific Mission in Central Asia. Odessa, 1895. (In Russian).

(b) An Anthropological Sketch of the Turkoman (Transactions, Anthropological Society of the Imperial Military Medical Academy, vol. 2, pp. 145206, Petrograd, 1897).

Yule, Col. Sir Henry. Travels of Marco Polo. Edited by Cordier. London, 1903.

Zaborowski, 11. Sur Dix Cranes de Rochefort, Les Blonds et les Proto-Caucasians (Bulletin, Société d'Anthropologie de Paris, tome 15 (4th series), pp. 28-65, 1894). 



\section{INDEX}

Abakin Tatars, 30.

Abdal, 91.

Abjui, 142.

Abkhas-Cherkess Group, 142.

Acknowledgments, $3-$.

Adighe. See Cherkess.

Administration, Turkestan, $71-72$.

Administrative, changes under the Soviets, 118-124; divisions, Siberia, 13; divisions of the Caucasus, 138, 139 ; divisions of the Cancasus under the Soviets, 15 s 159.

Adshar, 142.

Adultery, customs comected with, Sarts, 100.

Afghan, 113, 116, 169, $23 \mathrm{~S}$.

Agriculture, attempt at introduction in Kamchatka, 50, 53; Azerbaijan, 154; camels used in, S2; Kara-Kalpak, 122; hirghiz, s0, 130; recent introduction to Yakut, 27; Tadjik, 110, 111; Turkoman, 95 .

Agul, 145 .

Ainu, 5S-59, 67-69, 118, 180, 206, 213, 218 , 222; dance, 220; languages, 247 .

Aissor, 152-153.

Aiwanat Eskimo, 61, 62.

Alan, 242; identified with Ossete, 166; influence on Magsar, 18.

Alchin, 129.

Aleut, 63, 64, 207, 213; colonization of Commander Islands, 62-63; Commander, classification with Americanoids, 60 .

Aliel, 91.

Alphabets, Kirghiz, 79-S0.

Altai Tatar, 28-32, 191, 195, 19 S.

Altai-Tatar Kumandintzy, 205.

Americanoid languages, peoples speaking, 245-249.

Amerieanoids, of Siberia, 43-64; various elassifications of, $43-44$.

Amulets, Koryak, 214; Yukaghir and Tungus, 212.

Amur Orochon, 39.

Amur Tungus, 213.

Andi, 145 .
Animal, breeding, Kirghiz, 80-82, 130; breeding, nomadic peoples, 187 ; dances, 219-220; dances, Koryak, 222 223.

Animals, domesticuted, Central Asia, 74; Commander Islands, 64; Kamchadal, 50; Kïrghiz, S0-S1; Tadjik, 112; owned in Turkestan by provinces, 124 .

Anouli, 91.

Arabachi, 91.

Arabs, Caucusus, 153; Turkestan, 116.

Archeological evidence, bearing on original home of the Yakut, 26-27; previous occupation by Ainu population, $6 \mathrm{~S}$.

Archæology, Asiatic Steppe provinces, 125.

Archin, 145.

Aretic or Hyperborean races, tribes included under, 43.

Area, Armenia, 159; Azerbaijan, 159; Caucasus, 137; Kara-Kalpak Autonomous province, 122; Kara-Kirghiz Autonomous province, 121; Republic of Georgia, 158; Tadjik Autonomous Republic, 121; Turkestan, 71; Turkmanistan, 120-121; Uzbekistan, 119, 120.

Argyn, 128.

Arin, 65.

Armenia, administration of, 159.

Armenian, peoples speaking, 248.

Armenians, 146-149, 170.

Art, conventionalization, introduced by Buddhism, 215; graphic, 213; influence of religion on, 215-216; palæolithic, examples of in Western Siberia, 230; realism, forbidden by Mohammedism, 215.

Artifacts, Magdalenian, Irkutsk District, 231 ; microlithic, near Krasnoyarsk, 230; neolithie, in Mongolıa, 232; neolithic, near Olekminsk, 232; palæolithie, Angara Valley, 230; palæolithic, in the Caucasus, 229; palæolithic, near Krasnoyarsk, 229-231; palæolithic, vicinity of Irkutsk, 230. 
Aryan, family, Iranian peoples members of, 162; pcoples, in Central Asia, 71. Aryans, 106-115, 180.

Asiatic Eskimo, 60-62, 211, 213.

Asiatic Russia, former administrative divisions of, 24.

Assam, 65 .

Assur. See Aissor.

Ata, 91 .

Autonomous states in Cis-Caucasia, 159160.

Avar, 19, 145, 242.

Azerbaijan, 150, 153-154, 159, 169.

Bactrians, 168.

Bagpipe, Gypsy, 217.

Balkar, 156, 239.

Baltic Finns, 19-20.

Baluchi, 169, 238.

Baraba Tatars, 28.

Bark-covered tents, Altai Tatar, 191192, 195.

Barley, grown in Kamchatka, 53.

Bartering dance, Chukchee, 221-222.

Bashkir, 18, 127, 128, 136, 195, 198, 203.

Basmachi uprising, Kirghiz, 78 .

Basques, language spoken by, 138.

Bear, ceremonies, 222; cult, Goldi, 223; dance, Kamchadal, 220; festival, Ainu and Gilyak, 222; festival. Gilyak, 59.

Bedjiye, 88.

Beltir, 23, 32.

Birar, 38.

Birchbark, tent covers, 191, 195.

Black-Kirghiz. See Kara-Kirghiz.

Block houses, Siberian natives, 203, 204.

Boats, Commander Aleut, 64; skin, lacking among Kamchadal, 49, 53.

Body painting, not practised by north and central Asiatic peoples, 210.

Bokharan Jews, 115.

Boshas, 151.

Brachycephalic peoples, 178, 179.

Brahman peoples, 244.

Brahmanism, in India, 171.

Bride price, Kirghiz, 83; Sarts, 99; Tadjik, 111; Turkoman, 94, 96; Uzbeg, 86.
Bronze age, remains of, 234 .

Buddhism, Buryat conversion to, 130; conversion to by aborigines of Siberia and Central Asia, 243; in India, 171; influence on art, 215; spread in Turkestan, 75; Tungus, 41.

Buddhist peoples, 244; Buryat, 34; Kalmuck, 106, 157.

Buddhists, drums used by, 216 .

Budukha, 145.

Bukei-Kirghiz, 198.

Bukeyef, 125, 128.

Bulgarian Finns, 20-21.

Burial, customs, Kirghiz, 83, 103; customs, Sarts, 104; methods, Iron and Bronze age peoples, 235; mounds, Asiatic Steppe Provinces, 125; mounds, Transbaikalia, southern Siberia, and southern Russia, 237.

Burusheski, 138.

Burut. See Kara-Kirghiz.

Buryat, 33, 34, 130, 180, 188, 195, 198, 203, 211, 212, 225-227.

Buryatized Tungus, 34 .

Bzyby, 142.

Camel breeding, Turkestan, 81-82.

Canoe, dugout, Gilyak, 60.

Carving, 214-215; realistic, Koryak, 214.

Caste marks, Hindoo, 210.

Castes, in India, 171.

Cattle, Bering Island, 64; breeding, Kamchadal, 50; breeding, Kirghiz, 81, 122; brceding, Siberian Cossacks, 134; importation in Kamchatka, 50; skins, used for clothing, 212.

Caucasian, languages, peoples speaking, 248; Mongoloids, 153-157; Osmanli, 156.

Caucasus, peoples of the, 137-160; peoples, historical wanderings, 238239.

Central Asia, administrative divisions of under the Sovicts, 117.

Cephalic index, Ainu, 69, 178; Aissor, 153; Armenians, 146, 178; Chinese, 178; distribution, 176-178; Dungan, 178; Finnic Lapps, 178; Gilyak, 178; 
Kanchadal, 53; Gỵpsies, 172; Kiilghiz tribes, 128; Kurd, 149; Persians, 163; Tadjik, 108; Tungus, 178; Turkoman, 17s; Zyryan, 178.

Cephatic module, 182-184.

Cephalic module stature index, 1St-186.

Cereals, origin of cultivation in Central Asin, 74 .

Ceremonial cycle, Asiatic Eskimo, 223; Maritime Chukehce, 223.

Ceremonies, Chukchce, 221-222; Reindeer Chuckchee, 223; Reindeer horvak, 223.

Chamaeprosopic peoples, 181.

Chan. See Lazes.

Chechen group, $1+3$.

Cheremiss, 20, 21.

Cherneviye Tatars, 29.

Chinese, 17S; domination in Central Asia, 75 ; peoples speaking, 248 .

Chinesized peoples, 104-105; Manchu, 241; Dungan, $17 \mathrm{~S}$.

Christian peoples, 50.

Christianity, conversion to, Tungus, 41 ; in Turkestan, 76 .

Chud, 233.

Chudes, remains of, 126 .

Chukchee, 45-46, 187, 195, 206-211, 216, 221-222.

Chukchee-Koryak-Kamchadal physicocultural complex, 53-54.

Chulyma Tatars, 28.

Chuvantzy, 54-57.

Chuvash, 20, 21.

Circle dance, 218-219.

Circumcision rites, Kirghiz, 83; Sarts, 102-103.

Circumpolar culture, components of, 54 .

Cis-Caucrsia, autonomous states in, $159-160$.

Clan, defined, 129; heads, Kirghiz, 130; organization, Kírghiz, 129; syustem, Kirghiz. 84.

Clans, Dog-Breeding Yukaghir, 56 ; Gilyak, 59; haragas, 32; Kara-Kalpak, 96-97; Kirghiz, 79; KirghizKaisak, s.; Reindeer Yukaghir, 55; Saryk, 91 ; segregation by kin groups,
Turkonan, 95-96; Uzbeg, 86, S8.

Clarinet, played in Turkestan, 217.

Class system, Kara-Kirghiz, 45; K̈irghizKaisak, 84 .

Clergy, Sart conception of, 76-77.

Colonization, Commander Islands, 62-63; Russian, of Steppe Provinces, 133.

Comedians, Sarts, 102.

Common law, Kirghiz-Kaisak, 84; Turkonıan, 95; Uzbeg, 97.

Comonians, 97.

Conical tents, 189-195; Kirghiz, 131.

Conquest, Chinese, of Mongolic peoples, 157; Kurd, by Turks, 164; Mohammedan, of Khorezm, 167-168; of Peking, by Jenghis Khan, 105; Russian, of Khanate of Kokand, 87; Russian, of Steppe provinces, 127, 133; Russian, of Turkestan, 71, 95, 97, 168; Seythians, by Sarmatians, 166; of Turkestan, 75; Turkestan, by Arabs, 116; Turkestan, by Jungarians, 127.

Cooking, Kirghiz, 80.

Cossacks, Steppe provinces, 133, 134-135.

Costume, 212-213; Afghans, 116; Aleut, 64; Hindoos, 113-114; Kirghiz, 8384; Sarts, 87, 104; Tadjik, 87, 112; Tungus, 42; Turkestan Jews, 116; Turkoman, 93; Uzbeg, 87.

Courts, Turkoman, 95.

Covers, for conical tents, types of, 189 , 191-195; for cylindro-conical tents, types of, 196-198; for pyramidal dwellings, 201; for shades and screens, 189.

Crests, antiquity of, Kirghiz subclans, 129-130.

Crime, definition of, Turkoman, 95.

Culture, affinitics, Yukaghir and Chukchee and Koryak, 55; general characterizations of, Aissor, 153; Azerbaijan, 154; Bokharan Jews, 115-116; Bulgarian Finns, 20; Buryat, 34; Chcremiss, 21; Cherneviye Tatars, 29; Chukchee, 45; Dinlin, 236; Dungan, 105; Gilyak, 60; Gruzian and Gorsky Jews, 152; Gypsies, 172; Gypsies of Turkestan, 114 115; Kamchadal, 4950; Kara-Kalpak, 96; Kipchak, 97; 
Kirghiz-Kaisak and Kara-Kirghiz, 79; Koryak, 47; Kumyk, 154, 156; Kurds, 149; Lapps, 22; Magyar, 18; Ostyak Samoyed, 23; Sart-Kalmuck, 106; Soyot, 23; Soyot and Karagas, 24; Suomi Finns, 19; Tadjik, 108, 110; Tadjik and Ihlat, 163; Tungus, 42, 241; Tungus proper, 39, 40; Turkestan, 73, 74; Turkoman, 95; Turks of the Altai Mountains, 29; Uzbeg, 78, 85-86; Votyak, 20; Yakut, 27; Zyryan, 20; influence of Aryan on Bronze and Iron age peoples, 234; influences, Turkic and Arabic in Turkestan, 75; palæolithic, in Siberia, 231; resemblances, Americanoids and Northwest Coast Indians, 53-54; sequences in Turkestan, 233.

Cylindro-conical tents, 195-198.

Cylindro-dome or cupola-shaped felt tents, 198-199.

Dance, mourning, Sarts, 104.

Dances, dramatic, and mimetic, 219; religious, 222-223; Sarts, 101-102; Turkestan, 221.

Dancing, 218-223; boys, Sarts, 101; steps, Yukaghir and Yakut, 218-219; women, Sarts, 102.

Danube Bulgarians, 21.

Darghin, 145.

Daur, 38, 39.

Dead, customs connected with, Kirghiz, 83; Sarts, 103-104; Tadjik, 113; feasts in memory of, Kirghiz, 131; method of disposal, Parsis, 163.

Decoration, personal, 210-213; Yakut birchbark tent, 191.

Deformation of head, Sarts, 99.

Designs, on ceremonial objects, 216; carpet, Persia, Central Asia, Daghestan, Caucasus, Turkoman, 213; for decoration of fur clothing, 212; motives for, in decorating clothing, 213; ornamental, Yakut, 215.

Dialectic, affinities, Tungus tribes, 39; groups, Amur peoples, 38.

Dialects, Asiatic Eskimo, 62; Eskimo,
61; Finnic, 17; Kamchadal, 49; Turkic, 79, 92, 98; Yeniseian compared with Mongoloid, 66.

Didol, 145.

Digor, 150.

Din, 65.

Dinlin, 65, 129, 235-237.

Disharmonic faces, 180.

Distribution, cephalic index, 176-178; circle dance, 218; conical tents with skin and birchbark covers. 191; cylindro-conical tent, 197-198; cylindroconical felt tent, 198; cylindro-dome or cupola-shaped felt tent, 198; drum, 216-217; earth huts, 206-208; Finnic peoples, 16; Jew's harp, 217; Kalmuck, 33; Lapps, 21-22; log houses, 203; Mordvin, 20; neolithic man in Asia, 231; peoples in the Caucasus, 159; religions, 243; Samoyed, 23; stature, 173-176; Tungus, 38; Tungus proper, 41; Turkic tribes, 25; Western Mongol or Kalmuck, 33.

Divorce, Sarts, 100.

Djek, 145.

Dog, breeding, Commander Aleut, 64; driving, Bering Island, 64; driving, Gilyak, 59; use and care of, Kamchadal, 50 .

Dolgan, 26, 203.

Dolichocephalic peoples, 178 .

Dome-shaped tents, Torgout, 131.

Domestication of animals, Central Asia, 74; reindeer, 24. See Animals.

Donkey, importance in nomadic life in Turkestan, 82.

Dravidians, 170.

Drawing, 213-214.

Dress, 210-213; men's and women's, Kirghiz, 84; mourning, Sarts, 104; Tadjik women, 107; Turkoman, men's and women's, 93; Uzbeg, 87; winter, northern Siberian natives, 212. See Costumes.

Drums, Siberian, 216; types in Turkestan, 216-217.

Dulat, 129.

Dungan, 97, 104-106, 178, 180, 208. 
Durani Afghan, 116.

Dwellings, 154, 185-210; Azerbaijan, 20S; Central Asiatic natives, 20S; classified as to form, 158; Commander Aleut, 63; Dungan, 20s; Galcha, 209; Kara-Kalpak, 208; Kirghiz, 80, 131133, 20S; Kolyma Yukaghir, 200; northeastern Siberian peoples, 206207; remains on Lake Baikal, 27; Sarts, 20S; summer and winter, 203; Turkoman, 93, 205; Uzbeg, 87, 208; Yakut, 200.

Earrings, Koryak and Chukchee, 211.

Earth, houses, Bering Island, 63; huts, 204-20s; Yakut, 191, 195, 203.

Embroidery; bead and silk, 213; practised by men, Tadjik, 113.

Engravings, Arctic peoples, 213-214.

Epic tales, Buryat, 225-227; Yukaghir, 225.

Epicanthic eyefold, Americanoids, 53.

Ersar, 91.

Eskimo, 61, 207, 211, 216, 223; dialects, 249; disharmonic faces, 180 ; tribal names, 60 .

Esthonians, 19.

Ethnographic map, Asiatic Russia, 13.

Europeans, Caucasus, 151.

Eye, color, Aissor, 153; Armenians, 146; Burusheski, 13s; Kurd, 149, 165; Ossete, 167; Persians and primitive Iranians, 164; Sarts, 99; Uzbeg, 85; Yeniseians, 65; forms, Americanoids, 53; Aissor, 153; Gilyak, 58; KirghizKaisak, 79; Sarts, 99; Turkoman, 92; Ural-Altaic peoples, 15.

Eyebrows and eyelashes, painting, in Turkestan, 210.

Face, form, Gilyak, 5S; Kara-Kalpak, 96; Kara-Kirghiz, 79; Kirghiz-Kaisak, 79; Sarts, 99; Turkoman, 92; Uzbeg, 85; painting, Kamchadal, Ainu, and Koryak, 210; piercing, 211; Sarts, 99-100; width, Americanoids, 53.

Facial index, 180-182; Kurd, 165; Ossete, 167.
Family life, Sarts, 99-102.

Farms, Uzbeg, 86-87.

Fast, Kirghiz, 131.

Feast, circumcision, Sarts, 103; funeral, Sarts, 104.

Felt-covered tents, 191, 195, 198-199.

Festivals, religious, Kirghiz, 131.

Finuic languages, peoples speaking, 247.

Finnic Lapps, 178.

Finnic tribes, 16-25.

Finno-Ugrian stocks, place of origin, 1617.

Finus, place of origin of, 17 ; relation to Samoyed, 22.

Fireplaces, in conical tents, 189, 191; Yakut houses, 201.

First Omolon clan, Yukaghir, 56.

Fish skins, use for clothing, 213.

Fishermen, stature of, 175 .

Fishing, methods, Kamchadal, 49; peoples, 188; Ural Cossacks, 135.

Flat-roofed block houses, 203.

Flat-roofed dwellings, of various materials, 208-210.

Flute, not used by Siberian peoples, 217 .

Folklore, Gilyak, 59; Kirghiz, 80; Uzbeg 86.

Food, Azerbaijan, 154; Commander Islands Aleut, 63-64; Kamchadal, 50; Kirghiz, 80, 81; Tadjik, 112; Tatar, 112; Turkoman, 94-95; Uzbeg and Sart, 87.

Footwear, Tadjik, 112; Turkoman, 93.

Forest Cheremiss, 21.

Forest Kamassintzy, 32.

Fortresses, ruins of Tadjik, 108, 113.

Fowl, domesticated, Commander Islands, 64.

Framework, conical tent, 189; cylindroconical tent, 195-197; cylindro-dome or cupola-shaped felt tent, 198-199; pyramidal dwellings, 201; shades and screens, 189.

Fuel, Commander Islands, 63.

Funerals, Sarts, 103-104.

Fur-bearing animals, Commander Islands, 64.

Fur clothing, northern Siberia, 212. 
Gagauzy, 96.

Galch ‘ 108, 168, 169-170, 209, 238.

Galga. See Ingush.

Gens, defined, 129.

Geometric designs, 216.

Georgia, administration, 158-159.

Georgians, 140-142, 146.

German colonists, Steppe provinces, 135.

Ghilzai, 116.

Gilyak, 57-60, 178, 206, 207, 213.

Ghuz Turks, 96.

Goblets, for kumiss, decoration of, 215 .

Goklan, 91 .

Goldi, 38, 39, 223.

Gorsky Jews, 152.

Government, Armenians, 148, 159; Azerbaijan, 159; Georgia, 159; Kurdistan, 149; Samoyed, 22; Siberia, 13; Slavonized Finns, 21; republics of Bokhara, Khorezm, and Turkestan, 118-119.

Great Horde, Kirghiz, 127, 129.

Greek Catholicism, adoption by peoples of the Caucasus, 243.

Greek Catholic peoples, Abkhas, 142; Chechen, 143; Daghestan, 145; Siberian Cossacks, 134; Swan, 142.

Grusians, 140.

Gruzian Jews, 152.

Gruzinized peoples, 150 .

Guitar, 218.

Gurians, 142.

Gursinized Megrels, 142.

Gypsies, 172, 180; Caucasus, 151 ; Iranians, 170-172; Turkestan, 114115.

Habitat, Abdal, 91; Abkhas, 142; Afghans, 116; Agul, 145; Aissor, 152; Aiwanat, 62; Arabachi, 91 ; Arabs in Turkestan, 116 ; Archin, 145; Armenians, 146; Ata, 91; Avar, 145; Azerbaijan, 153; Balkar, 156; Baraba Tatars, 28; Bashkir, 18; Beltir, 2324; Bokharan Jews, 115; Bukeycf, 125; Buryat, 34; Caucasian Osmanli, 156; Chechen, 143; Cheremiss, 20, 21; Cherkess, 142; Chernevive Tatars, 29;
Chukchee, 45; Chulyma Tatars, 28; Darghin, 145; Dinlin, 235-236; DogBreeding Chuvantzy, 57; Dog-Breeding Yukaghir, 57; Dolgan, 26; Dravidians, 170; Dungan, 105; Ersar, 91; Esthonians, 19; Finnic peoples, 25; Forest Cheremiss, 21 ; Forest Kamassintzy, 32; Gagauzy, 239; Georgian stocks, 140-142; Gilyak, 57-58; Goklan, 91; Gorsky Jews, 152; Gruzian Jews, 152; Gurians, 142; Hindoos, 113, 170; Igdyr, 91; Ingush, 143; Jews in the Caucasus, 152; Kabardin, 142; Kachin Tatars, 30, 32; Kakhetins, 142; Kalmuck, 33, 157; Kamchadal, 49; Kamassintzy, 24; Karachai, 156; Karagas, 24; "Karelians, 19; Kara-Kalpak, 96; Kara-Kirghiz, 77, 78; Khevsur, 143; Kipchak, 97; Kirghiz, 78, 125; Kirghiz-Kaisak, 77; Kist, 143; Kizyl Tatars, 30; Koibal, 23-24; Koryak, 47; Kumandintzy, 29; Kumyk, 154; Kurds, 149, 164; Kurin, 145; Lapps, 21-22; Lak or Kazi-Kumuk, 145; Lazes, 142; Lebeddintzy, 29; Lesghin, 144-145; Magyar, 242; Maritime Chukchee, 46; Maritime Koryak, 47; Megrel, 142; Mordvin, 20; Mountain Chechen, 143; Narym Samoyed, 65; Nogais, 156 ; nomadic peoples Turkestan, 74 ; Nookalit, 62; Ogurdjal, 91; Ossete, 149-150, 166, 238; Ostyak, 17; Oudin, 145; Peekit, 62; Persians, 113; Ratcha, 142; Reindeer Chukchee, 4546; Reindeer Chuvantzy, 56; Reindeer Koryak, 47; Rutul, 145; Sagai Tatars, 32; Salor, 91; Salyr, 91; Samoyed, 66; Sart-Kalmuck, 106; Sarts, 98; Saryk, 91; sedentary - peoples of Turkestan, 74; Shortzy, 29; Siberian Bukhartzy, 28; Sogdians, 168; Soyot, 23, 24; Swan, 142; Tabsaran, 145; Tadjik: 106; Talysh, 150; Taranchi, 97, 98, 240; Tatars, 97; Tate, 150; Tawgi Samoyed, 23; Tckke, 88, 91; Teleut, 29, 205; Thushi. 143; Tobolsk Tatars, 28; Tomsko- 
Kisunctzk Taturs, 29; Tsova-Thushi, 143; Tungus, $37,42,66,241$; Tungus proper, 39-41: Turkic tribes, 235; Turkoman, ss, 157; Turks of the Altai Mountains, 29; [lovkk, 142; I'ral-iltaic peoples, 14; U'riankhai, 25; I'zbeg. S5; V'csp, 19; Vod, 20; logul, 17; Votvak, 20; Western Mongol or Kalmuck, 33; Wooteclit, 26; Yagnobtzy; 16s; Yakut, 241-242; Yeniseinns, 66; Yezidis, 149; Yikirganlit, 62; Yomud, 91; Yurak samoved, 23; Zurran, 20.

Hair, body, Gilyak, 5s-59; color, Aissor, 153; Kürghiz-Káaisak, 79; Kurd, 165; Ossete, 167; Persians, 178; Persians and primitive Iranians, 164; Samoyed, 65; Sarts, 99; Tungus, 65; Ugrian Ostyak, 65; Uzbeg, 85; Western Finns, 16; Yeniseians, 65; dressing, 211-212; Afghans, 116; Hindoos, 114; Kirghiz, 83-84; Sarts, 101; Tadjik, 112; form, Chukchee, Koryak, and Kamchadal, 53; Ural-Altaic peoples, 15; ornaments, Northeastern Siberian peoples, 211.

Hazara tribes, 33.

Head form, Ainu, 234; Americanoids, 53; Armenians, 146; Asiatic peoples, 233; Burusheski, 138; Chud, 233-234; Georgians, 146; Gilyak, 58, 59-60; Gruzian and Gorsky Jews, 152; Gypsies, 172; Jews of lemen, 152; Kirghiz-Kaisak, 79; Kurd, 149, 165; Ossete, 167; Persians, 163-164, 17s; Sarts, 99; Tadjik, 108; Turkoman, 92; Uzbeg, 85; Yeniseians, 234.

Headgear, Kíirghiz, 84; Persia and Sarts, 104; Tadjik, 112; Turkoman, 93; Uzbeg, 87 .

Height-length-breadth head index, 182 18.3.

Hezare. See Hazara.

Hindoo, $113-114,170-172$.

Historical, background, Ainu, 67; data, on the Kirghiz, 125-12s; wanderings. $237-243$.

History, Armenians, 146-148.
Hittite, connected with Armenians, 238; l:mgurge, 146.

Hordes, Kirghiz, 126-128.

Houses, Arctic peoples of Eurasia, 54; Azerbaijan, 154; Central Asiatic natives, 20s; Commander Aleut, 63; construction of Yakut, 201; Liskimo and Chukchee, 60; Gilyak, 59, 210; Famchadal, 210; Karachni, 202; Karapapak, 156; $\log$, distribution of use, 203; Sarts, 99; Tadjik, 111-112, 202, 210; underground, remains of, 60 . See Dwellings.

Horses, breeding, Yakut, 27; care and use, Kamchadal, 50 ; representation in Yakut art, avoided, 215; sacrifice of, Kirghiz, 131; skins, use for clothing, 212 ; types domesticated by Kirghiz, SO- 81 .

Hun-nu, 235.

Huns, 126.

Hunting, ceremonies, Yukaghir, 223; Commander Aleut, 64; grounds, assigned, Northeastern Siberia, 187; methods, Kamchadal, 49-50; peoples, 187.

Hyperbrachycephalic peoples, 178, 179.

Igdỵr, 91.

Ihlat, 163.

Illiteracy, Armenian and Azerbaijan, 154; Kirghiz, 79.

Imeretins, 140 .

Immigration, Russians into Steppe Provinces, 133.

Implements, agricultural and mining, Bronze Age, 235.

Indo-Europeans, 149-150; languages, 162,164 ; peoples, 137,138 .

Indo-Germanic family, 162, 171.

Industani-liuli, Indian gypsies, 115.

Ighilois, 140.

Inheritance, of office, Kíara-Kírghiz, 81 .

Inner Horde, Kirghiz, 12S.

Inseriptions, pictographic, on the Yenisei and Orkhon, 65 66, 168.

Interior arrangement, Azerbaijan houses 154; conical tent, 189-191; cylindro- 
conical tent, 198; Kirghiz tents, 131132; Kirghiz winter house, 132; Yakut house, 201, 203.

Intermarriagc, Kurd with Turkic women, 165; Shiites and Sunnites, 163.

Intoxicants, used by Sarts, 101 .

Inuti, 62.

Invasion, Arab, of Persia, 75; Magyar of Western Europe, 19.

Iranian, languages, peoples speaking, 247-248; peoples, 161-172, 238; peoples, historical wanderings, 237 238; peoples of Turkestan, influence of, on invaders, 77; peoples of Turkestan, subjugation of, 75 .

Iranic Turks, 92.

Iron. See Ossete.

Iron age, memorial tablets of, 234 .

Iron working, Tomsko-Kusnetzk Tatars, 29.

Irrigation system, Tadjik, 111; ancient Turkestan, 72.

Ismailite sect, peoples belonging to, 245; Tadjik belong to, 111 .

Ivenki, 38.

Jagatai dialect, peoples speaking, 85, 98 . Japhetic-Aryan language, 146.

Japhetic languages, peoples speaking, 137-140.

Japhetides, 145-151, 180.

Japhetism, theory of, 137-140.

Japhetized Aryans, 151.

Jat, 172.

Jewelry, Turkoman women, 93.

Jews, Caucasus, 151; Bokharan, 115;

Turkestan, 115-116.

Jew's harp, distribution, 217.

Jungarians, 127.

Kabardin, 142.

Kachin, 30.

Kachin Tatars, 26, 198.

Kaitak, 158.

Kakhetins, 142.

Kalmuck, 33, 106, 127, 136, 157, 180, 198, 199, 239.

Kamassintzy, 24.
Kamchadal, 49-53, 59, 188, 206, 212, 213, $218,220$.

Kangli, 19, 88, 129.

Kan-giu, 129.

Karachai, 155, 156, 239.

Karachi, 172.

Karagas, 24, 32-33.

Kara-Kalmuck, 29.

Kara-Kalpak, 96-97, 122, 198, 208.

Kara-Kalpak Autonomous Province, 122.

Kara-Kirghiz, 77, 78, 120, 121, 125.

Kara-Kirghiz Autonomous Province, 121.

Kara-Nogai, 198.

Karapapak, 156.

Kara-Klobub. See Kara-Kalpak.

Karaliuli, 115.

Karelians, 19.

Kartvelians, 140-142.

Kazi-Kumuk, 145.

Kerek Koryak, 47.

Keretkin ceremony, 221, 223.

Khagas. See Kirghiz-Kaisak.

Khalkas, 33.

Khanate of Kokand, Russian conquest of, 87 .

Khaput, 145.

Khazar, 19, 25, 154.

Khevsur, 140, 143.

Khinalug, 145.

Khodja, 91.

Khorezmians, 167-168.

Kibi, 38.

Kinship, reckoning of, Kirghiz, 129.

Kipchak, 97, 120, 128.

Kirei, 128.

Kirghiz, 33, 65, 77-75, 97, 106, 113, 122 , 125-133, 134, 180, 198, 199, 203, 208. $236,242$.

Kirghiz-Kaisak, 77, 84, 88, 120, 125, 126.

Kist, 143.

Kitchi-juz, 127.

Kizyl Tatars, 30.

Koibal, 23, 32.

Koreans, 38.

Kolyma Yukaghir, 191.

Koropok-guru, 68.

Koryak, 47-49, 198, 207, 211, 212, 213. 214. 216, 222-223. 
Kott, 65 .

Kuman, 128.

Kumandintzy, 29.

Kumiss, festivals, lakut, 27; important summer food of Kirghiz, $\mathrm{S} 0$; not used by Turkoman, 95; not used by Uzbeg, 87; preparation and use in Turkestan, \$2.

Kumyk, 154-156.

Kumyk-Tatar dialect, 145.

Kurdistan, 164.

Kurds, 148. 149, 161-166.

Kurilian. See Kamchadal.

Kurin, 145.

Labor, division of, care of tent, 191; constructing dwellings, 189; constructing felt-covered tent. 199; Kirghiz, 83; Tadjik, 112-113; Turkoman, 92: Uzbeg, 86.

Labrets, Diomede Islanders, 62; Eskimo, 211.

Lak, 145.

Languages, 245-249.

Language, Abakan Tatars, 30; affinities, Gilyak, 58; Adshar, 142; Aissor, 152; Andi, 146; Arines, Assan, Kotts and Yeniseian Ostyak, 65, 236; Armenians, 146, 148; Asiatic Eskimo, 62; Avar, 145; Azerbaijan, 154, 239; Balkar and Karachai, 156; Baraba Tatars, 28; Basques, 138; Bulgarian Finns, 20; Bureshki, 138; Buryat, 34; Caucasian aborigines, 137; Caucasian gypsies, 151; Caucasian Persians, 151; Central Asiatic Jews, 116; Chechen, 113; Cheremiss and Mordvin, 20-21; Cherneviye Tatars, 29; Chulyma Tatars, 28; Chuvash, 21; Danube Bulgarians, 21 ; Darghin, 145; Dolgan, 26; Dungan, 104, 105; extinct of the Etruscans, Pelasgians, and Iberians, 135; Finnic, 22; Finno-Ugrian, 17; Forest Cheremiss, 21; Galcha, 169; Gruzian and Gorsky Jews, 152; Gypsies, 172; Hazara, 33; Hemshin, 118; Hindoo, 171; Hittite, 146;
Hungarian, 19; Indo-European, 17; Japhetic, 137, 138; Kabardin, 142; Kachin Tatars, 32; Kalmuck, 157; Kamchadal, 49; Karachai, 155; KaraKalpak, 96; Khazar, 154; Kirghiz divisions, 79; Küghiz-Kaisak, 126; Kizyl Tatars, 30; Kumandintzy, 29; Kumyk, 154; Kurds, 149, 164-165, 23S; Lapps, 22; Lazes, 142; Lebedintzy, 29; Mediteranean, 139-140; Nogais, 154; Ossete, 150, 166; Persian, 162, 164; relationship between Finnic and Indo-Germanic, 18; Russians of the Steppes, 133; Sagai Tatars, 32; Salar, 104; Samoyedic, 22; Samoyedic elements in Karagas, 32; Shortzy, 29; Siberian Bukhartzy, 28; Siberian Mongoloids, 16; Siberian Turks, 32; Slavonized Finns, 21; Sogdian, 168; Sogdian and Khorezmian, 167; Swan, 142; Tadjik, 107108; Talysh, 150, 239; Taranchi, 98; Tate, 150, 239; Tomsko-Kusnetzk Tatars, 29; Tungus, 39, 41; Turkestan, 75-77; Turkestan gypsies, 115; Turkestan Jews, 116; Turkic, distribution, 25; Turkic, spoken by Azerbaijan, 153; Turkoman, 90, 92; Turks of the Altai Mountains, 29; Ugro-Finnic, 16; Ural-Altaic, 15, 17; Uzbeg, 85; Yakut, 26; Yeniseians, 66-67; Yukaghir, 75. Lamaists, Buryat, 34, 42; Tungus, 41.

Lamut, 39.

Lapps, 21-22, 191.

Law, Kirghiz, 84; Turkoman, 95; Uzbeg, 86.

Lazes, 142, 180.

Lebedintzy, 29.

Lesghin group, 143-146.

Lesghinka dance, 221.

Linguistic affinities, Siberian Mongoloid tribes, 16.

Little Russians, 135.

Log houses, Yakut, 191.

Luri, 172.

Magyar, 17-19. 
Maimunyliuli, 115.

Makhtum, 91.

Managhir, 39.

Manchu, 38, 39.

Manegri, 38.

Manichæism, rise and diffusion in Turkestan, 75 .

Maritime Chukchee, 46, 62, 206-207, 223.

Maritime Koryak, 47-49, 188, 206.

Marriage customs, Chukchee, 221-222;

Georgian and Armenian, 149; Kirghiz, 83; Kirghiz-Kaisak, 84; Sarts, 99; Tadjik, 86,111; Turkoman, 96; Uzbeg, 86.

Masked ballets, Buddhist Lamaist priests 222

Masks, Koryak. 223.

Massacres, of Armenians, 148, 164.

Mat-covered tents, 195.

Material culture, Yakut, change in, 27.

Mazdeism, Yezidism an offshoot of, 149.

Medians, 168.

Megalithic monuments, 232.

Megrel, 142.

Mekhinle, 91.

Meletski Tatars, 28.

Memorial tablets, stone, 125.

Mesocephalic peoples, 178, 179.

Mesoproscopic peoples, 180-181.

Metal, Tadjik work in, 112.

Middle Horde, Kirghiz, 127, 128.

Migrations, Abkhas-Cherkess group, 238; Ainu, 68; Aissor, 239; Asia to America, 44; Azerbaijan, 154; causes for, 233; Cherkess, 142; Chukchee, 241; Dungan, 240; Finnic tribes, 15; Gypsies, 172; historical, Asiatic peoples, 237-243; and history, 229249; Japanese, 67; Kara-Kalpak, 96. 239; Kirghiz-Kaisak, 126-127; Mohammedan Georgians, 238; NeoSiberians, 15-16; peoples of Asiatic Steppe provinces, 126; prehistoric, 229-234; Reindeer Chukchee, 240; Samoyed, 222, 242; Sarts, 240; Tatars, 97, 240; Tate, 238-239; Tungus, 37, 39, 241; Yeniseians, 66.

Military, duties, Cossacks, 134; servicc, peoples of Asiatic Russia, 78.

Milk, Kamchadal uses of, 50 .

Mingrel, 142.

Mode of life, 187-227.

Mohammedan, influence on art, 215; peoples, 150, 244-245; Abkhas, 142; Andi, 146; Azerbaijan, 153; Chechen, 143; Daghestan, 145; Hemshin, 148; Ihlat, 163; Kumyk, 154; Kurds, 149; Sart-Kalmuck, 106; Tadjik, 163.

Mohammedanism, Afghans, 116; conversion to, aborigines of Siberia and Central Asia, 243; conversion of Turkoman to, 88; Dungan, 105; in India, 171; introduction in to Turkestan, 116, 240; Georgians proper, 140; Kabardin, 142; Kirghiz, 83, 130; Lazes, 142; Siberian Cossacks, 134; spread, in Central Asia, 75; Tadjik, 108, 111; Tatars, 97 ; in Turkestan, 76 ; Turkestan Gypsies, 115; Turkoman, 92; Uzbeg, 86.

Mongol divisions, 33.

Mongolic, languages, peoples speaking, 246-247; tribes, 33-34; tribes, Caucasus, 157-158; tribes, Turkestan, 104106.

Mongoloid, characters, Bulgarian physical type, 21; influences on Magyar, 18; physical characters, Magyar, 18; Slavonized Finns, 21; traits, Kirghiz, 79; Ural-Altaic peoples, 15; Western Finns, 16; Yakut, 26.

Mongoloids, Asia and Europe, 13-42; Caucasian, 153-157; Siberian, 16.

Mongols, 15, 37, 198.

Mordvin, 20.

Morphological modifications, Yeniseian languages, 66.

Mosques, Turkoman, 92.

Mountain Chechen, 143.

Mountain Cheremiss, 21.

Mountain Kalmuck, 28.

Mountain Kirghiz. See Kara-Kirghiz.

Mountain Tadjik, 108, 111, 156, 169, 238.

Mourning dance, Sarts, 104.

Murchali, 91.

Murder, punishment and avenging for, 
Turkoman, 96.

Music, 216-215; Caucasian Lesghinka dance, 221; Kirghiz, s0; Turkoman, 83; Uzbeg, so.

Musical instruments, Kíirghiz, s0; Sarts, 101, 102; Turkoman, 90; Uzbeg, 30, so.

Mykhad. See Rutul.

Nagda, 39.

Naiman. 128.

Names, Upper Yenisei rivers, Turkic origin of, 234.

Nakhchi. See Chechen.

Nani, 38.

Narym-Samored, 23, 65.

Nasal index, Kirghiz, 128; Ossete, 167.

Nawars, 172.

Negidaltzy, 38.

Neolithic, man, distribution in Asia, 231; remains, Krasnoyarsk district, 230; stations, in Siberia, 231-232.

Neo-Siberians, migrations, 15-16.

Nestorianism, spread in Turkestan, 76 .

Nestorians, Aissor, 152.

New Persian language, 150 .

Nobilitỵ, Kïghiz, 130; Kirghiz-Kaisak, S4.

Nobles, Tungus, 42.

Nogai, 128.

Nogais, 156, 195.

Nogai Pechenyeg, 96.

Nookalit, 62.

Nose, flute, Hindoo, 217; form, Americanoids, 53; Armenians, 146; Gilyak, 58; Kara-Kalpak, 96; Kirghiz-Kaisak, 79; Sarts, 99; Turkoman, 92; UralAltaic peoples, 15; rings, Salyr, 93.

Nukhurli, 91.

Odul, 55 .

Offering festival, Kirghiz, 131.

Ogurdjal, 91.

Ogus, $88,91$.

Oirat. See Kalmuck, 157.

Okhotsk Tungus, 196.

Olchi, 38, 39.

Omok clans, Yukaghir, 56.
Ordas, Kïrghiz, 79 .

Origin, Afghan and Baluchi, 23s; Ainu, $6 \overline{7}-6 \mathrm{~S}$; Aissor, 152, 239; Armenians, 146, 23s; Aryan Hindoo, 238; Asiatic, American aborigines, 44-45; Asiatic, of Iman, 229; Azerbaijan, 153; Caucasian Jews, 152; Chechen and Lesghin groups, 238; Chukchee, Koryak and Lamchadal, 45; Chuvash, 21; DogBreeding Yukaghir, 57; Dolgan, 26; Dungan, 104; Durani Afghan, 116; Finno-Ugrian stock, 16, 17; Finns, 17; Georgian tribes, 238; Georgians or Kartveliens, 140; Ghilzai, 116; Gilyak, 58-59; Gypsies, 172, 238; Iranian peoples, 161-162, 237; Kara-Kalpak, 96; Kara-Kirghiz, 77; Khakas, 126; Khazar, 19; Khorezmians, 238; Kirghiz, 239; Kirghiz-Kaisak, 77-78, 128; Kirghiz Middle Horde, 128; Kumyk, 154, 239; Kurd, 164, 165-166, 237; Magyar, 17-18; Mongols, 15; Ossete, $150,166,237-238$; Samoyed, 16, 17, 22; Samoyed and Finno-Ugrian peopless, 242; Sarts, 98; Siberian Bukhartzy; 28; Siberian Cossacks, 134; Slavonized Finns, 21; Sogdians, 238; Soyot and Karagas, 24; Tadjik, 106, 108, 164, 168; Talysh, 151; Taranchi, 97; Tatars, 15; Tate, 150; Tungus groups, 38-39; Tungus-Manchu, -15; Turkic tribes, 23; Turkic tribes of Turkestan, 71; Turkoman, 88, 239; Turkomanized peoples, 91 ; Turks, 16; Ural Cossacks, 135; Uzbeg, 85, 239; Yakut, 27, 241; Yeniseians, 66-67.

Ornamentation, Siberian clothing, 212.

Orochi, 38.

Orochon, 38, 39.

Ornament, 210-213.

Orok, 39.

Oroki, 39 .

Osmanli, 156, 239.

Osmanly language, 148.

Ossete, 149-150, 166, 238.

Ostyak, 16, 17, 22, 65, $180191,206,218$, 243.

Ostyak-Samoyed. 22. 
Ostyak-Vogul, 211.

Oudin, 145.

Pahlavi, Persian language of the middle Iranian period, 162.

Painting, 210.

Palaeasiatics, 43-44.

Palæolithic remains, in Central Caucasus, 229; not found in Mongolia, Manchuria, Korea, Japan, and China, 232; in the Yenisei region, 229-230; site, near Krasnoyarsk, 229; stations, near Irkutsk, 230; in the Yenisei valley, 230.

Paleo-Siberians, 44.

Pantomime, 219-221.

Pantomimic dances, Caucasian, 221; Kamchadal, 220.

Parsis, 163.

Partridge dance, Kamchadal, 220.

Pechenyeg, 19, 88, 96, 126, 128.

Peekit, 46, 62.

Pent-roofed dwellings, 203.

Permians, 20.

Persia, derivation of name, 162 .

Persians, 113, 151, 163.

Physical type, Afghan, 169; Ainu, 69; Aissor, 152; Altaian Turks and Chern Tatars, 235; Armenians, 146; Azerbaijan, 153; Caucasus people, 235; Cheremiss, 21; Chuvash, 21; Danube Bulgarians, 21; Dinlin, 65, 236; Chukchee, Koryak, and Kamchadal, 53; Dungan, 105; Forest Cheremiss, 21; Galcha, 169; Georgians, 146; Gilyak, 58; Gruzian and Gorsky Jews, 152; Gypsies, 172; Indian Aryans, 170171; Iranian, 161-162; Kalmuck, 157; Kara-Kalpak, 96; Kirghiz, 79, 128; Kirghiz-Kaisak, 126; Kurds, 149, 165-166; Lapps, 22; Magyar, 18; Ossete, 150, 167; Persians, 163-164; Russians of the Steppes, 133; Samoyed in Karagas, 32; Sarts, 98-99, 169; Slavonized Finns, 21; Tadjik, 108; 109, 169; Talysh, 151, 239; Tate, 150, 239; Tekke, 92; Transbaikalian peoples, 237; Turkoman, 90, 91-92;
Ural Cossacks, 135; Ural-Altaic peoples, 15; Usun, 126; Uzbeg, 85; Vogul and Ostyak, 16; Votyak and Zyryan, 20; Yakut, 24, 26; Yeniseians, 65, 67; Yenisei Ostyak, 236; Yezidis, 149; Yukaghir, 54.

Pictographic inscriptions, Yenisei and Orkhon, 65-66.

Pictographic writing, Asiatic Steppe Provinces, 125; Bronze Age, 234; Yukaghir, 214.

Pictographs, prehistoric Siberian, 213.

Pile dwellings, 210.

Place names, South Russian explained by Ossetian language, 166.

Plains Tadjik, 108, 169.

Poems, Sarts, 217.

Poetry, 224-227; development among Mohammedan peoples, 224; Turkoman, 93; Yukaghir, 224, 225.

Political, history, Khorezm, 167-168; organization, Kirghiz, 129; status, Finland, 19.

Polovtzy, 19, 96, 97, 128.

Polygamy, Aissor, 152; Kirghiz, 133; Sarts, 99, 100-101; Tadjik, 111; Turkoman, 94.

Population numbers, Abdal, 91; Abkhas, 142; Adshar, 142; Afghans, 116; Agul, 145; Ainu, 67; Aissor, 152; Andi, 145; Arabachi, 91; Arabs in Turkestan, 116; Archin, 145; Armenia, 159; Armenians, 148; Ata, 91; Avar, 145; Azerbaijan, 153, 159; Balkar, 156; Baraba Tatars, 28; Bashkir, 156; Beltir, 32; Bukeyef, 125, 128; Buryat, 33, 34; Caucasus, 137; Caucasus gypsies, 151; Caucasian Osmanli, 156; Caucasian Persians, 151; Chechen, 143; Cheremiss, 21; Cherkess, 142; Cherneviye Tatars, 29; Chukchee, 45; Chulyma Tatars, 28; Chuvantzy, 55, 57; Chuvash, 21, 156; Commander Islands, 63; Darghin, 145; Didol, 145; DogBreeding Yukaghir, 56; Dungan, 105; Eastern and Western Mongol, 33; Ersar, 91; Eskimo, 92; European in 
the Caucasus, 151; Finland, 19; Finnic peoples, 15; Forest Clieremiss, 21; Gagauzy, 96; Georgians proper, 140; Georgian stocks, 140; Gilyak, 57; Goklan, 91; Gorsky Jews, 152; Gruzian Jews, 152; Gurians, 142; Gypsies, 172; Hindoos, 113; Igdyr, 91; Imcretins, 140; Jews in the Caucasus, 151152; Kachin Tatars, 32; Kalmuck, 157; Kamchadal, 49; Karachai, 156; Kara-Kalpak, 96; Kara-Kalpak Autonomous Province, 122; Kara-K̈irghiz, 78, 120; Kara-lïrghiz Autonomous Province, 121; Karapapak, 156; Karelians, 19; Kihinalug, 145; Kipchak, 97, 120; Kirghiz, 33, 75, 83, 121, 125; Kirghiz Steppe Provinces, 133; Kirghiz-Kaisak, 77, 120, 156; Kizyl Tatars, 30; Koibal, 32; Koryak, 47; Kumandintzy, 29; Kumyk, 154; Kurds, 149; Kurin, 145; Lak or KaziKumuk, 145; Lapps, 21; Lazes, 142; Lebedintzy, 29; Magyar, 17; Manchu, 35; Megrel, 142; Mongols, 33; Mordvin and Western Finns, 20; Narym Samoyed, 65; Nogais, 156; Ogurdjal, 91 ; Ossete, 149-150; Ostyak, 17; Oudin, 145; Persians, 113; Persians, Turkoman Soviet Socialist Republic, 121; Reindeer Chukchee, 45-46; Reindeer Koryak, 47; Republic of Georgia, 158; Russians in the Caucasus, 151; Russians, in Turkoman Soviet Socialist Republic, 121; Russian, in Uzbekistan, 120; Rutul, 145; Sagai Tatars, 32; Salor or Salyr, 91; Samoyed, 22; Sart-Kalmuck, 106; Sarts, 9S, 156; Saryk, 91 ; Shortzy, 29; Siberia, 13-14; Siberian Bukhartzy, 28; Siberian Turks, 32; Steppe Kamassintzy, 32; Steppe Kirghiz, 125; Swan, 142; Tabsaran, 145; Tadjik, 106, 107, 120, 121; Tadjik Autonomous Republic, 122; Talysh, 150; Taranchi, 98; Tatars, 97; Tate, 100; Tekke, 88; Teleut, 29; Tobolsk Tatars, 28; Tomsko-Kusnetzk Tatars, 29; Tungus, 38, 39, 41,
42; Tungusized Yukaghir, 56; Turkcstan, 72, 74-75; Turkestan Gypsies, 114; Turkestan Jews, 116; Turkestan Republic, 123; Turkic tribes, 25; Turkmanistan, 121; Turkoman, 88, 121, 157; Turks of the Altai Mountains, 29; Uzbeg, 85, 86, 120, 121; Uzbekistan, 119-120; Vesp, 19; Vod, 19-20; Vogul, 17; Votyak, 20; Western Mongols, 33; Yagnobtzy, 168; Yakut, 25-26; Yeniseians, 66; Yezidis, 149; Yomud, 91; Yukaghir, 55; Zyryan, 20; relation between urban and rural, Turkestan, 73 ; relative number of native and Russian, 74.

Pottery, Kamchadal, 69; Kirghiz, 80; Koryak sites, 232; neolithic, in Siberia, 231; Tadjik, 110; Yakut, 27.

Prehistoric, contact, Turks and Aryan, 235; migrations, 229-234.

Property marks, Kirghiz, 129.

Protestant peoples, 244.

Proverbs, Kirghiz, 83, 84-85; Sart, 72. Provinces, Turkestan, 71-72.

Pshav, 140.

Pyramidal dwellings, 201.

Racial composition, Siberian Cossacks, 135.

Rainfall, Turkestan, 72.

Rainproof clothing, Aleut and Asiatic Eskimo, 213.

Rank, Turkoman, 94, 95.

Ratcha, 142.

Raven dance, Chukchee, 220.

Realistic designs, on ceremonial objects, 215-216.

Reed-pipes, 217.

Reindeer, breeders, stature of, 175; breeding, Chukchee, 60; breeding, Karagas, 32; breeding, Yukaghir, 55; breeding complex, diffusion of, 54; culture, Yakut, 27; domestication of, 24; driving, Chukchee and Koryak, 59; hunting, Kamchadal, 49; skins, for clothing, 212; types and riding gear, Karagas, 24-25.

Reindeer Chukchee, 45-46, 223, 240. 
Reiıdeer Chuvantzy, 56.

Reindeer Koryak, 47, 223, 241.

Reindeer Tungus, 241.

Religion, Abkhas, 142; Adshar, 142; Andi, 146; Armenian, 148; and art, 215-216; Buryat, 34; Chuvantzy, 57; Dungan, 105; Georgians, 140; Hazara, 33; Indian peoples, 170; Kabardin, 142; Kalmuck, 106, 157; Khazar, 19; Kirghiz, 78, 83, 130-131; Kurds, 149; Medians, 168; Oudin, 145; Parsis, 163; Persian and Turkic Aissor, 152; Persians, 113; Sart, 76; Sart Kalmuck, 106; Siberian Bukhartzy, 28; Siberian Cossacks, 134; Tadjik, 108, 111, 163; Tate, 239; Tungus, 41-42; Turkestan, 75-77; Turkestan Gypsies, 115; Uzbeg, 86; Votyak, 20; West Siberian Tatars, 32; Yeniseians, 66; Yezidis, 149; Yukaghir, 57; Zyryan, 20.

Religious, classification, 243-245; dances, 222-223.

Republic of Bokhara, 118-119.

Republic of Georgia, 158-159.

Republic of Khiva, 119.

Republic of Khorezm, 118.

Revolt, against Chinese, Dungan, 105. 106.

Ritual dances, 222-223.

River Ostyak, 188.

Roman Catholic peoples, 244; Chechen, 143; Swan, 142.

Russianized peoples, Buryat, 34; Cherneviye Tatars, 29; Chulyma Tatars, 28; Kamchadal, 206; Kizyl Tatars, 30; Ossete, 150; Siberian Bukhartzy, 28; Steppe Kamassintzy, 32; Teleut, 29.

Russianized Chuvantzy, 57.

Russianized Kamchadal, 49.

Russianized Koryak, 47.

Russianized Yukaghir, 56.

Russians, in the Caucasus, 151; in the Steppes, 133-136; in Uzbekistan, 120; influence on peoples of Turkestan, 74; influence on Siberian natives, 13 ; influence on Turkic peoples, 32-33; influence on Yeniseians, 65.

Rutul, 145.

Sacrifice, ceremonies, Maritime Chukchee, 223; horses, Kirghiz, 131.

Sagai, 65 .

Sagai Tatars, 32.

Sakhá, 26.

Salar, 104.

Salor, 91 .

Salyr, 91, 93.

Samaghir, 38, 39

Samoyed, 16, 17, 22-23, 191, 231.

Samoyedic dialects, 247.

Samoyed Ostyak, 22, 65.

Samurrakan, 142.

Sarmatians, 166.

Saryk, 91.

Sarticized Tadjik, 108.

Sart-Kalmuck, 106.

Sarts, 74, 76-77, 86, 87, 97, 98-104, 115, $136,169,198,208,218$.

Scarification, 210.

Screens, 189.

Sculpture, development of, peoples of Eurasia, 214

Sea dog dance, Kamchadal, 220.

Sealing methods, Kamchadal, 49-50.

Seal hunting, Commander Aleut, 64.

Sealskins, use for clothing, 212-213.

Sea mammals, hunting, Kamchadal, 49-50.

Seid, 91.

Selenga Buryat, 195.

Semites, Turkestan, 115-122.

Semitic, languages, peoples speaking, 249; peoples, 151-153.

Semito-Hamite peoples, 138.

Settlements, Commander Islands, 62; Russian on Kurile Islands, 67; summer, on Bering Island, 63; summer, on Copper Island, 53.

Shades, 189.

Shaman, Yakut, dress of, 215.

Shamanism, peoples practising, 245; Buryat, 34, 130; Irano-Turkic tribes, 75; Tungus, 41-42.

Shaman's dances, 223. 
Shamanistic beliefs, K̈irghiz, s3; performances, 223; performances, lukaghir, 225.

Sheep breeding. Kirghiz and Turkoman, S1; breeding, Tadjik, 112; economic importance, among Kïrghiz, S1.

Shellmounds, 232 .

Shiite sect, peoples belonging to, 245; Azerbaijan, 153; Persians, 113, 164; Tadjik, 111, 163; Tate, 150; in Turkestan, 76,77 .

Shik, 91.

Shortzy, 29.

Shrouds, Afghanistan and Sart, 104.

Siberian Americanoids, 43 .

Siberian Bukhartzy, $2 S$.

Siberian Cossacks, 134.

Singing, circle dance, 219; Chukchee dances. 220; Sarts, 101.

Sinti, 172 .

Skin, boat, not found among Gilyak, 60 ; not used by Commander Aleut, 64; clothing, 212-213; color, Aissor, 153; color. Americanoids, 53; color, Kirghiz-Kaisak, 79; color, Sarts, 99; color, Tadjik, 108; color, Turkoinan, 92; color, [ral-Altaic peoples, 15; color, Uzbeg, 85; cover, conical tent, 190; cover, cylindro-conical tent, 196; covers for tents, 191, 193, 195.

Skulls, dolichocephalic, Chudes, 126.

Slavery, Kirghiz, 130; Persian, 113; Turkoman, 94, 95, 115.

Slavonized Fiuns, 21.

sledge, Gilyak, 59; Kamchadal, 50; Reindeer Koryak, $51-52$.

Sloping-roofed block houses, 203.

Small Horde, Kirghiz, 127, 129.

smoke hole, use as entrance to house, Gilyak. 59.

Snowhouse, an Eskimo invention, 54; Eskino and Kerek, 208.

Snowshoes, Aleut, 64 .

Social, life. Kirghiz, 130; organization, Kirghiz. \$4-85; organization, Kirghiz-Kaisak, S4, 130; organization, Kúmyk, 156; organization, Turkoman, 90-91; organization, Lzbeg, 86.
Sod huts, Kirghiz, 132

Sogdians, 167-168.

Solon, 35,39 .

Somatology; 173-1S6; Kirghiz, 12S-129.

Songs, animal, Chukchee, 220; Buryat shaman, 225; contests in improvisation of, s0; Sarts, 102.

Soviets, administrative changes under the, $117,11 \mathrm{~S}-124$; administrative divisions of the Caucasus under the, 158-159.

Soyot, 23, 24, 25.

Spirits, recognized by Tadjik, 111 .

St. Lawrence Eskimo, 62.

Statistical data, on Turkestan Republic, 122-124.

Stature, Aissor, 152-153; determining factors in, 173-175; distribution of, 173-176; Georgians, 146; Gruzian and Gorsky Jews, 152; Kara-Kalpak, 96; Kara Kirghiz, 79; Kirghiz-Kaisak, 79, 12S; and occupation, 175; Ossete, 167; Sarts, 99; Tadjik, 108; Turkoman, 92, 96; Uzbeg compared with Kirghiz, 85.

Steppe Kamassintzy, 32.

Steppe Kirghiz, 125.

Steppe Provinces, Asiatic, 125-136.

Steppes, Russian population of, 133-136.

Storehouses, Kamchadal, 209, 210.

Stringed instruments, 217-218.

Subclans, Kirghiz, 129.

Sunnite sect, peoples following, 244-245;

Abkhas, 142; Adshar, 142; Afghans, 116; Andi, 146; Chechen, 143; Dingestan, 145; Georgians, 140; Hemshin, 148; Ihlat, 163; Kabardin, 142; Kirghiz, 83, 130; Kurds, 149, 164; Lazes, 142; Ossete, 150; Tadjik, 108, 163; Turk'stan, 76; Turkoman, 92; Uzoleg, 86.

Summer dwellings, Kirghiz, 80, 131; Yikut, 191.

Suomi Finns, 19.

Swan, 142.

Siwan dance, Yukaghir, 219

Swanet, 142.

siwiur breeding, in Turkestan, 82. 
Tabsaran, 145.

Tadjik, 74, 86, 87, 98, 106-113, 120,

162-163, 164, 168, 169-170, 180, 238.

Tadjik Autonomous Republic, 121-122.

Tagaur, 150.

Talysh, 150-151.

Tambourine, 216.

Taranchi, 97-98, 218, 240.

Tatarized Arin, 65.

Tatarized peoples, Baraba Tatars, 28;

Samoyed, 24; Steppe Kamassintzy, 32.

Tatars, 15, 25, 26, 27-32, 83, 97, 128, 242.

Tate, $150,169$.

Tattooing, 210-211.

Tauli. See Balkar.

Tawgi Samoyed, 22, 23.

Teeth, painting of, 210 .

Tekke, 88, 91, 92, 95.

Tekkintzi, 88.

Teleut, 29.

Tents, conical, 189-195; felt-covered, 154.

Thanksgiving ceremonial, Chukchee, 223.

Theft, adjustment for, Turkoman, 95.

Thushi, 143.

Tobacco, used by Turkoman, 95 .

Tobolsk Tatars, 28.

Tomsko-Kusnetzk Tatars, 29.

Tonchi, 68 .

Torgout, 131, 157, 180.

Trade, Cossacks with Kirghiz, 134.

Trading dance, Chukehee, 221-222.

Transportation methods, Azerbaijan, 154; Commander Aleut, 64; migratory peoples, 187; Tadjik, 112; Turkestan, importance of camel in, 81-82.

Transverse cephalo-facial index, Kirghiz, 128.

Trees, Commander Islands, 63.

Tribal organization, Kirghiz-Kaisak, 129130.

Trombones, 217.

Trumpets, 217.

Truncated pyramidal dwelling, 201-203.

Tsova-Thushi, 143.

Tual, 150.

Tuba, 24.

Tundra Yukaghir, 196, 211, 212.
Tungus, $34,37-42,66,178,187,191,198$, 211, 212, 218.

Tungusized Yukaghir, 55, 56, 57.

Tungus-Manchu, 15, 247.

Turkestan, Mongolic tribes of, 104-106; nations of, 71-124; peoples, historical wanderings of, 239-240.

Turkestan Republic, 118.

Turkestan Semites, 115-122.

Turkic, languages, distribution, 25; peoples speaking, 245-246; tribes, $23,25-33$.

Turkic-Altaic family, 43.

Turkicized peoples, 25; Dinlin, 236; Iranians, 162; Kaitak, 158; Samoyed, 23-25; Sarts, 169; Yeniseians, 65-66,

Turkmanistan. 120-121.

Turkoman, 74, 88-96, 113, 121, 153, 157, 178, 180, 198, 208, 239.

Turkomanized peoples, 91 .

Turkoman Soviet Socialist Republic, 120-121.

Turko-Tatar languages, 79.

Turks, 16, 28.

Tushin, 140.

Tzygany, 172.

Ubykh, 142.

Ugrians, 17-19.

Ugrian Ostyak, 17, 65.

Ugro-Finnic languages, 16.

Uigur, $65,104,126$; alphabet, 168; characters, used by Kirghiz, 79-80; inscriptions on stone, 125-126; writing, 213.

Ulu-juz, 127.

Underground dwellings, 59, 204-208.

Ural-Altaic, languages, 17 ; peoples, 1416.

Ural Cossacks, 134, 135.

Uriankhai, 25, 26.

Urta-juz, 127.

Usun, 126, 128, 233, 237.

Uzbeg, 78, 85, 88, 92, 96, 97, 116, 129 , 168, 180, 198, 208.

Uzbeg Socialist Soviet Republic, 119.

Uzbekistan, 119-120. 
Vesp, 19.

Viliages, Aleut, 67; Bering Island, 63; Chukchee, 45, 46; Commander Aleut, 63; Copper Island, 63; German Colonists, Steppe Provinces, 135; Koryak, 49; Little Russians, Steppe Provinces, 135; Maritime Koryak, 47; Tadjik, 111, 112.

Violin, two stringed, Ostyak, 218.

Violincello, Mongol, 218; Sarts, 217.

Vod, 19-20.

Vogul, 16, 17, 211, 218.

Volga Bulgarians, 21.

Volga Kalmuck, 157.

Votyak, 20.

Water supply, Turkestan, 72.

Weaving, Turkoman, 93; Yakut, 215.

Westerı Finns, 19.

Western Siberians, 242-243.

West Siberian Tatars. See Tobolsk Tatars.

White Kalmuck, 28.

Wind instruments, 217.

Winter dwelling, Kirghiz, 80, 131, 132; Uzbeg, 87.

Wives, exchange of, Chukchee, 221-222.

Women, position, among Kirghiz, 83; among Sarts, 83, 86, 99-100; among Tadjik, 86, 112; among Turkoman, 93-94; among Uzbeg.

Wooteelit, 62.
Writing, Kirghiz, 79-80; picture, in the Irkutsk country, 213.

Yagnob, 108.

Yagnobtzy, 168.

Yaik Cossacks, 135.

Yak, domestication of, 81 .

Yakut, 24-27, 188-189, 191, 195, 200, $201,203,204,211,212,215,218-219$.

Yakutized tribes, Dolgan, 26.

Yakutized Tungus, 201.

Yakutized Yukaghir, 57.

Yezidis, 149.

Yikirgaulit, 62.

Yomud, 91.

Yu'it, 62.

Yugria, 242, 243.

Yukaghir, 5ł-57, 200, 207, 211, 212, 218$219,225$.

Yurak, 22, 23.

Yurak Samoyed, 23.

Yeniseian dialects, peoples speaking, 247.

Yeniseian Kott, 32.

Yeniseians, 65-67.

Yenisei Ostyak, 32, 65, 236.

Yenisei Samoyed, 22.

Zarathustra, religion of, 168 .

Zoroaster, Persian doctrine of, 148, 163.

Zoroastrianism, spread in Turkestan, 75. Zyryan, 20, 178. 




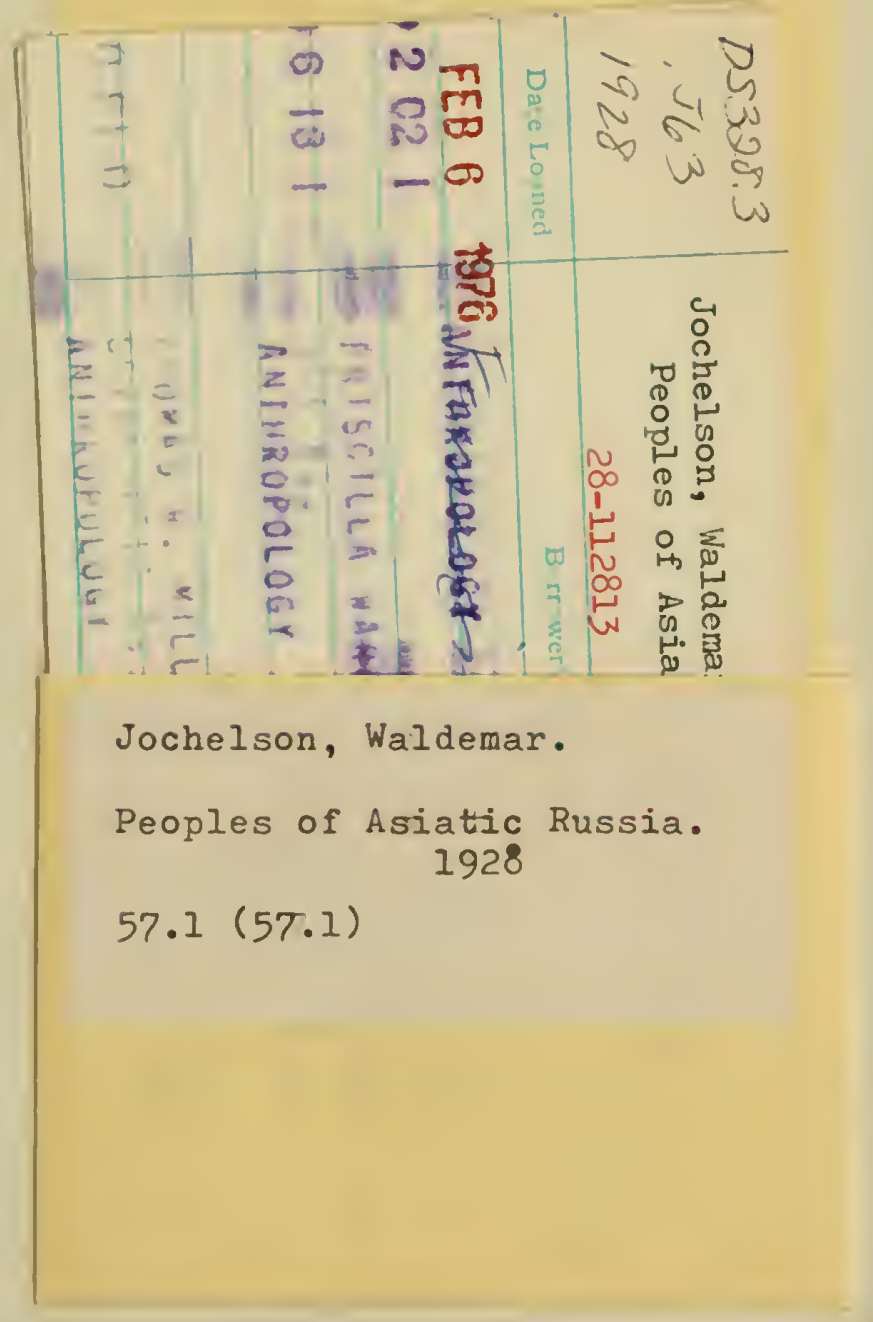




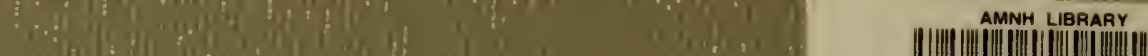

